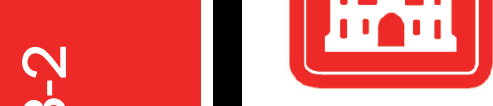

US Army Corps of Engineers ${ }_{\circledast}$

Engineer Research and

Development Center

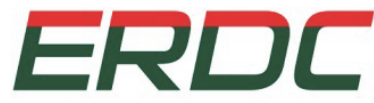

INNOVATIVE SOLUTIONS for a safer, better world

Dredging Operations and Engineering Research Program

\title{
Developing and Testing TernCOLONY 1.0: An Individual-based Model of Least Tern Reproduction
}

Casey A. Lott, Steven F. Railsback, Colin J.R. Sheppard, June 2013 and Michael C. Koohafkan 
The US Army Engineer Research and Development Center (ERDC) solves the nation's toughest engineering and environmental challenges. ERDC develops innovative solutions in civil and military engineering, geospatial sciences, water resources, and environmental sciences for the Army, the Department of Defense, civilian agencies, and our nation's public good. Find out more at www.erdc.usace.army.mil.

To search for other technical reports published by ERDC, visit the ERDC online library at http://acwc.sdp.sirsi.net/client/default. 


\title{
Developing and Testing TernCOLONY 1.0: An Individual-based Model of Least Tern Reproduction
}

\author{
Casey A. Lott \\ Coastal and Waterways Program Coordinator \\ American Bird Conservancy \\ 1209 Shenandoah Drive \\ Boise, ID 83712 \\ Steven F. Railsback, Colin J.R. Sheppard, \\ and Michael C. Koohafkan \\ Lang, Railsback, and Associates \\ 250 California Ave. \\ Arcata, CA 95521
}

Final report

Approved for public release; distribution is unlimited.

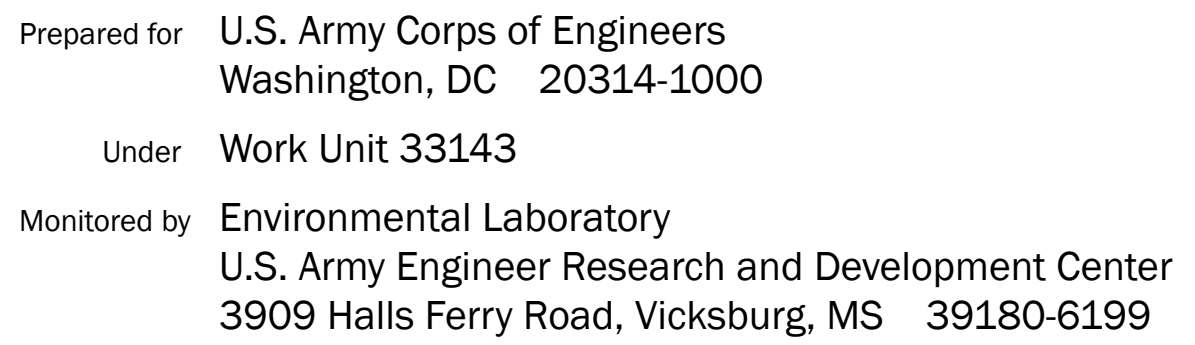




\section{Abstract}

The TernCOLONY simulation model is an individual-based model of Least Tern reproduction that was developed to better understand how reservoir operations (and other management activities) affect Least Tern breeding populations on large rivers. This report documents the process of model development, including defining the model's purpose, its structure, its various submodels, and major inputs. This document supplements the TernCOLONY model description (Lott et al. 2012a), which provides the complete formulation of the model with enough detail to make the model reproducible. This document summarizes the pattern-oriented approach taken in developing the model's major behavioral traits and submodels (adult tern colony and nest site selection, site abandonment, re-nesting, and various mortality submodels). The report also documents the extensive process of independent verification of the model's code that was undertaken prior to a whole model sensitivity analysis and parameter calibration (also reported here). The tests reported in this document provide the basis for the final submodels, behavioral traits, and parameter values that are reported in the model description and represented in the model' s code (Lott et al. 2012a). The web version of the model, available at http://www.leasttern.org, is introduced. The web version provides the graphical interface through which most users will explore TernCOLONY. Finally, future directions in the implementation of TernCOLONY on different river reaches are summarized to address a variety of different management applications and discuss the potential for adapting the model to other contexts (e.g., other habitats or species).

DISCLAIMER: The contents of this report are not to be used for advertising, publication, or promotional purposes. Citation of trade names does not constitute an official endorsement or approval of the use of such commercial products. All product names and trademarks cited are the property of their respective owners. The findings of this report are not to be construed as an official Department of the Army position unless so designated by other authorized documents. 


\section{Contents}

Abstract...................................................................................................................................... if

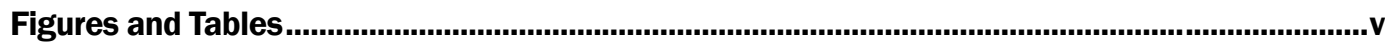

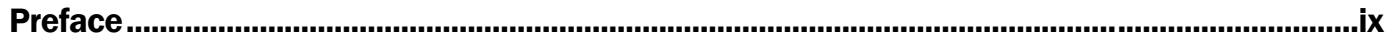

Unit Conversion Factors........................................................................................................xi

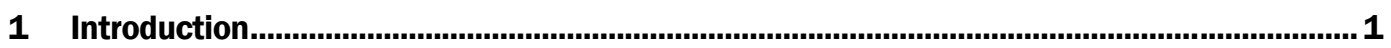

What is TernCOLONY? ............................................................................................... 1

What is an individual-based model? ................................................................................ 2

What is this document? ........................................................................................... 3

2 Objectives and Project Structure.................................................................................. 5

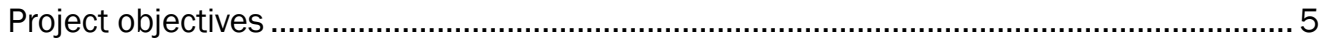

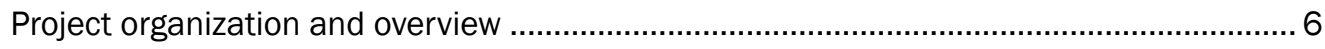

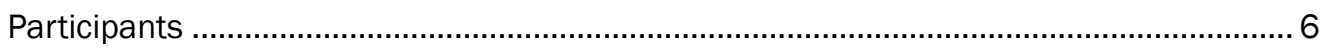

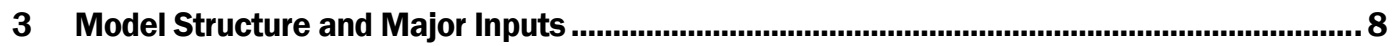

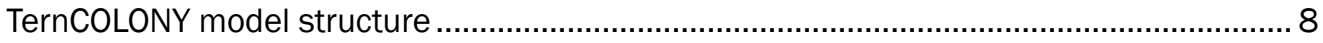

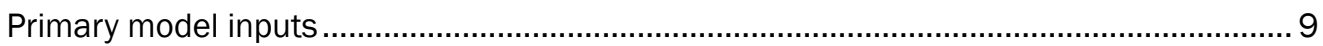

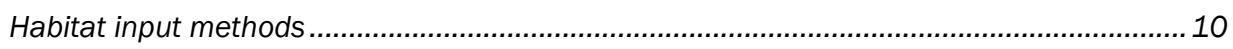

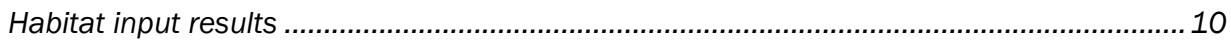

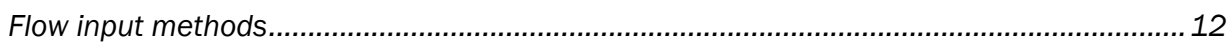

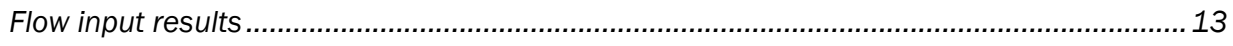

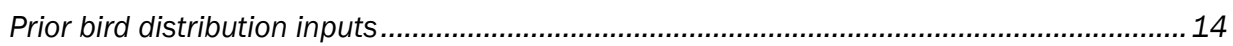

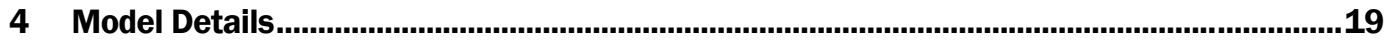

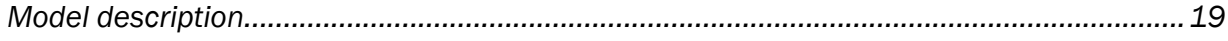

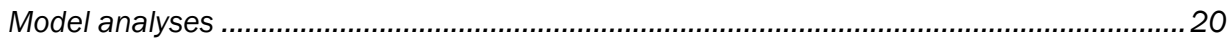

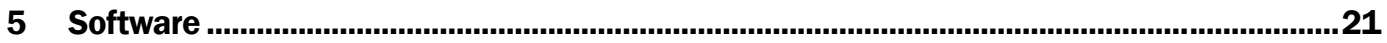

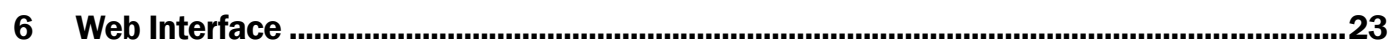

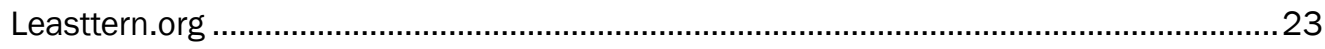

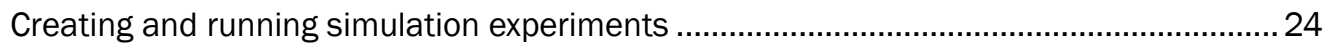

Exploring simulation results .......................................................................................... 24

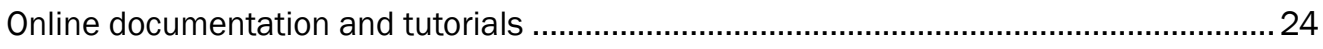

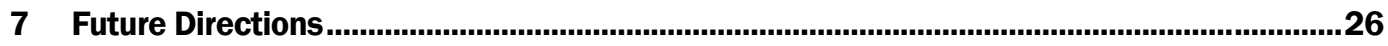

References.............................................................................................................................27

Appendix A: Colony Site Selection Submodel Development ........................................................28 
Appendix B: Nest Site Selection Submodel Development......................................................66

Appendix C: Site Abandonment Submodel Development..............................................................80

Appendix D: Pattern-oriented Testing of Mortality and Reproductive Performance ....................90

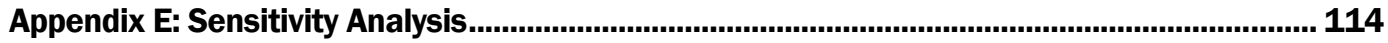

Appendix F: Model Calibration ....................................................................................................... 163

Appendix G: Software verification ................................................................................. 183

Report Documentation Page 


\section{Figures and Tables}

\section{Figures}

Figure 1. TernCOLONY model structure illustrating the model major inputs, objects, and submodels.

Figure 2. Illustration of the three major habitat input sets that were created as model habitat inputs for the implementation of TernCOLONY on the Arkansas River below Keystone Dam.

Figure 3. Thirty-two annual flow inputs for the implementation of TernCOLONY on the Arkansas River below Keystone Dam, categorized by water year type.

Figure 4. Prior nesting bird distributions for the Arkansas River below Keystone Dam management area based on Tulsa District bird survey data from 2005 and 2008.

Figure 5. Information flow used by TernCOLONY.

Figure A1. Annual hydrographs for a number of rivers within the ILT breeding range.

Figure A2. Histogram of the ratio of site/river-wide arrival date ranges in the Missouri River data set..

Figure A4a. Colony size distributions for six years on the Garrison reach of the Missouri River.

Figure A4b. Colony size distributions for six years on the Gavins Point reach of the Missouri River. 35

Figure A5. Colony size distribution for 2008, Keystone reach, Arkansas River...

Figure A6. Location (X axis; approximate river mile) and habitat quality (at normal hydropower flows) of potential colony sites in the Keystone reach.

Figure A7. Histogram of site habitat quality at normal hydropower flow.

Figure A8. Time series (left axis; solid lines) of number of sites with some suitable habitat, and (right axis; dashed lines) total acres of high-quality habitat in the study reach during water years 1991 (low, steady) and 1993 (high, descending).

Figure A9. Relationship between the date a site is first selected and its colony size, for (left) 1991 and (right) 1993, site identification trait 1.

Figure A10. Range of dates over which each site was selected, for (left) 1991 and (right) 1993, site identification trait 1.

Figure A11. Relationship between colony size and range of dates site was selected, 1991, site identification trait 1.

Figure A12. Relationship between site quality and colony site, for (left) 1991 and (right) 1993, site identification trait 1.

Figure A13. Colony size distributions for 1991 (left) and 1993 (right), site identification trait 1.

Figure A14. Range of dates over which each site was selected, for (left) 1991 and (right) 1993, site identification trait 2 .

Figure A15. Relationship between site quality and colony site, for (left) 1991 and (right) 1993, site identification trait 2.

Figure A16. Relationship between site isolation and colony site, 1991, site identification trait 2. 
Figure A17. Colony size distributions for 1991 (left) and 1993 (right), site identification trait 2.

Figure A18. Colony size distributions for 1991 (left) and 1993 (right), site identification trait 3.

Figure A19. Colony size distribution for 1991 (left) and 1993 (right), site evaluation trait 2..........53

Figure A20. Colony size distribution for 1991 (left) and 1993 (right), site evaluation trait 3..........54

Figure A21. Ranges of dates (grey bars) over which sites were selected, site identification trait 3 and site evaluation trait 3, 1991.

Figure A22. Colony size distributions with site identification trait 3 and site evaluation trait 3, 1991 (left) and 1993 (right).

Figure A23. Ranges of dates (grey bars) over which sites were selected, site identification trait 4 and site evaluation trait 3, 1991 (left) and 1993 (right).

Figure A24. Colony size distributions with site identification trait 4 and site evaluation trait 3, 1991 (left) and 1993 (right).

Figure B1. Observed nest freeboard distributions at 15 sites in the Gavins Point Reach, Missouri River, 2004-6.

Figure B2. Distributions of nest differences from peak elevation in the Gavins Point data............ 70

Figure B3. Distribution of distances from mean nest elevation in the Gavins Point data. ............... 70

Figure B4. Simulated nest freeboard distributions, by Arkansas River site and year........................72

Figure B5. Distribution of simulated nest elevation differences from peak......................................74

Figure B6. Horizontal location of nests, version 1 of nest site selection trait. ................................ 75

Figure B7. Simulated nest freeboard distributions, by Arkansas River site and year, nest site selection trait 2

Figure B8. Distribution of simulated nest elevation differences from peak, trait 2........................ 77

Figure B9. Horizontal nest locations, with nest site selection trait 2 ….........................................78

Figure C1. Adult mortality experiment................................................................................... 83

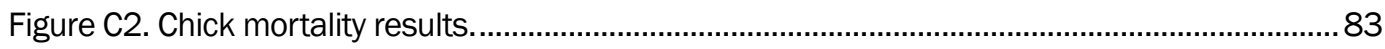

Figure C3. Results of the combined mortality experiment........................................................... 84

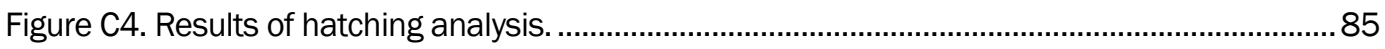

Figure C5. Abundance experiment results for adults (left) and chicks (right).................................86

Figure C6. Nest mortality results at extremely low adult abundances. The legend provides the total number of adults, with one nest for every two adults.

Figure C7. Rate of mortality (percent killed within the 5-day survival horizon) causing unnested adult terns to abandon a site.

Figure C8. Results of the sensitivity analysis for adminExpectedFledges. The legend refers to the value of adminExpectedFledges.

Figure D1. Box and whisker plot of annual reproductive success for a 32-km study reach of the Canadian River between 1991 and 1998.

Figure D2. Results for Pattern 1. Distributions of annual reproductive success, as the total number of successful fledglings divided by the total number of females in the management area.

Figure D3. Reproductive success vs. density of females, for each site, year, and replicate...........101

Figure D4. Histogram of reproductive success (as fledglings per nested female) by site and year, including five replicate simulations. 
Figure D5. Size distributions of colonies with (top) zero and (bottom) nonzero reproductive success.

Figure D6. Distribution of site reproductive success, at sites with success greater than zero; the same results as Figure D5 except that sites with zero nesting success are excluded.

Figure D7. Comparison of reproductive success (fledglings per female) with excellent vs. degraded habitat; distribution of management-area results over 10 water years.

Figure D8. Distribution of (left) nest flooding and (right) chick drowning rates (percentage of all nests and chicks that were destroyed by flooding, by year) for excellent vs. degraded habitat conditions.

Figure D9. Number of sites with nest and chick mortality due to drowning, excellent vs. degraded sites.

Figure D10. Distribution of nest freeboard (elevation difference between a nest and the water surface elevation at maximum hydropower flow, ft) for excellent vs. degraded habitat, 1999

Figure D11. Percentage of nests (left) and chicks (right) killed by predators and ORVs with excellent vs. degraded habitat. Distributions are annual results from 1998-2007......

Figure D12. Percent of sites with any nest predation, comparing excellent vs. degraded habitat. Distributions are of results from water years 1999-2007.

Figure F1. Site selection analysis results: response of SSD in nest abundance to parameters manareaFracDispersers and adultSiteSelectionDistance.

Figure F2. Contour plot of the total number of nests created on two new sandbars, in an experiment otherwise identical to the 2006 site selection calibration experiment.

\section{Tables}

Table A1. Pattern 8 results for site identification trait 3. 52

Table A2. Pattern 8 results for site evaluation trait 2.

Table A3. Pattern 8 results for site evaluation trait 3.

Table A4. Pattern 8 results for site identification trait 3 and evaluation trait 2

Table A5. Pattern 8 results for site identification trait 3 and evaluation trait 2

Table A6. Pattern 8 results for site identification trait 3 and evaluation trait 2 .

Table A7. Summary of pattern-oriented analysis of colony site selection traits.

Table A8. Results of the site identification distance sensitivity experiment. 61

Table D1. Main causes of mortality vary among years within a region.

Table D2. Productivity at five different Least Tern nesting sites on a 32-km study reach of the Canadian River, 1995-1999.

Table D3. Results for Pattern 2, variation among years in nest and chick fate. Data are the number of nests or chicks that fail due to several causes or succeed.

Table D4. Variation among sites in reproductive success (fledglings per nested female), for one replicate.

Table D5. Nest mortality causes by site for 1998, a low-flow year; results from one replicate...........105

Table D6. Nest mortality causes by site for 2004, which had a flow reversal; results from one replicate.

Table D7. Drowning mortality of nests and chicks by year. Values are sums over all sites and five replicates. 
Table E1. Parameter value ranges and basis......................................................................... 117

Table E2. Water year type and habitat condition scenarios for sensitivity analysis........................120

Table E3. Sensitivity analysis results for reproductive success. Parameters are listed in order of highest to lowest sensitivity........................................................................................123

Table E4. Sensitivity analysis results for flooding loss.................................................................. 124

Table F1. Calibration criteria for site selection. ...............................................................................166

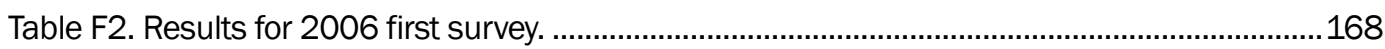

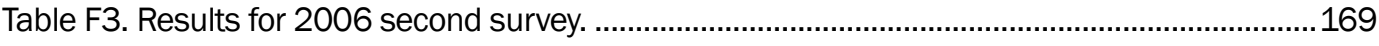

Table F4. Results for 2008 first survey. ..................................................................................... 170

Table F5. The number of fledglings per female adult tern is greater than 1.0, averaged

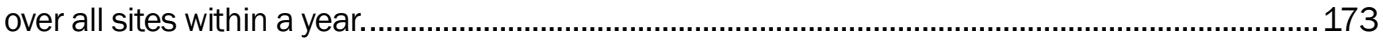

Table F6. Literature for calibration of fledging success.................................................................. 174

Table F7. Reproductive success calibration results for experiment 1: the parameter combinations that met at least four of the five calibration criteria, averaged over five water

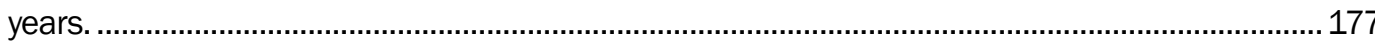

Table F8. Reproductive success results with parameter values resulting from calibration: mean and range over five replicates of each of the calibration years. ............................................180

Table G1. Interior Least Tern Model Software Verification Log......................................................184 


\section{Preface}

The TernCOLONY simulation model is an individual-based model of Least Tern reproduction that was developed to better understand how reservoir operations (and other management activities) affect Least Tern breeding populations on large rivers.

The model was collaboratively developed by American Bird Conservancy (ABC) and Lang, Railsback, and Associates (LRA). Dr. Richard Fischer of the U.S. Army Engineer Research and Development Center (ERDC), Environmental Laboratory (EL), provided feedback throughout model development.

This effort was jointly supported by funding from the U.S. Army Corps of Engineers Dredging Operations and Technical Support (DOTS), and Dredging Operations and Environmental Research (DOER) Programs. The Program Managers for DOTS and DOER, respectively, are Cynthia Banks and Dr. Todd Bridges. Dr. Bridges is the US Army's Senior Research Scientist for Environmental Science.

This document is the second in a series of three documents related to the TernCOLONY model. The first document in the above-mentioned series is the TernCOLONY model description (Lott et al. 2012a). The TernCOLONY model description follows the "ODD" (Objectives, Design Concepts, and Details) protocol of Grimm et al. (2006) as updated by Grimm et al. (2010) for describing individual-based models. This protocol starts with general and conceptual characteristics; followed by the detail needed to make the model reproducible. TernCOLONY is the first complex individual-based model that is completely accessible via the web at http://www.leasttern.org. Lott et al. (2012b) provide a guide for preparing model inputs for those seeking to implement the TernCOLONY model in new locations. Additional documentation of the model's software and code is also available at http://www.leasttern.org.

The habitat and flow inputs underlying the first regional application of TernCOLONY (on the Arkansas River below Keystone Dam) were documented previously in Lott and Wiley (2012), which described research 
on Least Tern nesting habitat measurements funded by the U.S. Army Engineer District, Tulsa.

The authors would like to thank Merrie Morrison, Danny Cunningham, and David Pashley of American Bird Conservancy for administrative support during this project. Technical review of the manuscript for ERDC was provided by Dr. Richard A. Fischer and Mr. Jonathon J. Valente, EL.

The primary contact for TernCOLONY is Casey Lott of American Bird Conservancy at clott@abcbirds.org. The ERDC points of contact are Dr. Richard A. Fischer (502-315-6707; Richard.A.Fischer@usace.army.mil) or the focus area manager of the Dredging Operations and Environmental Research Program, Dr. Todd Swannack (601-634-2068;

Todd.M.Swannack@erdc.usace.army.mil).

Commander of ERDC was COL Kevin J. Wilson. Director of ERDC was Dr. Jeffery P. Holland. 


\section{Unit Conversion Factors}

\begin{tabular}{|l|c|l|}
\hline Multiply & By & To Obtain \\
\hline acres & $4,046.873$ & square meters \\
\hline cubic feet & 0.02831685 & cubic meters \\
\hline feet & 0.3048 & meters \\
\hline inches & 0.0254 & meters \\
\hline miles (U.S. statute) & $1,609.347$ & meters \\
\hline miles per hour & 0.44704 & meters per second \\
\hline square feet & 0.09290304 & square meters \\
\hline
\end{tabular}




\section{Introduction}

\section{What is TernCOLONY?}

TernCOLONY is an individual-based model of LeastTern reproduction. The model was designed to simulate Least Tern breeding seasons across a wide range of user-specified conditions. Simulations occur at the spatial scale of regional breeding populations (e.g. the population of $\sim 450$ terns nesting on $\sim 64$ miles of the Arkansas River below Keystone Dam).

The first version of this model, TernCOLONY 1.o, was designed to simulate breeding seasons on rivers, where the federally listed interior population of the Least Tern nests primarily on riverine sandbars (U.S. Fish and Wildlife Service (USFWS) 1990, Lott 2006). Consequently, the model represents habitat as a network of potential nesting sandbars that are affected by dam releases and downstream flows. Since dam releases vary daily due to operations for hydropower production, flood control, and other purposes (Lott and Wiley 2012), TernCOLONY simulates Least Tern breeding seasons in daily time-steps, where flows change each day, exposing and/or inundating different portions of nesting sandbars.

During model simulations, as in real tern populations, individual adult Least Terns arrive from spring migration in breeding areas and make decisions about where they will join breeding colonies and where they will place their individual nests. Then, adult terns, nests, and chicks (if nests hatch) are subjected to a variety of potential mortality sources (e.g., flooding from high dam releases, predators, or human disturbance). If an adult's nest survives the incubation period and its chicks survive the chick rearing period, fledglings (young birds that can fly) are produced. If not, adults may re-nest, repeating colony and nest-site selection, unless it is too late in the breeding season, at which point both adult terns and the current year's fledglings depart for fall migration.

As a simulation model, TernCOLONY was designed to encourage rapid learning about Least Tern population and management dynamics through repetitive simulation of different sets of scenarios. Users can set up simulation experiments where they can easily simulate hundreds of breeding seasons, comparing one (or more) set(s) of initial conditions with others. For example, users may wish to understand how terns might respond to one 
habitat restoration scenario versus another (e.g., "would there be a difference in Least Tern reproductive success if we built three restoration sandbars or if we built 10?"). A web-based graphical user interface (GUI) at http://www.leasttern.org allows users to set up different scenarios, run these as simulations, and view (and save) their results.

\section{What is an individual-based model?}

An individual-based model (IBM) is a population model in which the actions of each individual in the population are represented explicitly (Grimm and Railsback 2005). IBMs are also simulation models. The behaviors of each individual in a population (in this case, adult Least Terns) are simulated within a representation of the physical environment (in this case, sandbars on large rivers with variable flows). Each of the individuals in the model makes decisions about how it will act in different environmental contexts based on key behavioral submodels, called "traits" in the IBM literature. The key behavioral models in TernCOLONY relate to the processes of colony and nest site selection, and site abandonment under extreme mortality pressure.

Behavioral models were designed following a protocol called the "patternoriented theory development cycle" (Grimm and Railsback 2005). For example, using this protocol to develop the colony site selection trait in TernCOLONY (Appendix A) required the following steps:

1. From the literature and field observations, develop a set of seven characteristic patterns of site use at the population level.

2. Also based on literature review, pose a large number of traits (behavioral models that individuals use to make decisions) for colony site selection to be tested, as hypotheses, in simulations.

3. Simulate the conditions under which the characteristic population-level patterns are expected to emerge in TernCOLONY.

4. Reject as false the hypothesized traits (models for individual behavior) that did not reproduce the population-level patterns during simulations.

5. In iterations throughout this cycle, revise promising traits and identify additional patterns for additional testing.

The premise behind this approach to modeling is that characteristics of populations emerge from the interactions of fitness-seeking individuals (Grimm and Railsback 2005). If population-level patterns can be reliably reproduced by simulating the behavior of individuals (interacting with 
each other and their environment) across a wide range of environmental contexts, IBMs can then be applied to novel situations where population response may be predicted. This requires confidence that the key behaviors of individuals are represented by traits that will faithfully predict the emergent properties of populations (e.g., distribution of individuals across sites, reproductive success) in simulations.

\section{What is this document?}

Since IBMs are typically more mechanistic (and thus complex) than other types of models, it is often a challenge to communicate their formulation and testing in ways that are both completely transparent and reproducible (Bart 1995, Grimm et al. 2006). The principal documentation for any IBM is the "Model Description" (Lott et al. 2012a). IBM model descriptions employ a standard format for communicating the details of an IBM thoroughly enough so that the model may be reproduced in other software (Grimm et al. 2006, 2010).

This document describes, in detail, the process of developing and testing Version 1 of the TernCOLONY model. Four of the major TernCOLONY submodels were complex enough to merit extensive testing on their own. Therefore, this document references four appendices that describe the pattern-oriented development of these submodels: colony site selection (Appendix A), nest site selection (Appendix B), site abandonment (Appendix C), and the various mortality submodels (Appendix D). Two additional appendices describe the two major whole-model tests that occurred after the first formulation of the full model: a parameter sensitivity analysis (Appendix E) and the calibration of several model parameters related to colony site selection and mortality (Appendix F). Appendix G documents the extensive verification of TernCOLONY's software implementation in Repast Simphony. Lott et al. (2012b) provides instructions for preparing model inputs for other regional applications of TernCOLONY.

Users who wish to begin using TernCOLONY without reading this documentation are encouraged to access the documentation and tutorials on the web-based version of TernCOLONY at http://www.leasttern.org. However, all users are encouraged to review the complete documentation to better understand why some of the behaviors that they observe during model simulations may occur and to help frame inferences that they may draw during model exploration. 
Additional documentation of the model's software and code, the relational database that stores model inputs and outputs, and a python script that was developed to prepare model inputs are available at http://www.leasttern.org. 


\section{Objectives and Project Structure}

\section{Project objectives}

This report documents the process of developing and testing TernCOLONY. The project's overall goal is to develop technology to better understand how reservoir operations and other management actions affect reproductive success of federally listed Least Tern (Sternula antillarum) populations that nest on large river sandbars, collectively referred to as the Interior Least Tern (ILT) population.

The project's main product is TernCOLONY, a web-available simulation model that addresses this goal. However, development and application of the model required several major project components conducted by several groups; these components are assembled and integrated in this report.

TernCOLONY is envisioned as a practical tool that can be actively explored to inform the development of species-focused management strategies at regional scales that are frequently addressed during Section 7 consultations under the Endangered Species Act (ESA). The model is designed to evaluate the potential effectiveness of multiple alternative management strategies to increase Least Tern reproductive success on a variety of different regulated river systems.

For example, simulation experiments can be developed to compare how two different predator management strategies or two different water control plans might affect Least Tern reproductive success. Simulations can be repeated with a range of different initial conditions (e.g., drought scenarios versus heavy rainfall scenarios, outstanding initial habitat conditions versus degraded initial habitat conditions) to assess how the outcomes of management strategies might vary in different environmental contexts.

Model exploration occurs through an intuitive and user-friendly web-based interface at http://www.leasttern.org. The goal of this interface is to translate a rather complex model into a learning environment that makes the model accessible to a wide range of users, maximizing the use of the model to increase understanding of Least Tern river management systems, 
particularly the mechanisms that lead to increases or decreases in reproductive success.

\section{Project organization and overview}

Understanding how ILT reproductive success is affected by reservoir flow releases and other management actions requires understanding processes ranging in scale from very broad (river flows throughout a reach; tern migration) to very fine (nest locations and peak water elevations on sandbars). Consequently, the TernCOLONY model requires input that is both detailed and extensive. Also, because of its scale, TernCOLONY is particularly challenging to observe: to understand and test its results, one needs to observe what happens over relatively short distances on each of many sandbars throughout a long river reach. To deal with these challenges, a strategy was used that separated the methods and software for (1) preparing input, (2) simulating the system), and (3) observing the simulation results. The link among these three components is a relational database that holds model inputs and outputs (http://www.leasttern.org).

One objective of this report is to document these project components. Chapter 3 describes the development of major model inputs for habitat, flows, and birds (see also Lott and Wiley 2012). Chapter 4 describes the TernCOLONY model itself, including the relational database (see also Lott et al. 2012a). Chapter 5 describes the web-based graphical interface for observing model results at http://www.leasttern.org.

\section{Participants}

The development of TernCOLONY was a collaborative effort among three major partners with funding from the U.S. Army Corps of Engineers (USACE). Casey Lott of American Bird Conservancy (ABC) conceptualized the project and was the project manager, working with partners to design both the model and the user interface with the river management community in mind as end-users. Casey Lott also prepared both flow and habitat inputs for the first application of TernCOLONY on the Arkansas River (Lott and Wiley 2012). Steve Railsback of Lang, Railsback, and Associates (LRA) was the primary modeler who worked with Casey Lott to formulate the model (Lott et al. 2012a) and then developed and tested each of the model's major submodels. Colin Sheppard, an associate of LRA, programmed the model in the Repast Simphony platform and designed the relational database to store model inputs and outputs. Colin Sheppard and 
Michael Koohafkan, also an associate of LRA, performed many model tests and verifications under the supervision of Steve Railsback. Steve Crawford of Penn State University's Center for Environmental Informatics (PSU-CEI) developed the majority of the GUI tools in Flex, and Blake Ketchum designed the website that surrounds the GUI at http://www.leasttern.org . Doug Miller, Brian Bills, John Miley, and Mike Stryker participated throughout the project on elements of the GUI, web-site, or data infrastructure to allow the model to be run remotely from the server at PSU-CEI. Rich Fischer was the primary point of contact for TernCOLONY's development within the USACE's Engineer Research and Development Center's Environmental Laboratory (ERDC-EL). Jonathon Valente of ERDC-EL and Matt Rubino, an independent consultant, worked on aspects of how to prepare model inputs so that TernCOLONY can easily be applied to other rivers. 


\section{Model Structure and Major Inputs}

\section{TernCOLONY model structure}

TernCOLONY simulates Least Tern breeding seasons in daily time-steps. Model adult terns arrive at breeding areas after spring migration and select colony and nest sites given variable habitat conditions. Nests and chicks survive or suffer mortality due to predators, flooding, ORVs, or other causes. Adults may re-nest after failed breeding attempts. The TernCOLONY model structure is illustrated in Figure 1.

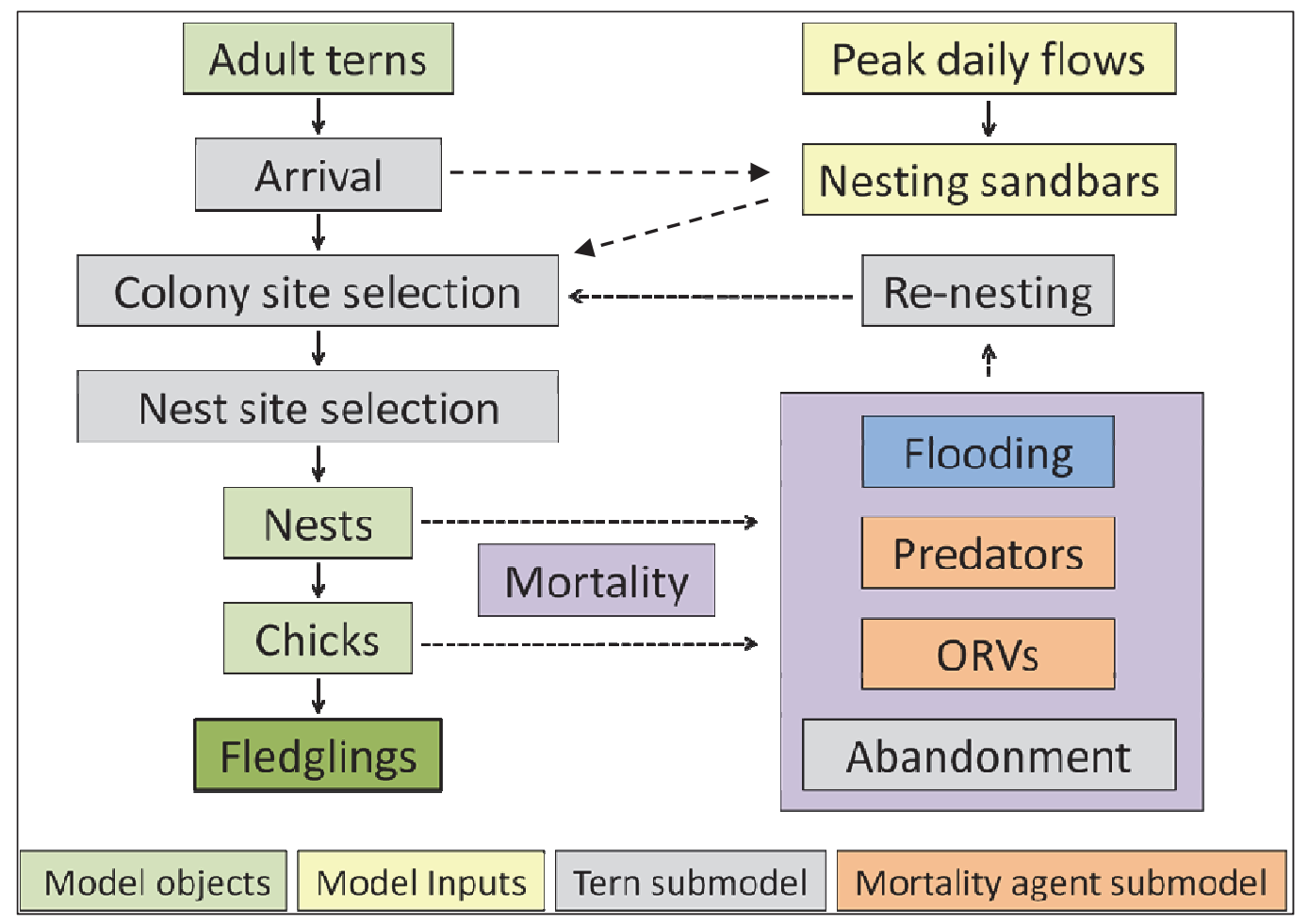

Figure 1. TernCOLONY model structure illustrating the model major inputs, objects, and submodels.

Through the web-based interface, users design simulation experiments to test how various initial conditions (or management treatments) affect Least Tern reproductive output. A variety of graphical displays encourage exploration of underlying mechanisms that drive reproductive success or failure. 


\section{Primary model inputs}

TernCOLONY represents potential sandbar nesting habitat as discrete sites. Habitat quality varies both among and within sites according to physical habitat covariates that are measured at the resolution of $36-\mathrm{ft}^{2}$ habitat cells. The exposure and quality of nesting habitat are affected by variation in daily flows, so the model updates habitat conditions at each daily time-step. Chapters 3 and 6 of the model description (Lott et al. 2012a) detail the properties of habitat input data.

Because dam releases and river flows exert strong effects on tern habitat availability and reproductive success, TernCOLONY requires time-series inputs of peak daily flows. Chapter 7 of the model description (Lott et al. 2012a) details the properties of flow input data. Peak daily flows (rather than mean daily flows, which are more widely available) are required as model inputs, since one of the primary objectives of the model is to assess flooding mortality of Least Tern nests and chicks. Mean daily flows consistently under-estimate flooding risk on regulated rivers with extreme sub-daily flow variation, which often includes many low-flow hours (Lott and Wiley 2012).

The critical behavioral trait of TernCOLONY is the submodel for Least Tern site selection (the location at which terns choose to form a colony and create nests). Site selection in any one year is affected by the distribution of nesting effort in the previous year through the behavior of site fidelity (Thompson et al. 1997). Therefore, the model also requires inputs on the prior distribution of nesting birds. Properties of these inputs are detailed in Chapter 8 of the model description.

While the model description details the characteristics of major input data, and how these inputs are used by the model, the section below overviews the field and/or analytical methods that were employed to prepare these inputs and illustrates the types of habitat, flow, and bird inputs that have been created for the first management area where this model has been applied: the Arkansas River below Keystone Dam. This section is intended to describe the process of preparing habitat inputs to meet the specific objectives of one regional application of TernCOLONY. Detailed methods for preparing model inputs for the Arkansas River management area are presented in Lott and Wiley (2012) and general considerations and tools for preparing model inputs for subsequent regional applications of TernCOLONY are presented in Lott et al. (2012b). 


\section{Habitat input methods}

Inputs for site-based variation in habitat quality on the Arkansas River below Keystone Dam were provided in one of two ways:

- From field measurements of sandbar nesting habitat.

- By creating simulated habitat datasets in ArcGIS.

Lott and Wiley (2012) describe field habitat data collection methods, GIS methods for post-processing field habitat data, methods for constructing site-specific relationships between flow and water surface elevations, and GIS methods for creating simulated habitat datasets.

These methods result in spatial data files representing habitat variation (e.g., shape files or digital elevation models) that can only be displayed in ArcGIS. Therefore, a script was developed using the programming language Python, to take spatial data inputs describing variation in habitat quality among sites and convert these into standard text file outputs that are then used to import habitat data into the Postgres database that stores TernCOLONY model inputs and outputs (http://www.leasttern.org).

This script has been found to be a tremendous time-saver and and it should be considered for use in preparing future habitat inputs for TernCOLONY. However, this is not required, as the model is designed to accept habitat inputs as text files that fit the standard formatting of the project's database tables, regardless of their derivation. Lott et al. (2012b) is a step-by-step user's manual for preparing all required tabular inputs to set up any new regional application of TernCOLONY.

The documents referenced above will be helpful in developing inputs for model applications in new management areas; however, it is expected that details of model input preparation will vary among applications, depending on the nature of the topographic and spatial data that are available (or need to be collected) for new management areas. Consequently, new applications should be preceded by area-specific implementation plans.

\section{Habitat input results}

For the Arkansas River below Keystone Dam, three different sets of sitebased habitat inputs reflecting different conditions/time periods were created. Each of these sets of site-based inputs is referred to as a "habitat 
input set." The preparation of these three discrete habitat input sets had two major objectives:

- To assess how variation in initial habitat conditions affects reproductive success (from the excellent habitat conditions that follow major habitat-forming flows to the degraded habitat conditions that occur due to plant succession and erosion several years after major habitat-forming flows).

- To explore how different strategies of mechanical habitat creation might increase Least Tern reproductive success.

The following three habitat input sets are available as inputs to the TernCOLONY model for the Arkansas River below Keystone Dam.

- Keystone 2008. This habitat input set, based on field habitat measurements, includes 32 sandbars that formed during the high dam releases of 2007 and 2008. These sandbars are relatively high in elevation and mostly free of vegetation. They represent the kind of "excellent" habitat conditions below Keystone Dam that have probably only existed three or four times in the 34 years since both Kaw and Keystone Dams have been in place, due to the low frequency of sustained high dam releases like those from 2007 and 2008 that tend to occur under normal dam operations.

- Keystone 2006. This simulated habitat input set represents the 25 sites that were present before the high flows of 2007. In general, these sites were lower and smaller than the 2008 sandbars. In many cases, they had quite a bit of vegetation on them. In some cases, really low sites that were regularly inundated were completely bare (but subject to extreme flooding risk). This habitat input set represents the "degraded" conditions that tend to occur on this river when high, habitat-forming flows do not occur for several years and both vegetation succession and erosion degrade existing sandbars. These conditions have been common during the post-dam era.

- Keystone Created. This simulated habitat input set includes 17 sites that users may add to the model as potential habitat restoration sites (e.g., representing mechanically constructed sandbars in new locations or efforts to completely remove vegetation and increase bare sandbar elevations by depositing new sand in areas where degraded sandbars currently occur). 


\section{Flow input methods}

Inputs for sandbar-specific time series of peak daily flows were created by the following process, which is presented in much greater detail in Lott and Wiley (2012):

- Hourly Keystone Dam release data were obtained directly from the U.S. Army Engineer District, Tulsa, Water Control Branch, and hourly flow data from downstream gauges at Tulsa and Haskell Dams were downloaded from the instantaneous data archive at: http://ida.water.usgs.gov/ida covering the time period from 1990-2008. 1990 was the earliest year that hourly data were available from both sources.

- After extensive data proofing, peak daily flow values were queried from hourly flow datasets.

- Mean daily flows for U.S. Geological Survey (USGS) gauges at Tulsa and Haskell Dams were downloaded for the entire post-dam time period covering 1977-2008 from http://waterdata.usgs.gov/nwis .

- For the 19 years between 1990 and 2008, where peak daily flows (from the hourly flow dataset) and mean daily flows were available, highly predictive regression models were created to predict peak daily flows from mean daily flows for both the Tulsa and Haskell Dam gauges (Lott and Wiley 2012).

- These models were then applied to the 13 years from 1977-1989 for which only mean daily flows were available. This extended the time series of peak daily flow inputs to the 32 years between 1977 and 2008 (Lott and Wiley 2012).

- Straight line interpolation by distance was used to generate sandbarspecific time series of peak daily flows at sites that were variable distances from gauges (Lott and Wiley 2012).

- Peak daily flow time series of sandbar-specific flows were imported to the database for all potential habitat input sites, spanning the dates from April 1- September 30. This range of dates conservatively brackets early and late dates for observations of Interior Least Terns in breeding areas from Montana through Texas (Thompson et al. 1997).

- Exploratory cluster analysis was used to classify each of the annual flow inputs into one of three different breeding season water year types using peak daily flow data from the Tulsa gauge, which most closely reflected the operations of Keystone Dam (Lott and Wiley 2012).

More detail on the steps that were taken to prepare flow inputs for the Arkansas River below the Keystone Dam management area can be found in 
Lott and Wiley (2012). This document can help to guide the preparation of flow inputs for other applications of the TernCOLONY model in different areas. However, similar to habitat inputs, the model is designed to accept text files with peak daily flow inputs that fit the standard formatting of the project's database tables, regardless of their derivation. Therefore, other methods of preparing peak daily flow time series are possible, as long as data are formatted properly for import into the TernCOLONY database. Lott et al. (2012b) includes instructions on how to prepare all required tabular inputs to set up any new regional application of TernCOLONY.

\section{Flow input results}

A single flow input set was created for the Arkansas River below the Keystone Dam management area (Lott and Wiley 2012). This set includes 32 annual flow inputs (from 1977-2008) of sandbar-specific peak daily flows for each of the potential nesting site input locations in the model. This flow input set reflects the post-dam era on the Lower Arkansas River. 1977 was chosen as the cut-off for this period to reflect completion dates (and reservoir fill times) for both Kaw and Keystone Dams.

Although they have not as yet been prepared, additional flow input sets could be created based on:

- Empirical flow data or models of daily flow conditions prior to dam construction (e.g., the pre-dam era).

- Models of peak daily flows that might occur under different water control strategies (e.g., flow management alternatives).

The 32 years of annual flow input data for the post-dam era flow input set were classified into three different water year types:

- Low-water years (50\% of all years): breeding seasons where peak daily flows are consistently near or below peak hydropower releases of $\sim 13,000 \mathrm{cfs}$ through the majority of the breeding season, presenting little flooding risk for nests or chicks. If higher flows occurred, they were usually less than 20,000 cfs and happened early in the breeding season.

- Years with early low water, with mid- to late-season flooding ( $28 \%$ of all years): breeding seasons where flows were low early in the season, during colony site selection and nest initiation, but where moderate flooding (e.g., flows between 20,000-50,000 cfs) occurred during the 
second half of the breeding season. These years have the potential for large amounts of nest or chick mortality.

- High-water years (22\% of all years): Sustained high flows (>40,000 cfs) covering a large part of the breeding season may have precluded nesting entirely (due to the inundation of all sandbars) or caused extensive mortality to nests or chicks (if flooding occurred after nest initiation).

Water year types reflect common annual flow patterns during the Least Tern breeding season. These will vary by river system due to differences in reservoir operations and regional differences in precipitation and runoff in contributing areas below dams. The analysis used to classify water years to water year types specific to the Arkansas River below Keystone Dam are presented in Lott and Wiley (2012). Similar analyses could define different "water year types," and classify individual years to types for other river systems.

\section{Prior bird distribution inputs}

TernCOLONY's arrival submodel (see Chapter 8 of the model description report) requires a tabular input detailing a prior distribution of tern nesting. This distribution can be unique to a particular flow input set. Lott et al. (2012b) illustrate the format these tabular inputs must take.

Two prior bird distribution inputs were created for the Arkansas River below Keystone Dam:

- The first prior bird distribution input is based on 2005 bird surveys by the Tulsa District. This is used as the prior bird distribution input for the Keystone 2006 habitat input set. In 2005, a brief flood in June wiped out all nesting, but flows were appropriate for successful renesting throughout the study area late in the season. The nest counts used were obtained on 28 July from Tulsa to Muskogee (the majority of all nesting sites) and on 2 August for the two sites upstream of Zink Island. Since no reliable nest counts were available for Zink Island during this time period, a value of 15 nests was input for Zink Island, reflecting peak nesting totals for this site in 2004 (and an adult count of 25 birds in mid-June of 2005).

- The second prior bird distribution input is based on 2008 bird surveys by the Tulsa District. This is used as the prior bird distribution input for the Keystone 2008 habitat input set. Nesting was delayed in 2008 due to high flows early in the season, which inundated sandbars. 
Counts obtained on 23 July from Zink Island to Muskogee were used. Upstream areas were not surveyed in 2008. However, one site in this area was used in 2009. A nest count of 5 (from a survey of this site in 2009) was added.

A bird distribution input set specific to the Keystone-created habitat input set was not developed. Sites in this category will be added to the model after either the Keystone 2006 or Keystone 2008 habitat input sets (and their associated bird distribution inputs) have been selected. A simulation using this input set will examine how creating four restoration sandbars might improve reproductive success given the degraded habitat conditions that prevailed in 2006. 


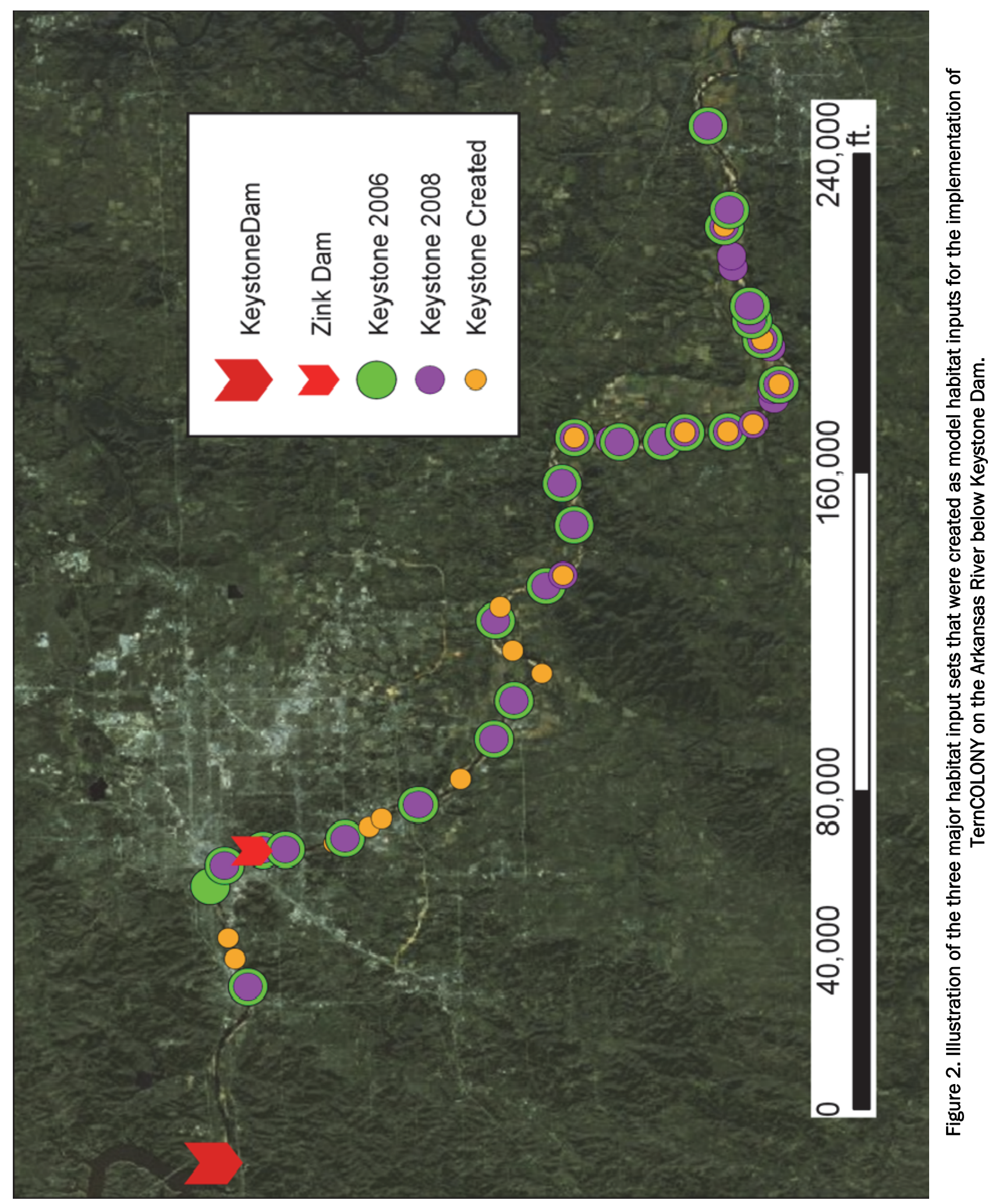




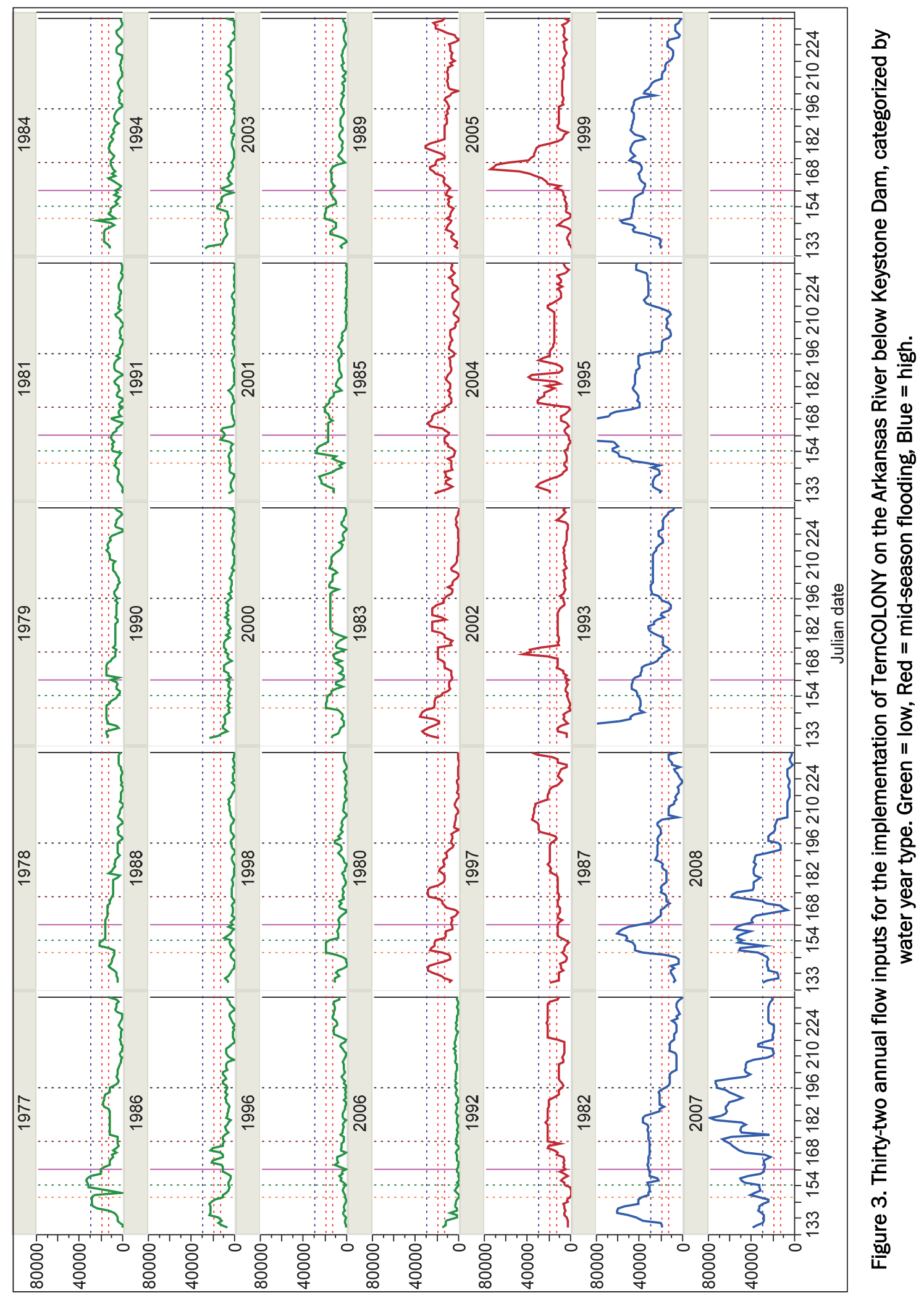




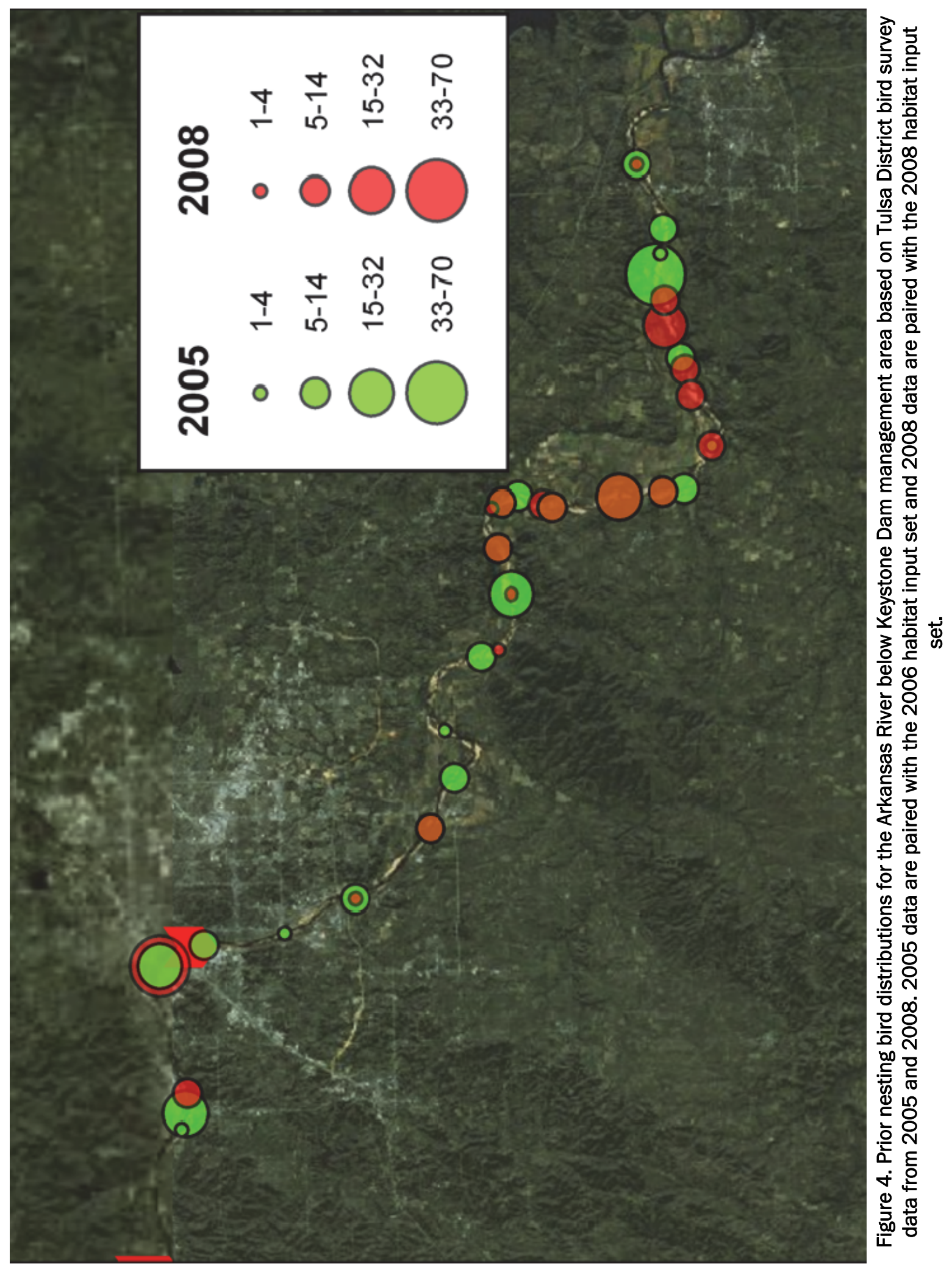




\section{Model Details}

TernCOLONY is the individual-based simulation model developed under this project as a tool for predicting and understanding effects of management actions on ILT reproductive success. Developing TernCOLONY was not just a process of inventing a model formulation (its assumptions, equations, and parameter values) and programming it. Instead, model development included thorough review of literature and field studies to identify an efficient model structure-the kinds of entities, processes, and variables needed to meet the model's objectives without unnecessary detail; thorough analyses of the submodels that represent important processes; and analysis and calibration of the full model. These steps are documented here.

\section{Model description}

The formulation, or model description, of TernCOLONY 1.0 is fully documented in Lott et al. (2012a). This document is designed solely to describe the model itself, not its application to any particular site. The model description attempts to describe the model in enough detail so that it could, in principle, be exactly re-implemented in new software. While a few exceptions are likely, the authors strived to ensure that all assumptions and methods used in the model's software are documented in its written description.

The model description also documents the basis for the model's assumptions and parameter values. Parts of the model were based on literature or even just judgment based on field experience. However, its most important processes were based on extensive "theory development" analyses (Grimm and Railsback 2005): posing alternative theories for how terns make key decisions and then testing them by how well they reproduce observed patterns.

This report contains three appendices that document the detailed analysis used to develop one of TernCOLONY's three key processes: colony site selection (Appendix A), nest site selection (Appendix B), and site abandonment (Appendix C). 


\section{Model analyses}

After TernCOLONY was designed and implemented in software, it was analyzed extensively to understand its behavior and calibrate it. Three analyses are documented in this report.

The mortality analysis examined and calibrated the mortality submodel; it is documented in Appendix D. TernCOLONY represents mortality risks as "agents," each of which represents a general kind of predator or other cause of mortality. The model version documented here includes four kinds of mortality agents: nest predators (animals such as coyotes that eat tern eggs), chick predators (animals such as owls that kill chicks), adult predators (such as falcons), and off-road vehicles (ORVs) that can destroy nests and result in the death of chicks. The analysis used simulation experiments to find parameter values that produce realistic levels of mortality due to these agents.

The sensitivity analysis, documented in Appendix E, systematically analyzes how strongly each of the model's parameters affects several key model results. This kind of parameter sensitivity analysis is considered a standard, important part of model development. Its sensitivity to each parameter is one way the model indicates how important each of its processes is to reproductive success. Sensitivity analysis is also important in identifying the best parameters for calibrating the model.

The final analysis is calibration, a process of adjusting the values of key parameters to make the model reproduce observed patterns or more closely resemble empirical data on reproductive performance. The calibration is documented in Appendix F. 


\section{Software}

TernCOLONY was programmed using the Repast Simphony platform (http://repast.sourceforge.net). Repast was used as a library of Java code supporting individual-based modeling inside the Eclipse software development environment. Repast's graphical display capabilities were not easily adapted to TernCOLONY with its simultaneous representation of many different sandbars.Therefore, the model was programmed to write output for subsequent display in the web-based interface (Chapter 6) instead of having its own graphical displays.

The extensive input needed by TernCOLONY, and the extensive output it produces for display in the web interface, are stored in a relational database. The database is implemented in PostgreSQL software (www.postgresql.org). Database contents can also be accessed and analyzed via the popular statistical platform R. The entire flow of information through the modeling process is illustrated in Figure 5.

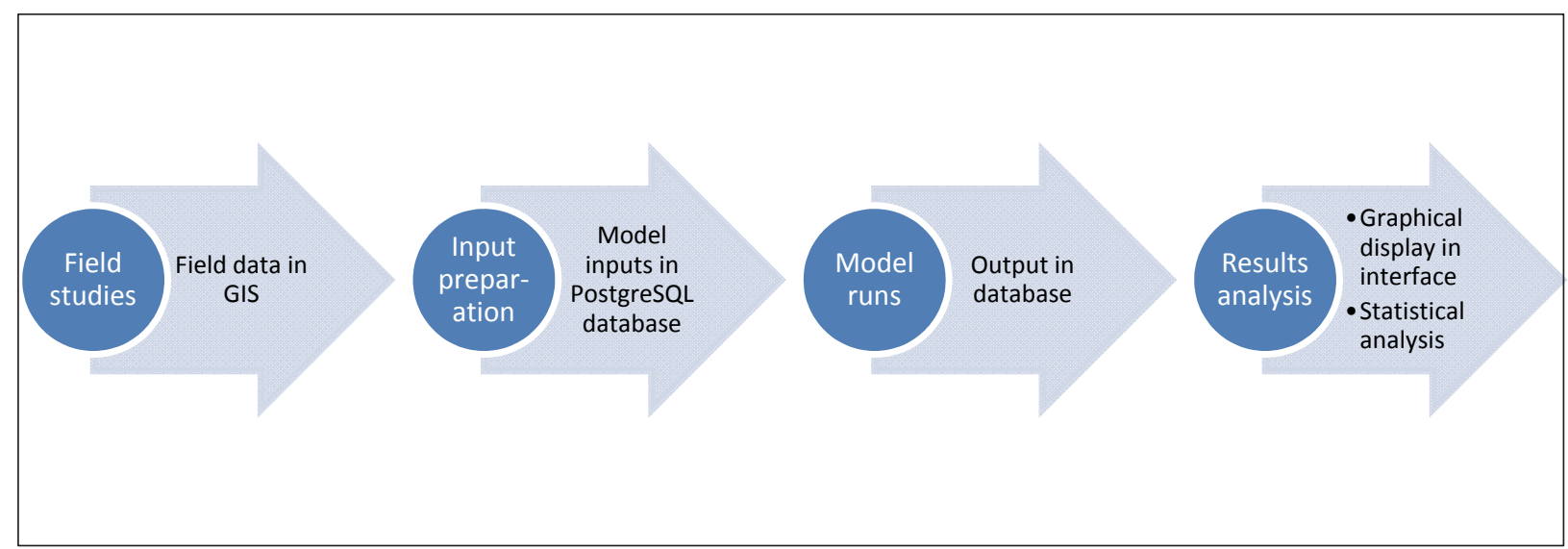

Figure 5. Information flow used by TernCOLONY. Circles represent analysis tasks, and text in the arrows describes the information produced. Field studies produce data that are interpreted and prepared as model input using geographic information system (GIS) software. From GIS, the input is entered into the PostgreSQL database. The TernCOLONY model software reads its input from, and writes output to, the database. Results can then be viewed and analyzed from the database via the web interface or by using statistical software.

It is anticipated that most users of TernCOLONY will set up and execute model runs through its web interface at http://www.leasttern.org instead of installing the Repast software locally and running it directly. However, several kinds of software documentation are still important. 
First, guidance for installing the model software is provided to support users who want a local copy of the software and also to support updates on the web interface server. This guidance is available at http://www.leasttern.org.

Second, the PostgreSQL database is described to facilitate its use in statistical analyses and its future maintenance and modification. The database is quite complex, with contents including all the inputs to the model, results of model runs, and metadata to identify and document model runs and multi-run simulation experiments. This guidance is available at http://www.leasttern.org.

Finally, software testing is extremely important for a model as complex as TernCOLONY. An extensive series of tests was conducted to verify that the code implements the model's written description accurately. Documentation of these tests provides users with assurance that the software was tested extensively, and supports future re-testing as the model and software are updated. This documentation includes a number of extremely large computer files that are archived, and available upon request, with a summary description in Appendix G. 


\section{Web Interface}

TernCOLONY is unique among complex individual-based models in that it is fully web-accessible, allowing users that are unfamiliar with development or analysis environments (e.g., Repast Simphony, $R$ ) to fully configure and explore simulation experiments. While this report includes seven appendices and references several other reports that provide the full documentation for TernCOLONY, additional documentation is available with the webbased version of the model at http://www.leasttern.org. At a bare minimum, this document, plus the context-specific tutorials available online, should provide enough instruction for users who are unfamiliar with the full model documentation to use the online version of the model. These users should then be able to learn about least tern populations and alternative management scenarios to increase reproductive success; they should also be able to interpret and share their findings with others.

\section{Leasttern.org}

TernCOLONY is docked within a website, http://www.leasttern.org, with two main content blocks. Two of the main website channels, just below the masthead, link to background information about Least Tern biology and management issues that TernCOLONY users should find useful to generate ideas for simulation experiments. For additional context on Least Tern biology, a large, searchable bibliography (with >800 references) is available through the Bibliography channel. A second content element of the http://www.leasttern.org site is the "features" link that frames many pages. Features provide additional context, highlighting topical publications, tutorials, or sample applications of TernCOLONY. The primary functional elements of TernCOLONY are reached from the four prominent buttons on the http://www.leasttern.org home page, which are described below.

While the site is open to all participants, registration is required to obtain a user name and password. This allows users to call up only the results of their own simulation experiments (plus publically available experiments that are used in tutorials) from the database. Without this feature, dropdown lists to "select previous experiments" would quickly become lengthy or confusing if each user was viewing stored data from all users. 


\section{Creating and running simulation experiments}

The "Create your own experiment" button at http://www.leasttern.org links to a series of nine screens that guide users through the process of creating their own simulation experiments. By following instructions on these screens, users specify model inputs for habitat, flows, predators, human disturbance, and tern population size. Using these screens, users may also specify factorial designs for their simulation experiments (e.g., comparing tern reproductive performance among different combinations of habitat and predator inputs). The "Create your own experiment" screen can also be used to quickly view complete metadata for previous simulation experiments.

\section{Exploring simulation results}

Two of the main TernCOLONY buttons are related to exploring the results of previous simulation experiments. The "Explore previous experiments" button links to a powerful graph creation tool that allows users to explore data from simulation experiments (e.g., batches of multiple model runs) for a large number of metrics (e.g., reproductive success, number of breeding attempts/female, causes of mortality) by various data groupings (e.g., by levels of each experimental factor, water year type, or year). This tool also presents a number of standard data summaries for users who would like to begin with this information and then modify standard charts to suit their individual needs. All graphs created by this tool can be exported as .png or .pdf images to be imported into reports and presentations. Users may also download raw simulation data as text files if they prefer to explore or analyze it in other platforms.

The "Observe a single breeding season" button allows users to observe any of the single breeding seasons from any of their saved simulation experiments, in daily time-steps. Panels of maps and graphs illustrate daily changes in habitat conditions, the bird population, and causes of mortality. While the "Explore previous experiments" button is very useful for summarizing the results of many breeding seasons, the "Observe a single breeding season" button allows users to watch more closely for mechanisms that may be driving model outputs.

\section{Online documentation and tutorials}

The "Learn how to use the model" button directs users to the model's full documentation (this report, with all appendices, plus the Lott and Wiley 
[2012] publication that provides many details about model inputs). It also references several tutorials that will help to get users started with online model exploration and answer questions about how to perform specific tasks. 


\section{Future Directions}

This document reflects the development of the first release of TernCOLONY, release 1.0, which was made publically available on 30 September 2011. This version has been applied to only a single management area: the Arkansas River below Keystone Dam in Oklahoma. American Bird Conservancy has plans to implement an application of the model to the Red River below Denison Dam, using existing habitat data from habitat measurements conducted in 2008. The USACE ERDC-EL has plans to implement two applications of the model on the Missouri River, one below Garrison Dam and the other below Gavins Point Dam, using both historic habitat measurements as well as new habitat measurements that were collected when water receded from the unprecedented floods of 2011. The website at http://www.leasttern.org was designed to make these applications available upon completion.

While the web version of TernCOLONY 1.0 is more thoroughly tested by users, the development team from ABC, PSU, and LRA will pursue publication of the model (and model applications) via peer-reviewed outlets. These publications will expand upon some of the analyses documented in this report and appendices, as well as tackling specific management issues on the Arkansas River, and other new subject areas. All new publications will be made available at http://www.leasttern.org.

While TernCOLONY 1.0 was designed for Least Tern populations nesting on large rivers, it could potentially be adapted for other river nesting species (e.g., piping plovers, various sandbar-nesting turtles), for groundnesting birds in other habitat types (e.g., coastal Least Terns or black skimmers), and potentially for other species of colonial nesting birds in other systems (e.g., herons, gulls, other seabirds). To discuss potential applications of TernCOLONY to other species or contexts, please contact Casey Lott of American Bird Conservancy, clott@abcbirds.org. 


\section{References}

Bart, J. 1995. Acceptance criteria for using individual-based models to make management decisions. Ecological Applications 5: 411-420.

Grimm, V., and S.F. Railsback. 2005. Individual-based modeling and ecology. Princeton Press.

Grimm, V., U. Berger, F. Bastiansen, S. Eliassen, V. Ginot, J. Giske, J. Goss-Custard, T. Grand, S. Heinz, G. Huse, A. Huth, J. U. Jepsen, C. Jørgensen, W. M. Mooij, B. Müller, G. Pe'er, C. Piou, S. F. Railsback, A. M. Robbins, M. M. Robbins, E. Rossmanith, N. Rüger, E. Strand, S. Souissi, R. A. Stillman, R. Vabø, U. Visser, and D. L. DeAngelis. 2006. A standard protocol for describing individual-based and agent-based models. Ecological Modeling 198:115-296.

Grimm, V., U. Berger, D. L. DeAngelis, G. Polhill, J. Giske, and S. F. Railsback. 2010. The ODD protocol: A review and first update. Ecological Modeling 221: 2760-2768.

Lott, C.A. 2006. Distribution and abundance of the interior population of Least Tern (Sternula antillarum) 2005: A review of the first comprehensive range-wide survey in the context of historic and ongoing monitoring efforts. ERDC/EL TRo6-13. Vicksburg, MS: U.S. Army Engineer Research and Development Center.

Lott, C.A., and R.L. Wiley. 2012. Effects of dam operations on Least Tern nesting habitat and reproductive success below Keystone Dam on the Arkansas River. ERDC/EL CR-12-4. Vicksburg, MS: U.S. Army Engineer Research and Development Center.

Lott, C.A., S.F. Railsback, and C.J.R. Sheppard. 2012a. TernCOLONY 1.o model description. ERDC/EL CR-12-3. Vicksburg, MS: U.S. Army Engineer Research and Development Center.

Lott, C.A., J.J. Valente, R.A. Fischer, and C.J.R Sheppard. 2012b. Preparing model inputs for new applications of the TernCOLONY simulation model. ERDC/EL CR-1232. Vicksburg, MS: U.S. Army Engineer Research and Development Center.

Massey, B.W., and J.M. Fancher. 1989. Renesting by California Least Terns. Journal of Field Ornithology 60: 350-357.

Szell, C. C., and M. S. Woodrey. 2003. Reproductive ecology of the Least Tern along the Lower Mississippi River. Waterbirds 26: 35-43.

Thompson, B.C., J. A. Jackson, J. Burger, L. A. Hill, E. M. Kirsch, and J. L. Atwood. 1997. Least Tern: Sterna antillarum. In Birds of North America. ed. A. Poole and F. Gill. Philadelphia, PA and Washington, DC: The Academy of Natural Science and the American Ornithologists Union.

U.S. Army Corps of Engineers (USACE). 2009. Least Tern and Piping Plover Monitoring Handbook. Omaha, NE: U.S. Army Engineer District, Omaha.

U.S. Fish and Wildlife Service (USFWS). 1990. Recovery plan for the interior population of the Least Tern ( $\sim$ Sterna antillarum $)$. Twin Cities, MN. 


\section{Appendix A: Colony Site Selection Submodel Development}

\section{Introduction}

The objective of the research documented here is to develop an individualbased trait for colony site selection in Interior Least Terns (ILT). An individual-based trait is a model of individual behavior that has been tested and shown, in an individual-based model, to reproduce observed patterns that characterize the population level (Grimm and Railsback 2005).

Colony site selection and nest site selection are treated as two different (and hierarchical) behaviors that result in the actual location of nests. In this document, the word "colony" refers to a group of ILT that have individually selected a site where they will later place nests. Colony site selection thus refers to the actual behavior of adult terns choosing a site (in this study, a river sandbar) to form (or join) a colony. This decision occurs prior to the behavior of "nest site selection," which has been developed as a separate behavioral model that results in the placement of a nest in an exact location (from all available locations) on a sandbar where a colony has formed (Appendix B).

Development of the full TernCOLONY model required the early development of both the arrival and colony site selection submodels. Consequently, the colony site selection submodel was developed using an early version of the code that lacked submodels for site abandonment or re-nesting after mortality. Early versions of the code also did not include the mating submodel, which may affect how synchronized nest initiation dates may be within a colony (Lott et al. 2012). Similarly, the tests reported on herein used an early version of model habitat inputs that included only a subset of the 32 sandbars that existed after the 2007 floods below Keystone Dam (main report, Chapter 3).

Colony site selection is likely to be affected by both the processes listed above and by initial habitat conditions. Consequently, tests will be re-run with the full version of the TernCOLONY 1.0 model in the near future. This document will be updated accordingly and the model description will be 
updated, if necessary, if future tests result in any changes to the colony site selection trait.

\section{Methods}

The pattern-oriented theory development cycle of Grimm et al. (2005) and Grimm and Railsback (2005) was followed in designing the colony site selection trait in TernCOLONY.

\section{General approach}

Literature and field observations were used to develop a set of seven characteristic patterns of site use at the population level. A literature review was also used to develop a number of traits (behavioral models that individuals use to make decisions) for colony site selection. These traits will be tested, as hypotheses, in simulations. The conditions under which the characteristic population-level patterns of site use are expected to emerge in TernCOLONY were then simulated. The hypothesized traits (models for individual behavior) that did not reproduce the populationlevel patterns during simulations were rejected as false. In iterations throughout this cycle, promising traits were revised and patterns appropriate for additional testing were identified.

The patterns used to develop and test the colony site selection trait are relevant to the purpose of the model. The primary purposes of this IBM are to understand and predict how reproductive success is affected by (a) river flows during the breeding season, and (b) the number, location, and habitat characteristics of sandbars. To meet this purpose, the model needs to represent how the number of terns selecting a site is affected by the spatial arrangement of sites, flow variation, and the site's habitat characteristics. Hence, the patterns characterize the relations among colony site selection, site characteristics, and flow.

\section{Patterns of ILT site use}

The characteristic patterns of site use that were used to test alternative colony site selection traits were identified from several sources. Some patterns were identified from literature. Others were identified from unpublished field observations, particularly data on nest locations and timing collected from 1999-2006 on the Missouri River (partially reported in U.S. Army Corps of Engineers (USACE) 2011) and from 2005-2009 on the Keystone Reach of the Arkansas River. 
The authors agree with Jones (2001) that "habitat selection is a process, not a pattern." Specifically, habitat selection is a behavioral process, which always occurs within a specific environmental context, where individuals choose among all available alternatives (e.g., one site is chosen from a range of potential sites). Habitat use patterns are simply the end result of the habitat-selection process. Various behaviors, interacting with environmental contexts, may be responsible for observed patterns of habitat use. The challenge in IBM trait development is creating a model that represents how individuals make decisions, across a range of contexts, and that reproduces patterns of site use in simulations that occur across a wide range of contexts.

Patterns in ILT site use emerge-in the IBM as well as in reality-from decisions made by individual birds that are affected by the habitat conditions that are present when each bird selects a colony site. Therefore, patterns of site use in the same river reach can change from year to year as patterns in the timing, magnitude, or duration of flows or in the habitat characteristics of sandbars also change.

The first three patterns defined below are very basic and used to screen out any traits that would not reproduce the most basic elements of colony site selection behavior from further analysis. This document does not include detailed analysis of any alternative traits that did not reproduce these three basic patterns in simulations.

It should be noted here that ILT colony site selection on rivers occurred for many years during a time period when flows typically declined rapidly during nest initiation (Figure A1). However, the patterns of site use documented here, and used for model development, have been observed after dam placement has caused major alteration to both hydrographs and sandbar characteristics.

It is possible that, prior to river alteration, colony site selection may have been more strongly influenced by falling hydrographs than it is today. Consequently, a trait was designed that forced terns to base their colony selection decision on which site was most recently exposed. However, this trait failed to reproduce several of the test patterns described below and was thus rejected from future consideration. 


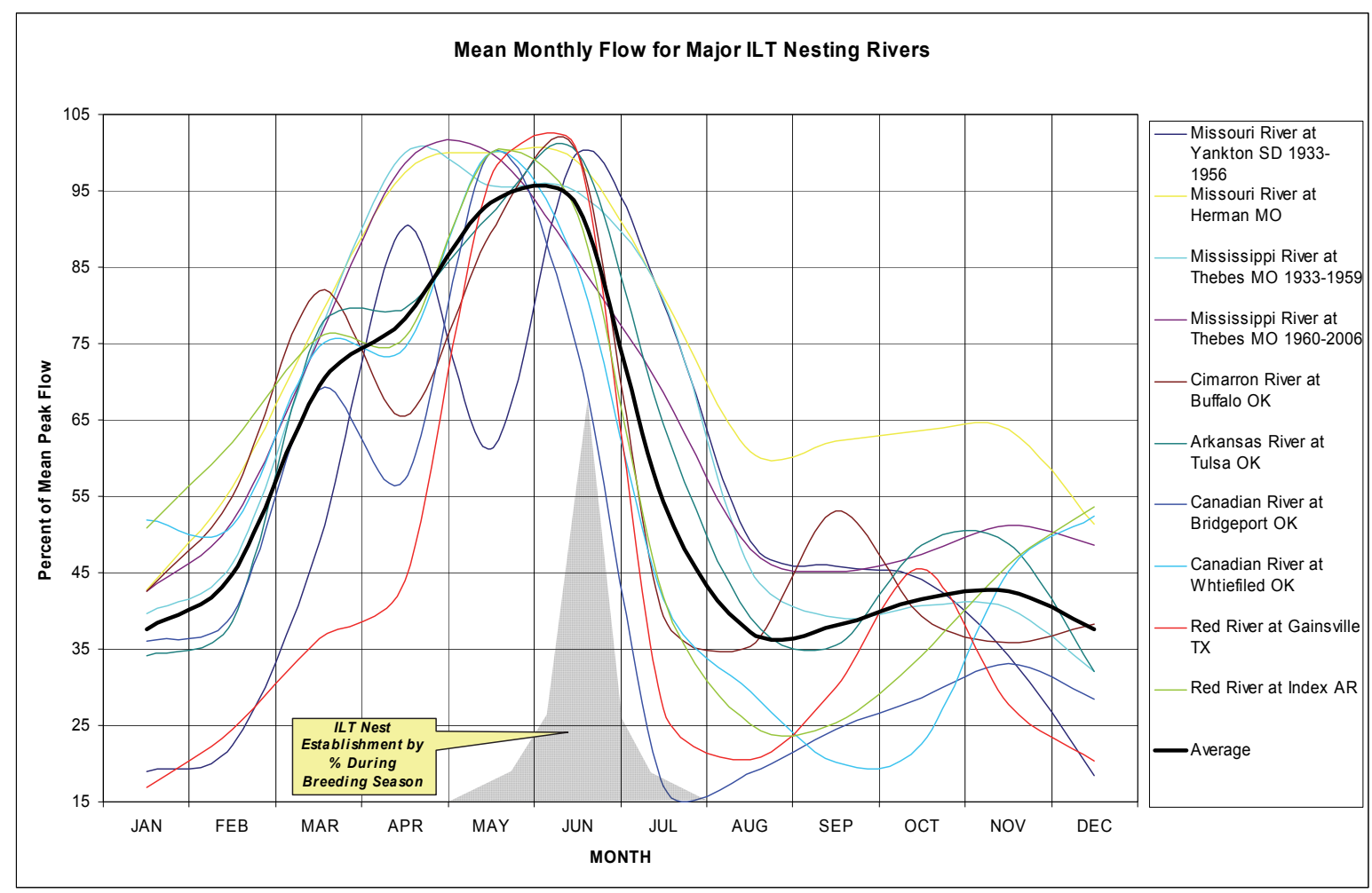

Figure A1. Annual hydrographs for a number of rivers within the ILT breeding range. These hydrographs represent pre-alteration conditions on currently managed rivers or locations where minimal alteration to the hydrograph has occurred after alteration.

\section{Basic test patterns for screening out implausible traits ${ }^{1}$}

\section{Pattern 1: Terns select multiple sites}

This pattern simply assumes that ILT in a river reach nest on many different sandbars. This pattern is met if the population of terns always nests on more than a single sandbar. An example trait that would not reproduce this pattern is for all terns to select the one site in the reach with highest-quality habitat.

\section{Pattern 2: Colony abundance varies over time}

This pattern assumes that the number of ILT at a site increases over time as adults arrive from migration, instead of all the colony's terns selecting the site simultaneously. The pattern is met if, for all colonies, the time between first and last selection of the site is more than three days. The pattern is supported by the Missouri and Arkansas River field observations. Traits 
that assume colony site selection is highly synchronized across the population (because all terns arrive in breeding areas at the same time) or across sites (e.g., because all of a colony's terns migrate together) would not reproduce this pattern.

Pattern 3: Use of new high-quality sites

New potential colony sites can be created artificially as a management technique, or by flooding that creates new, bare bars. Terns have been observed to occupy such new sites as soon as these sites are available (USACE 2011). This pattern is met if ILT select sites that did not exist the previous year. Traits that assume terns always return to the sites they used the previous year would not reproduce this pattern if new sites are spatially isolated.

Note: this pattern was not addressed during initial development of the colony site selection trait. However, it was confirmed during calibration experiments (Appendix F) that this pattern was met using the final colony site selection trait described in Lott et al. (2012).

\section{More detailed patterns for trait evaluation}

The remaining patterns are evaluated explicitly in Section 3 of this appendix, "Results."

Pattern 4: Largest colonies by the end of the season are not always occupied first

The Missouri and Arkansas River data show that the largest colonies are not necessarily at the sites that were occupied first. This pattern is met if the largest colony is not always the first occupied, across simulations with different annual flow inputs, including replicate simulations (large colonies could be occupied first by chance or unusual circumstances such as extremely high flows). Traits that assume terns all select the "best" site until some site capacity limit is met are not expected to reproduce this pattern. 
Pattern 5: Many sites are selected over a relatively narrow range of dates. ${ }^{1}$

Field observations of when nests are formed imply that the range of dates over which terns select individual sites is often smaller than the entire range of arrival dates for all sites. In particular, the Missouri River data set includes an estimate of the date on which nests were initiated at 123 sites. These data allow comparison of the range of dates over which nests were initiated at each site (the last date of nest initiation minus the first date of nest initiation, plus one) and the total range over which nests were initiated in the whole river reach, for each year. The ratio of site to total range of nesting dates varied widely among sites (Figure A2), but approximately 70\% of sites had a ratio less than 0.5 , and about $90 \%$ of sites had a ratio less than 0.7. Applying these nest initiation observations to colony site selection requires assuming that the time between colony site selection and nesting is relatively constant, whereas behaviors such as mating could further synchronize nest initiation. Therefore, this pattern is defined as being met if, for the dates on which terns select sites, the ratio of site date range to river-total date range is 0.7 or less at $50 \%$ or more of sites.

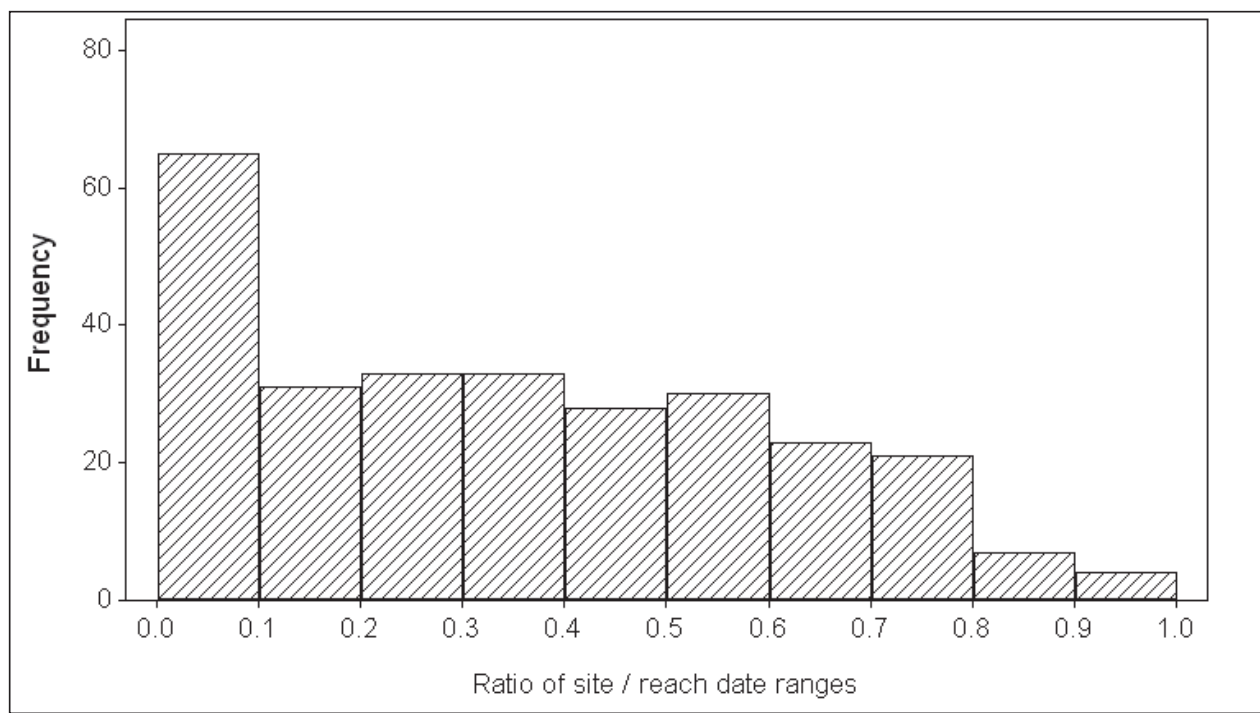

Figure A2. Histogram of the ratio of site/river-wide arrival date ranges in the Missouri River data set. Separate values were determined for each occupied site in each year. The ratio had a mean of 0.35 and median of 0.32 .

\footnotetext{
${ }^{1}$ Initial tests were based on the dates by which adult terns selected sites. Future tests, to be more consistent with the source data that were used to define the patterns, will be based on nest initiation dates.
} 
Pattern 6: Habitat quality has a limited effect on colony site

Sandbar nesting sites vary in habitat quality as evaluated by factors such as freeboard (the difference in elevation between the highest part of the sandbar and the water surface) and distance from vegetation and forest (see Lott et al. 2012). When high-quality sites are relatively abundant compared to the ILT population size, the relationship between site habitat quality and colony size is typically positive, but weak. Specifically, this pattern is defined by three criteria:

1. Some (one or more) high-quality sites have few terns, defined here as being selected by fewer than four adult terns. "High-quality sites" are defined as those with habitat quality index values (as defined in the model description) in the upper third of all sites (including sites not selected by any terns).

2. Some low-quality sites are used for nesting, defined here as selected for nesting by at least four terns. "Low-quality sites" are defined as those with habitat quality values in the lower third of all sites.

3. Across all sites, there is a weak but positive relationship between site habitat quality and colony size; colonies on high-quality sites tend to be larger than those on low-quality sites but there is a high degree of variation in the relation. Specifically, this pattern is defined as being met if a regression of colony size versus habitat quality index has a slope that is positive and significant at $\mathrm{p}=0.1$ but with $\mathrm{R}^{2}$ less than 0.5 .

Although habitat quality varies with flow, the values used for this analysis included the maximum habitat quality cell at each site with a standard flow of 13,000 cfs as an index to site habitat quality.

Pattern 7: Colony sizes follow a characteristic distribution within a region

Both the Missouri and Arkansas River datasets produce a regional colony size distribution with several distinct attributes that seem to characterize colony site selection when relatively high-quality sandbars are abundant (Figures A3-A5). Colony size distribution refers to the shape of a graph of colony sizes by site, with the $\mathrm{X}$ axis representing the site rank (in order from largest to smallest colonies, starting at 1 for the site with the largest colony) and the $\mathrm{Y}$ axis representing the cumulative proportion of all nests at the sites. Hence, the first point on the graph (at $X=1)$ shows what proportion of all nests were at the largest colony; the $\mathrm{Y}$ value of the second point on the graph is the proportion of all nests in the first- and 


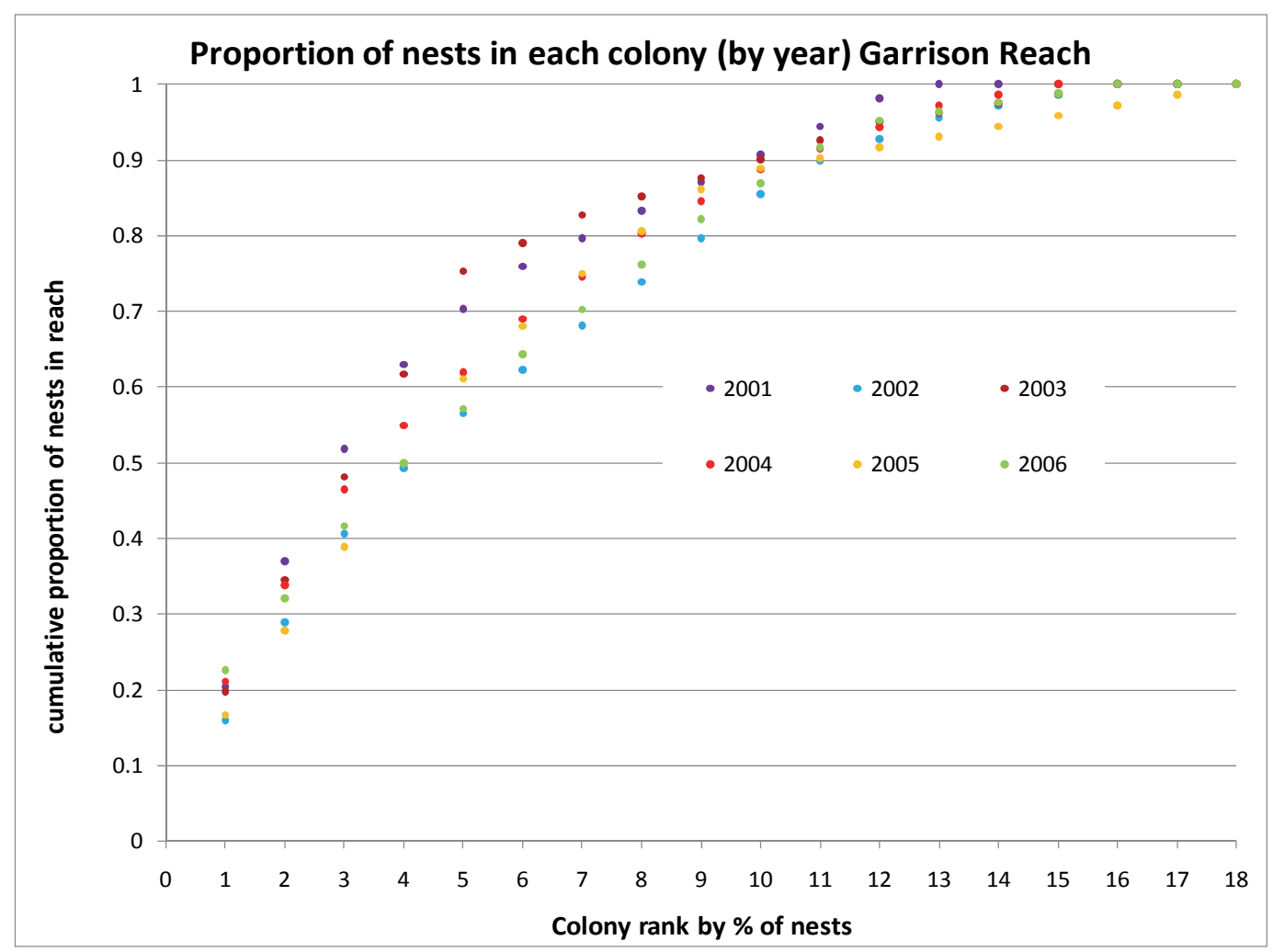

Figure A3. Colony size distributions for six years on the Garrison reach of the Missouri River.

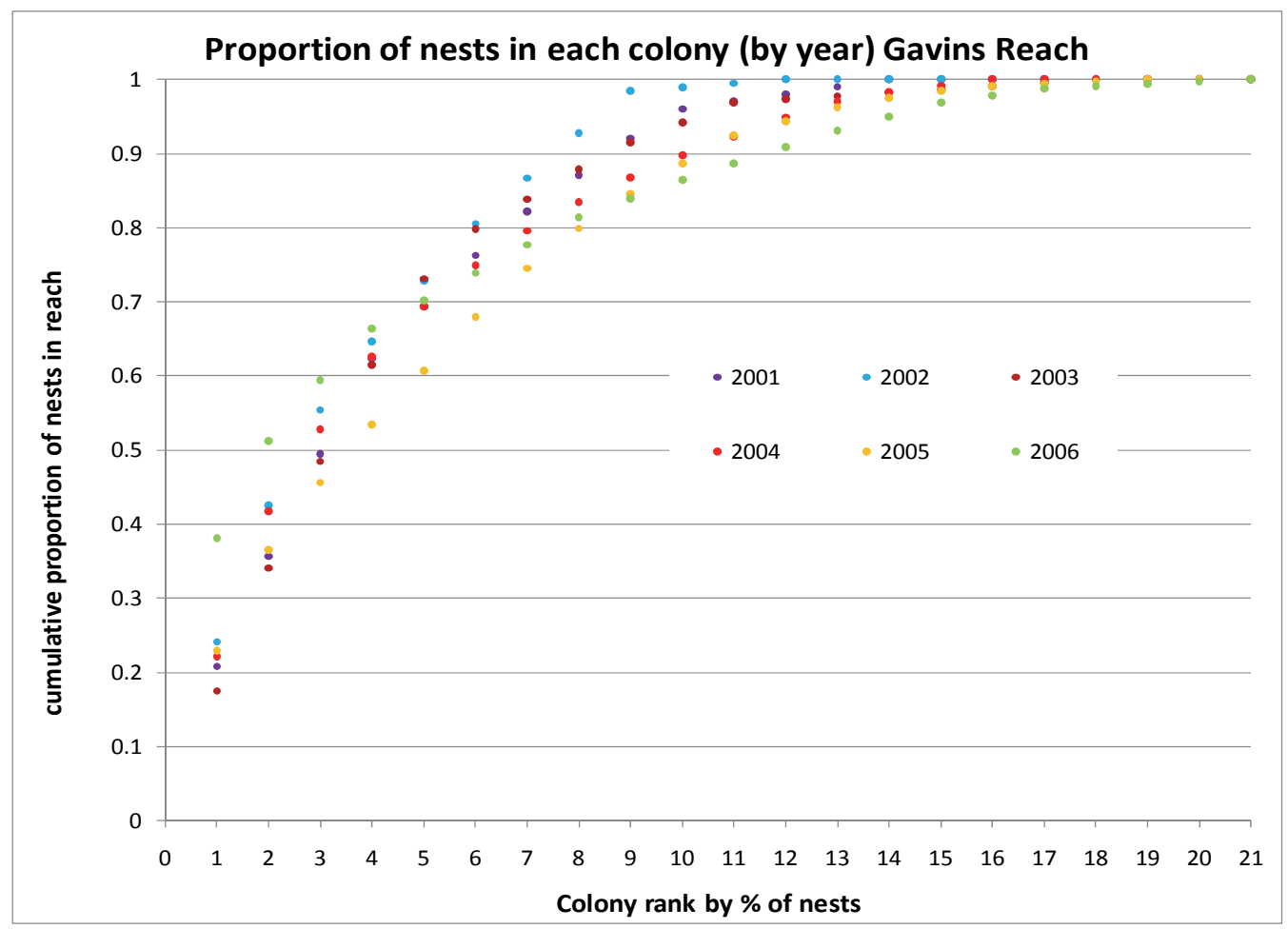

Figure A4. Colony size distributions for six years on the Gavins Point reach of the Missouri River. 


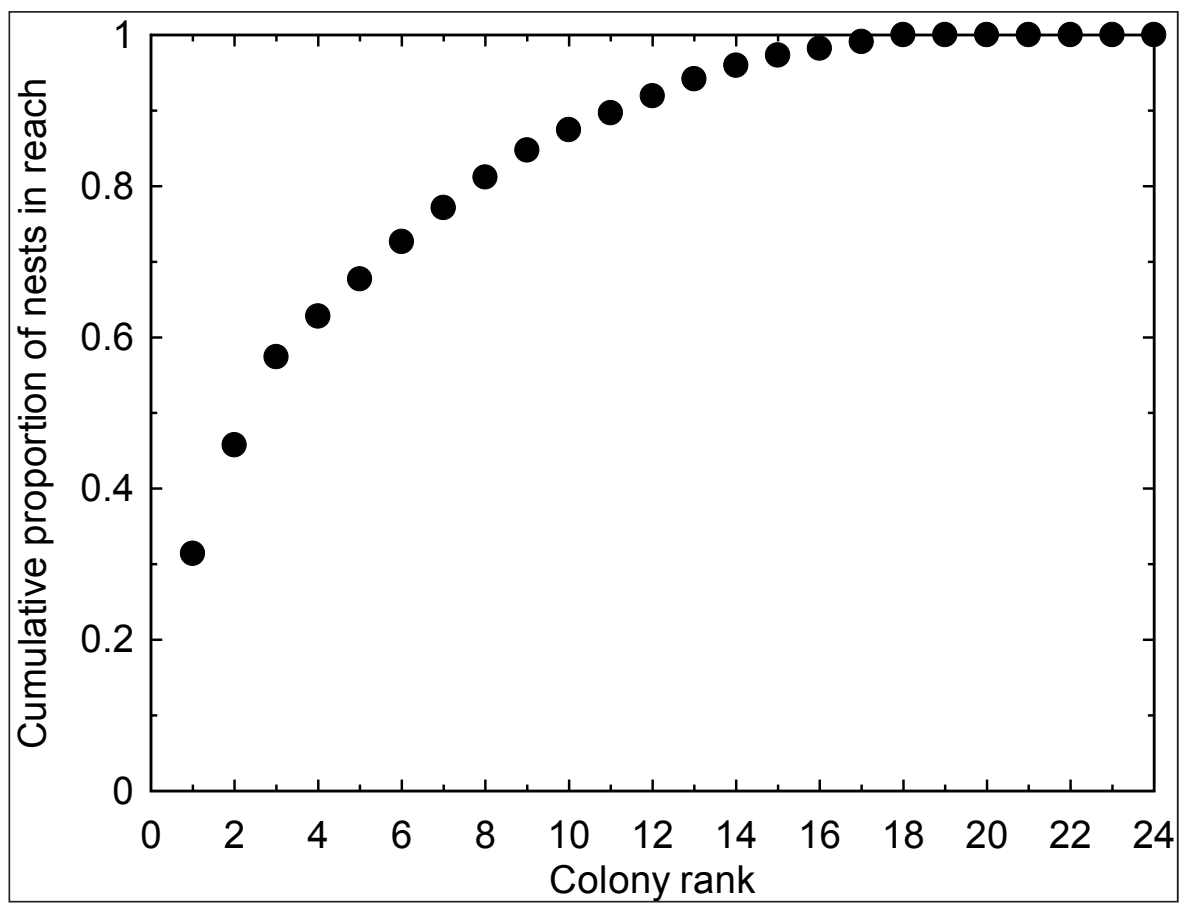

Figure A5. Colony size distribution for 2008, Keystone reach, Arkansas River.

second-largest colonies, etc. It is assumed that the number of nests in a colony is proportional to the number of adults that selected the site. Therefore, this pattern can be tested by examining the number of terns selecting each site.

The distinct attribute of the colony size distributions that defines this pattern is an uneven distribution of sizes: a few large colonies, many small ones, and a variety of colony sizes between largest and smallest. Specific criteria for this pattern are:

The largest colony was selected by $15-35 \%$ of all terns,

1. The highest-ranked (smallest) $25 \%$ of colonies were selected by fewer than $10 \%$ of terns, and

2. The relationship between rank and cumulative colony sizes (e.g., Figure A5) is distinctly curved between the largest site (rank =1) and where the Y axis reaches 1.0.

Pattern 8: Frequent return to previously used sites

ILT are widely believed to nest at, or near, the site where they nested (or were born) the previous year (Thompson et al. 1997). The ability for a colony site selection trait to reproduce observed degrees of such "site 
fidelity" may be important to the IBM if it is used to model multiple years with habitat conditions changing among years: a tendency to return to the same site could interact with habitat to determine colony site selection and hence reproductive success.

It is important to distinguish between "site fidelity" as an observed rate of birds returning to the same site and "site fidelity" as a behavior causing individuals to prefer previously used sites. In some circumstances relatively high rates of returning to the same site could occur without any behavioral preference to do so. For example, if only four sites are available and terns select sites randomly, one would expect 100 out of 400 terns to return to the site they used the previous year; and 6-7 individuals to appear "highly loyal," returning to the same site for 4 consecutive years.

The extent to which ILT return to previous sites was observed by Renken and Smith (1995) in a reach of the Mississippi River. Their study reach included $201 \mathrm{~km}$ with 18 potential nesting sites, and colonies ranged from 2 to 468 nests.The study reach used in this report has 19 sites over $93 \mathrm{~km}$, and typically 2 to 70 nests per site. Renken and Smith banded adults and chicks for a period of 5 years and observed them in subsequent years. Their observations relevant to this pattern include: (1) a large minority of adult terns selected the site where they nested the previous year; (2) very few birds built their first nest at the same site where they were born the previous year; (3) the tendency of birds to use the same site in subsequent years was not related to nesting success; and (4) the median distance between the sites a tern selected in two succeeding years was roughly equal to the median distance between adjacent sites, indicating a tendency to return to the same short section of river.

The IBM documented in this report does not simulate multiple years of nesting, but initializes each adult tern returning from winter migration with the location (as a river mile along the thalweg) where it is assumed to have nested the previous year. These previous-year nesting locations are based on field observations within the Arkansas River management area during the breeding season immediately preceding the habitat measurements that provided model inputs for sandbars. However, these previous-year nests are located at 17 points, not all of which are exactly at one of the sandbar sites represented in the model (12 of the 17 previous-year locations are clearly at one of the sites: the location has one, and only one, sandbar site within 0.25 river miles of it.) 
Considering the literature on site fidelity and how the IBM represents previous-year nesting locations, Pattern 8 is defined by three criteria. In these criteria, nesting at the same site as in the previous year is defined to mean that the site chosen this year is the closest site to the previous-year location that the tern was assigned.

The percent of terns that nest at the same site as in the previous year is between 30 and $60 \%{ }^{1}$

1. The percent of terns that nest at any one site and also nested there the previous year is not higher than $80 \%$ at any site (i.e., the overall moderate tendency to return to the same site does not result from a few sites that terns always return to and others that are rarely returned to).

2. The median (among terns) distance between sites selected in the previous and current years is between 1 and 5 miles. (The median distance among sites at the study reach documented herein is 1.85 miles or $3.0 \mathrm{~km}$ ).

\section{Alternative traits}

To develop a colony site selection trait, a variety of plausible traits were identified and tested. To provide a baseline for comparison of the alternatives, "null" traits that assume no decision-making by the individual birds were also tested. To identify alternative traits, the relatively sparse literature on mechanisms that real terns use to select colony sites was reviewed, and plausible mechanisms and simple ways to implement them in a behavior model were considered. The mechanisms considered (some of which conflict with each other and hence are treated as alternative hypotheses) were:

1. ILT could migrate to breeding areas in spring by following rivers, in which case it is reasonable to assume that they have flown over and observed many of the sites in their management area.

2. ILT migrate more directly north-south instead of following rivers, so they arrive at their management area at the point where their migration path intersects the reach. In this case it is reasonable to assume terns observe and evaluate sites over only a relatively short length of river. Observations of migrating ILT at locations such as reservoirs, which are not along rivers

1 Few traits reproduced this pattern, given these criteria, in initial tests. After re-reading the literature on site fidelity, which mostly reports return rates aggregated across sites within a region, the authors will re-define the first two criteria on this list in future tests to focus on the spatial scale of the management area rather than the scale of sites. 
with breeding populations, support the plausibility of this migration mechanism.

3. ILT may select sites based on their distribution in previous breeding seasons due to the behavior of site fidelity (Thompson et al. 1997).

4. ILT may be attracted to sites that already have other terns, and may be more attracted to sites with more terns and especially more unmated terns. This process makes sense ecologically because it makes mating success more likely. The controlled field study on coastal least terns by Burger (1988) indicates that terns are more likely to select sites with more single terns.

5. Sites with higher habitat quality should be more attractive, because habitat quality (as defined in Lott et al. (2012) has fitness benefits such as reduced vulnerability to mortality via drowning and predation.

The trait for colony site selection can be broken into two steps, which each tern executes upon arriving from migration. First is "site identification"; the tern identifies the subset of sites it will evaluate and select from. Second is "site evaluation and selection"; the tern evaluates all of the identified sites and selects one.

The first three mechanisms in the list above relate primarily to arrival location and site identification, whereas the last two mechanisms on this list relate to site evaluation and selection.

\section{Site identification traits}

For the first step of identifying potential sites to select from, four alternative traits are considered. Here, "sites" are sandbars that have at least one cell exposed at the daily peak flow on the day the tern is selecting a site.

Site identification trait 1: Terns consider all sites within their management area

This trait assumes that terns sense conditions at all sites within a breeding reach. 
Site identification trait $2:^{1}$ Terns consider sites within a limited distance upstream and downstream from a random arrival location in their breeding reach

This trait assumes that terns arrive from migration at a random location along the river and consider potential colony sites that lie within a limited range of this point. This assumption is implemented simply by having adult terns, on the day they arrive, randomly pick one of the points defining the thalweg of the breeding reach, with equal probability for all points. The tern's potential sites are then all the sites that are either upstream or downstream of this location within a maximum distance (the "site identification distance"), which is given a value of $20,000 \mathrm{ft}$. (The study reach documented in this report is approximately 400,000 ft long, so each adult tern will consider sites across 40,000 $\mathrm{ft}$ of the thalweg, which is roughly one tenth of the reach-unless they arrive close to one end of the reach.) If a tern needs to repeat site identification, it does not draw a new random location but continues to search for sites in the same length of river.

Site identification trait $3:^{2}$ Terns consider sites within a limited distance of the location they nested or were born at the previous year

This trait accounts for the effects of previous site use on colony site selection. A tern's potential colony sites are all of those within the site identification distance (still with a value of 20,000 ft), upstream or downstream, of the location where it nested, or was born, the previous year. The IBM documented in this report simulates only one breeding season at a time, so the previous year's nesting location was simply assigned to adult ILT when they were initialized. Previous nesting locations are represented as points within the river channel, rather than linked to specific sandbar sites because (in later versions of the model with habitat dynamics; and in the field data) the number and location of sandbar sites can vary from year to year. Data from a July 2008 census of nests throughout the Keystone reach were used to define previous nest locations for model runs that use this trait. These data were collected at the same time as the site habitat data, so they are a realistic representation of how nesting terns were distributed in the breeding reach modeled.

\footnotetext{
1 This is site identification trait 5 in the current software.

2 This is site identification trait 4 in the current software.
} 
Site identification trait $4:{ }^{1}$ A small fraction of "disperser" adults use trait 2, while the remaining adults ("returners") use site identification trait 3

Adults that select sites near a random location are called "dispersers" because they represent birds that used other management areas in the previous year; hence, they have no preference for locations within the simulated management area. The fraction of adults that are dispersers is equal to the parameter "manareaFracDispersers," which has a value here of o.1. $^{2}$ (One other change was made when this trait was implemented: terns identify all sites, both upstream and downstream, within one half of the site identification distance. The site identification distance, still $20,000 \mathrm{ft}$, is therefore the total distance over which birds identify sites.)

For all four site identification traits, there is the possibility that a tern identifies no sites. During an extreme flood that submerges all sites, no terns will be unable to identify any sites. In this case when there are no exposed sites in the entire reach, the tern is assumed to delay colony site selection until the next day, at which time it repeats its entire site identification trait. When traits 2-4 are used, it is possible that no sites are currently exposed-or even exist-within the site identification distance. In such cases, the tern simply selects the nearest site no matter how far or which direction it is. ${ }^{3}$

\section{Site evaluation and selection traits}

For the second step of evaluating and selecting sites from among the potential ones, three alternative traits are considered. The traits differ depending on whether the primary objective of colony site selection is habitat quality or mate availability.

\section{Site evaluation trait $1^{4}$ : Select randomly}

This is a "null trait" that assumes no decision-making except avoidance of unsuitable habitat. Terns are assumed to sense only the presence of each site and whether there is any habitat of "suitable" quality. For a definition

\footnotetext{
1 This is site identification trait 4 in the software as of version 3.2. Trait 3 can be used by setting the site selection trait parameter to 4 and manareaFracDispersers to 0.0.

2 After calibration (Appendix G), this parameter was set to 0.15 in the model description (Appendix A).

3 This was true in the early version of the software that was used for these tests. However, in more recent versions, different methods are used to determine what terns will do if no habitat is observed on their first day of site selection (see Appendix A).

4 In the software this is currently trait 10.
} 
of "suitable" habitat (see Lott et al., 2012). Terns choose their colony site randomly from among all potential sites that have at least one cell of suitable quality, with all such sites having equal probability. If none of the potential sites has any suitable habitat, the tern delays colony site selection until the next day, when it repeats both site identification and site evaluation. Site identification is repeated because changing flows may make more sites available.

Site evaluation trait $2:{ }^{1}$ Select the site with highest nesting habitat quality Habitat quality is the primary colony site selection criterion. Terns select the site with the highest value of a continuous habitat quality index at the time of their arrival. ${ }^{2}$ See Lott et al. (2012) for a description of this habitat quality index. Specifically, the site with highest nesting habitat quality is the site containing the one cell with highest value of the quality measure defined in the model description. However, if there are no sites with habitat quality above the "suitable" threshold (also defined in the model description), then the tern delays site evaluation for a day, and repeats both site identification and evaluation the next day.

Site evaluation trait $3:^{3}$ Select the site with the most unmated terns

Terns base colony site selection primarily on the number of other unmated terns present. Terns select the site having the most unmated terns (of either sex). If none of the sites has any unmated terns, the tern selects a site using trait 2. If more than one site has the same highest number of unmated terns, one of them is chosen randomly.

\section{Study site}

The simulation experiments to develop traits used input representing the Keystone Reach of the Arkansas River, described in detail elsewhere in project reports. This reach is 86 miles long and has 23 potential colony sites with diverse habitat characteristics. The sites are much closer together in the lower half of the reach, with only four sites in the upper half (Figure A6).

\footnotetext{
1 In the software this is currently trait 8.

2 Other site-based indices of habitat quality will be evaluated in future tests.

3 In the software this is currently trait 9.
} 


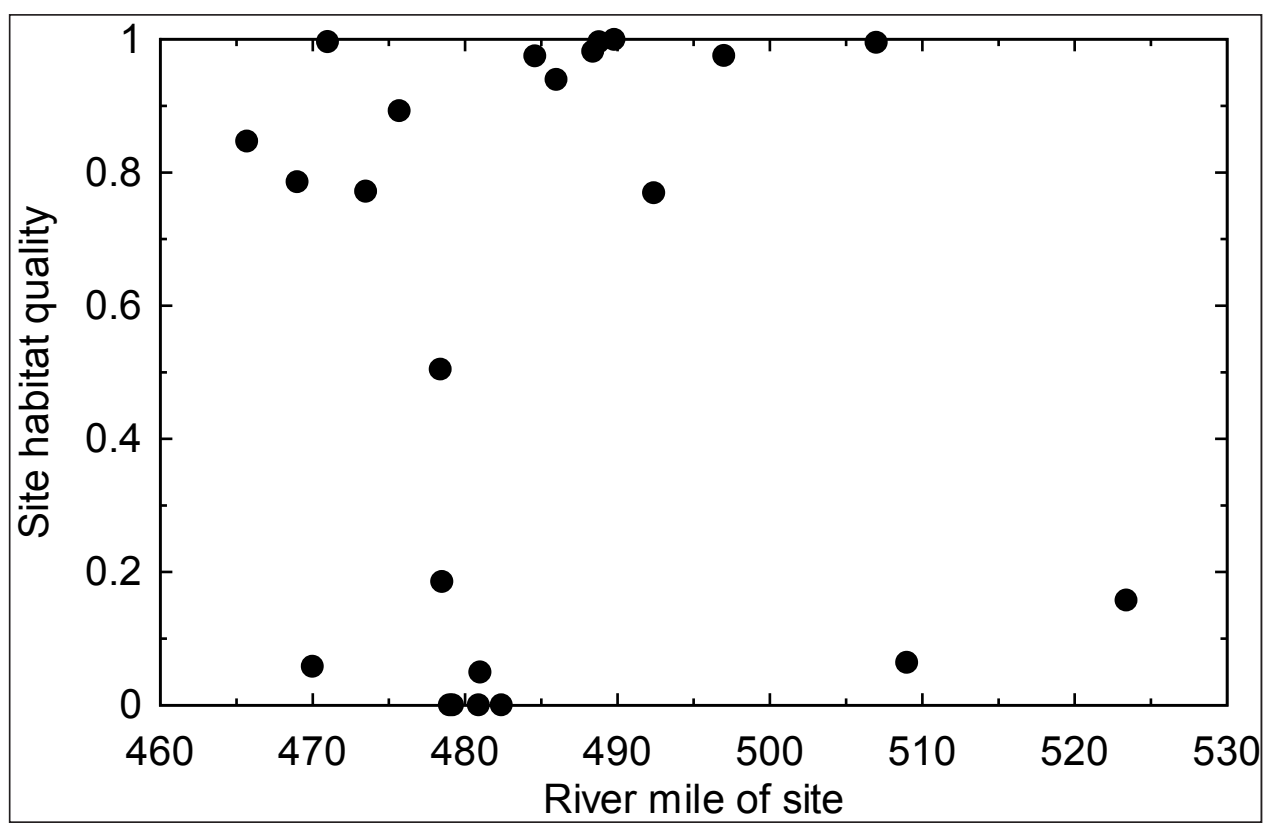

Figure A6. Location ( $\mathrm{X}$ axis; approximate river mile) and habitat quality (at normal hydropower flows) of potential colony sites in the Keystone reach.

The flow occurring in normal hydropower operations (both turbines at Keystone Dam operating at capacity for several hours per day) is used as a characteristic daily maximum flow because it is by far the most common flow in this controlled reach. At normal hydropower flow, 22 of the 23 sites have some "suitable" nesting habitat and nine of the sites have some "high-quality" habitat. The continuous habitat quality index at this flow is high ( $>0.5$ ) at 14 sites (Figure A6). Three sites around river mile 480 have habitat quality of zero at normal hydropower flows. ${ }^{1}$ The distribution of habitat quality is very bimodal, with the most common values being very low and very high (Figure A7).

The simulations assumed that approximately 500 adult terns arrive from migration over a period starting on Julian date 131 (May 11) and ending on date 193 (July 12), with peak arrival at date 148 (May 28).

The colony site selection trait experiments were conducted under two highly contrasting hydrologic year types. The first was a year (1991) with low and stable flows throughout the nesting season (except for one pulse around day 160), so habitat availability changed little over time. The

\footnotetext{
1 These sites have been removed as inputs to Version 1.0 of TernCOLONY, which now contains two different habitat input sets, one representing excellent habitat conditions (with 32 sites), one representing degraded habitat conditions (with 25 sites) (Lott et al. 2012a). Both of these habitat input sets will be used in future tests of the colony site selection trait.
} 
second year type was chosen to resemble "natural" flows that are high at the beginning of the season and decline throughout the season; 1993 was chosen for this high flow year type. The two flow scenarios produce very different time series of habitat availability (Figure A8).

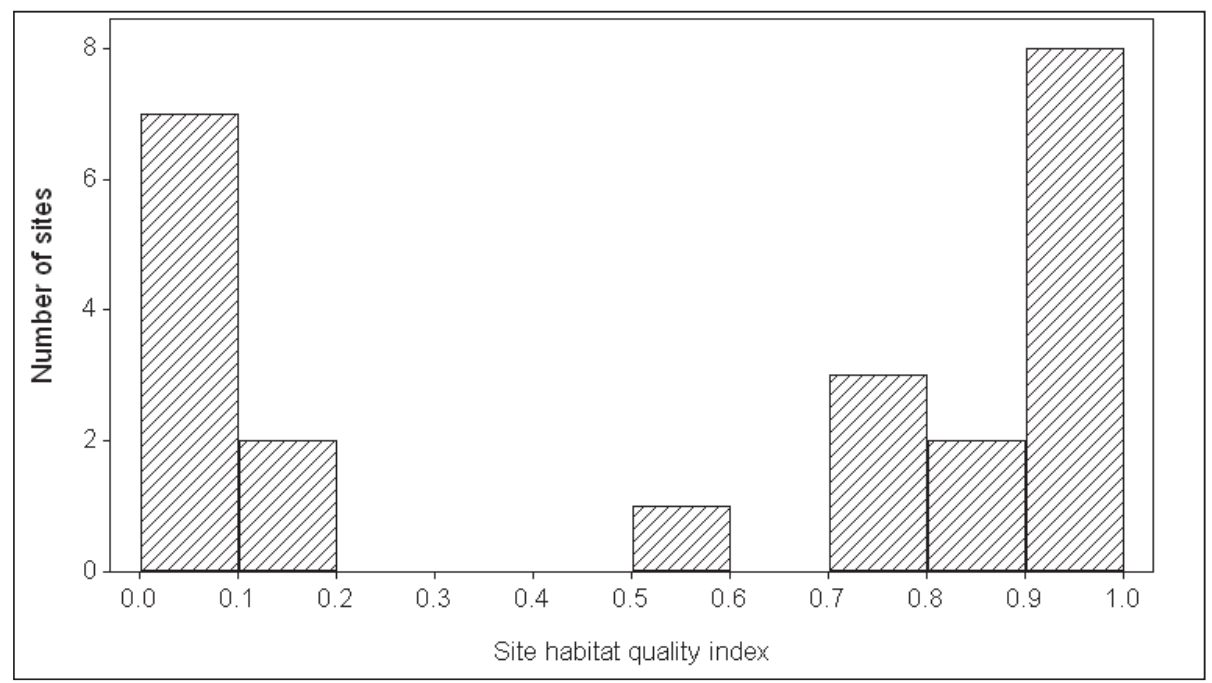

Figure A7. Histogram of site habitat quality at normal hydropower flow.

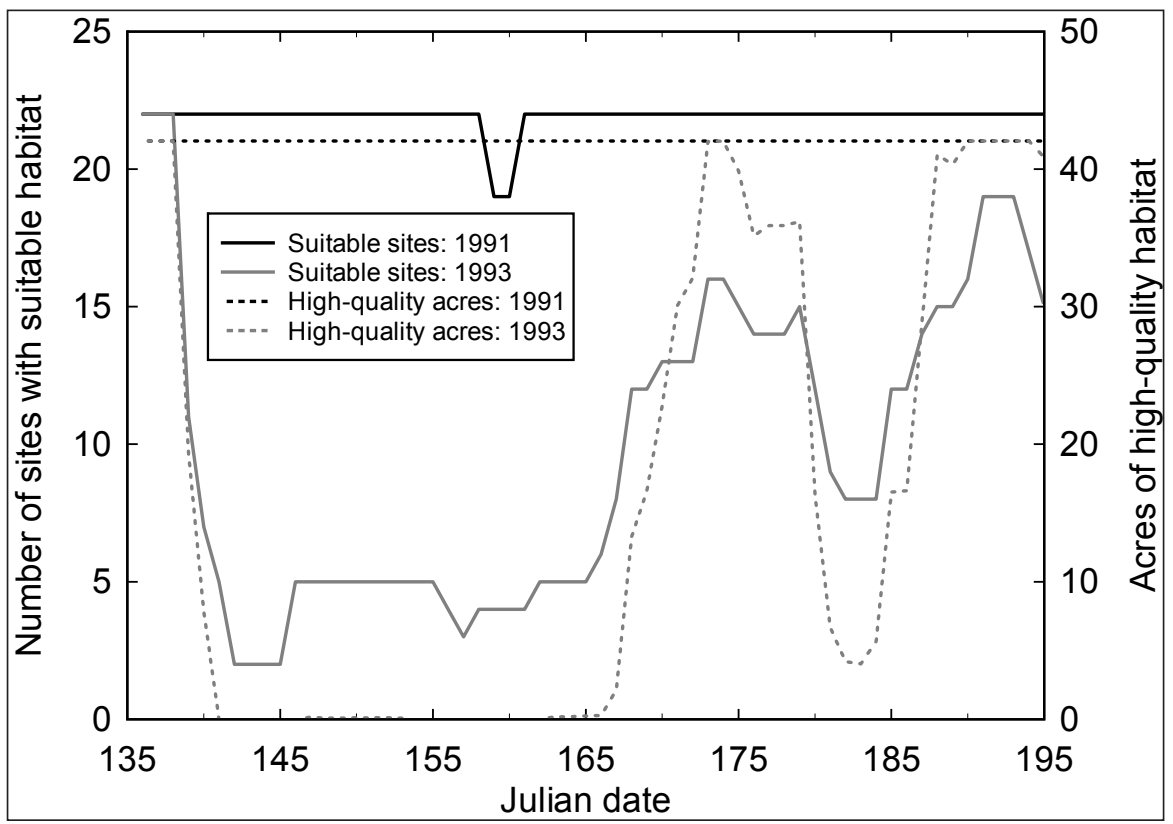

Figure A8. Time series (left axis; solid lines) of number of sites with some suitable habitat, and (right axis; dashed lines) total acres of high-quality habitat in the study reach during water years 1991 (low, steady) and 1993 (high, descending). 


\section{Results}

This section reports the extent to which the IBM, using each alternative site identification and evaluation trait, reproduces patterns 4 through 8 . All site identification traits and evaluation traits are examined, organized as (a) a comparison of the site identification traits, (b) a comparison of the site evaluation traits, (c) an evaluation of site identification trait 3, and (d) an evaluation of site identification trait 4. Table A6 summarizes all of the results. This section also examines the sensitivity of results to the site identification distance parameter.

\section{Comparison of site identification traits}

This analysis compares the three site identification traits, combined with the "null" site evaluation trait (evaluation trait 1, random selection among alternative sites).

\section{Site identification trait 1}

This trait assumes adult terns select among all sites that have at least one cell exposed.

Pattern 4-This pattern was met for both the low (1991) and high (1993) flow years. In both years, the largest colony was among the first selected but was not selected before any other sites were (Figure A9).
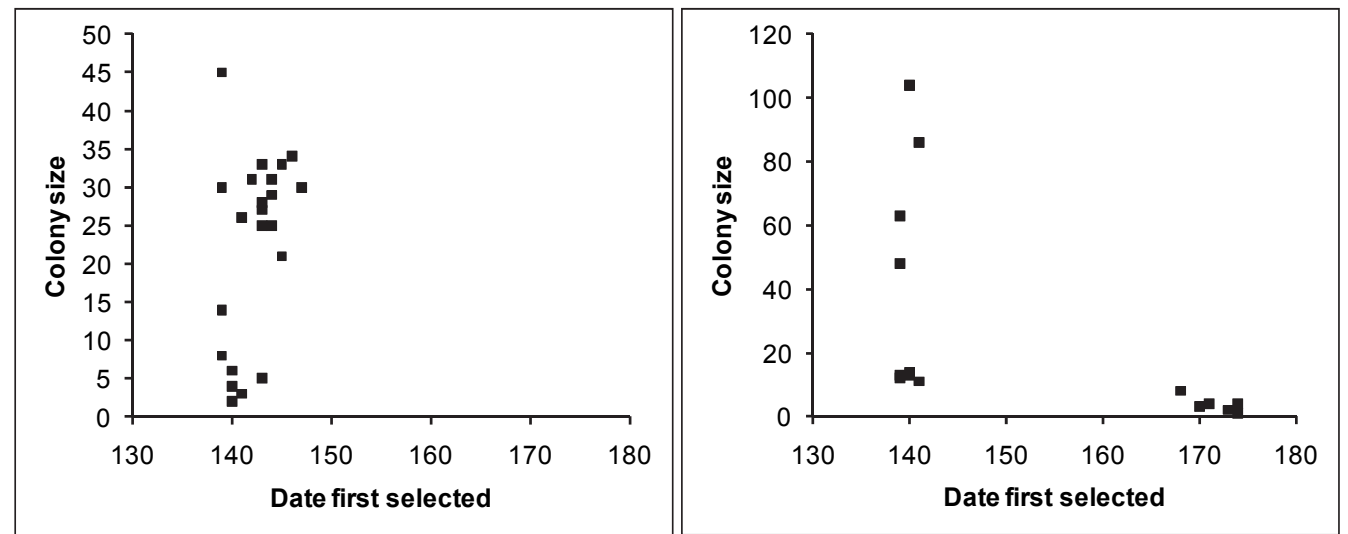

Figure A9. Relationship between the date a site is first selected and its colony size, for (left) 1991 and (right) 1993, site identification trait 1. Each point represents one site.

Pattern 5-This pattern was met only for the low flow year, when 50\% of the sites were selected within a date range $70 \%$ or less of the full range (Figure A10). Only $38 \%$ of sites were selected over a narrow date range in 
1993. Selection of sites over a narrow date range appeared to be caused by two different mechanisms in the two flow years. In the low-flow year, some sites were selected only over a small range at the start of the season, apparently because only a few terns selected those sites. In fact there was a very strong positive relationship between the number of terns selecting a site and the range of dates over which it was selected (Figure A11). Such a relationship is expected when colony site selection is highly random: when more terns select a site, it is more likely that some of them will select it very early and some very late.
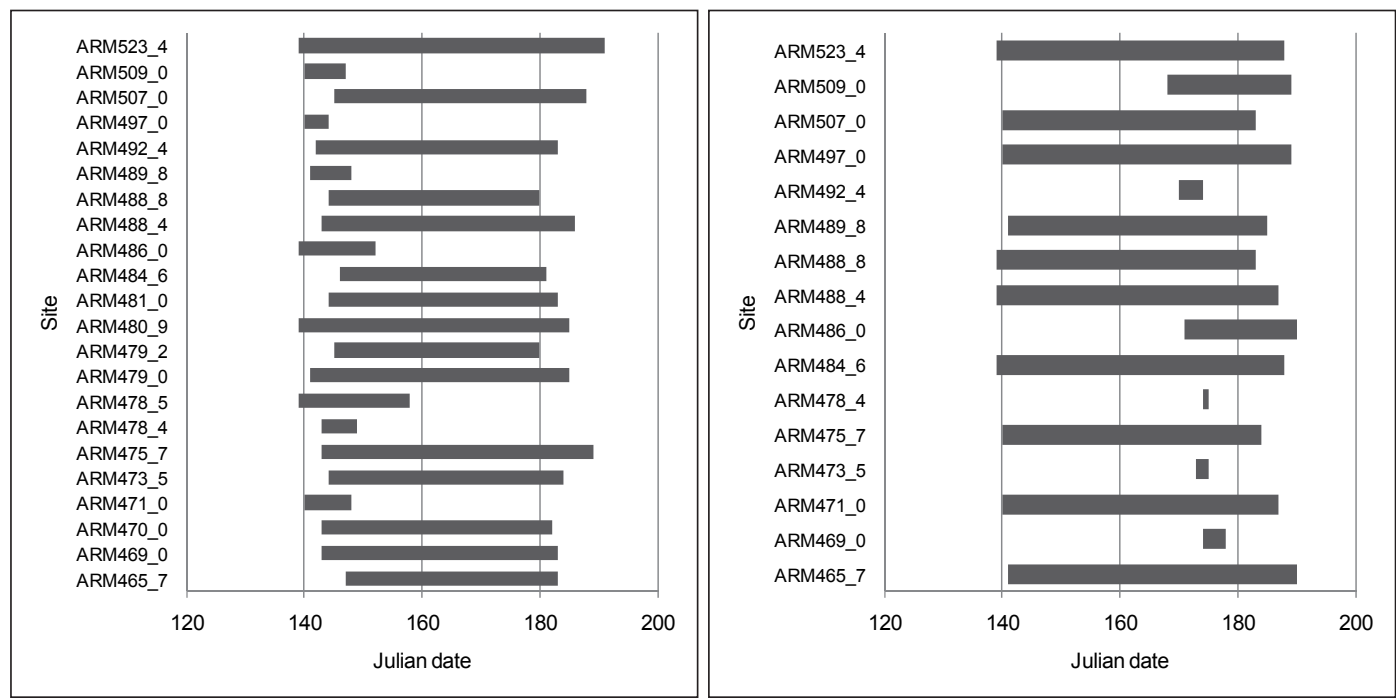

Figure A10. Range of dates over which each site was selected, for (left) 1991 and (right) 1993, site identification trait 1.

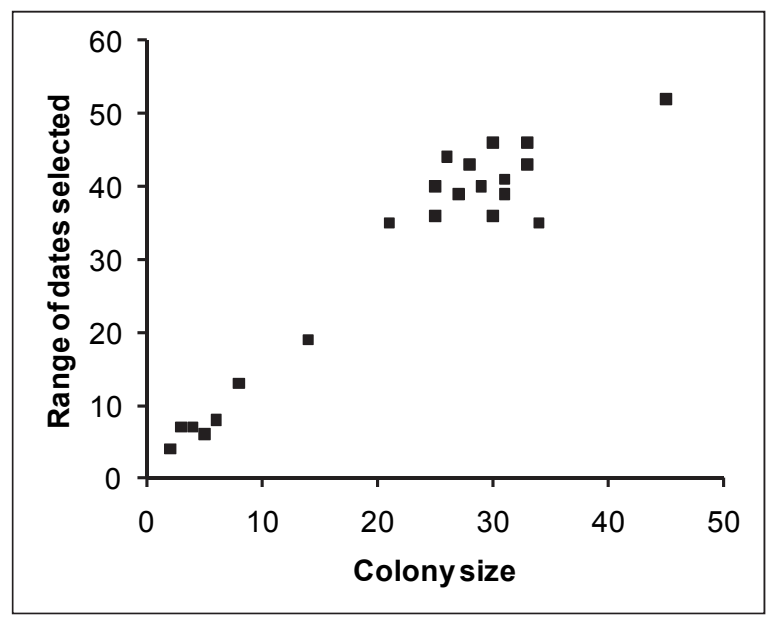

Figure A11. Relationship between colony size and range of dates site was selected, 1991, site identification trait 1. Each point represents one site. 
In 1993, the mechanism causing some sites to be selected over a narrow range is simply that many sites were completely submerged until the end of the arrival season. Hence, some colonies were not selected until late in the season (Figure A9). (The sites that were selected over a broad range of dates are those that were exposed and available for a few days at the beginning of the season; Figure A8).

Pattern 6-This pattern was not met in 1991, the low-flow year; there was no positive or significant correlation between site quality and colony size (Figure A12, left panel). However, the pattern was met in 1993, with colonies occurring at several low-quality sites, no colony at one high-quality site, and a significant correlation between colony size and site quality. The pattern was presumably met in 1993 because higher-quality sites were exposed during more of the time when flows were high (Figure A12, right).
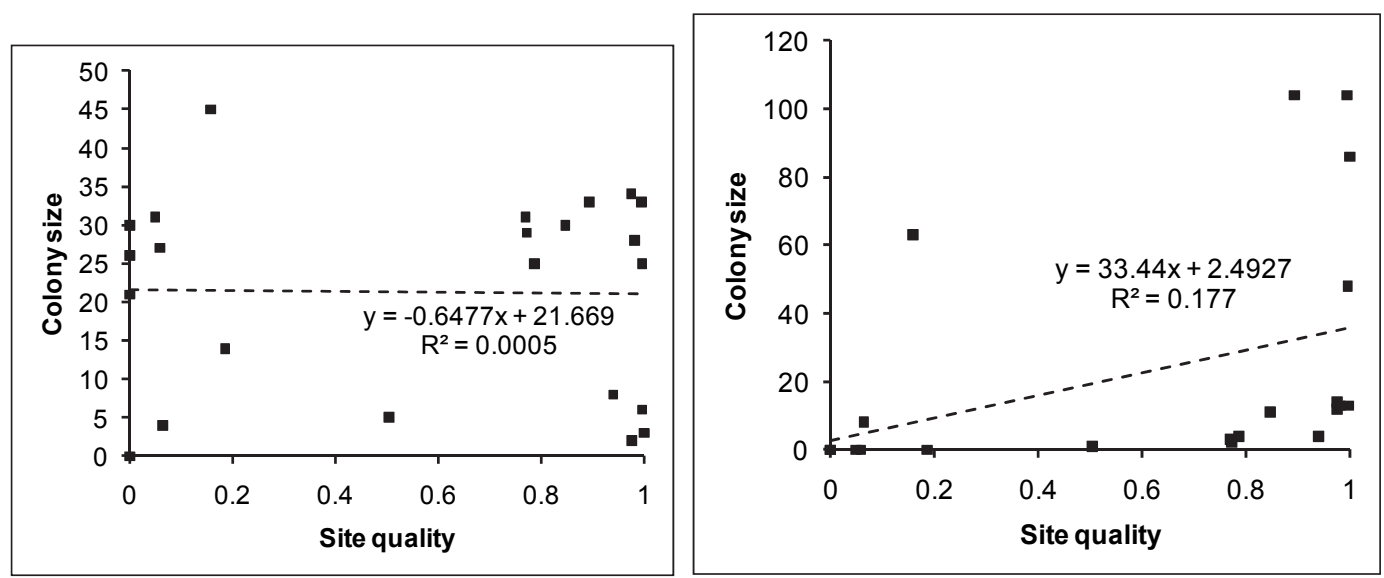

Figure A12. Relationship between site quality and colony site, for (left) 1991 and (right) 1993, site identification trait 1 . Each point represents one site, and the linear regression is illustrated by the dashed line and equation.

Pattern 7-The pattern of uneven colony size distribution was fully met only in 1993, the high flow year. In 1991, two criteria for this pattern-the largest site having $20 \%$ or more of all terns, and a curved size distribution-were not met (Figure A13, left). With random selection among sites when most or all sites are available, many sites were selected by 25-35 terns, a relatively even colony size distribution. In 1993, many sites were not available for much of the arrival season, producing an uneven distribution of colony sizes (Figure A13, right).

Pattern 8-This pattern was not met. In both 1991 and 1993, the percent of terns returning to their previous site was about $6 \%$, well below the criterion of $30 \%$. (However, this percent was above 30 at several individual sites, 
including some small and some large colonies.) The mean distance between previous- and current-year sites was over 16 miles in both years, well above the criterion of 5 miles.
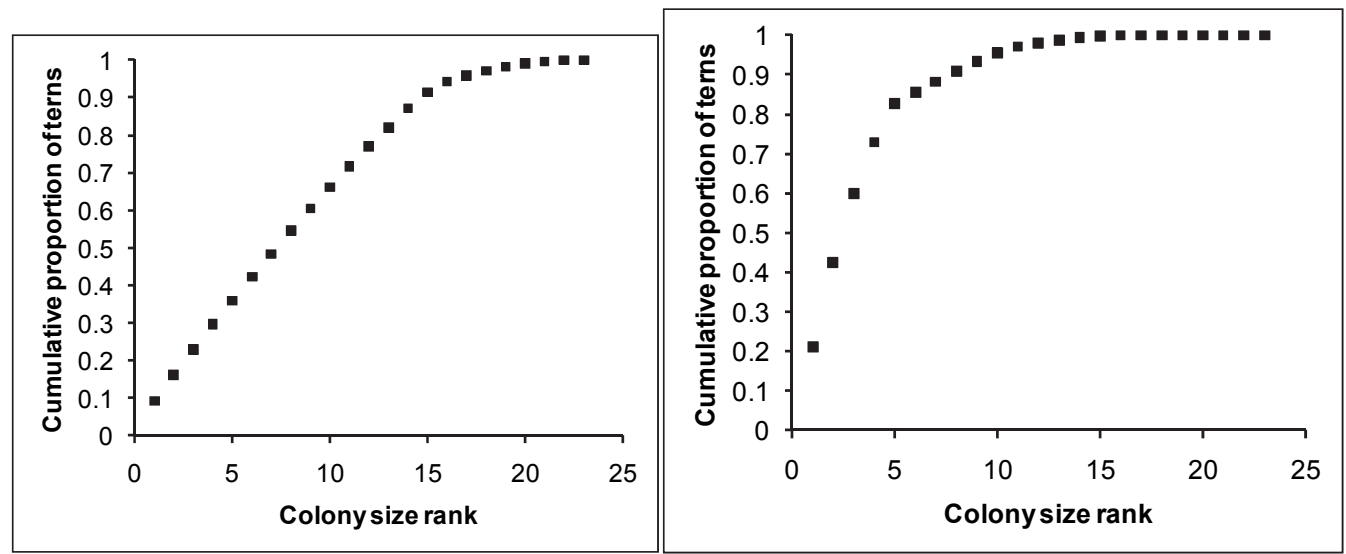

Figure A13. Colony size distributions for 1991 (left) and 1993 (right), site identification trait 1. Format is the same as in Figure A5.

Site identification trait 2

This trait assumes adult terns select only from among sites within a limited distance of a random location along the river channel.

Pattern 4-This pattern was met for low- (1991) and high- (1993) flow years; the largest colony was selected on the first day, but several other sites were also selected on that first day.

Pattern 5-This pattern was met only in the high flow year. In 1991, only $41 \%$ of the sites were selected within a date range $70 \%$ or less of the full range, but in 1993, 53\% of sites were selected over a narrow date range (Figure A14). Selection over a narrow date range in the high flow year happened at more sites than with site identification trait 1 (Figure A10, right panel). The reason appears to be that site identification trait 2 lets fewer terns consider each site. As a result, both mechanisms that limit the range of dates a site is selected (stochasticity when few terns select a site, and unavailability of sites while inundated by high flow; see previous section) acted in this scenario.

Pattern 6-This pattern was not met in 1991 or 1993. In both flow years there were some low-quality sites with colonies and some high-quality sites without colonies, but in neither year was there a significant positive relationship between site quality and colony site (Figure A15). 

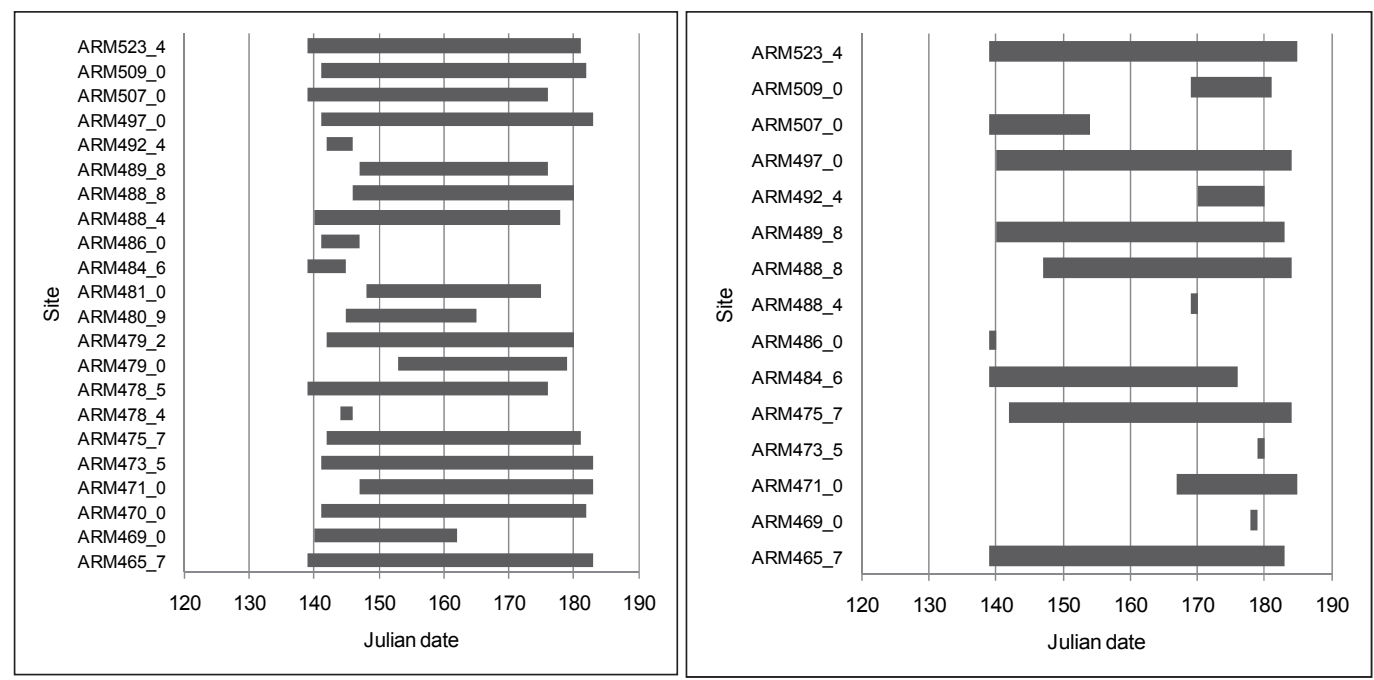

Figure A14. Range of dates over which each site was selected, for (left) 1991 and (right) 1993, site identification trait 2.
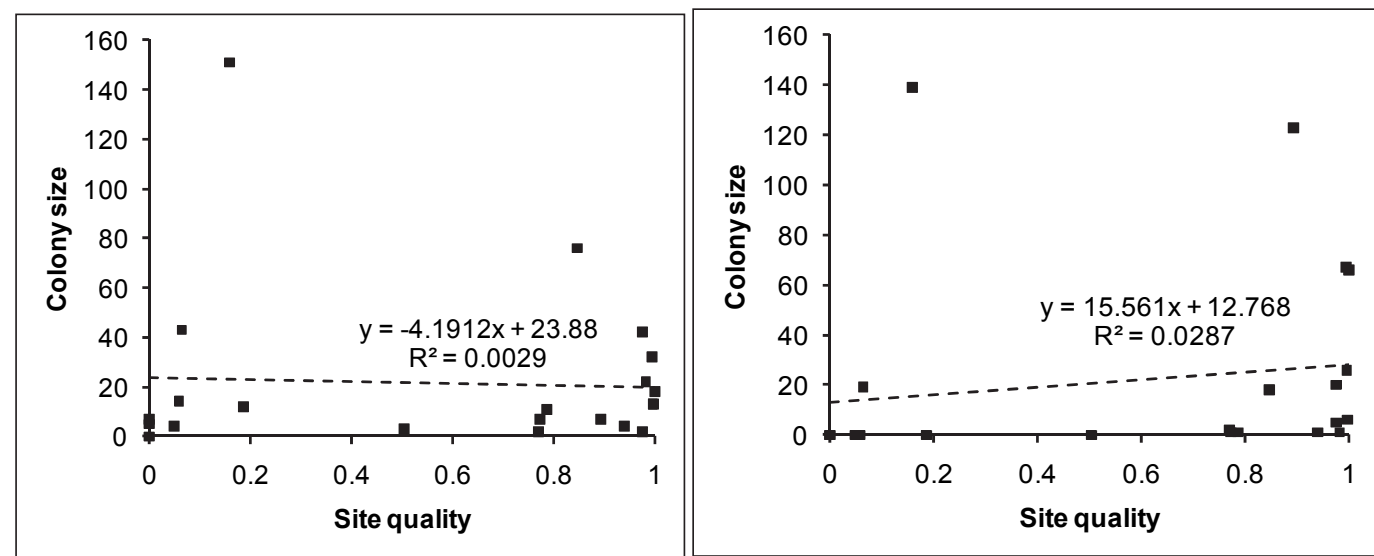

Figure A15. Relationship between site quality and colony site, for (left) 1991 and (right) 1993, site identification trait 2. Each point represents one site, and the linear regression is illustrated by the dashed line and equation.

The weaker relationship between site quality and colony size in 1993 (compare the right panels of Figure A11 and Figure A15) is due to one site (ARM-523.4) with a quality value of 0.15 being selected by 139 terns. This site was chosen by many terns because it is geographically isolated; any tern arriving over a long length of river selects that site because it is the only one available. In fact, there is a strong correlation between a site's isolation and its colony size, especially in 1991 when the relationship was not confounded by high flows (Figure A16).

Pattern 7-The pattern of uneven colony size distribution was met in both 1991 and 1993 (Figure A17). Site identification trait 2 causes enough variability among sites in the colony for this pattern to be reproduced, even in low- and steady-flow years. 


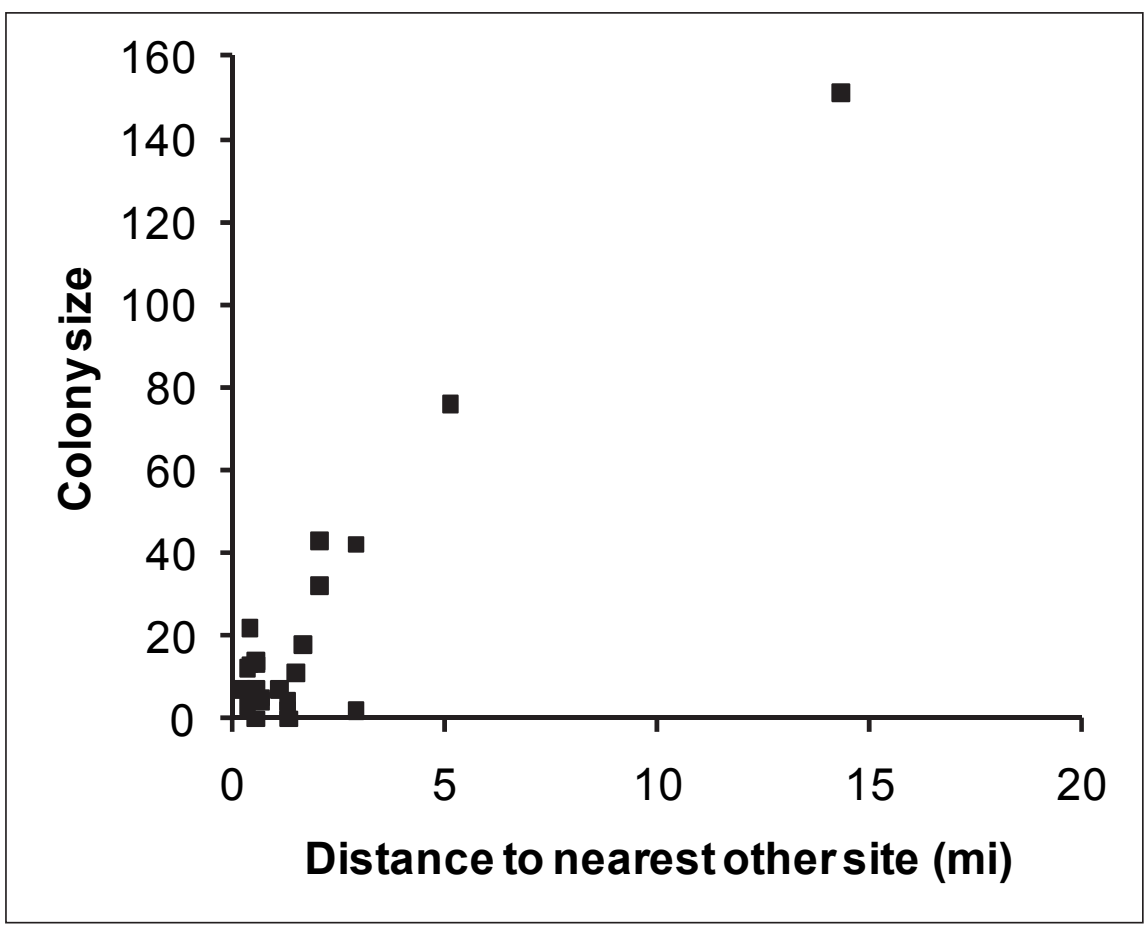

Figure A16. Relationship between site isolation and colony site, 1991, site identification trait 2. Isolation is evaluated as the distance between a site and the nearest other site. More isolated sites tend to be selected by many more terns.
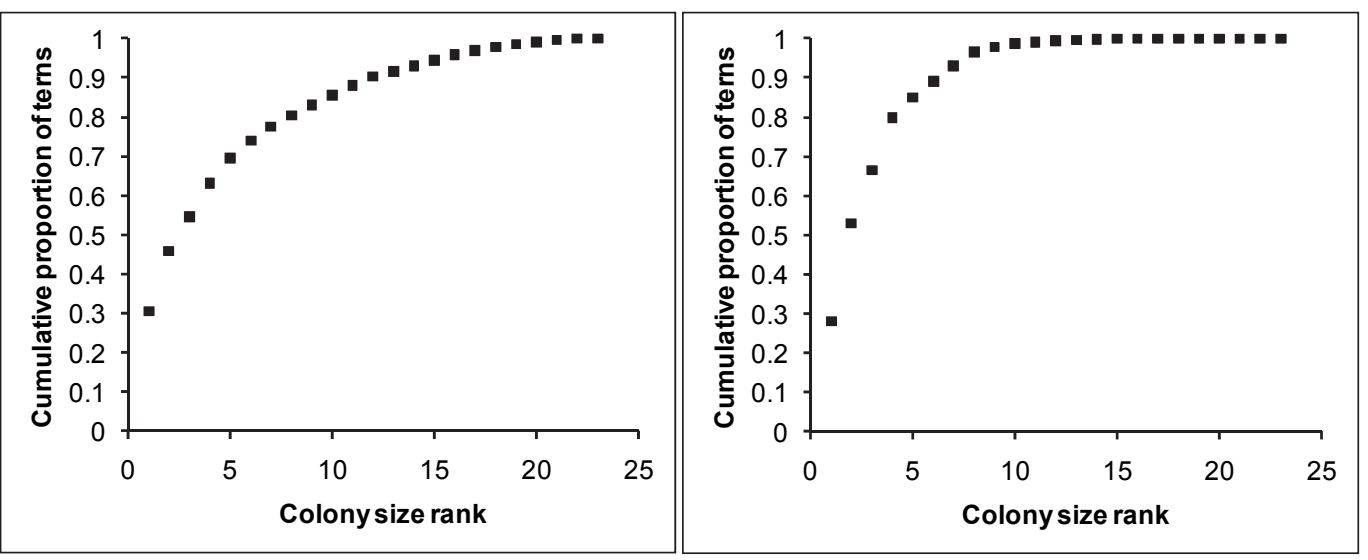

Figure A17. Colony size distributions for 1991 (left) and 1993 (right), site identification trait 2.

Pattern 8-This pattern was not met in either 1991 or 1993. The percent of terns returning to their previous site was about 8-10\%, below the criterion of $30 \%$.

Site identification trait 3

This trait assumes adult terns select from among sites within a limited distance of the location where they nested, or were born, the previous year. 
Results were similar to those for site identification trait 2, with the exception of pattern 8 .

Pattern 4-This pattern was met for 1991 and 1993; the largest colony was among several selected on the first day that terns selected sites.

Pattern 5-This pattern was met only in the high-flow year, when $81 \%$ of sites were selected over a narrow date range. In 1991, only $41 \%$ of the sites were selected within a date range $70 \%$ or less of the full range.

Pattern 6-This pattern was not met in 1991 or 1993. There was a positive, but not significant, relationship between site quality and colony site in 1993; in 1991 this relationship was slightly negative.

Pattern 7-The pattern of uneven colony size distribution was met in both 1991 and 1993 (Figure A18). Arrival of terns at their previous-year nesting location introduces enough variability among sites in the colony for this pattern to be reproduced, and (compared to site identification trait 2, Figure 17) reduces the difference in colony size distribution between lowand high-flow years.

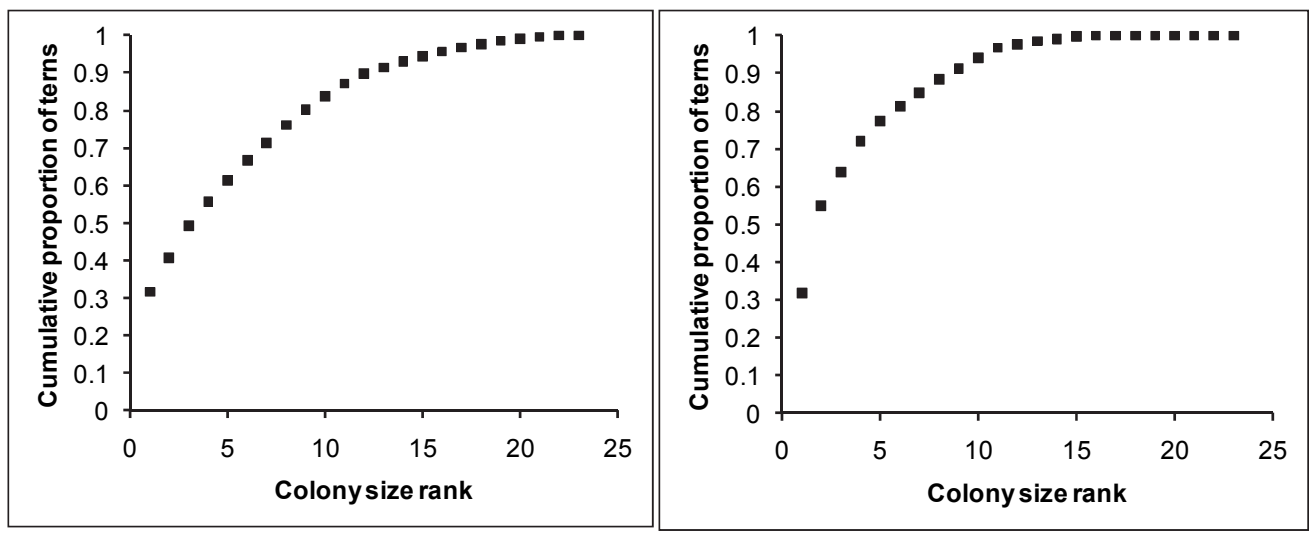

Figure A18. Colony size distributions for 1991 (left) and 1993 (right), site identification trait 3.

Pattern 8-The three criteria for this pattern were not all met in either 1991 or 1993 (Table A1). Especially in the high-flow year, this trait produced a higher level of return to previous sites than the pattern allows. At several sites, including the ones with most terns, $90-100 \%$ of terns selected the site used the previous year. 
Table A1. Pattern 8 results for site identification trait 3 . Shaded cells indicate criteria that were not met.

\begin{tabular}{|l|l|l|}
\hline Criterion & 1991 & 1993 \\
\hline $30-60 \%$ of terns return to previous site & $46 \%$ & $63 \%$ \\
\hline Highest percent of terns returning to any one site < 80\% & $100 \%$ & $100 \%$ \\
\hline Median distance between previous and current site is 1-5 mi & $1.1 \mathrm{mi}$ & $0.4 \mathrm{mi}$ \\
\hline
\end{tabular}

\section{Comparison of site evaluation and selection traits}

This section compares and evaluates the effects of the alternative traits terns use when selecting sites to form a colony. These simulations used site identification trait 2, which assumes terns select among sites within a limited distance of a random location.

[When these site evaluation traits were combined with site identification trait 1, which assumes terns consider all the sites, the results were uninteresting. First, the combination of site identification trait 1 and site evaluation trait 1 was already examined in a previous section of this report. Second, when site evaluation traits 2 and 3 were simulated with terns selecting among all sites, all the terns selected only one or (in 1993, due to decreasing flood flows) two sites.]

Site evaluation and selection trait 1

This combination of traits was previously evaluated.

Site evaluation and selection trait 2

Under this trait, terns select the site with the highest nesting habitat quality.

Pattern 4-This pattern was met. In both 1991 and 1993, the site with the largest colony was one of several initially selected on the first day that terns selected sites.

Pattern 5-Quotas for this pattern were not met in either flow year; the percent of sites selected over a relatively narrow date range was $25 \%$ and 42\% in 1991 and 1993.

Pattern 6-In both flow years there was a positive, but not significant, relationship between site quality and colony size. Therefore, quotas for 
this pattern were not met. The relationship was not significant because although site ARM-523.4 has relatively low habitat quality, it has the largest colony size because it is geographically isolated.

Pattern 7-The colony size distribution pattern was met only during the high-flow year. In 1991, half of the sites were selected by 27-49 terns each, a relatively even distribution (Figure A19, left). While fewer sites were selected in 1993, more were selected by few terns, producing the uneven distribution (Figure A19, right).
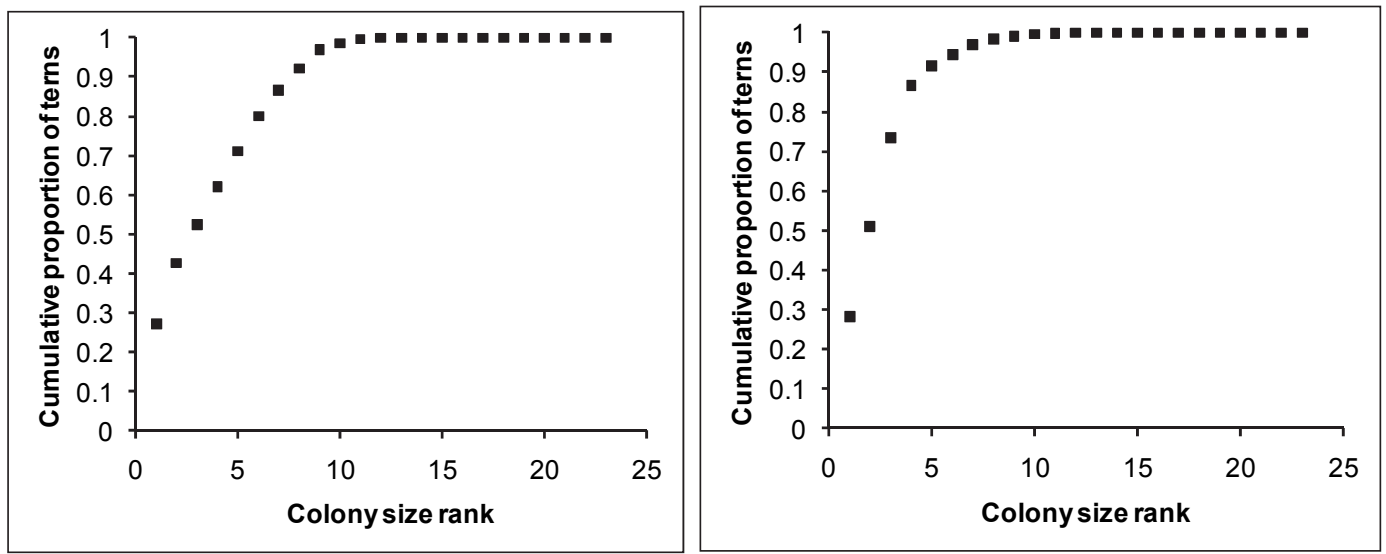

Figure A19. Colony size distribution for 1991 (left) and 1993 (right), site evaluation trait 2.

Pattern 8-Too few terns used the same sites as in previous years for this pattern to be met (Table 2).

Table A2. Pattern 8 results for site evaluation trait 2 . Shaded cells indicate criteria that were not met.

\begin{tabular}{|l|l|l|}
\hline Criterion & 1991 & 1993 \\
\hline $30-60 \%$ of terns return to previous site & $11 \%$ & $7 \%$ \\
\hline Highest percent of terns returning to any one site < 80\% & $33 \%$ & $30 \%$ \\
\hline Median distance between previous and current site is 1-5 mi & $23 \mathrm{mi}$ & $20 \mathrm{mi}$ \\
\hline
\end{tabular}

Site evaluation and selection trait 3

This trait causes terns to select the site with the highest number of unmated terns; if there are no unmated terns, they select the site with the highest habitat quality. 
Pattern 4-Criteria for this pattern were met. In both 1991 and 1993, the site with the largest colony was one of several initially selected on the first day that terns selected sites.

Pattern 5-Criteria for this pattern were met in 1993 (55\% of sites selected over a relatively narrow date range) but not in 1991 (43\% of sites selected over a narrow range of dates).

Pattern 6-In both flow years there was a positive, but not significant, relationship between site quality and colony size. Therefore, criteria for this pattern were not met. The reason for the non-significant relationship is the same as for site evaluation trait 2: one low-quality site was selected by many terns because it is isolated.

Pattern 7-The colony size distribution pattern was met during both lowand high-flow years (Figure A20).
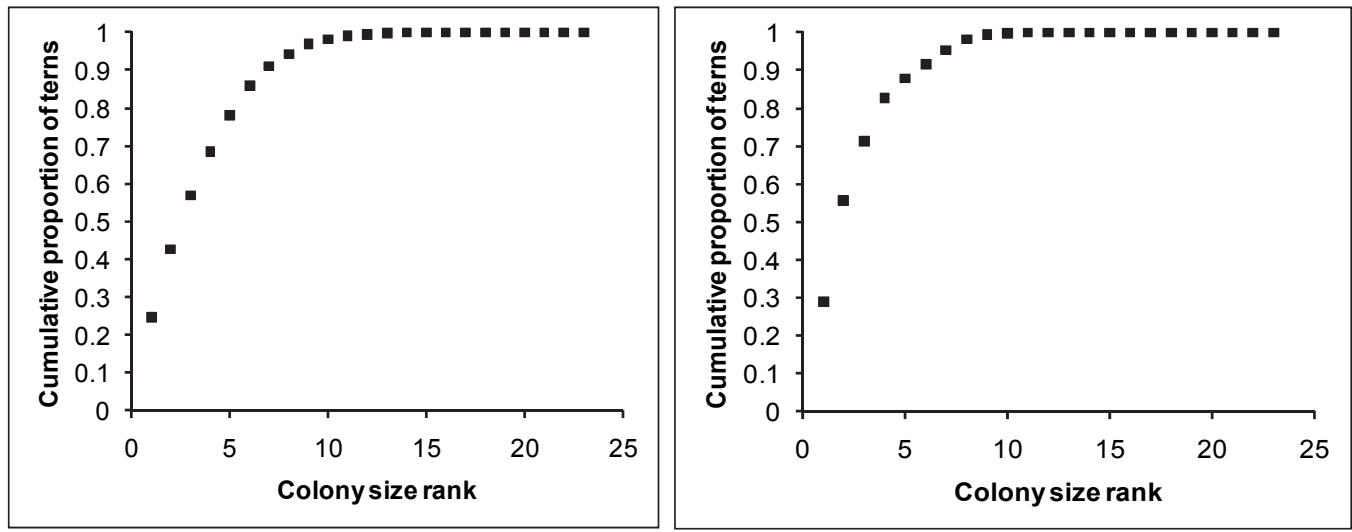

Figure A20. Colony size distribution for 1991 (left) and 1993 (right), site evaluation trait 3.

Pattern 8-This pattern was not met because few terns used the same sites as in previous years (Table A3).

Table A3. Pattern 8 results for site evaluation trait 3 . Shaded cells indicate criteria that were not met.

\begin{tabular}{|l|l|l|}
\hline Criterion & 1991 & 1993 \\
\hline $30-60 \%$ of terns return to previous site & $12 \%$ & $10 \%$ \\
\hline Highest percent of terns returning to any one site < 80\% & $28 \%$ & $50 \%$ \\
\hline Median distance between previous and current site is 1-5 mi & $21 \mathrm{mi}$ & $19 \mathrm{mi}$ \\
\hline
\end{tabular}




\section{Effect of arrival from migration at previous year's site}

The third analysis repeats the second except for using the third site identification trait, which assumes that terns arriving from migration evaluate sites near where they nested, or were born, the previous year. This analysis, in comparison to the previous one, illustrates the effect of "site fidelity," a tendency to return to previous nesting sites.

Site evaluation and selection trait 1

This trait combination was previously evaluated.

Site evaluation and selection trait 2

With this trait, terns select the site near where they nested previously that has the highest habitat quality.

Pattern 4-Criteria for this pattern were met in both 1991 and 1993.

Pattern 5-In 1991, only 42\% of sites were selected over a narrow date range, so criteria for the pattern were not met. In 1993 the pattern was met, with $64 \%$ of sites selected over a narrow range; in 1993, many sites were submerged until near the end of the season.

Pattern 6-In both low- and high-flow years, this pattern was not met, but only because the relationship between colony size and site quality was not significant. The lack of significance was because one low-quality site (ARM 523.4) had the largest colony.

Pattern 7-In both 1991 and 1993, the colony size distribution met this pattern.

Pattern 8-Criteria for this pattern were not met because too many, not too few, terns selected the same site they used the previous year. The main reason the pattern was not met was the anomalous site ARM 523.4, where (in both years) all 155 terns selecting the site had used it the previous year. In each year there were also two other small colonies in which all terns had used the same site the previous year. 
Table A4. Pattern 8 results for site identification trait 3 and evaluation trait 2 . Shaded cells indicate criteria that were not met.

\begin{tabular}{|l|l|l|}
\hline Criterion & 1991 & 1993 \\
\hline $30-60 \%$ of terns return to previous site & $58 \%$ & $55 \%$ \\
\hline Highest percent of terns returning to any one site < 80\% & $100 \%$ & $100 \%$ \\
\hline Median distance between previous and current site is 1-5 mi & $0.4 \mathrm{mi}$ & $0.4 \mathrm{mi}$ \\
\hline
\end{tabular}

Site evaluation and selection trait 3

With this trait, terns select the site near where they nested previously that has the most unmated terns.

Pattern 4-Criteria for this pattern were met in both 1991 and 1993.

Pattern 5-Criteria for this pattern were met in both 1991 (55\% of sites selected over a range of dates $70 \%$ or less of the total range of colony site selection dates) and 1993 (70\% of sites selected over a narrow date range). During 1991, the low-flow year, sites were more often selected over narrower date ranges (Figure A21; compared to when site evaluation traits 1 and 2 were used) apparently because several sites were selected for a short period early in the season, after which terns instead selected nearby sites-likely because there were no longer any unmated terns at the first-selected sites.

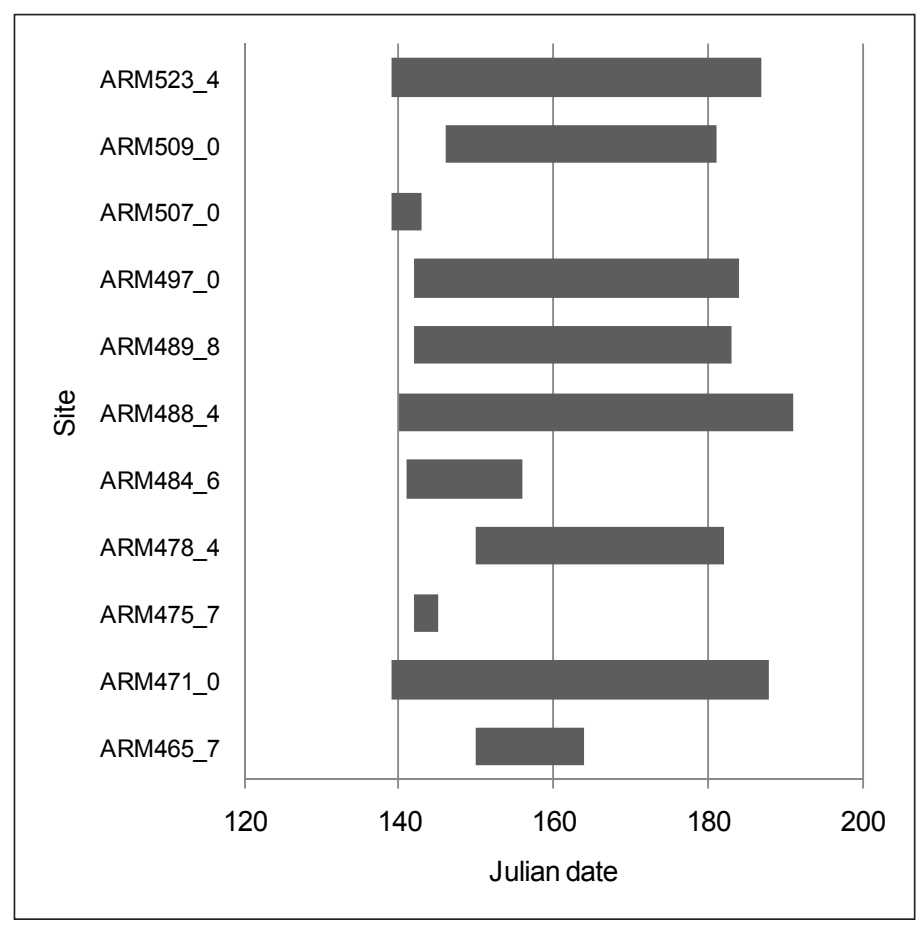

Figure A21. Ranges of dates (grey bars) over which sites were selected, site identification trait 3 and site evaluation trait 3, 1991. 
Pattern 6-Criteria for this pattern were not met only because the relationship between colony size and site quality was not significant, a result of site ARM 523.4 having the largest colony but low habitat quality.

Pattern 7-In both 1991 and 1993, the colony size distribution met the criteria for this pattern. In the 1991 simulation, 11 sites were selected even though the terns were initialized with 15 different sites used the previous year.
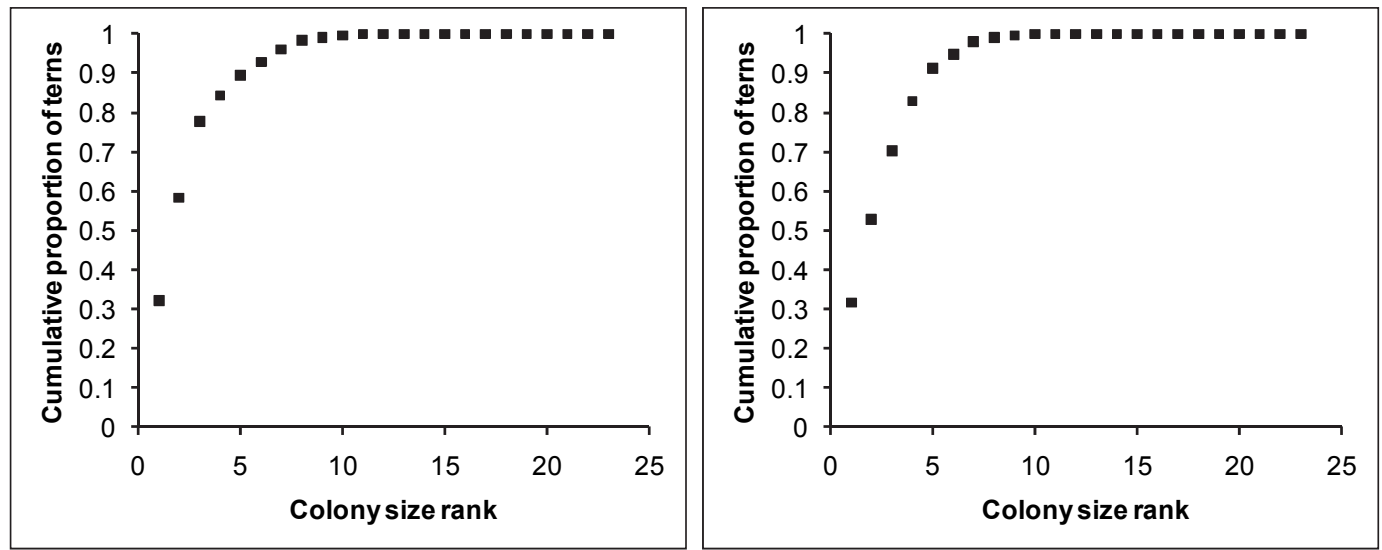

Figure A22. Colony size distributions with site identification trait 3 and site evaluation trait 3 , 1991 (left) and 1993 (right).

Pattern 8-Criteria for this pattern were not met because too many, not too few, terns selected the same site they used the previous year. The main reason the pattern was not met was again site ARM 523.4, where (in both years) all 155 terns selecting the site had used it the previous year. In each year there were also two other small colonies where all terns had used the same site the previous year.

Table A5. Pattern 8 results for site identification trait 3 and evaluation trait 2 . Shaded cells indicate criteria that were not met.

\begin{tabular}{|l|l|l|}
\hline Criterion & 1991 & 1993 \\
\hline $30-60 \%$ of terns return to previous site & $58 \%$ & $56 \%$ \\
\hline Highest percent of terns returning to any one site < 80\% & $100 \%$ & $100 \%$ \\
\hline Median distance between previous and current site is 1-5 mi & $0.4 \mathrm{mi}$ & $0.4 \mathrm{mi}$ \\
\hline
\end{tabular}

\section{Combination of "dispersers" and "returners"}

This section evaluates the fourth site identification trait, which assumes that $10 \%$ of terns arrive at a random location (and are called "dispersers") and the remaining $90 \%$ arrive from migration near where they nested, or 
were born, the previous year. This experiment (unlike the previous ones) used the final version 3.2 of the model description and software, with standard parameter values except that site abandonment and predation mortality were turned off.

Site identification trait 4 is examined only in combination with evaluation and selection trait 3 (the combination used in version 3.2 of the Interior Least Tern model). With this trait, terns select the site near where they nested previously that has the most unmated terns; if there are no unmated terns, the site with best habitat quality is selected. Results are compared mainly to those from site identification trait 3 and selection trait 3 .

Pattern 4-Criteria for this pattern were met: the largest colony was occupied first in 1993 but not in 1991.

Pattern 5-Criteria for this pattern were not met in either 1991 or 1993; in both years only $21 \%$ of sites ( 3 of 14 occupied sites) were selected over a narrow date range. This difference from site identification trait 3 appears to result from the "disperser" terns causing a more even distribution of colony sizes (Pattern 7), so there were more colonies of the intermediate size (roughly 20-50 adults) that tend to be selected over longer time periods (Figure A11).
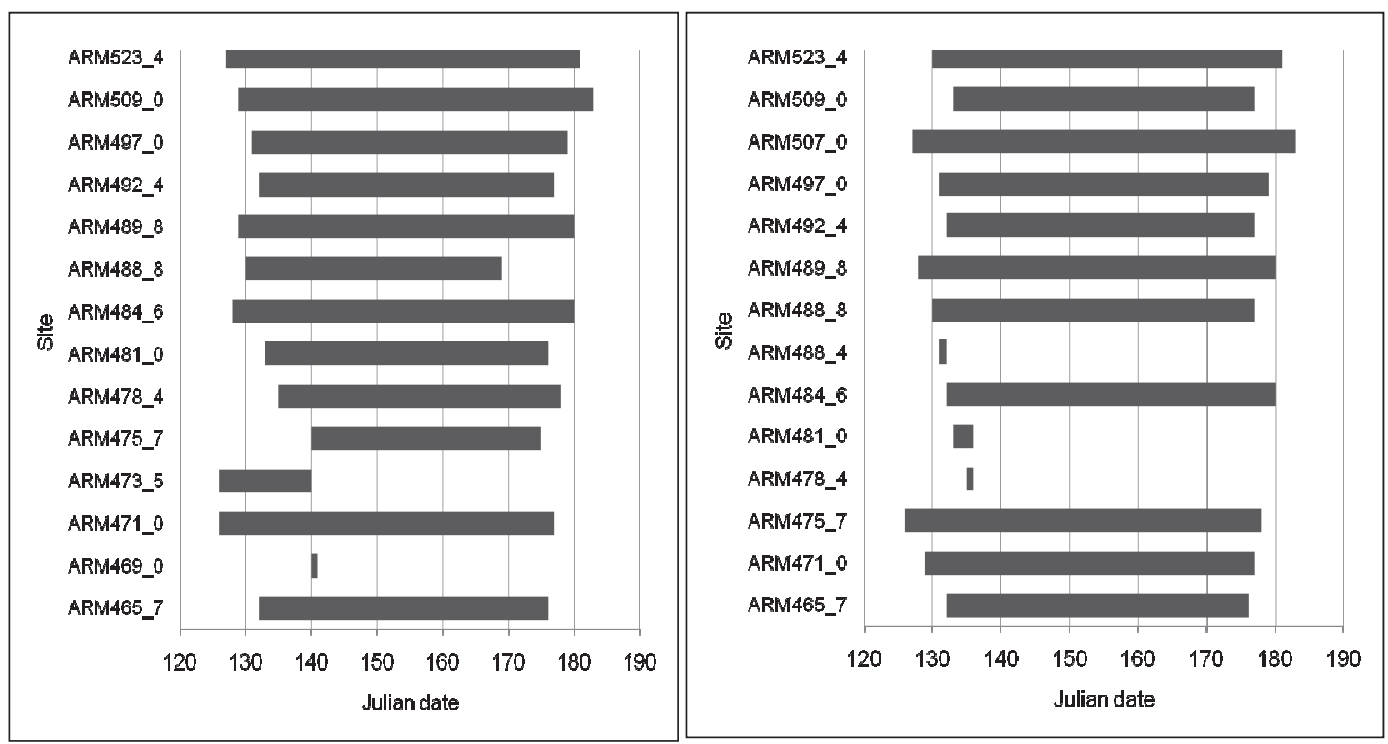

Figure A23. Ranges of dates (grey bars) over which sites were selected, site identification trait 4 and site evaluation trait 3, 1991 (left) and 1993 (right). 
Pattern 6-As with site identification trait 3, this pattern was not met only because the relationship between colony size and site quality was not significant. The pattern would have been met without site ARM 523.4, which again had one of the largest colonies, but had low habitat quality.

Pattern 7-The size distribution criterion was met for both 1991 and 1993, and the colony size distribution met this pattern. The addition of disperser terns increased the number of colonies to 14 , and made their size distribution a little more even.
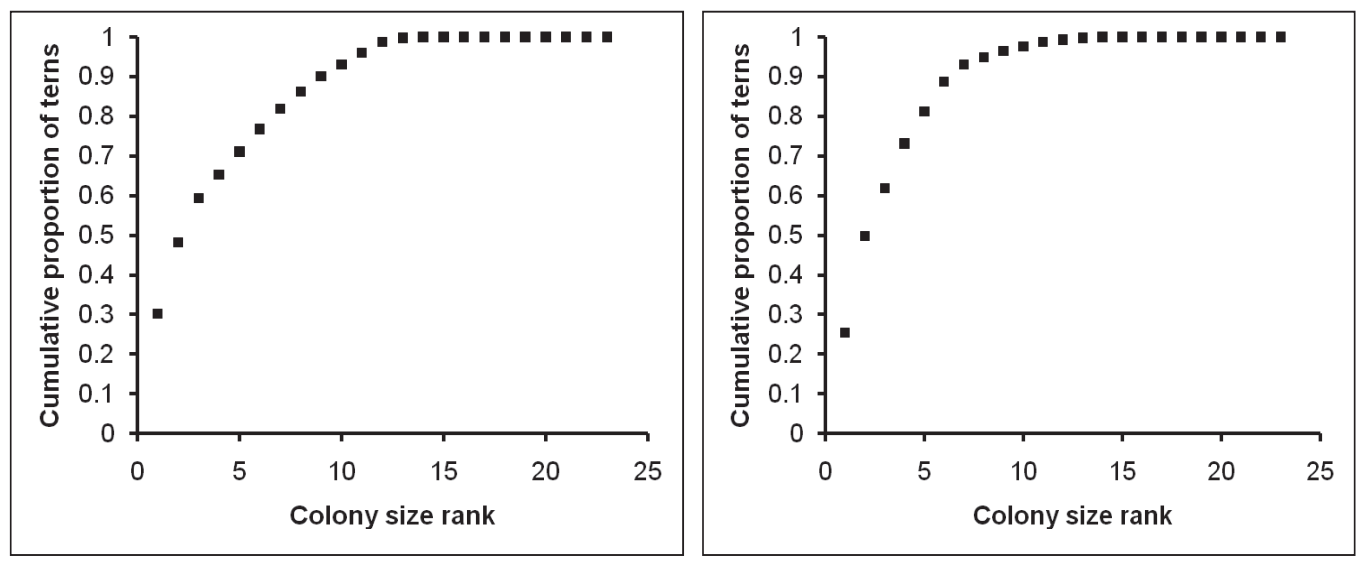

Figure A24. Colony size distributions with site identification trait 4 and site evaluation trait 3 , 1991 (left) and 1993 (right).

Pattern 8-This pattern was again not met because too many terns selected the same site they used the previous year. In addition to almost all terns from site ARM 523.4 returning to it, all (1993) or almost all (1991) adults returned to several sites that had high habitat quality and were close to several other sites.

Note that the criterion for median distance between the previous and current sites cannot be computed directly for this site identification trait because the previous-year location of the "disperser" terns is unknown. However, the dispersers are only $10 \%$ of all terns and if one assumes that they nested far away the previous year, then they should not alter the median from the values obtained with site identification trait 3 .

Table A6. Pattern 8 results for site identification trait 3 and evaluation trait 2 . Shaded cells indicate criteria that were not met.

\begin{tabular}{|l|l|l|}
\hline Criterion & 1991 & 1993 \\
\hline $30-60 \%$ of terns return to previous site & $73 \%$ & $40 \%$ \\
\hline Highest percent of terns returning to any one site < 80\% & $96 \%$ & $100 \%$ \\
\hline Median distance between previous and current site is 1-5 mi & - & - \\
\hline
\end{tabular}




\section{Summary table}

Results of the trait analysis are summarized in Table A7. In this table, unlike the previous discussion, criteria for pattern 6 (in particular, a significant relationship between site habitat quality and colony size) are considered to be met if they are met when the anomalous site ARM-523.4 is ignored.

Table A7. Summary of pattern-oriented analysis of colony site selection traits.

\begin{tabular}{|c|c|c|c|c|c|c|}
\hline $\begin{array}{l}\text { Site identification } \\
\text { trait }\end{array}$ & $\begin{array}{l}\text { Site } \\
\text { evaluation } \\
\text { trait }\end{array}$ & $\begin{array}{l}\text { Pattern 4: } \\
\text { Largest } \\
\text { colonies not } \\
\text { occupied first }\end{array}$ & $\begin{array}{l}\text { Pattern 5: } \\
\text { Narrow } \\
\text { date } \\
\text { range }\end{array}$ & $\begin{array}{l}\text { Pattern 6: } \\
\text { Habitat } \\
\text { quality effect } \\
\text { on colony } \\
\text { size }\end{array}$ & $\begin{array}{l}\text { Pattern 7: } \\
\text { Colony size } \\
\text { distribution }\end{array}$ & $\begin{array}{l}\text { Pattern 8: } \\
\text { Return to } \\
\text { previously } \\
\text { used sites }\end{array}$ \\
\hline \multirow[t]{3}{*}{ 1. All sites } & Random & $\checkmark$ & & & & \\
\hline & $\begin{array}{l}\text { Highest } \\
\text { habitat } \\
\text { quality }{ }^{1}\end{array}$ & & & & & \\
\hline & $\begin{array}{l}\text { Most } \\
\text { unmated } \\
\text { terns }^{1}\end{array}$ & & & & & \\
\hline \multirow{3}{*}{$\begin{array}{l}\text { 2. Sites within } \\
\text { limited distance of } \\
\text { random location }\end{array}$} & Random & $\checkmark$ & & & $\checkmark$ & \\
\hline & $\begin{array}{l}\text { Highest } \\
\text { habitat } \\
\text { quality }\end{array}$ & $\checkmark$ & & $\sqrt{2}$ & & \\
\hline & $\begin{array}{l}\text { Most } \\
\text { unmated } \\
\text { terns }\end{array}$ & $\checkmark$ & & $\sqrt{2}$ & $\checkmark$ & \\
\hline \multirow{3}{*}{$\begin{array}{l}\text { 3. Sites within } \\
\text { limited distance of } \\
\text { previous-year's site }\end{array}$} & Random & $\checkmark$ & & & $\checkmark$ & 3 \\
\hline & $\begin{array}{l}\text { Highest } \\
\text { habitat } \\
\text { quality }\end{array}$ & $\checkmark$ & & $\sqrt{2}$ & $\checkmark$ & 3 \\
\hline & $\begin{array}{l}\text { Most } \\
\text { unmated } \\
\text { terns }\end{array}$ & $\checkmark$ & $\checkmark$ & $\sqrt{2}$ & $\checkmark$ & 3 \\
\hline $\begin{array}{l}\text { 4. Sites within } \\
\text { limited distance of } \\
\text { previous-year's site, } \\
\text { plus "dispersers" }\end{array}$ & $\begin{array}{l}\text { Most } \\
\text { unmated } \\
\text { terns }\end{array}$ & $\checkmark$ & & $\sqrt{2}$ & $\checkmark$ & 3 \\
\hline
\end{tabular}

1These traits were not evaluated because Pattern 1 was not met; all terns selected 1-2 sites.

2Pattern 6 was met if the analysis ignores site ARM-523.4, where habitat quality is low but colony size was high because the site is isolated.

3Pattern 8 was not met because too many, not too few, terns selected their previous-year site. 


\section{Site identification distance sensitivity experiment}

The site identification distance parameter clearly can have a strong effect on the results of experiments using site identification traits 2 and 3. When this parameter is low, each tern identifies only a few or just one potential site; when it is high, terns consider many sites. To understand the effects of the site identification distance on results of the trait evaluation experiments, some of the experiments were repeated using values lower (10,000 $\mathrm{ft}$ ) and higher $(40,000 \mathrm{ft})$ than the parameter's standard value $(20,000 \mathrm{ft})$. When the site identification distance parameter is 10,000 , the mean number of sites identified by terns was 1.6, but the median was only one site, and the maximum only five sites. With a parameter value of 20,000 , the mean, median, and maximum number of sites identified were $2.8,3$, and 9 . When the site identification distance is 40,000 , the mean, median, and maximum number of sites identified was $6.4,8$, and 14 .

The sensitivity experiment examined only 1991, the low-flow year, because site identification during the high-flow year was largely controlled by which sites are submerged instead of by the site identification parameter. Only site identification trait 3 (sites near the previous year's nesting location) was used; similar results would be expected for trait 2. Both site evaluation traits 2 (select site with highest habitat quality) and 3 (select site with most unmated terns) were used.

The results of this sensitivity experiment (Table A8) show that site identification distance does affect whether some patterns are met. Neither the higher nor lower values appear better than the standard value of 20,000 $\mathrm{ft}$. An additional simulation result is that the number of selected sites is strongly affected by the site identification distance. At a parameter value of 40,000, all terns selected only six sites for both trait combinations simulated. At the standard value of 20,000 ft, terns selected 11-12 sites; at a parameter value of $10,000 \mathrm{ft}$, terns selected $14-15$ sites.

Table A8. Results of the site identification distance sensitivity experiment.

\begin{tabular}{|c|c|c|c|c|c|c|}
\hline $\begin{array}{l}\text { Site } \\
\text { Evaluation } \\
\text { Trait }\end{array}$ & $\begin{array}{l}\text { Site } \\
\text { Selection } \\
\text { Distance }\end{array}$ & $\begin{array}{l}\text { Pattern 4: } \\
\text { Largest Colonies } \\
\text { Not Occupied } \\
\text { First }\end{array}$ & $\begin{array}{l}\text { Pattern 5: } \\
\text { Narrow } \\
\text { Date Range }\end{array}$ & $\begin{array}{l}\text { Pattern 6: } \\
\text { Habitat Quality } \\
\text { Effect on } \\
\text { Colony Size }\end{array}$ & $\begin{array}{l}\text { Pattern 7: } \\
\text { Colony Size } \\
\text { Distribution }\end{array}$ & $\begin{array}{l}\text { Pattern 8: } \\
\text { Return to } \\
\text { Previously Used } \\
\text { Sites }\end{array}$ \\
\hline \multirow{3}{*}{$\begin{array}{l}\text { Highest } \\
\text { habitat } \\
\text { quality }\end{array}$} & 10,000 & $\checkmark$ & 1 & $\sqrt{2}$ & $\checkmark$ & 3 \\
\hline & 20,000 & $\checkmark$ & & $\sqrt{2}$ & $\checkmark$ & 3 \\
\hline & 40,000 & $\checkmark$ & & & $\checkmark$ & 3 \\
\hline
\end{tabular}




\begin{tabular}{|l|l|l|l|l|l|l|}
\hline $\begin{array}{l}\text { Site } \\
\text { Evaluation } \\
\text { Trait }\end{array}$ & $\begin{array}{l}\text { Site } \\
\text { Selection } \\
\text { Distance }\end{array}$ & $\begin{array}{l}\text { Pattern 4: } \\
\text { Largest Colonies } \\
\text { Not Occupied } \\
\text { First }\end{array}$ & $\begin{array}{l}\text { Pattern 5: } \\
\text { Narrow } \\
\text { Date Range }\end{array}$ & $\begin{array}{l}\text { Pattern 6: } \\
\text { Habitat Quality } \\
\text { Effect on } \\
\text { Colony Size }\end{array}$ & $\begin{array}{l}\text { Pattern 7: } \\
\text { Colony Size } \\
\text { Distribution }\end{array}$ & $\begin{array}{l}\text { Pattern 8: } \\
\text { Return to } \\
\text { Previously Used } \\
\text { Sites }\end{array}$ \\
\hline $\begin{array}{l}\text { Most } \\
\text { unmated } \\
\text { terns }\end{array}$ & 10,000 & $\checkmark$ & & $\checkmark 2$ & $\checkmark$ & 3 \\
\cline { 2 - 7 } & 20,000 & $\checkmark$ & $\checkmark$ & $\checkmark 2$ & $\checkmark$ & 3 \\
\cline { 2 - 7 } & 40,000 & $\checkmark$ & & & $\checkmark$ & 3 \\
\hline
\end{tabular}

$147 \%$ of sites were selected over a narrow date range, close to the criterion of $50 \%$.

2Pattern 6 criteria were met except for the anomalous site ARM-523.4, where habitat quality is low but colony size was high because the site is isolated.

3Pattern criteria were not met because too many, not too few, terns selected their previous-year site.

\section{Conclusions}

The following conclusions can be drawn from the simulation experiments.

- Pattern 4 criteria were always met. In almost all scenarios, the site with the largest colony was one of several sites selected on the first day that terns started selecting sites.

- Pattern 5 criteria were rarely met, ${ }^{1}$ but they were met in several scenarios even though traits include no behaviors that impose criteria directly. When terns did select sites over relatively narrow date ranges, it appeared to result from one of two causes. First, when many sites are selected by few terns each, the range of dates tends to be narrow at each site due to chance alone. Second, high flows can limit selection of low-freeboard sites to a narrow date range.

- Pattern 6 criteria can be met during high-flow years, even without behaviors encouraging terns to select sites with high habitat quality, because the definition of high quality includes having high elevation so the site is more often exposed during high flows. However, meeting criteria for this pattern during low-flow years requires a trait that includes some tendency to select for habitat quality.

- Pattern 7 criteria can sometimes be met just as a consequence of high flows, with even random selection among non-inundated sites. During low-flow years, this pattern was not met when colony site selection was random, in which case colony sizes were too similar (there were many sites of nearly the same size).

- Trait combinations that let terns select among many sites to meet some criterion (highest habitat quality, etc.) produce unrealistic results: 
terns select only a few sites in large numbers. (This tendency might not occur if the model included any negative effects of colony size on colony site selection, but no empirical basis was found to include these in the tern literature.)

- The trait combination that best reproduced the characteristic patterns is the one that limits terns to sites near where they nested or were born the previous year, and select the one with most unmated terns or (if there are no unmated terns) highest habitat quality. However, this trait produced a higher level of "site fidelity"-returning to the previous year's site-than reported in the literature. ${ }^{1}$ Simulated site fidelity was extremely high, especially at isolated sites because terns had no alternatives to their previous year's site; it is not known how realistic this high site fidelity at isolated sites is.

- The trait combination that assumes terns consider sites within a random river reach and select the one with the most unmated terns or the highest habitat quality also performed relatively well. It reproduced all the patterns except pattern 5 (which was almost met) and pattern 8 (because it did not impose "site fidelity").

- Assuming that $10 \%$ of adult terns are "dispersers" with no previouslyused site in the management area (site identification trait 4) resulted in use of more sites but did not produce better results in meeting criteria for pattern 8 than did site identification trait 3 .

- In limited testing of pattern 3 during calibration experiments, site identification trait 4 resulted in the emergence of pattern 3 (new and isolated sites are used by nesting terns). While this result may also emerge with site identification trait 1 , this trait did not reproduce other patterns well.

- The trait combinations that best reproduced the observed patterns caused terns to occupy fewer sites than were observed in 2008 field data. ${ }^{2}$ For the 1991 simulation, the model terns occupied 11 sites, whereas the 2008 field observations identified 18 colony locations. Site evaluation traits that cause more sites to be occupied use either (a) random selection among the identified sites, or (b) a smaller value of the site identification distance.

\footnotetext{
1 This observation may have been related to how the criteria at the spatial scale of sites were defined, rather than management areas (as it is often reported in the literature). This result will be re-evaluated in future tests.

2 This result will be re-evaluated with the final habitat inputs that are available in TernCOLONY 1.0. The result reported here may simply be related to the incomplete habitat datasets used during this testing.
} 
- Based on these initial tests, the combination of site identification trait 4 and site evaluation trait 3 was found to best reproduce the characteristic patterns of site use across the widest range of environmental contexts. Therefore, this combination was chosen as the colony site selection trait for Version 1.o of TernCOLONY (Lott et al. 2012). The two parameters that affect this trait were then calibrated: the distance that terns search for potential sites from their arrival location and the fraction of the populations that are "dispersers," during model calibration.

\section{Future tests of TernCOLONY's colony site selection trait}

The colony site selection trait will be re-tested using the final version of TernCOLONY 1.0, which includes a number of submodels that were not included in these original tests.

Similarly, this trait will be re-tested with the full suite of habitat inputs (degraded sites versus high-quality sites, different scenarios with restoration sandbars included) and flow inputs (three different water year types with 32 annual flow inputs from 1977-2008) that are now available for the Arkansas River (Main report, Chapter 3).

Major improvements that have been made to the code and the model's relational database will facilitate this testing (across a much wider range of environmental context), which would have been very difficult in previous versions of the code.

Similarly, some of the criteria associated with patterns will be defined more explicitly so that database queries can be built to allow easier assessment of whether or not patterns have been met for a larger number of replicates.

It is anticipated that these tests will support the initial decision to use the colony site selection trait described in the "Conclusions" section of this document and in the model description (Lott et al. 2012a). However, if results of future tests indicate that this colony site trait does not result in the emergence of test patterns, the process of pattern-oriented trait development (see "Methods") will be continued until such a trait can be designed.

\section{References}

Burger, J. 1988. Social attraction in nesting least terns: Effects of numbers, spacing, and pair bonds. The Condor 90:575-582. 
Grimm, V., E. Revilla, U. Berger, F. Jeltsch, W. M. Mooij, S. F. Railsback, H.-H. Thulke, J. Weiner, T. Wiegand, and D. L. DeAngelis. 2005. Pattern-oriented modeling of agent-based complex systems: Lessons from ecology. Science 310:987-991.

Grimm, V., and S. F. Railsback. 2005. Individual-based modeling and ecology. Princeton, NJ: Princeton University Press.

Jones, J. 2001. Habitat selection studies in avian ecology: A critical review. The Auk 118(2):557-562.

Lott, C.A., S.F. Railsback, and C.J.R. Sheppard. 2012. TernCOLONY 1.o model description. ERDC/EL CR-12-3. Vicksburg, MS: U.S. Army Engineer Research and Development Center.

Renken, R. B., and J. W. Smith. 1995. Interior least tern site fidelity and dispersal. Colonial Waterbirds 18: 193-198.

Thompson, B.C., J. A. Jackson, J. Burger, L. A. Hill, E. M. Kirsch, and J. L. Atwood. 1997. Least Tern: Sterna antillarum. In Birds of North America. ed. A. Poole and F. Gill. Philadelphia, PA and Washington, DC: The Academy of Natural Science and the American Ornithologists Union.

U.S. Army Corps of Engineers (USACE). 2011. Final Programmatic Environmental Impact Statement for the Mechanical and Artificial Creation and Maintenance of Emergent Sandbar Habitat in the Riverine Segments of the Upper Missouri River. U.S. Army Engineer District, Omaha. 


\section{Appendix B: Nest Site Selection Submodel Development}

\section{Introduction}

Nest site selection-the female tern behavior of deciding the exact habitat cell on a sandbar to place a nest-is critical for TernCOLONY's accuracy in modeling how river flows affect nest survival. This trait determines the elevation at which nests are placed and, therefore, how vulnerable they are to mortality via flooding.

One potential way to model nest site selection is empirically: by building and using a statistical model (a "resource selection model") of how nest locations selected by real terns vary with habitat variables such as elevation above the normal water surface, distance to forest and river edge, etc. Many observations of nest site selection were made at 15 sites in the Gavins Point reach of the Missouri River, in 2004-2006 (U.S. Army Corps of Engineers (USACE) 2011). This information could be used to fit a resource selection model but doing so would require a great deal of analysis (and, potentially, information that is not readily available) to determine how the probability of a cell being used for nesting varies with habitat characteristics.

The alternative approach used here is to develop a theoretical nest selection submodel that is informed by field observations and then evaluated by how closely it reproduces observed patterns that are crucial to TernCOLONY's success. The theoretical submodel simply assumes terns place nests in the cell that (a) provides the best combination of several habitat variables (has highest "habitat quality"), and (b) is not already occupied by other nests at a density exceeding that observed in real terns. The habitat variables and the functions relating them to "habitat quality" were selected considering key results reported in USACE (2011) that tern nests were generally placed at higher elevations on sandbars that were also distant from gallery forests or other large trees, riverbanks, or in close proximity to low vegetation on sandbars.

Considering these observations and the fact that higher elevation reduces the probability of flooding mortality, the submodel assumes that nest habitat increases with horizontal distance from forests, banks, and 
vegetation; and with elevation. (Details of how habitat quality is quantified are found in Lott et al. 2012).

The objective of this analysis is to evaluate the theoretical nest site selection submodel by how well it reproduces patterns observed in the data reported in USACE (2011). The analysis starts by defining these patterns and why they are more or less important, and then conducts simulation experiments to evaluate how well the ILT model, when applied to the Keystone Reach of the Arkansas River, reproduces the patterns.

The analysis was completed for two alternative traits for nest site selection. The first trait is simply that terns place their nest in the cell with (a) space for another nest (no other nest in a 6- x 6-ft cell), and (b) the highest habitat quality. The second trait was analyzed to explore the effects of adding some stochasticity to the decision. Terns identify the highest habitat quality of any cell at their site, and then randomly select a cell among those with habitat quality within $20 \%$ of the highest.

\section{Methods}

\section{Observed patterns}

This section defines the observed patterns that the nest site selection submodel will be evaluated against. The patterns are divided into two categories: primary patterns that are important for the ILT model's accuracy in modeling nest flooding mortality, and secondary patterns that are not as important for model accuracy but could affect how "realistic" the model appears to tern biologists.

\section{Primary patterns (vertical patterns of nest site selection)}

These patterns are important because they concern the elevation at which nests are placed, which directly affects their vulnerability to flooding mortality. These were based on the distributions of nest elevations observed in the USACE (2011) study. Elevation was evaluated using several measures. "Freeboard" is the vertical distance between the water surface elevation and the nest (at a given flow). "Distance from peak" is the difference in elevation from the nest to the highest elevation on its sandbar site. "Distance from mean nest elevation" is the vertical distance a nest is from the mean elevation of all nests at the site, with positive values meaning the nest is 
above the mean elevation. The data summaries used to define these patterns are shown in Figure B1.

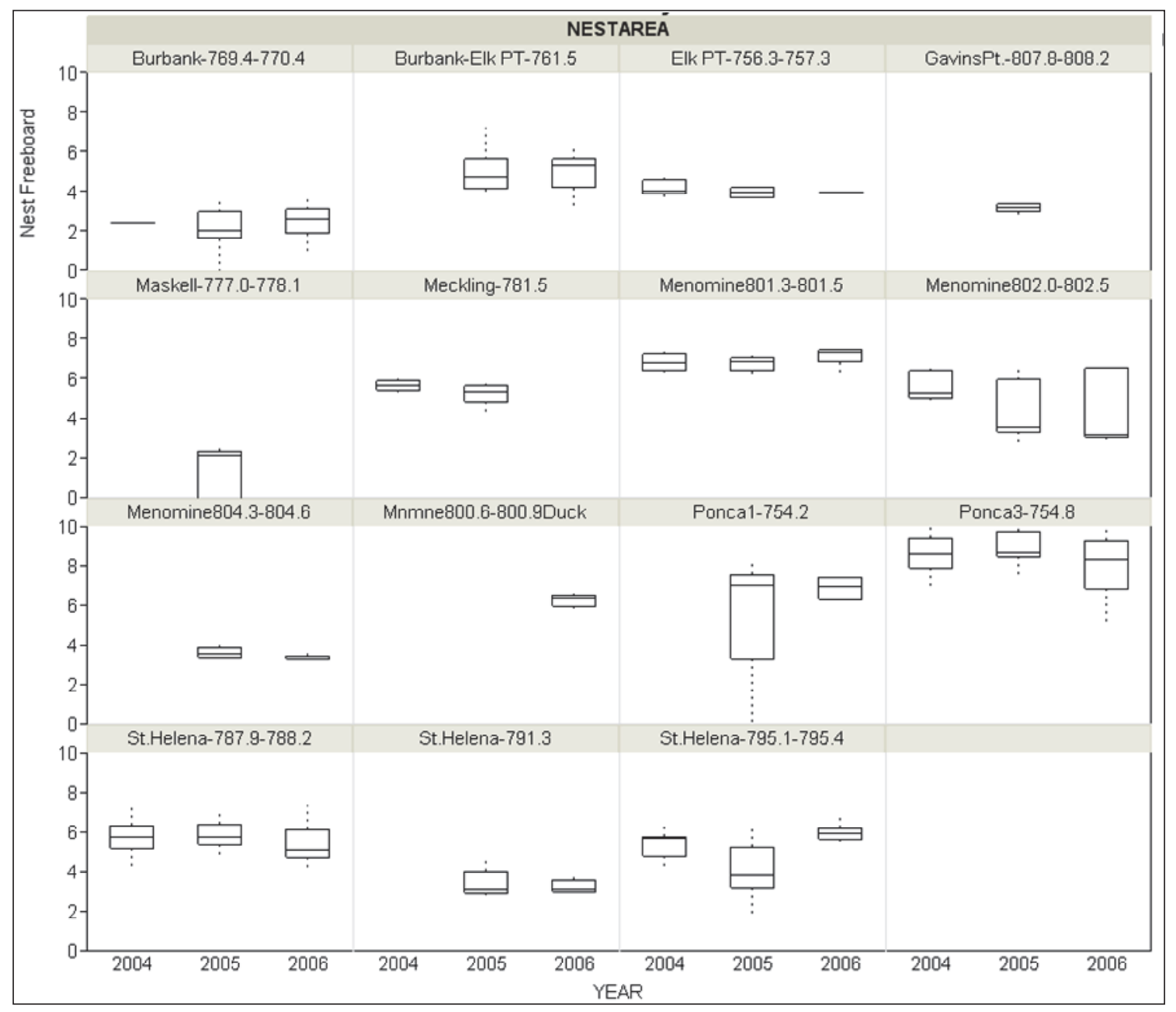

Figure B1. Observed nest freeboard distributions at 15 sites in the Gavins Point Reach, Missouri River, 2004-6. The box defines the central $50 \%$ of nests, with the horizontal line representing the median.

The USACE (2011) data were collected over a period of three years. ${ }^{1}$ These three years are treated here essentially as replicates, under the assumption that nest site selection was not affected by differences among the years in river flow.

The primary patterns are:

\footnotetext{
1 These results were not reported directly in USACE (2011) and the analyses reported here come from additional analyses of the same data.
} 
Pattern 1: There is little variation in nest elevations among years at the same site

Among years at each site, nests tend to be in the same range of elevations. At approximately 10 of the 12 sites where nests were observed in multiple years, the median nest elevation varied by less than $\approx 1 \mathrm{ft}$ over the $2-3$ years observed. A quantitative definition of this pattern is: The range of median nest elevations over three different flow years is less than $2 \mathrm{ft}$, at $75 \%$ or more of sites. (Calculate the median elevation of nests at one site, for each year. The range is the difference between minimum and maximum median elevation over the years.)

\section{Pattern 2: Nests are within a narrow range of elevations at each site}

The majority of nests at each site tended to be within a narrow range of elevations. The central 50\% of nest elevations were within a range of about $2 \mathrm{ft}$ in approximately 27 of the 34 combinations of site and year. However, in a few cases the central $50 \%$ of nest elevations were distributed over 3-6 ft. A quantitative definition of the pattern is: (a) the central 50\% of nest elevations at each site, each year, are within a range of less than $3 \mathrm{ft}$; but (b) at some sites and years, this range was greater than $3 \mathrm{ft}$.

\section{Pattern 3: Nest freeboard varies widely among sites}

Average nest freeboard varied widely among sites, but only rarely was below $2 \mathrm{ft}$. At about 12 of the combinations of site and year, most of the nests were less than $4 \mathrm{ft}$ above normal water elevation. (Freeboard is of course limited by the site's maximum elevation.) A quantitative definition of this pattern is: (a) fewer than $10 \%$ of site/year combinations have a median nest freeboard less than $2 \mathrm{ft}$, while (b) across all site/year combinations, median freeboard varies by at least $2 \mathrm{ft}$.

Pattern 4: Nests were rarely at a site's highest elevation and the elevation difference between nests and peak site elevations varied widely among sites

Nests were often not near the site's maximum elevation. At only 12 of the 34 combinations of site and year were at least $50 \%$ of the nests less than $2 \mathrm{ft}$ below maximum elevation. Nests ranged up to $8 \mathrm{ft}$ below maximum elevation of their site. A quantitative definition is simply that there are at least some combinations of site and year with median nest distance from peak greater than $2 \mathrm{ft}$. 


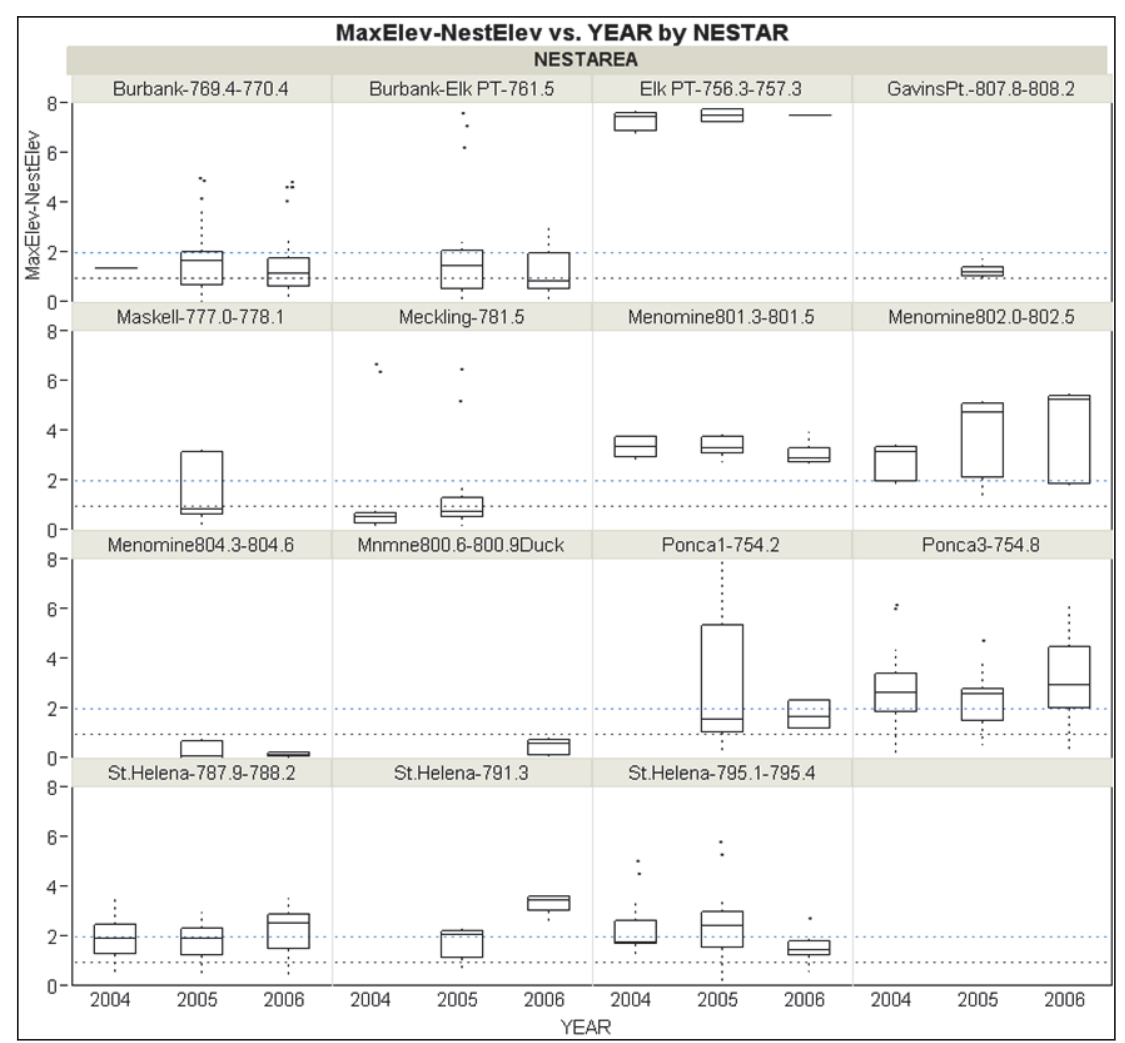

Figure B2. Distributions of nest differences from peak elevation in the Gavins Point data.

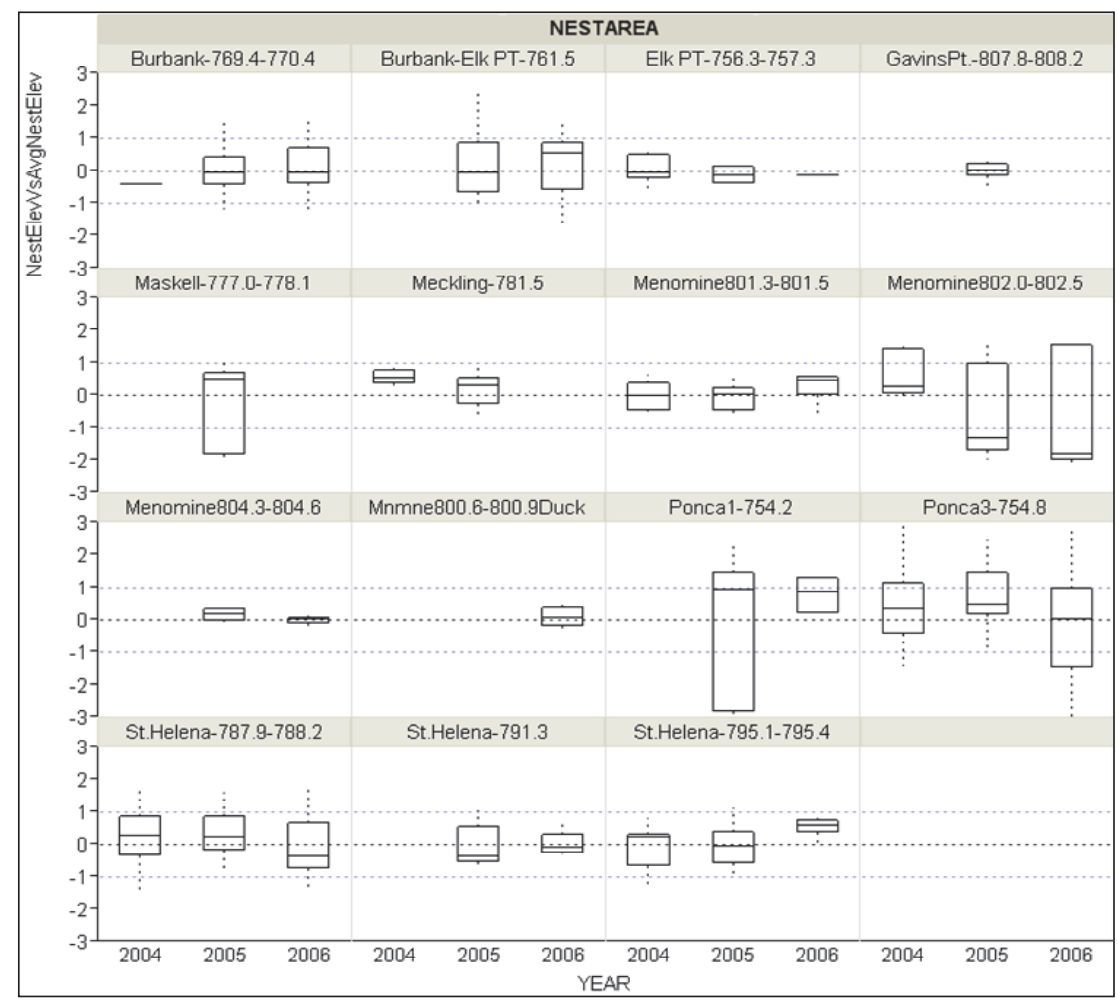

Figure B3. Distribution of distances from mean nest elevation in the Gavins Point data. 


\section{Secondary patterns (horizontal patterns of nest site selection)}

These patterns have been observed in the horizontal location of nests, so they are not as important for modeling flooding mortality. They are less quantitative than the primary patterns because there has been less analysis of the relationships among nest locations and horizontal habitat variables.

Pattern 5: Nests tend to be clustered in one or several areas of a site. Sites typically (but not always) have large areas unoccupied by nest

Pattern 6: Locations of nest clusters can vary among years at a site

\section{Simulation experiments}

The nest site selection submodel was evaluated by examining its results in two sets of simulations. The first used three similar water years that are treated as replicates, as in the Gavins Point data. These water years were chosen to be relatively low years so nest site selection was not strongly influenced by unusual flow conditions; the Gavins Point data used to define patterns were collected during relatively low-flow years. For convenience, the flow years simulated were the same three years used in the Gavins Point data (2004-6), although the choice of years is not expected to be important. At the Keystone reach, these were low-flow years except for a mid-season bump above maximum hydropower flow in 2004 and 2005. Results from these simulations were compared to the patterns defined above for the main analysis.

The second set of simulations were conducted simply to observe how the nest site selection model behaved under extremely low- and high-flow conditions; water years 1991 and 1993 were used to represent low- and high-flow years.

The simulations used a site selection trait that assumes terns select a site (sandbar) near where they nested the previous year that has the most unmated terns or (if there are no unmated terns) best habitat quality.

To evaluate the response of nearest neighbor distance to tern density, one experiment was conducted using the same year while varying the number of adult terns over a wide range.

The patterns were evaluated by examining these model outputs: 
- The distribution of nest freeboards, distance from peak, and distance from mean nest elevation at each site and year, comparable to Figure B4.

- Plots of the horizontal location of nests. (Here, simple XY plots of nest locations that do not show the boundaries of each site were used.)

- Mean nearest neighbor distance of nests, calculated from the location of each nest.

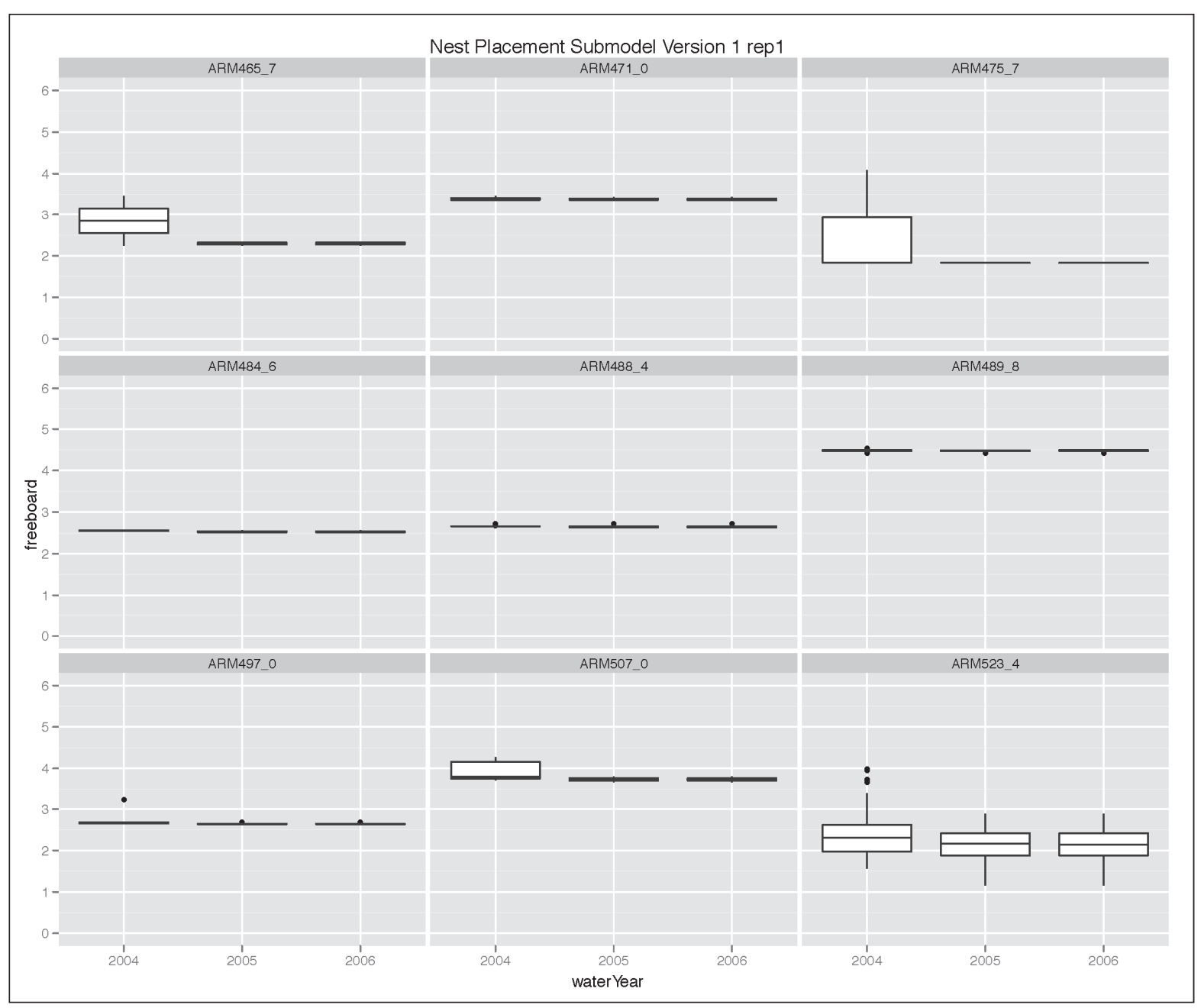

Figure B4. Simulated nest freeboard distributions, by Arkansas River site and year. Format is the same as in Figure B1.

\section{Results: Trait 1}

This section provides results for the original nest site selection trait, with nests placed on the vacant cell with highest habitat quality. 


\section{Primary patterns}

Pattern 1: Range of nest elevations at each site

The distributions of simulated nest elevations (represented as freeboard; the water level used as a basis for freeboard was constant during and among years, so nest elevation is equivalent to freeboard for this analysis) is at Figure B4.

This pattern was reproduced. The range of median nest elevations over the three flow years was less than $2 \mathrm{ft}$ at all sites. In fact, the median nest elevations were essentially identical among the three years at many sites, a much greater level of consistency than in the Missouri River data.

\section{Pattern 2: Narrow range of elevations}

This pattern can also be evaluated from Figure B4. This pattern was only partially met, with the central $50 \%$ of nest elevations within a range of $3 \mathrm{ft}$ or less at each site and year. However, in no cases was the range greater than $3 \mathrm{ft}$. The simulated range of elevations was often extremely narrow, much more so than in the Missouri River data.

\section{Pattern 3: Average nest freeboard}

This pattern was met, or nearly met, as illustrated in Figure B4. Median nest elevation was just below $2 \mathrm{ft}$ at one site (ARM475.7) on all three years. The highest median freeboard was approximately $4.5 \mathrm{ft}$, at site ARM489.8.

\section{Pattern 4: Average nest distance from peak}

The distances of nests from peak site elevation are displayed in Figure B5. This pattern is met if any site and year combinations have median distance from peak of greater than $2 \mathrm{ft}$; this criterion was met at sites ARM475.7, ARM507.0, and 523.4 on all three years.

\section{Secondary patterns}

The secondary patterns of nest horizontal location are illustrated in Figure B6. Note that the scale varies widely among these XY plots for different sites, and the $\mathrm{X}$ and $\mathrm{Y}$ scales are sometimes different. 


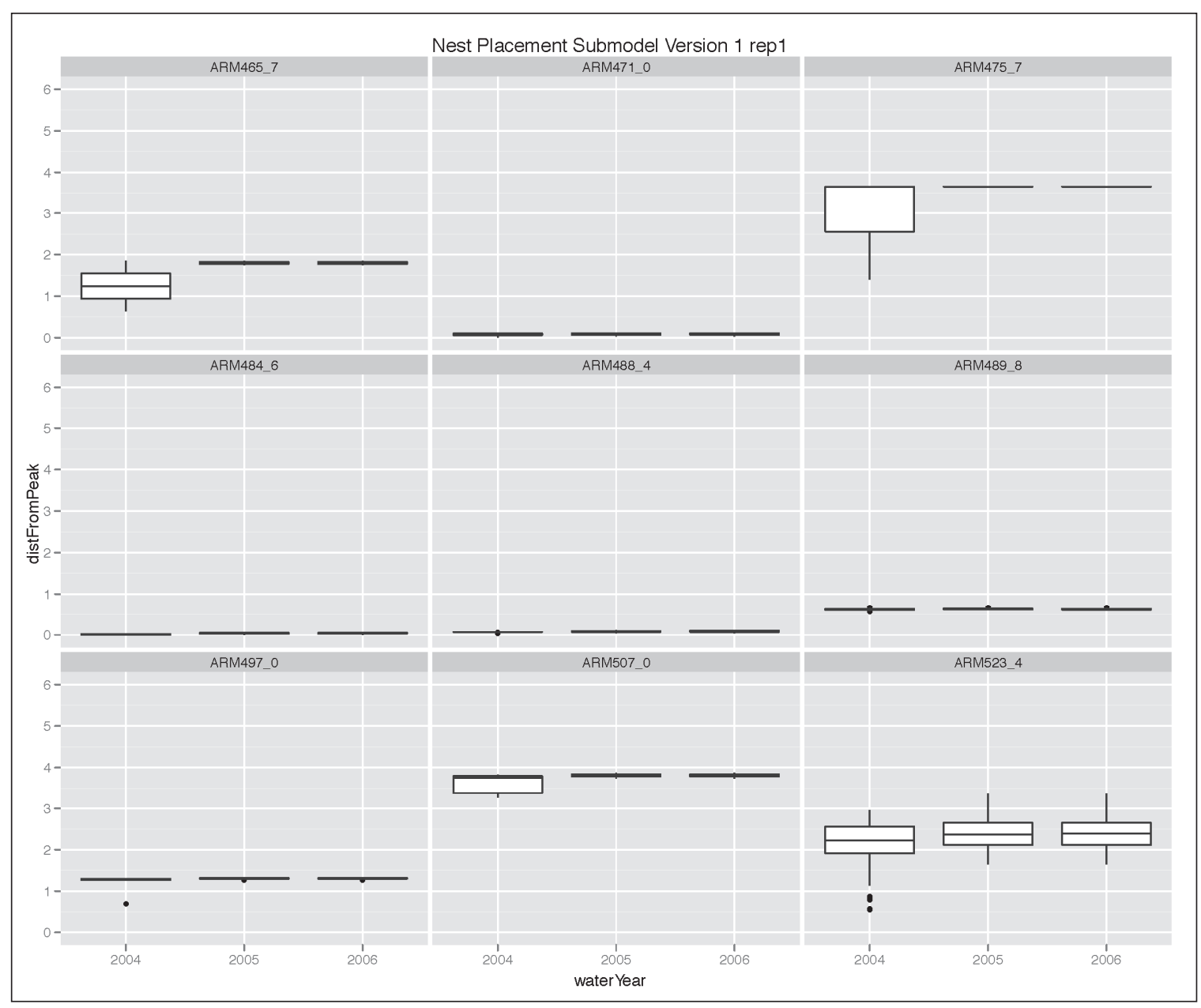

Figure B5. Distribution of simulated nest elevation differences from peak.

Pattern 5: Nest clustering

This pattern was met: the nests tend to be highly clustered. (These plots are not capable of showing how much of each site is unoccupied.) In fact, in almost all cases, the nests are clustered as closely together as possible.

Pattern 6: Variation among years

This pattern was met. At several sites the cluster of nests was at a different location in 2004 than in the other two years.

\section{Results: Trait 2}

This section provides results for the second nest site selection trait; under this trait, nest locations are chosen randomly from among the $20 \%$ of cells with highest habitat quality. 


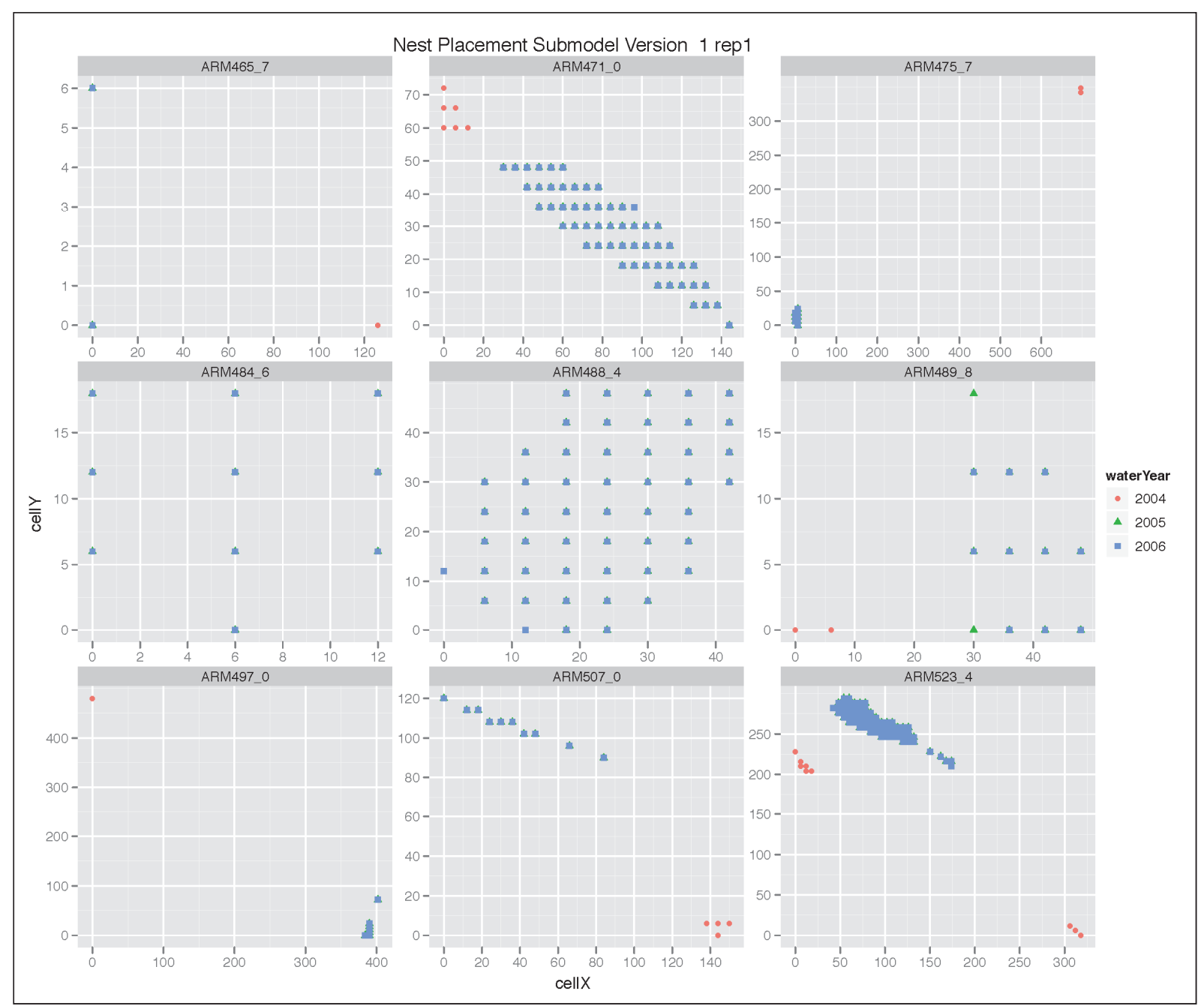

Figure B6. Horizontal location of nests, version 1 of nest site selection trait.

\section{Primary patterns}

Pattern 1: Range of nest elevations at each site

The distributions of simulated nest elevations (as freeboard) are shown in Figure B7. This pattern was reproduced. The range of median nest elevations over the three flow years was less than $2 \mathrm{ft}$ at all but one site, ARM507.7.

\section{Pattern 2: Narrow range of elevations}

This pattern can be evaluated from Figure B7. The pattern was met, with the central $50 \%$ of nest elevations within a range of $3 \mathrm{ft}$ or less at each site and year except one: site ARM475.7 in 2004. There was more variation within sites than with the first trait, with nest elevation ranges more similar to those in the Missouri River data. 


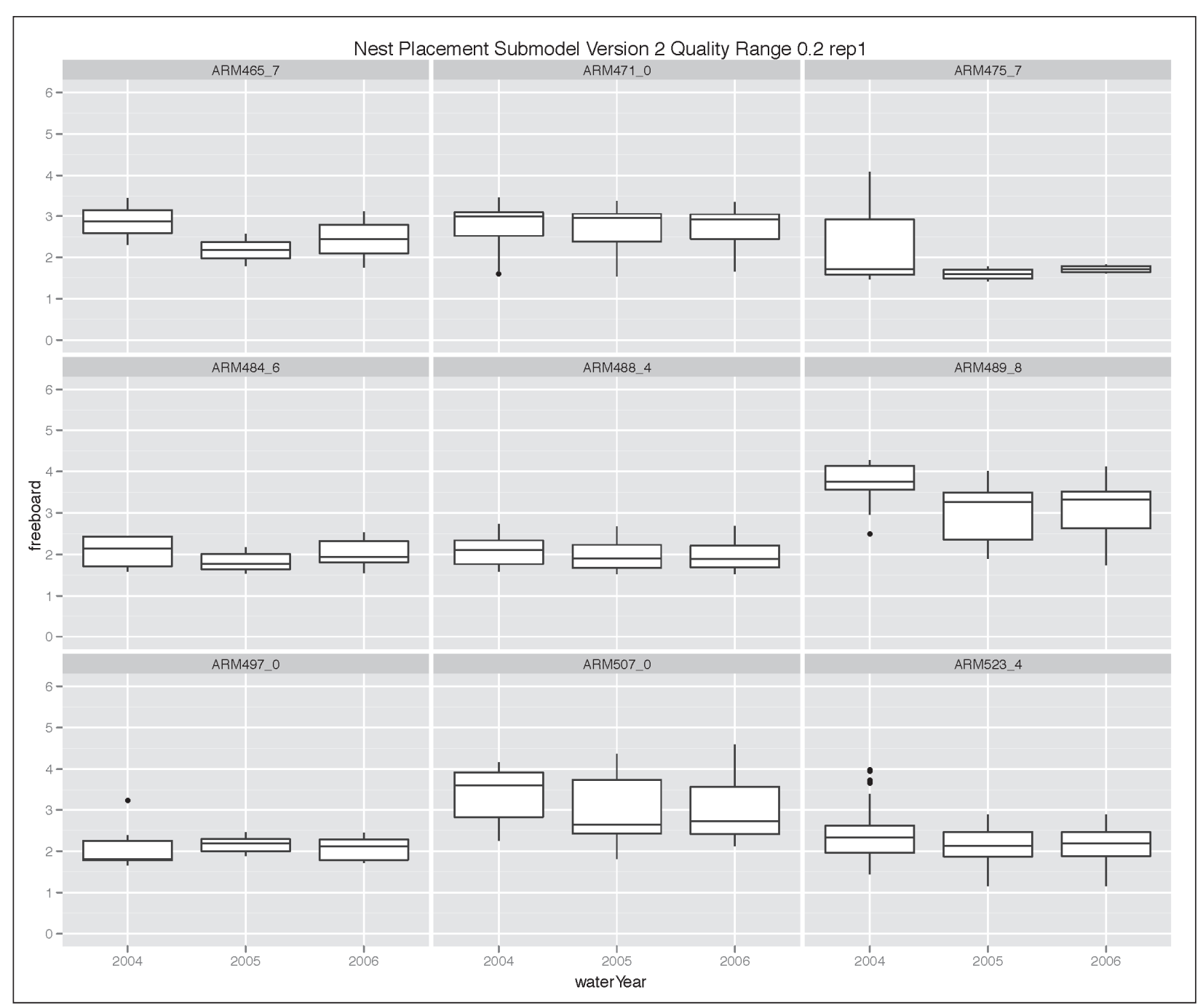

Figure B7. Simulated nest freeboard distributions, by Arkansas River site and year, nest site selection trait 2.

\section{Pattern 3: Average nest freeboard}

This pattern was less clearly met with Trait 2 compared to the first trait because median nest freeboard was (barely) less than $2 \mathrm{ft}$ in several more cases (e.g., two years at ARM484.6 and ARM488.4). The difference between traits causes an overall tendency to use lower-freeboard cells for nesting (compare Figure B7 to Figure B4).

Pattern 4: Average nest distance from peak

The distances of nests from peak site elevation are displayed in Figure B8. This pattern is met if any site and year combinations have median distance from peak of greater than $2 \mathrm{ft}$; this criterion was met at two sites (ARM475.7 and ARM507.0) in all three years. 


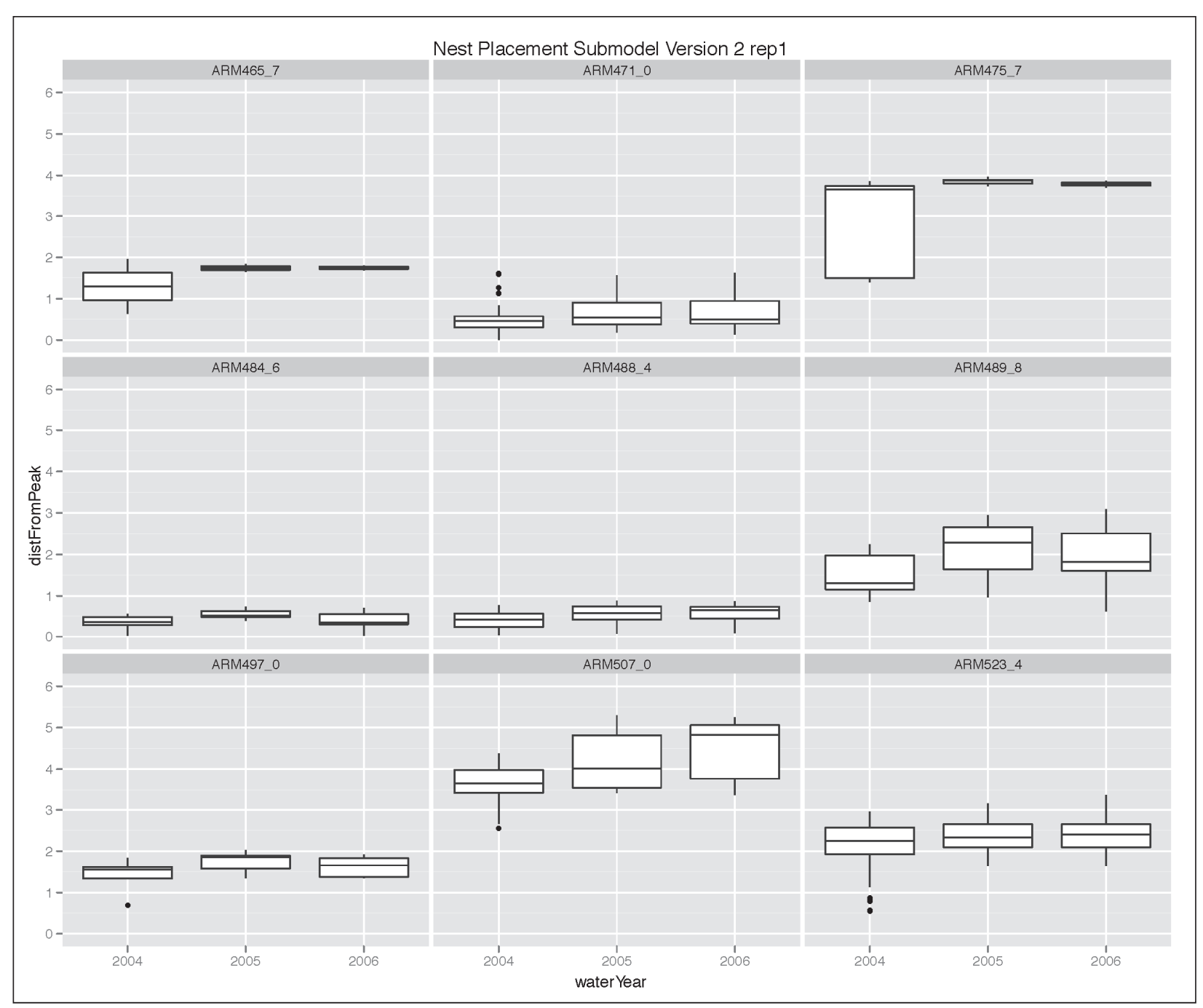

Figure B8. Distribution of simulated nest elevation differences from peak, trait 2.

Comparing Figure B8 to Figure B6 for sites where optimal nest habitat quality is near the peak elevation (ARM 471.0, 484.6, 488.4, 489.8) shows that Trait 2 causes many nests to be 1-2 ft lower than they would be if terns selected the best available cell under Trait 1 . This indicates that in some situations a substantial decrease in nest elevation can result in a relatively small change in nest habitat quality.

\section{Secondary patterns}

The secondary patterns of nest horizontal location are illustrated in Figure B9, which has the same format as, and can be compared to, Figure B6. 


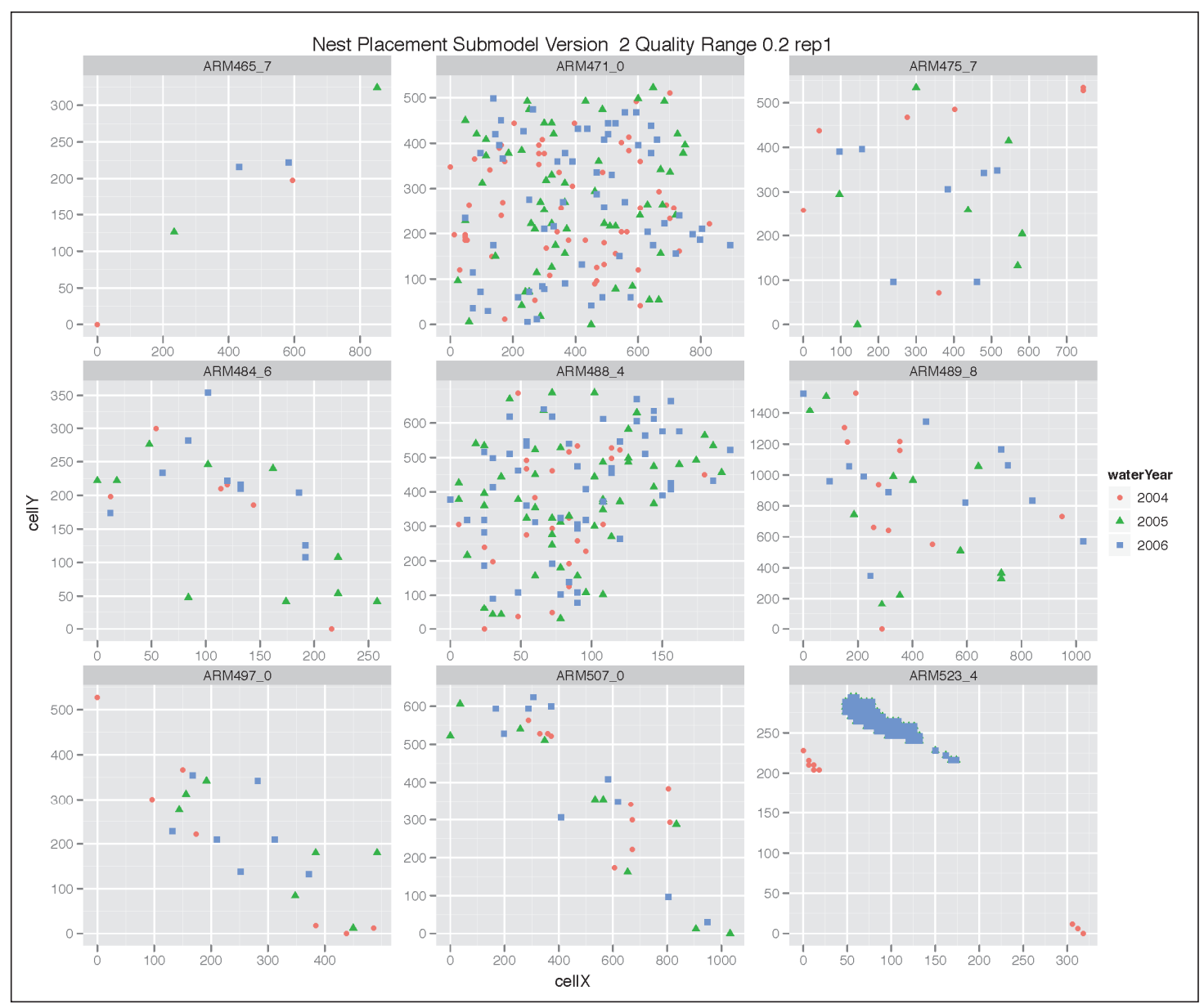

Figure B9. Horizontal nest locations, with nest site selection trait 2.

Pattern 5: Nest clustering

It is not clear from Figure B9 how well this pattern is met because the unused parts of each site are not shown. Nests are less tightly clustered than under Trait 1 but probably occupy a small part of most sites.

Pattern 6: Variation among years

This pattern was met. At one site (ARM 523.4) the cluster of nests was at a different location in 2004 than in the other two years.

\section{Conclusions}

This analysis supports several key conclusions.

First, the basic patterns of nest site selection observed in field studiesclustering of nests in horizontal and vertical dimensions, use of elevations 
well above normal water levels but not always at the peak elevationappear to emerge quite directly from how well nesting habitat is arranged spatially on sites. Assuming that terns simply place their nests where the habitat is best, the most basic patterns are reproduced.

Second, however, is that there appears to be more variability in real nest locations than the model indicates when assuming that terns pick the best available habitat. Underestimating variability in nest elevations is clearly a concern because it likely would cause underestimation of flooding mortality. Much of that additional variability can be reproduced by simply assuming, via Trait 2, that terns choose nest locations randomly from among the best cells.

Trait 2 represents an assumption that above a certain habitat quality threshold (as habitat quality is measured), habitat quality does not vary tremendously from cell to cell. Perhaps within high quality areas, nest site selection is influenced by other habitat variables that were ignored (e.g., use of topography to reduce nest visibility; ground-level wind conditions; presence/absence of driftwood) or social/ecological considerations such as positive and negative effects of proximity to other nests.

Patterns of nest location clearly depend strongly on what kind of habitat is available. Even patterns in easily measured variables such as freeboard are somewhat questionable to transfer among study sites without knowing the ranges available to the adult terns. Therefore, it seems unlikely that the nest site selection trait can be further refined without reliable observations from sites that can be simulated.

\section{References}

Lott, C.A., S.F. Railsback, and C.J.R. Sheppard. 2012. TernCOLONY 1.o model description. ERDC/EL CR-12-3. Vicksburg, MS: U.S. Army Engineer Research and Development Center.

U.S. Army Corps of Engineers (USACE). 2011. Final Programmatic Environmental Impact Statement for the Mechanical and Artificial Creation and Maintenance of Emergent Sandbar Habitat in the Riverine Segments of the Upper Missouri River. U.S. Army Engineer District, Omaha. 


\section{Appendix C: Site Abandonment Submodel Development}

\section{Introduction}

Site abandonment is an adaptive behavior in TernCOLONY, although it is a collective behavior of all the terns at a site. (The terns at a site are referred to here as a colony.) The behavior is a decision of whether the colony should abandon the site and any nests and chicks alive there, to select a different site. The behavior is a response to high mortality, whether caused by flooding or predators and other mortality agents.

The site abandonment submodel assumes that the colony abandons a site if its recent rates of adult, nest, or chick mortality are high enough to predict that reproductive success would be higher if the colony moved to a new site. While this conceptual basis is simple, the submodel requires a number of assumptions that are documented in Lott et al. 2012. One important parameter is adminAbandSurvivalHorizon, the number of days over which the terns evaluate mortality rates to determine if they should abandon a site. Small values of this parameter (e.g., 1-2 days) mean that terns consider only very recent mortality and "forget" about deaths occurring before the parameter's value was established. Higher values (e.g., 5-7 days) mean adult terns consider the overall mortality rate over more days, so they are less responsive to immediate bursts of mortality and more responsive to steady mortality. (However, even when values of this parameter are higher, the colony can respond immediately to a burst of high mortality; it does not necessarily wait through this time horizon before abandoning a site.) A second important parameter is adminExpectedFledges, the maximum number of successful fledglings each adult female is assumed to produce if a colony abandons a site and reproduction must be reinitiated. This parameter is also used to predict how many fledglings would be produced at the current site by females that have not yet nested.

The purpose of this analysis is to explore behavior of the site abandonment submodel and depict it so that any counterintuitive or questionable responses can be identified. There are insufficient data on this behavior to define specific patterns to evaluate or calibrate the model against. 


\section{Methods}

\section{Software implementation}

This site abandonment submodel analysis was implemented in a version of the submodel in the $\mathrm{R}$ statistical programming language. This $\mathrm{R}$ implementation was originally developed to test TernCOLONY's code for site abandonment (so it has been verified against the Repast code), and it is very convenient for this analysis.

The submodel considers a few characteristics of the individual terns in the model. These characteristics were generated in $\mathrm{R}$ by creating an array in which each row represents one individual. The following assumptions were used about the individuals.

- All adults were assumed to be mated.

- The number of eggs in each nest was drawn from a Poisson distribution with a mean of 2.5 eggs/nest. (This is slightly different from the ILT model's assumption about eggs per nest, which also has a mean of 2.5 eggs/nest, but allows no more than 3 eggs.)

- The number of days each nest has left to incubate was drawn from a uniform distribution with a range of 1-21 days.

- The number of days each chick has left before it fledges was drawn from a uniform distribution with a range of 1-20 days.

The R implementation represents one colony and considers how many adults, nests, and chicks are alive, and how many adults, nests, and chicks have died within the time horizon adminAbandSurvivalHorizon.and the $\mathrm{R}$ implementation also calculates whether the colony abandons the site.

\section{Simulation experiments}

The analysis was conducted by running the site abandonment submodel over various ranges of its inputs and parameter values. Each simulation experiment is described below along with its results. Most of the experiments were based on a standard scenario, which represents a colony of 100 pairs of terns that have nested, with half the nests hatched:

- Number of adult terns (alive or killed during the survival time horizon): 200

- Number of nests (alive or killed during the survival time horizon): 50 
- Number of chicks (alive or killed during the survival time horizon): 125

- Value of adminExpectedFledges: 1.0 chick per adult

- Value of adminAbandSurvivalHorizon: 5 days

- First date of nesting: Julian date 138

Results of the submodel depend on date, so they were produced for days 140-200. The simulations assumed that the last day on which chicks can fledge is day 244, so nests created after day 203 have no chance of success.

For these analyses, mortality is depicted by the percent of individuals killed within the survival horizon of five days. For example, an adult mortality rate of $10 \%$ means that 20 adults have died and 180 remain alive, so the daily survival rate is $0.9^{1 / 5}=0.979$.

The analysis results are presented as the level of mortality that causes site abandonment. Mortality rates equal to or greater than this level would cause the adults to abandon a site. These mortality levels that cause site abandonment were generally calculated only to the nearest $5 \%$.

\section{Results}

\section{Effects of adult mortality and date}

This experiment used the standard scenario and assumed that mortality occurs only for adult terns. The results (Figure $\mathrm{C} 1$ ) show that early in the breeding season (before day 170), the adult mortality rates causing site abandonment are between 10 and 20\%. However, as the date increases the terns become more and more resistant to site abandonment; by day 200 , adult mortality had to be $45 \%$ to cause abandonment.

\section{Effects of nest mortality}

This experiment used the standard scenario and varied mortality of nests. Under the modeled scenario, no level of nest mortality, up to $100 \%$, caused site abandonment at any time in the nesting season. In this scenario, in which chicks are also present, the nests did not contain enough of the colony's reproductive potential to cause site abandonment even if they were all lost. 


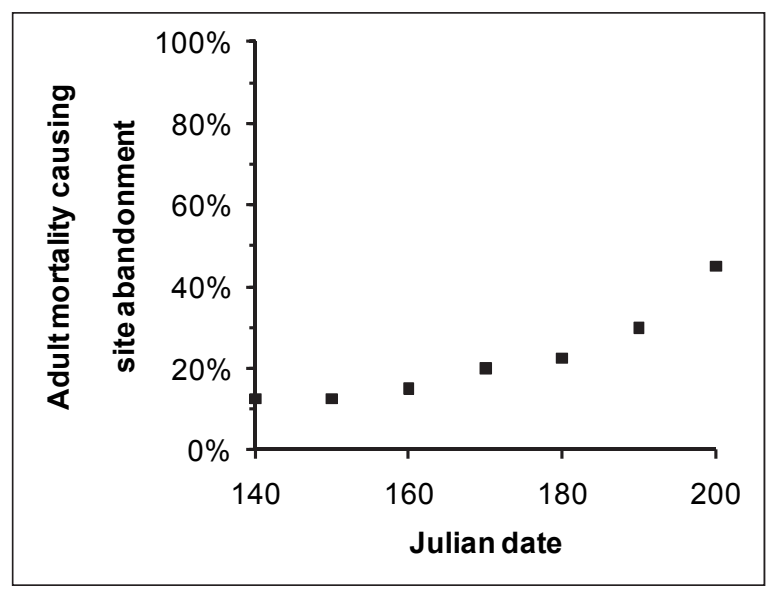

Figure $\mathrm{C} 1$. Adult mortality experiment. Each symbol indicates the adult mortality rate (\% killed in 5 days) at which sites would be abandoned, for dates from 140 to 200 .

\section{Effects of chick mortality and date}

In this experiment the standard scenario was used, varying mortality only of chicks. The results (Figure C2) are similar to those for adult mortality in that the colony's sensitivity to mortality is higher earlier in the season, with the mortality rate that triggers site abandonment increasing sharply as the season progresses. However, the chick mortality rate that causes site abandonment is higher than the adult rate; more than twice as many chicks as adults must die to cause site abandonment.

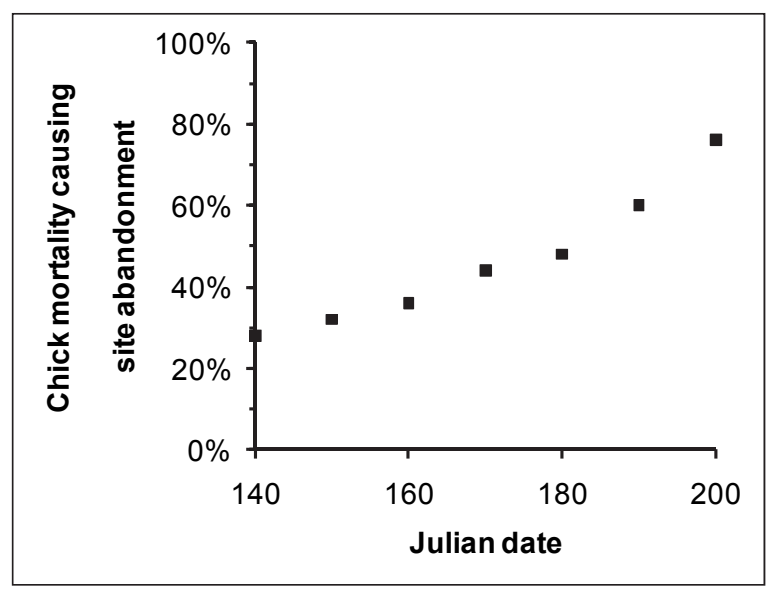

Figure $\mathrm{C2}$. Chick mortality results.

\section{Effects of combined mortality and date}

This experiment assumed that mortality occurs equally (at the same rate) to adults, nests, and chicks. Methods were the same as for the previous three experiments, except that the same mortality rate applied to all three 
life stages. The mortality rates at which the colony abandons its site (Figure $\mathrm{C}_{3}$ ) are very similar to those for adult mortality (Figure C11).

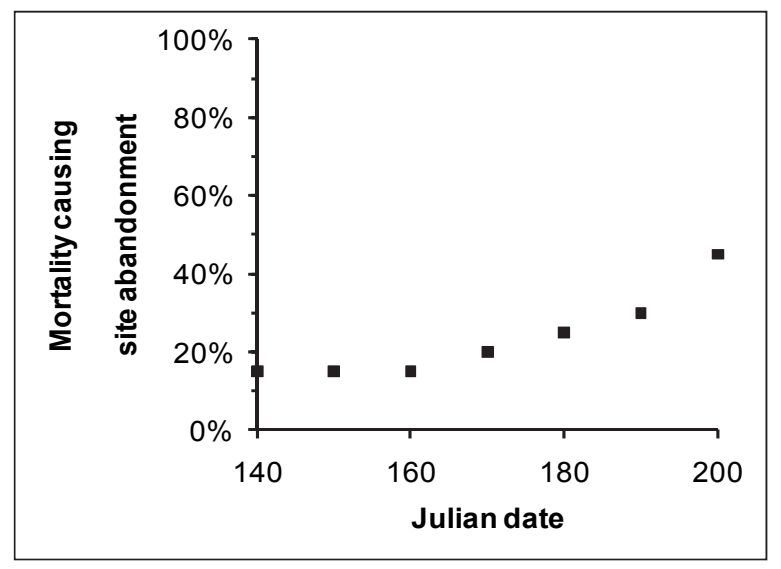

Figure C3. Results of the combined mortality experiment.

\section{Effects of hatching status}

This experiment looked at how the fraction of nests that have hatched affects site abandonment. The experiments on nest and chick mortality indicate that mortality of chicks has much more effect on site abandonment than mortality of nests, so this experiment looked at how the mortality rate causing site abandonment depends on how many of a colony's nests have hatched into chicks.

The experiment included 200 adults that produced 50 nests. Simulations determined that the nest and chick mortality rate causing site abandonment as the percent of nests hatched into chicks varied from o to 100. Mortality was assumed to occur at an equal rate to nests and chicks. Mortality causing site abandonment was determined only to the nearest $10 \%$ in this experiment. The date was constant at day 180.

When no nests had hatched, the submodel causes site abandonment at a relatively high mortality rate of $40 \%$, but abandonment happens at $30 \%$ mortality when only $20 \%$ of nests have hatched (Figure $\mathrm{C}_{4}$ ). This drop in mortality at site abandonment from 40 to $30 \%$, when the percent of nests hatches increases from o to $20 \%$, turns out to be an artifact of the submodel's assumption that future survival of chicks is $100 \%$ when no chicks are present. (The submodel estimates future survival from actual mortality events; there can be no chick mortality events when no chicks have been hatched.) As soon as some chicks have hatched and died, the submodel no longer assumes their survival is $100 \%$. 


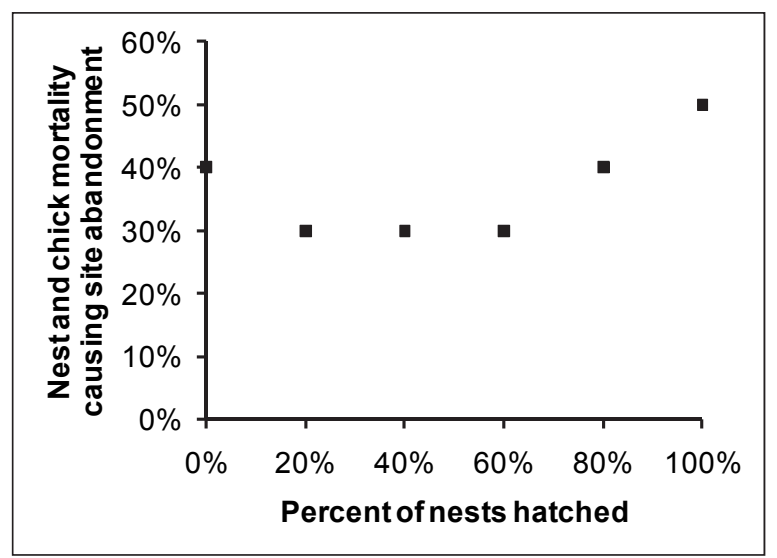

Figure C4. Results of hatching analysis.

Neglecting the anomalous result at o\% hatching, the mortality rate causing site abandonment rises as the percent of nests hatched approaches 100, especially at values above $60 \%$. This increase is mainly because chicks have a shorter time to survive until fledging than nests do.

This experiment shows that 40\% mortality causes site abandonment when only nests are present, whereas the nest mortality experiment found that no level of nest mortality caused site abandonment. The difference between these two experiments is that here, when the percent of nests hatched was zero, there were no chicks present, so all reproductive output was in the nests; in the nest mortality experiment, 125 chicks were always present.

\section{Effects of tern abundance}

This set of experiments analyzes how results such as those described previously depend on the initial abundance of terns (adults, nests, or chicks): Does site abandonment occur at lower mortality rates when there are fewer birds are alive?

These experiments repeat those described previously while varying the number of adults, nests, and chicks. The results indicate that the same mortality rate, as percent of birds killed per day, produces site abandonment behavior almost independent of abundance. Very early in the breeding season, higher abundance causes a slight increase in the mortality needed to cause site abandonment. 


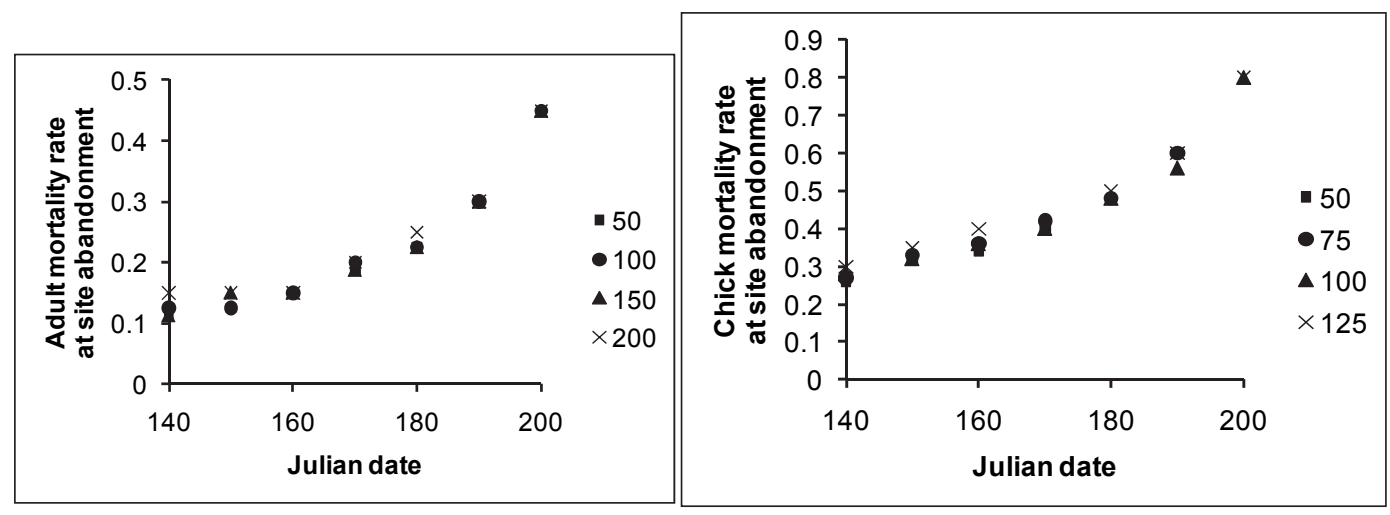

Figure C5. Abundance experiment results for adults (left) and chicks (right). The legend indicates the total abundance before mortality (e.g., for total abundance of 50 adults, when the adult mortality rate is $20 \%$, there are 40 live adults and 10 killed within the survival time horizon).

Another experiment looked at even lower abundances, focusing on nest mortality. The number of adults was varied from 10 to 20 , and one nest was assumed for each two adults. Nest mortality was then simulated. The results (Figure C6) are noisier than those in Figure $\mathrm{C}_{5}$ because there are only a few possible nest mortality rates when the number of nests is very low. This experiment indicates that terns are less likely to abandon nests when their abundance is low, although this tendency is likely an artifact of the discrete nature of mortality at low abundances.

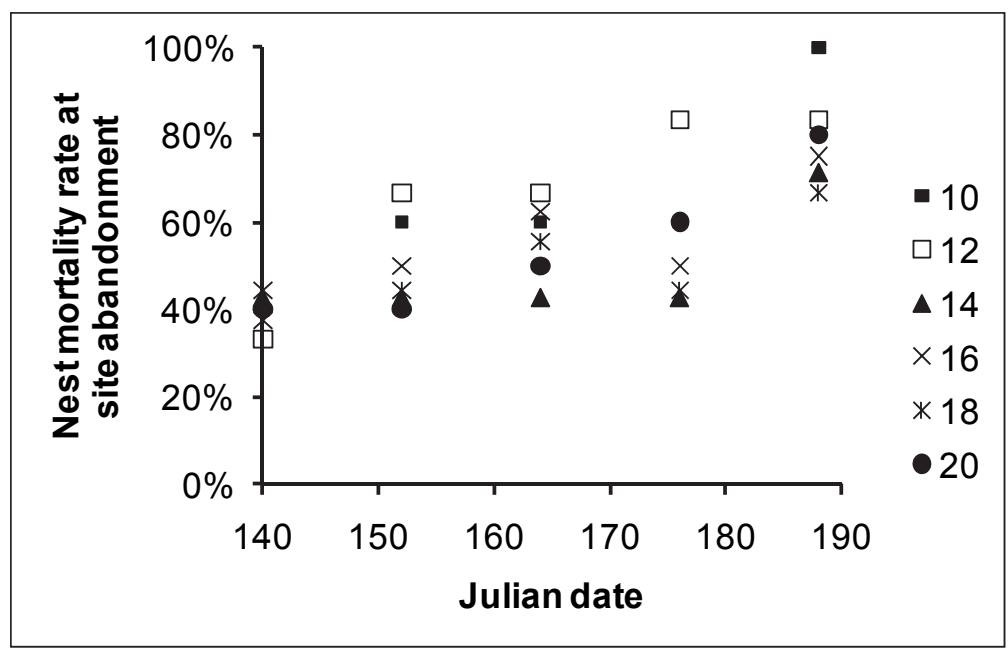

Figure C6. Nest mortality results at extremely low adult abundances. The legend provides the total number of adults, with one nest for every two adults.

\section{Abandonment by un-nested adults}

When adult terns first arrive at a site, before they mate and produce nests, they still abandon the site if the site's mortality rate is high enough that they 
would expect more success elsewhere. It is important to understand the site abandonment submodel's behavior during this period because any undesirable behavior could delay or confuse all the site selection and nesting simulations. This behavior was explored by calculating the mortality rate at which a site is abandoned when the only terns at a site are unmated adults. Because of the model's mathematical formulation, this rate does not vary with the number of such unmated adults.

The submodel causes unmated terns to abandon a site at low levels of mortality (Figure $\mathrm{C}_{7}$ ). During the date range when most nesting activity occurs (e.g., before day 180), mortality of even $2 \%$ of adults causes abandonment of a site where no nests have as yet been created.

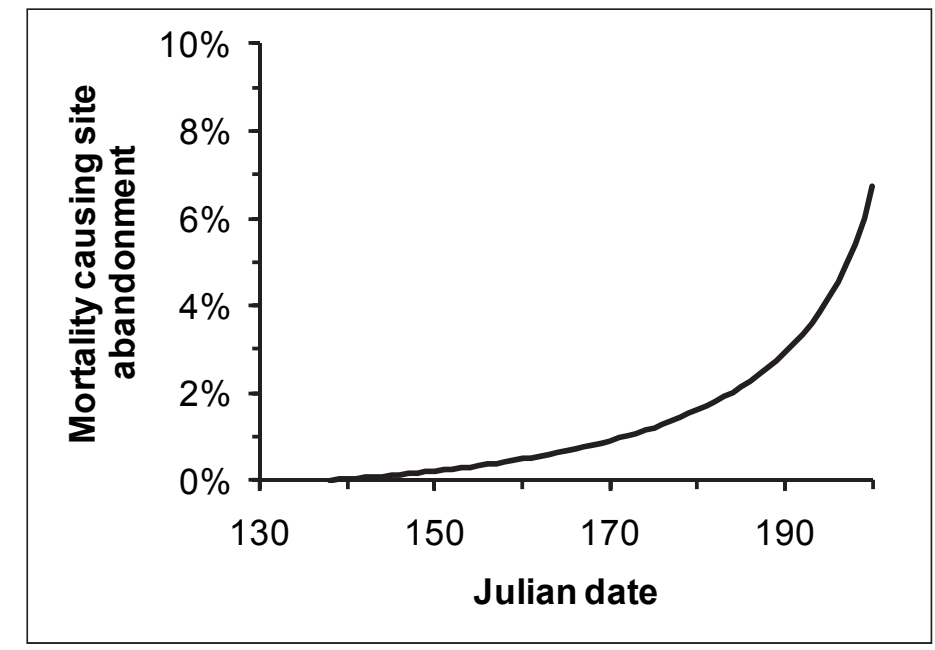

Figure C7. Rate of mortality (percent killed within the 5-day survival horizon) causing un-nested adult terns to abandon a site.

\section{Sensitivity experiment for adminExpectedFledges}

The parameter adminExpectedFledges is relatively uncertain because its value is hard to measure and is likely to be highly variable. To understand how its uncertainty could affect site abandonment submodel results, a sensitivity analysis was conducted. This experiment repeated the combined mortality experiment (Section 3.4) six times using values of adminExpectedFledges ranging from 0.5 to 1.0. This range covers values estimated in field and modeling studies (as discussed in the ILT model description).

The results indicate that simulated site abandonment is insensitive to adminExpectedFledges (Figure C8). Over the entire range of 0.5 to 1.0, this 
parameter affected the mortality rate causing site abandonment by no more than $5 \%$. This result indicates that uncertainty in adminExpectedFledges need not be a concern, as its value should have little effect on model results.

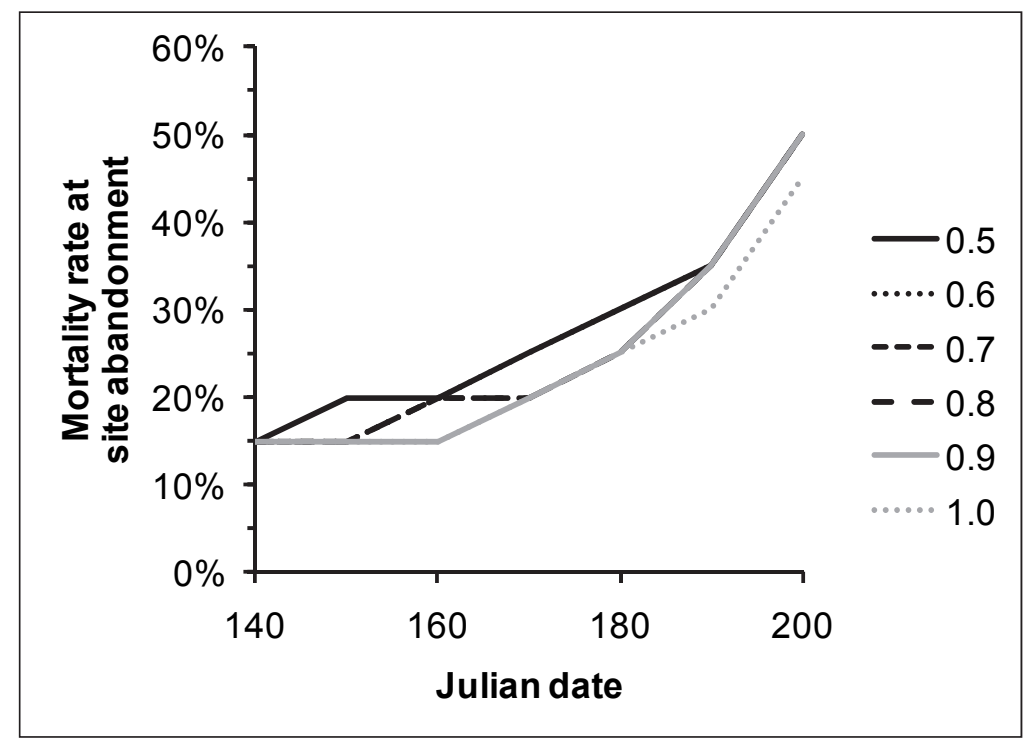

Figure C8. Results of the sensitivity analysis for adminExpectedFledges. The legend refers to the value of adminExpectedFledges.

\section{Conclusions}

This analysis was not conducted to directly test the site abandonment submodel against data or observations, because clear observed patterns are not available. Instead, it examined the general behavior of the submodel over a wide range of conditions so that any undesirable behaviors could be detected. The submodel exhibited these characteristics:

- As time proceeds through the breeding season, tern colonies require higher mortality before they abandon their sites. Colonies are relatively quick to abandon sites early in the season, but very resistant to abandonment late in the season.

- Nest mortality by itself does not cause site abandonment when substantial numbers of chicks are also present. However, nest mortality can cause site abandonment when few or no nests have hatched.

- Chick mortality rates that cause site abandonment are more than twice the adult mortality rates that cause abandonment.

- When both nests and chicks are subject to mortality, sites become less subject to abandonment as more of the nests hatch into chicks. 
- When site abandonment is evaluated as the percent of terns (including nests and chicks) that must be killed to cause abandonment, it is affected little by the total abundance of terns.

- Before nesting begins early in the breeding season, even the smallest rates of adult mortality cause site abandonment.

- The parameter adminExpectedFledges is important to the submodel because it is used to estimate reproductive success if a site is abandoned. However, the colony decisions made by the submodel change very little as this parameter is changed over its expected range of possible values, 0.5 to 1.0 fledge per female.

\section{Reference}

Lott, C.A., S.F. Railsback, and C.J.R. Sheppard. 2012. TernCOLONY 1.o model description. ERDC/EL CR-12-3. Vicksburg, MS: U.S. Army Engineer Research and Development Center. 


\section{Appendix D: Pattern-oriented Testing of Mortality and Reproductive Performance}

\section{Introduction}

One objective of TernCOLONY is to increase understanding of how different causes of mortality (e.g., flooding, predators, and human disturbance) affect reproductive success in ways that may limit tern populations. In this sense, it is important to understand the contexts in which specific causes of mortality occur (e.g., different types of water years, initial habitat conditions, or management regimes); as well as the frequency and magnitude of different causes of mortality under different contexts. Similarly, it is important to understand how the contribution of any one source of mortality affects reproductive success at spatial scales ranging from individual breeding sites/colonies to defined subpopulations/management areas and at temporal scales ranging from one breeding season, the average reproductive lifespan of Least Terns ( $\sim 10$ years from Thompson et al. [1997]), or decades (to project how different types of mortality may affect population persistence).

Three different elements of the TernCOLONY model cause mortality to occur: 1) nests and chicks die from river flooding if they are inundated as flows increase; 2) mortality agents such as predators or human disturbance agents cause direct mortality of adults, nests, or chicks; and 3) adult terns abandon viable eggs or chicks after mortality agents cause significant mortality within a colony, causing the mortality of abandoned eggs or chicks.

Each of these three primary sources of mortality is affected by how submodels interact with each other and with model inputs. For example, the frequency and magnitude of flooding mortality depends on how the site selection and nest site selection submodels interact with initial habitat conditions, as well as the time series of peak daily flows in any one year. Likewise, the frequency and magnitude of mortality due to mortality agents varies according to several different parameter values (and methods for introducing stochasticity) in the mortality agent submodel. Finally, the frequency and magnitude of mortality due to site abandonment depend on interactions between parameter values and assumptions inherent to the site 
abandonment submodel and the behavior of mortality agents (caused by the mortality agent submodel) in any one simulation.

Some effects of submodel behaviors on mortality have been previously examined during submodel testing. This document describes overall patterns of reproductive success, including some related to specific causes of mortality, from the literature and empirical data. It also tests how well TernCOLONY reproduces these patterns, with all (or a subset) of submodels running and in different contexts for testing (different inputs for water years, initial habitat conditions, or key parameter values). Similar to testing of the nest site selection submodel, testing in this case begins by defining test patterns, discussing why they are more or less important, and then conducting simulation experiments to evaluate how well TernCOLONY, when applied to the Keystone Reach of the Arkansas River, reproduces these patterns.

Two major differences are recognized between model outputs and the empirical data used to define patterns. First, the collection of field data on Least Tern reproductive success can be complicated by low or variable detectability of nests and chicks (depending on habitat conditions and field methods, which vary among studies). Second, the tern model does not address all potential causes of adult, nest, and chick mortality; only those that might directly tie to specific management alternatives (e.g., changes to dam release schedules, predator or disturbance management programs). Specifically, the model does not include a bioenergetics submodel that could address weather-related mortality due to heat or cold stress or starvation due to low food availability (and how these types of stresses might interact to increase mortality or site abandonment due to pressure from predators or humans). Therefore, one would not expect an exact match between model outputs (which are not subject to the same bias as field studies and do not account for all potential sources of mortality) and reproductive performance measures (e.g., nest success, annual reproductive success) from published empirical studies. Accordingly, patterns are defined qualitatively in ways designed to capture essential system behavior while remaining robust to inherent differences in field-collected and modelgenerated data.

An iterative approach was taken towards testing and calibrating portions of the model that relate to mortality. First, a simple version of the mortality agent submodel, written in NetLogo, was used to explore the consequences 
(e.g., numbers of eggs or chicks destroyed by mortality agents) of different parameter values for three of the most important sets of parameters in the mortality agent submodel (e.g., the rate at which mortality agents discover breeding sites, the number of consecutive days they destroy tern objects after they have found a site, and the number of tern objects that they destroy per day). This step provided draft parameter values for different mortality agents that were used in more extensive pattern-oriented testing running version 3.3 of the model's full software implementation in Repast Simphony. After evaluating how well these draft parameter values reproduced characteristic patterns of mortality under different sets of initial conditions (see below), model parameters were calibrated so that outputs for reproductive success were "reasonable" relative to published empirical studies.Calibration focused in particular on the relative magnitudes of different types of mortality within a population (Appendix F).

\section{Observed patterns}

This section defines the observed patterns of mortality that the Least Tern model will be evaluated against. From the literature, 12 patterns of Least Tern reproductive success or mortality causes were identified and classified into four different groups:

1. Two patterns of inter-annual variation when data are pooled across a region (patterns 1-2);

2. Four patterns of among-site variation, when data are summarized by site/year combination (patterns 3-6);

3. Three patterns of among-site variation across a region, within a single year (patterns 7-9); and

4. Three patterns of variation given different initial habitat conditions (e.g., excellent conditions the year after a habitat-forming flood versus degraded habitat conditions many years after the last habitat-forming event) (patterns 10-12).

\section{Key characteristics of the literature on Least Tern reproductive success and causes of mortality}

Least Tern nest and chick mortality due to flooding, predators, or human disturbance typically occurs as a discrete event (e.g., a coyote discovers a colony and eats eggs from several nests before leaving the area, a hailstorm destroys multiple nests within the same colony, severe rainfall results in a runoff event that floods nests at several colonies within a region) or a 
repetitive event at the same location (e.g., an owl discovers a colony and returns to eat several chicks a night until the colony is destroyed; ORV users repeatedly pass through the same colony, destroying a few eggs or chicks each time). Rarely do these events affect only a single nest or chick, and, in many cases, mortality events occur with regularity at one colony within a region and not others.

Despite the event-driven and site-specific nature of most nest and chick mortality, the majority of published literature presents data on reproductive performance metrics (e.g., nest success, annual reproductive success, fledge ratios) or causes of mortality (e.g., flooding, predators, human disturbance) aggregated by region or across several years. This may be partially due to the difficulty of assigning specific causes of mortality given the periodic nature of most data collection, where mortality events are rarely observed directly and are often difficult to infer from evidence remaining after the event (e.g., eggshells, carcasses). It also may be due to the common tendency for discussion sections of papers to compare reproductive performance metrics across studies or regions, or discuss these relative to demographic population models.

As detailed information on the nature of discrete mortality events is often obscured when data are aggregated, most of the patterns in reproductive success or mortality that were developed from the tern literature apply to system-level behavior, based on observations pooled across sites or years. The authors were unable to develop many useful quantitative test patterns that reflect the actual event-driven nature of most mortality. This is unfortunate, since management to reduce mortality and increase reproductive success is often directed towards reducing the frequency or magnitude of mortality events at specific sites (e.g., fencing, site closures, predator removal) or across a region (e.g., reducing the frequency of runoff events/dam releases that cause major mortality, implementing multi-site law enforcement patrols with a region).

\section{Patterns of inter-annual variation in regional reproductive success or mortality causes}

Two patterns define how reproductive success or causes of mortality vary among years when data are pooled across all sites and summarized by one metric for the whole region each year (e.g., annual reproductive success for the 120 adults that nested at four different tern colonies below Eufaula Dam in 2007 was 1.3 fledglings per female, or predators accounted for 
$35 \%$ of all nest mortality below Eufaula Dam in 2004). Each of these patterns was described from studies in the literature that involved at least 5 years of data collection. Consequently, they should be tested against at least 5 years of model output data. For each pattern, the method in which model outputs will be summarized is discussed and illustrated and explicit criteria are provided to determine whether or not the pattern has been met.

1. Regional reproductive success is highly variable among years (Byre 2000, Figure D1)

Model outputs will be presented as a box and whisker plot of annual reproductive success with $n$ reported for the number of simulated breeding seasons. This pattern will be met if the average CV for annual reproductive success across all simulations (SD of reproductive success/mean reproductive success) is $\sim 50 \%$ or more.

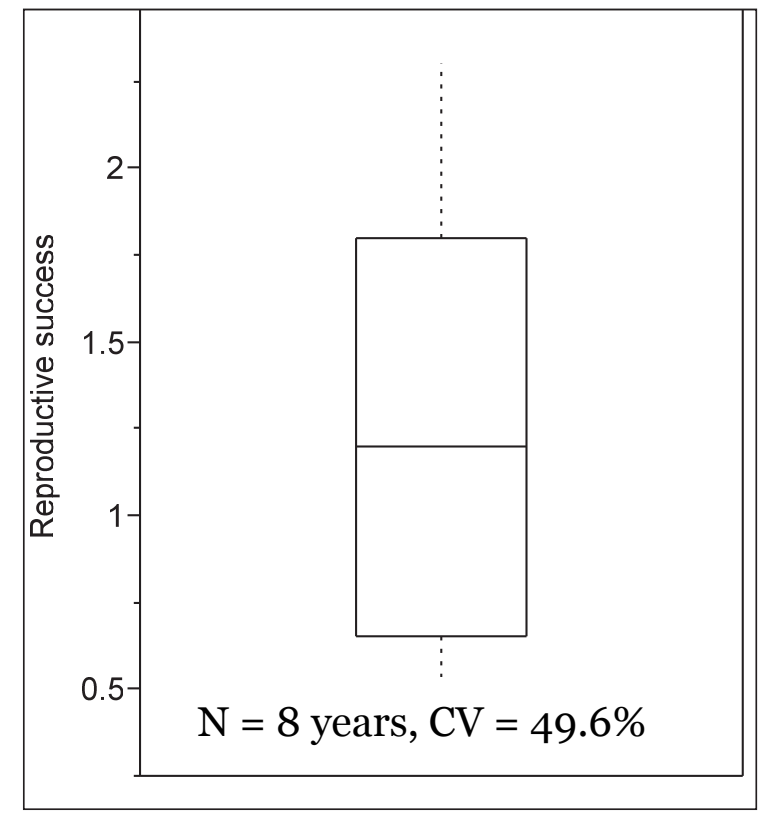

Figure D1. Box and whisker plot of annual reproductive success for a 32-km study reach of the Canadian River between 1991 and 1998. Between 19 and 61 pairs nested in 3 to 8 colonies during this period (Data summarized from Byre 2000).

2. Nest and chick fates vary among years (Byre 2000, Table D1)

This pattern simply illustrates that the relative magnitude of mortality due to its different sources changes from year to year; no one cause is always the greatest source of mortality. 
Table D1. Main causes of mortality vary among years within a region.

\begin{tabular}{|l|l|l|l|l|l|}
\hline Year & Flooding & Predators & ORV & Abandonment & Hatched \\
\hline 1991 & 35 & 12 & 5 & 16 & 218 \\
\hline 1992 & 155 & 9 & 22 & 8 & 55 \\
\hline 1993 & 20 & 88 & 50 & 21 & 177 \\
\hline
\end{tabular}

\section{Patterns of among-site variation in annual reproductive success, given at least 5 years of data collection for all sites across a region}

Four patterns are described in relation to how annual reproductive success varies among sites within a region, given a time series of 5 or more years of data collection. Patterns will be tested against at least 5 years of model outputs.

3. Reproductive success is not density-dependent (Figure 5 in Akçakaya et al. 2003)

There is no relationship between colony size (represented as the number of pairs, number of nests, or number of females with at least one nest at a site) and annual reproductive success. A scatter plot is presented in which $x$ represents the number of females with $\geq 1$ nesting attempt at a site and $y$ represents fledglings/number of females with $\geq 1$ nesting attempt at a site for all sites. If a site is used in multiple years, each year will represent a new data point. This scatter plot can be used to subjectively determine if the pattern has been met.

4. When numerous site/year combinations are plotted, the distribution of annual reproductive success is bimodal (Figure 3 in Akçakaya et al. 2003)

A histogram is used to present the frequency of site/year combinations of reproductive success values between $o$ and the maximum observed reproductive success with bins of 0.1 fledglings/pair. More detailed characteristics of this distribution will be evaluated in patterns 8-12.

5. Some sites have no reproductive success in some years (Figure 3 in Akçakaya et al. 2003)

In the distribution of annual reproductive success for all California Least Tern colonies across 19 years, $\sim 18 \%$ had o reproductive success (e.g., o fledglings produced in colonies that had at least one nest with one egg laid in it). Although there is no way of knowing what percentage of colonies in 
any one location will have o reproductive success, it is expected that this will occur for at least $>3 \%$ of colony/year combinations when $n$ is $>30$. Based on the histogram prepared for pattern 7, one can subjectively determine if this pattern has been met.

6. When numerous site/year combinations are plotted, sites with $>0$ reproductive success fit a log-normal distribution

In other words, mean reproductive success is less than the midpoint of the full range of values, values in 0.1 fledglings/pair bins lower than the mean are common, and values in 0.1 fledglings/pair bins greater than the mean are less common, covering a greater range of values than those lower than the mean (Figure 3 in Akçakaya et al. 2003). To evaluate this pattern, all sites with reproductive success values of o will be removed and a histogram of remaining sites overlaid with a log-normal distribution will be created. Since perfect matches to this pattern are not expected, tests of how well data fit this distribution will not be performed.Rather, these plots will be subjectively evaluated to see if results are "close enough" for this pattern to be met.

\section{Patterns of among-site variation in reproductive success or mortality causes across a region, within a single year}

Three patterns are described to illustrate how annual reproductive success or causes of mortality vary among sites across a region, within a single year.

7. Reproductive success varies among sites within a given year (Byre 2000, Table 2)

To illustrate this pattern, a table of reproductive success by site for each simulated breeding season is presented. This pattern will be met if the average $\mathrm{CV}$ for annual reproductive success across all sites (SD of reproductive success/mean reproductive success-- calculated separately for each year) is $>50 \%$.

8. Causes of mortality vary among sites within any one year (Corps, Omaha District, unpublished data)

To illustrate this pattern, a table is presented that includes the percentage of major mortality causes for each site for each individual year). These tables are subjectively evaluated to determine if the pattern has been met. 
Table D2. Productivity at five different Least Tern nesting sites on a 32-km study reach of the Canadian River, 1995-1999 (adapted from Table 6 in Byre 2000, with data made up for 1996-1999).

\begin{tabular}{|c|c|c|c|c|c|c|}
\hline \multirow[b]{2}{*}{ Colony name } & \multicolumn{5}{|c|}{ Productivity at each site } & \multirow{2}{*}{$\begin{array}{l}\text { Average among } \\
\text { site CV }\end{array}$} \\
\hline & 1995 & 1996 & 1997 & 1998 & 1999 & \\
\hline Indian Hills & 1.4 & 0.8 & 1 & 0.4 & 1.3 & \\
\hline New Castle & 0.1 & 0.4 & 0.9 & 0.3 & 1 & \\
\hline Polo Farm & 0.2 & 0.6 & 0.6 & 0.2 & 0.7 & \\
\hline Asphalt/Jenkins & 0 & 1.2 & 0.3 & 0.6 & 0.3 & \\
\hline Noble South & 0.9 & 0.1 & 1.4 & 0.5 & 0.6 & \\
\hline Among site CV & $117 \%$ & $67 \%$ & $50 \%$ & $40 \%$ & $49 \%$ & $64 \%$ \\
\hline
\end{tabular}

9. When flooding causes major regional mortality, it affects many sites in any one year (intuitive, no empirical data)

For each year, a table is presented that summarizes the percent of all nests and chicks in the region that die due to flooding as well as the percentage of sites with $>1$ nest that experienced flooding mortality. This table will be subjectively evaluated to determine if the pattern has been met.

\section{Patterns of variation in reproductive success or mortality causes related to initial habitat conditions}

Three patterns are described to illustrate how reproductive success or mortality causes vary in response to initial habitat conditions. In this case, expected differences between excellent habitat conditions (e.g., many high-elevation sandbars that are mostly devoid of vegetation, as might be expected after a major habitat-forming flow) and degraded habitat conditions (fewer, smaller sandbars, due to erosion are described, with less suitable habitat at higher elevations due to vegetation succession, as may be expected during a period with few habitat-forming flows). Evaluation of these patterns will require at least 5 years of simulated data with each type of model input (e.g., 5 years of simulations with excellent habitat inputs, 5 years of simulations with degraded habitat inputs).

10. Regional reproductive success is lower when habitat conditions are poor than when they are good (U.S. Fish and Wildlife Service (USFWS) 2003, Byre 2000)

Box and whisker plots of regional reproductive success will be presented, with $n$ reported for number of years of simulations, for each type of habitat 
input. These plots will be subjectively evaluated to determine if the pattern has been met.

11. Flooding mortality is higher (and more geographically extensive) when habitat conditions are poor than when they are good (USFWS 2005)

For each type of model input, box and whisker plots will be presented for the percentage of regional nests and chicks that were killed by flooding and the percentage of sites where flooding occurred. These plots will be subjectively evaluated to determine if the pattern has been met.

12. Predator mortality is higher (and more geographically extensive) when habitat conditions are poor than when they are good (Kruse et al. 2001, USFWS 2003, USACE- Omaha District, unpublished data)

For each type of model input, box and whisker plots will be presented for the percentage of regional nests and chicks that were killed by predators and the percentage of sites where predator mortality occurred. These plots will be subjectively evaluated to determine if the pattern has been met.

\section{Simulation experiments and results}

This section provides the methods and results for simulation experiments to test how well the tern model reproduces the patterns in mortality and reproductive success identified above.

\section{Patterns of inter-annual variation}

Variability among years is high

The model result analyzed is a metric of regional reproductive success: it consists of the total number of fledglings produced at all sites, divided by the number of females arriving from migration at the start of the season. To make the results comparable to field studies, which typically survey reproductive success for five or more successive years (Section 0), and to encompass a typical range of water years, water years 1998-2007 were simulted. This period included all of the water year types previously defined: low, reversal, and high (see Main report, Chapter 3). This period also includes the same distribution of the water year types as the whole period of record. Simulations were replicated five times by changing the random number seed. 
Results reproduce the pattern of high inter-annual variability, while the mean reproductive success is relatively constant among replicates (Figure D2). The CVs for reproductive success among years are, for the five replicates, 22, 48, 37, 41, and 51\%. The criterion of $\mathrm{CV}>\sim 50 \%$ was met in some, but not all, replicates.

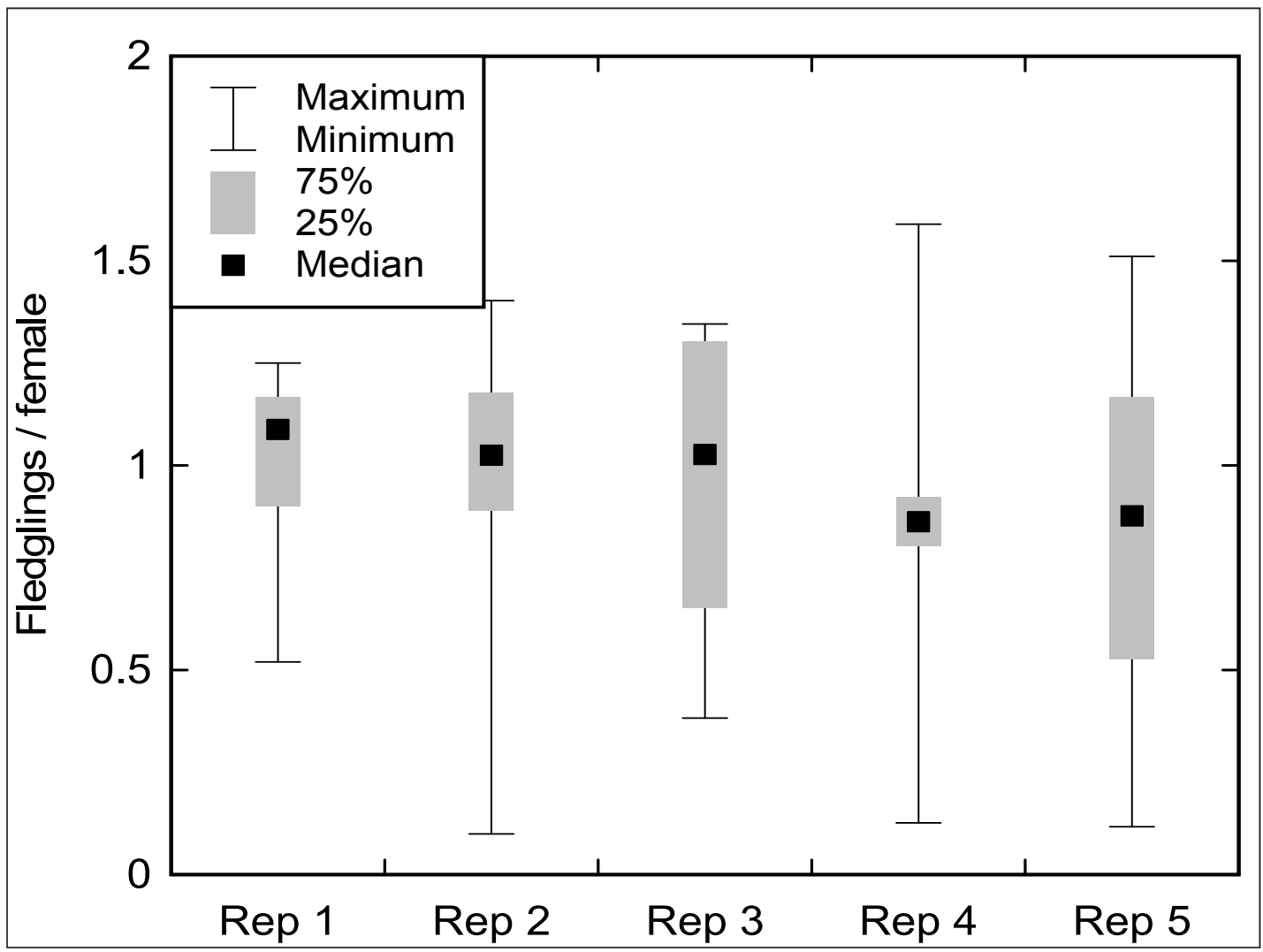

Figure D2. Results for Pattern 1. Distributions of annual reproductive success, as the total number of successful fledglings divided by the total number of females in the management area. Results are for five replicates of water years 1998-2007; each box-and-whisker plot illustrates the variation over the 10 water years.

Nest and chick fates vary among years

This pattern is addressed by reporting simulated nest mortality by cause (flooding; predators; human disturbance, which is via ORVs in these simulations; and abandonment), for each year. Results are presented separately for nests and chicks; results for only one replicate are presented because results are extensive and similar among replicates.

Mortality due to all sources is highly variable from year to year (Table D3). With the exception of nest predation, there was at least one year in which each cause produced little or no mortality. Yet there were also years in which each cause produced moderate to high mortality. 
Table D3. Results for Pattern 2, variation among years in nest and chick fate. Data are the number of nests or chicks that fail due to several causes or succeed (survive to hatch or fledge). The right column is the total number of nests or chicks created each year. Results are from one simulation.

\begin{tabular}{|c|c|c|c|c|c|c|}
\hline \multicolumn{7}{|c|}{ Nests } \\
\hline Year & $\begin{array}{l}\text { Failure by } \\
\text { Drowning }\end{array}$ & Failure by Predation & Failure by ORVs & $\begin{array}{l}\text { Failure by } \\
\text { Abandonment }\end{array}$ & Success & Total \\
\hline 1998 & 2 & 75 & 32 & 11 & 220 & 340 \\
\hline 1999 & 107 & 59 & 10 & 8 & 185 & 369 \\
\hline 2000 & 30 & 179 & 16 & 21 & 157 & 403 \\
\hline 2001 & 27 & 79 & 19 & 22 & 173 & 320 \\
\hline 2002 & 119 & 17 & 24 & 14 & 219 & 393 \\
\hline 2003 & 2 & 130 & 15 & 70 & 182 & 399 \\
\hline 2004 & 330 & 158 & 21 & 8 & 67 & 584 \\
\hline 2005 & 128 & 144 & 25 & 12 & 141 & 450 \\
\hline 2006 & 0 & 73 & 21 & 47 & 216 & 357 \\
\hline 2007 & 333 & 38 & 3 & 1 & 100 & 475 \\
\hline \multicolumn{7}{|c|}{ Chicks } \\
\hline 1998 & 0 & 172 & 12 & 0 & 300 & 484 \\
\hline 1999 & 8 & 157 & 1 & 0 & 249 & 415 \\
\hline 2000 & 0 & 69 & 4 & 0 & 295 & 368 \\
\hline 2001 & 0 & 113 & 4 & 8 & 262 & 387 \\
\hline 2002 & 15 & 162 & 3 & 0 & 313 & 493 \\
\hline 2003 & 0 & 72 & 8 & 3 & 320 & 403 \\
\hline 2004 & 5 & 5 & 4 & 0 & 133 & 147 \\
\hline 2005 & 27 & 61 & 3 & 0 & 224 & 315 \\
\hline 2006 & 0 & 166 & 15 & 8 & 295 & 484 \\
\hline 2007 & 0 & 2 & 0 & 0 & 216 & 218 \\
\hline
\end{tabular}

\section{Patterns of among-site variation in multiple years}

Reproductive success is not density dependent

This pattern is based on a graph of reproductive success (fledglings per pair) versus number of pairs, at each colony each year. The definition of "pair" is not clear or (likely) consistent in the studies this pattern is based on (compiled in Figure 5 of Akçakayaet al. 2003). To be consistent and compatible with the other analyses, the number of pairs at a site is equated with the number of unique females that initiate a nest at the site. Hence, 
the $\mathrm{x}$ axis of the results graph is the number of pairs defined as unique nesting females, and the $y$ axis is the number of fledglings at the site divided by this number of pairs.

There was no relation between reproductive success and female density (Figure D3; $\mathrm{r}^{2}=0.02$ ).

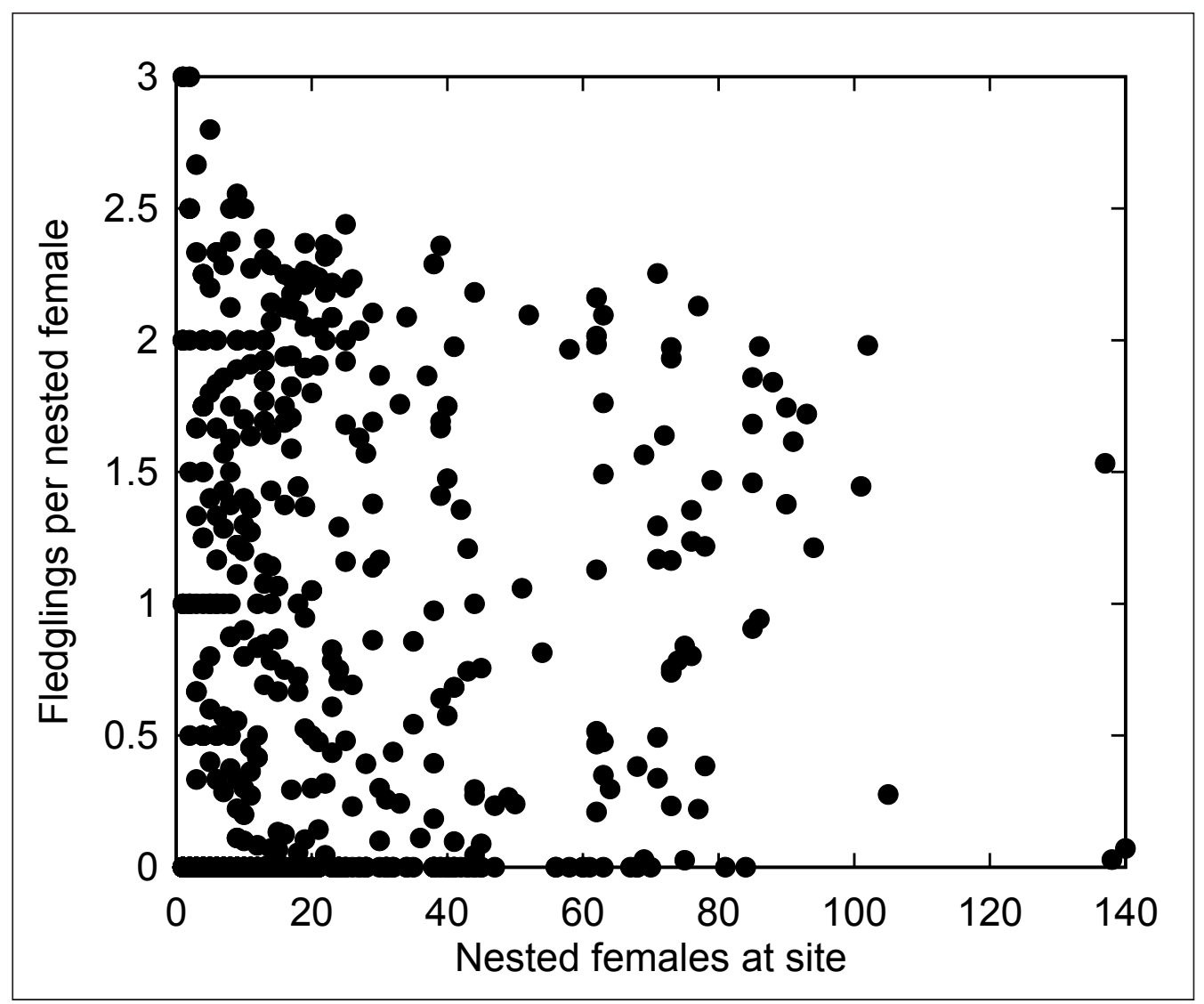

Figure D3. Reproductive success vs. density of females, for each site, year, and replicate.

\section{Distribution of annual reproductive success is bimodal}

This pattern is evaluated from a histogram of the results used in pattern 5 (Figure D4). (These results only depict sites where at least one female nested, not sites that were totally unused.) The simulations produced a large number of sites with zero reproductive success, then a somewhat humped distribution of values with its peak at 2.o fledglings per nested female. Very few sites had average success rates greater than 2.5 . 


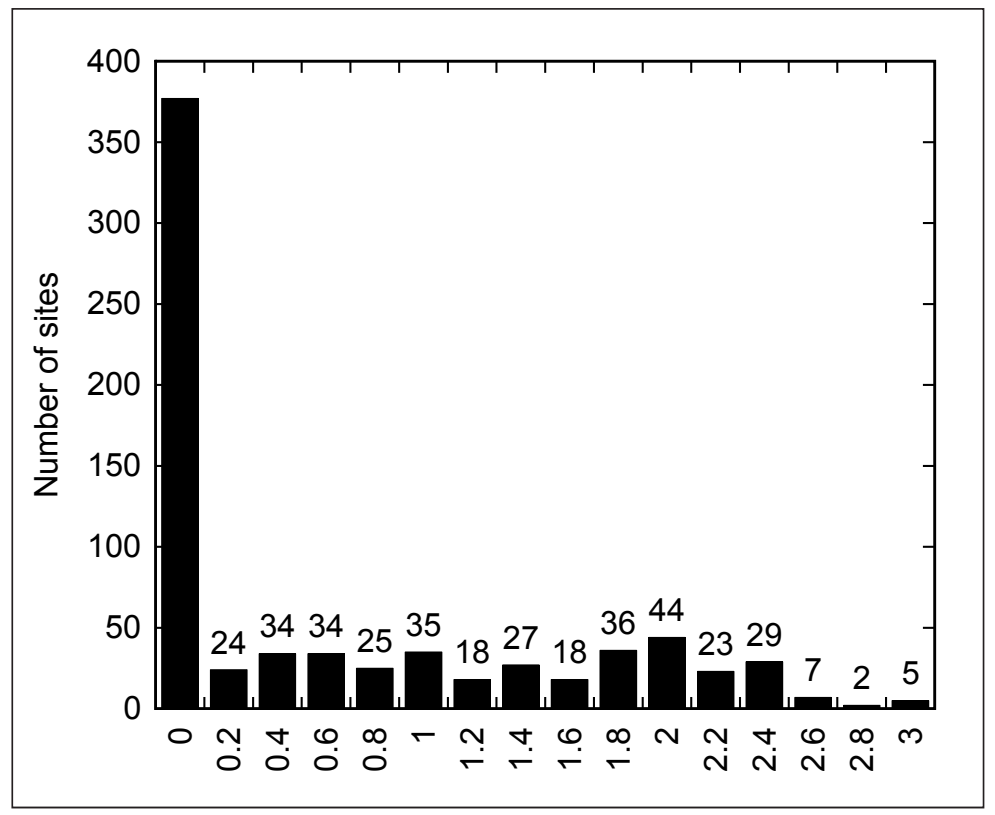

Figure D4. Histogram of reproductive success (as fledglings per nested female) by site and year, including five replicate simulations.

Some sites have no reproductive success in some years

This pattern is evaluated in Figure D5. There were actually many sites with zero reproductive success. While most nests were placed at sites with relatively few females, the completely failed sites were somewhat more likely to be small (Figure D5). Few sites with more than 50 females nesting there had complete reproductive failure (top panel, Figure D5).

The distribution of non-zero reproductive success is log-normal

This pattern is evaluated from the same data used for pattern 4, which are plotted without the values for completely failed sites (Figure D6). This pattern is not clearly met: the distribution of reproductive success values is not skewed toward lower values. While the mean and median are less than half the maximum of 3.0, they are equal at 1.3. The most common values are near 2.0 fledglings per nested female.

\section{Patterns of among-site variation within a year}

Reproductive success varies among sites within a year

The results produced for pattern 5 are broken out by site and year to evaluate this pattern (Table D4). The pattern of high CV among sites is met; the CV was above 50\% in all years but one, and the average over all years is $90 \%$. 

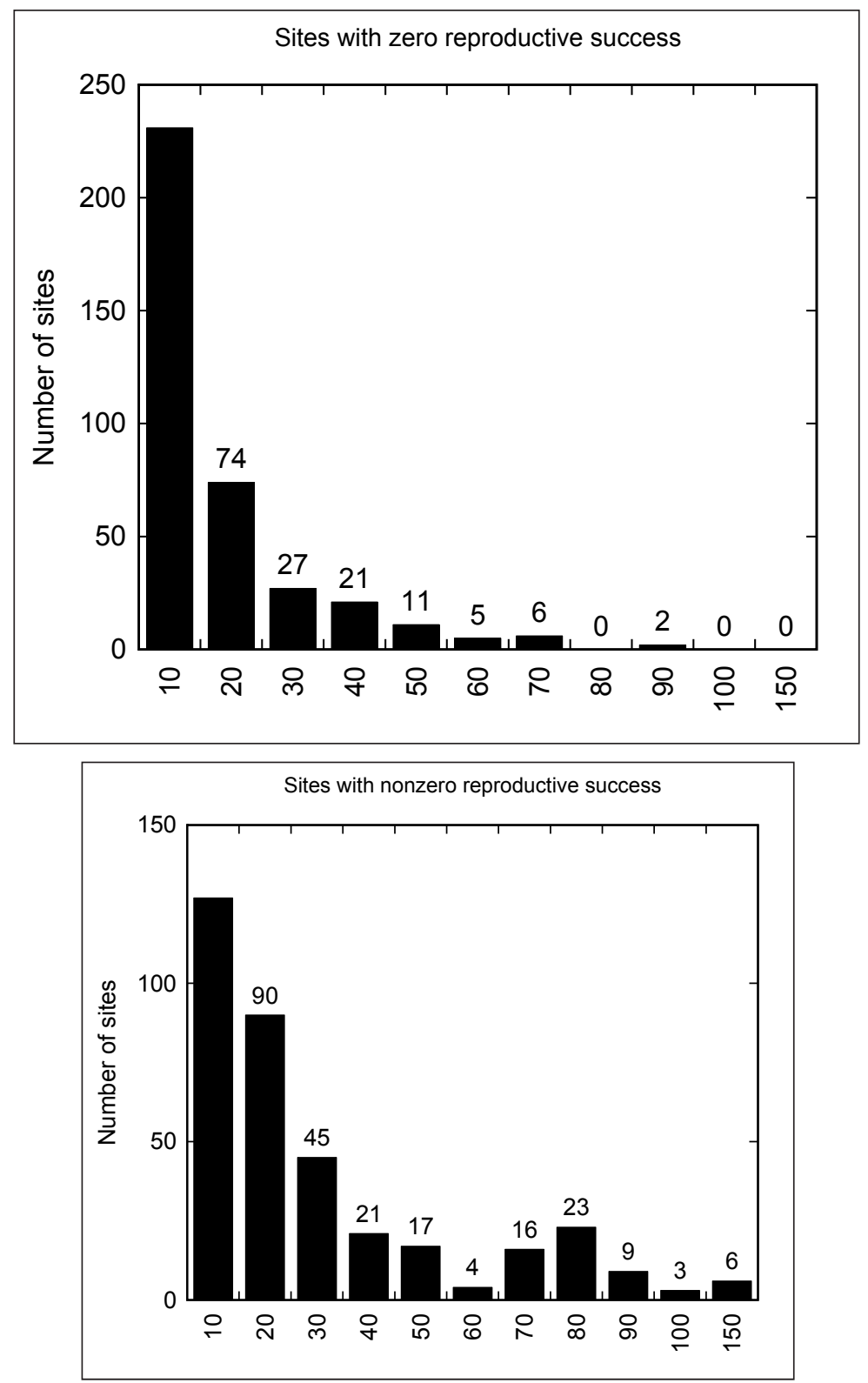

Figure D5. Size distributions of colonies with (top) zero and (bottom) nonzero reproductive success. The $x$ axis is number of nested females at the site. Results include separate values for each site and year, with five replicates.

The variation among years in CV was caused mainly by variation in mean reproductive success across sites, which ranged from 0.2 to 1.0 among years. The standard deviation ranged from 0.2 to 0.6 , but in seven years it was between 0.4 and 0.6 . 


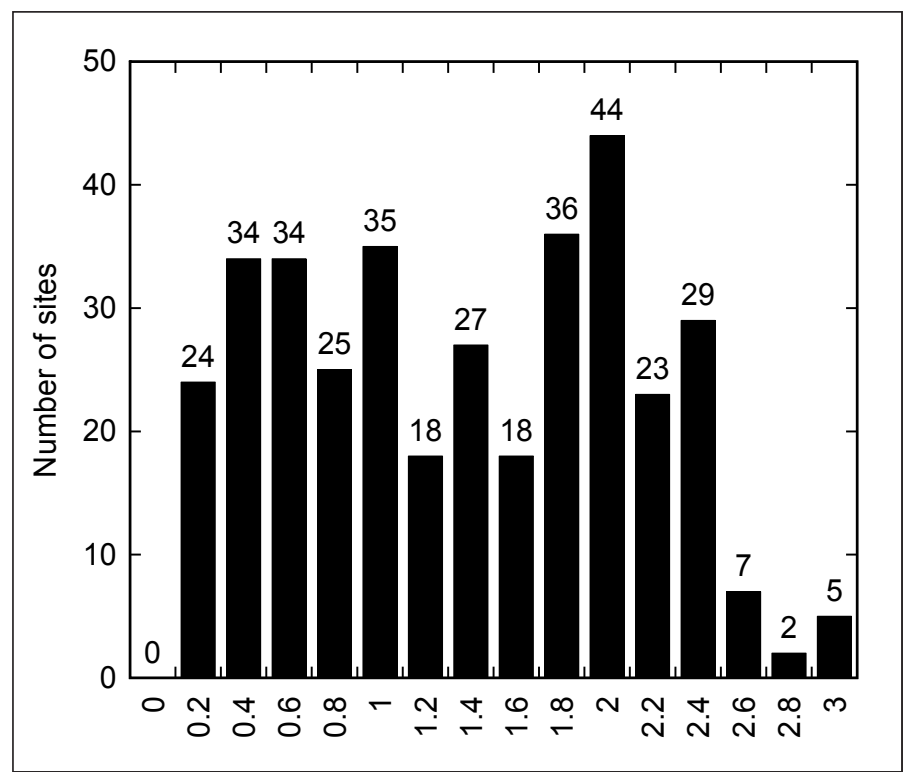

Figure D6. Distribution of site reproductive success, at sites with success greater than zero; the same results as Figure D5 except that sites with zero nesting success are excluded.

Table D4. Variation among sites in reproductive success (fledglings per nested female), for one replicate.

\begin{tabular}{|l|l|l|l|l|l|l|l|l|l|l|}
\hline $\begin{array}{l}\text { Site (nearest } \\
\text { Corps RM) }\end{array}$ & 1998 & 1999 & 2000 & 2001 & 2002 & 2003 & 2004 & 2005 & 2006 & 2007 \\
\hline 465 & 1.3 & 0.0 & 1.2 & 1.3 & 0.7 & 1.6 & 0.5 & 0.5 & 1.5 & 0.0 \\
\hline 470 & 0.5 & 0.0 & 0.0 & 0.0 & 0.0 & 0.5 & 0.0 & 0.2 & 0.0 & \\
\hline 472 & 0.6 & 0.4 & 1.2 & 0.8 & 0.2 & 1.0 & 0.2 & 0.3 & 1.6 & 0.2 \\
\hline 475 & & & 0.0 & 1.0 & 0.0 & 1.5 & 0.0 & 1.0 & 0.0 & \\
\hline 476 & 1.5 & 1.2 & 1.2 & 1.0 & 0.6 & 0.2 & 0.1 & 0.7 & 1.2 & 0.3 \\
\hline 478 & 0.9 & & 0.0 & 0.5 & 0.4 & 0.8 & 0.0 & 0.0 & 0.8 & \\
\hline 479 & 1.3 & & 0.0 & 0.0 & 0.4 & 0.1 & & 0.6 & 1.1 & \\
\hline 481 & 0.6 & & 0.1 & 0.8 & 0.1 & 0.6 & 0.0 & 0.1 & 0.7 & \\
\hline 485 & 1.1 & 0.0 & 1.2 & 0.5 & 0.2 & 1.5 & 0.1 & 0.3 & 0.9 & 0.0 \\
\hline 486 & 1.6 & 0.0 & 0.0 & 0.8 & 2.1 & 2.4 & 0.4 & 0.0 & 1.5 & 0.0 \\
\hline 487 & 1.4 & 0.0 & 0.8 & 0.6 & 0.3 & 0.7 & 0.1 & 0.3 & 1.1 & 0.0 \\
\hline 488 & 1.2 & 0.4 & 0.8 & 1.4 & 1.2 & 1.1 & 0.1 & 0.5 & 0.3 & 0.0 \\
\hline 489 & 0.9 & 0.3 & 0.9 & 1.5 & 0.5 & 0.8 & 1.0 & 0.9 & 0.9 & 0.1 \\
\hline 494 & 0.6 & 0.0 & 0.5 & 1.1 & 0.3 & 0.6 & 0.0 & 0.5 & 1.2 & \\
\hline 497 & 0.3 & 0.1 & 0.2 & 0.5 & 1.0 & 0.5 & 0.3 & 0.0 & 0.5 & 0.0 \\
\hline 507 & 1.2 & 1.1 & 1.3 & 0.6 & 0.4 & 0.7 & 0.2 & 1.0 & 0.8 & 0.6 \\
\hline 509 & 1.5 & 0.5 & 0.9 & 1.9 & 0.2 & 0.5 & 0.0 & 0.6 & 1.3 & 0.0 \\
\hline 523.4 & 1.4 & 1.1 & 1.2 & 1.0 & 0.7 & 1.0 & 0.3 & 1.0 & 0.6 & 0.1 \\
\hline CV & $40 \%$ & $124 \%$ & $84 \%$ & $57 \%$ & $99 \%$ & $62 \%$ & $138 \%$ & $73 \%$ & $54 \%$ & $166 \%$ \\
\hline
\end{tabular}


Causes of mortality vary among sites within a year

The variation among sites and years in mortality causes is evaluated with results produced for pattern 2, broken out by site as well as year. Results are presented for nest mortality in one low-water year with relatively little drowning (1998; Table D5) and one year with a flow reversal and extensive drowning mortality (2004; Table D6). The results indicate high variation among sites in the relative importance of different mortality sources. In 1998, each mortality source was the main cause of nest failure for at least one site. As expected, drowning dominated nest mortality in 2004, but even so, there was at least one site each where nest predators and ORVs were the largest cause.

Flooding mortality is related across sites

Regional trends in flooding mortality are evaluated by examining results for nest and chick mortality, broken out by year (Table D7). These results report the percent of nests and chicks that were drowned, over all sites and five replicate simulations. The pattern was reproduced: the prevalence of nest and chick mortality was clearly related to flow year across sites.

Table D5. Nest mortality causes by site for 1998, a low-flow year; results from one replicate.

\begin{tabular}{|l|l|l|l|l|l|l|}
\hline Site (nearest Corps RM) & Nests & Successful & Drowning & Nest predator & ORVs & Abandonment \\
\hline 465 & 4 & $25 \%$ & $0 \%$ & $0 \%$ & $0 \%$ & $75 \%$ \\
\hline 470 & 10 & $40 \%$ & $0 \%$ & $50 \%$ & $10 \%$ & $0 \%$ \\
\hline 472 & 54 & $46 \%$ & $0 \%$ & $44 \%$ & $9 \%$ & $0 \%$ \\
\hline 476 & 18 & $89 \%$ & $0 \%$ & $0 \%$ & $11 \%$ & $0 \%$ \\
\hline 478 & 4 & $75 \%$ & $25 \%$ & $0 \%$ & $0 \%$ & $0 \%$ \\
\hline 481 & 19 & $32 \%$ & $5 \%$ & $42 \%$ & $21 \%$ & $0 \%$ \\
\hline 485 & 27 & $81 \%$ & $0 \%$ & $15 \%$ & $0 \%$ & $4 \%$ \\
\hline 487 & 14 & $86 \%$ & $0 \%$ & $0 \%$ & $7 \%$ & $7 \%$ \\
\hline 488 & 5 & $20 \%$ & $0 \%$ & $60 \%$ & $20 \%$ & $0 \%$ \\
\hline 489 & 16 & $6 \%$ & $0 \%$ & $0 \%$ & $63 \%$ & $31 \%$ \\
\hline 494 & 19 & $47 \%$ & $0 \%$ & $53 \%$ & $0 \%$ & $0 \%$ \\
\hline 497 & 13 & $46 \%$ & $0 \%$ & $38 \%$ & $15 \%$ & $0 \%$ \\
\hline 507 & 3 & $33 \%$ & $0 \%$ & $33 \%$ & $33 \%$ & $0 \%$ \\
\hline 509 & 13 & $100 \%$ & $0 \%$ & $0 \%$ & $0 \%$ & $0 \%$ \\
\hline 523.4 & 121 & $83 \%$ & $0 \%$ & $12 \%$ & $4 \%$ & $1 \%$ \\
\hline
\end{tabular}


Table D6. Nest mortality causes by site for 2004 , which had a flow reversal; results from one replicate.

\begin{tabular}{|l|l|l|l|l|l|l|}
\hline Site (nearest Corps RM) & Nests & Successful & Drowning & Nest Predator & ORVs & Abandonment \\
\hline 465 & 35 & $43 \%$ & $54 \%$ & $3 \%$ & $0 \%$ & $0 \%$ \\
\hline 472 & 76 & $8 \%$ & $64 \%$ & $28 \%$ & $0 \%$ & $0 \%$ \\
\hline 475 & 17 & $0 \%$ & $100 \%$ & $0 \%$ & $0 \%$ & $0 \%$ \\
\hline 476 & 12 & $0 \%$ & $0 \%$ & $58 \%$ & $0 \%$ & $42 \%$ \\
\hline 478 & 8 & $13 \%$ & $38 \%$ & $13 \%$ & $38 \%$ & $0 \%$ \\
\hline 481 & 9 & $0 \%$ & $89 \%$ & $11 \%$ & $0 \%$ & $0 \%$ \\
\hline 485 & 54 & $0 \%$ & $19 \%$ & $72 \%$ & $9 \%$ & $0 \%$ \\
\hline 486 & 7 & $0 \%$ & $29 \%$ & $71 \%$ & $0 \%$ & $0 \%$ \\
\hline 487 & 35 & $20 \%$ & $77 \%$ & $0 \%$ & $3 \%$ & $0 \%$ \\
\hline 488 & 24 & $0 \%$ & $96 \%$ & $0 \%$ & $0 \%$ & $4 \%$ \\
\hline 489 & 10 & $60 \%$ & $40 \%$ & $0 \%$ & $0 \%$ & $0 \%$ \\
\hline 494 & 19 & $0 \%$ & $79 \%$ & $21 \%$ & $0 \%$ & $0 \%$ \\
\hline 497 & 42 & $14 \%$ & $81 \%$ & $5 \%$ & $0 \%$ & $0 \%$ \\
\hline 507 & 15 & $0 \%$ & $73 \%$ & $7 \%$ & $7 \%$ & $13 \%$ \\
\hline 509 & 17 & $0 \%$ & $76 \%$ & $0 \%$ & $24 \%$ & $0 \%$ \\
\hline 523.4 & 204 & $13 \%$ & $47 \%$ & $37 \%$ & $3 \%$ & $0 \%$ \\
\hline & & & & & & \\
\hline
\end{tabular}

Table D7. Drowning mortality of nests and chicks by year. Values are sums over all sites and five replicates.

\begin{tabular}{|l|l|l|l|l|l|}
\hline Year & Year Type & $\begin{array}{l}\text { Nests } \\
\text { Drowned }\end{array}$ & $\begin{array}{l}\text { Chicks } \\
\text { Drowned }\end{array}$ & $\begin{array}{l}\text { Sites with Nest } \\
\text { Drowning }\end{array}$ & $\begin{array}{l}\text { Sites with Chick } \\
\text { Drowning }\end{array}$ \\
\hline 1998 & low & $1 \%$ & $0 \%$ & $9 \%$ & $0 \%$ \\
\hline 1999 & high & $21 \%$ & $1 \%$ & $38 \%$ & $4 \%$ \\
\hline 2000 & falling & $8 \%$ & $0 \%$ & $30 \%$ & $0 \%$ \\
\hline 2001 & falling & $6 \%$ & $0 \%$ & $44 \%$ & $0 \%$ \\
\hline 2002 & falling & $28 \%$ & $3 \%$ & $63 \%$ & $17 \%$ \\
\hline 2003 & falling & $1 \%$ & $0 \%$ & $8 \%$ & $0 \%$ \\
\hline 2004 & reversal & $56 \%$ & $7 \%$ & $78 \%$ & $16 \%$ \\
\hline 2005 & reversal & $27 \%$ & $3 \%$ & $68 \%$ & $9 \%$ \\
\hline 2006 & low & $0 \%$ & $0 \%$ & $0 \%$ & $0 \%$ \\
\hline 2007 & high & $65 \%$ & $0 \%$ & $62 \%$ & $0 \%$ \\
\hline
\end{tabular}


Nest drowning was much more prevalent than chick drowning, a result expected because nests are immobile whereas chicks only drown if an entire site is submerged and because chicks appear later than nests. All but one year had some nests drowned. However, drowning was much more extensive in high and reversal flow year types. One exception was 2002, a falling year that still experienced some drowning.

\section{Patterns related to initial habitat conditions}

Regional reproductive success lower with poor habitat conditions

Evaluating this pattern requires simply repeating the analysis of pattern 1 using sandbar habitat input that represents degraded conditions. The simulations of water years 1998-2007 were repeated using habitat input developed to represent Arkansas River sandbars in 2006, before they were re-built and restored by the 2007 flood. These sandbars were generally lower and had more vegetation than those represented in the preceding simulations. Only one replicate was used, so all variation is due to differences among years and between habitat condition scenarios. Results with 2006 habitat input were compared to the first replicate analyzed for pattern 1.

This pattern was reproduced (Figure D7). While there was substantial overlap in the ranges of reproductive success over the 10 years, the mean reproductive success with degraded habitat was 0.68 fledglings per female, compared to 1.0 with excellent habitat. The median reproductive success with degraded habitat was well below the medians of all five replicates of excellent habitat in Figure D7. With degraded habitat, no fledglings were produced in the flood year 2007.

\section{Higher flooding mortality with degraded habitat conditions}

This pattern was analyzed with the same simulations as pattern 10. With degraded habitat, nest flooding and chick drowning were more frequent, though not by a large degree (Figure D8).

The lower elevation of degraded sandbars is evident in results for the flood year of 2007; with excellent habitat, $70 \%$ of nests were flooded, but with degraded habitat, $95 \%$ of nests flooded and no chicks were produced. 


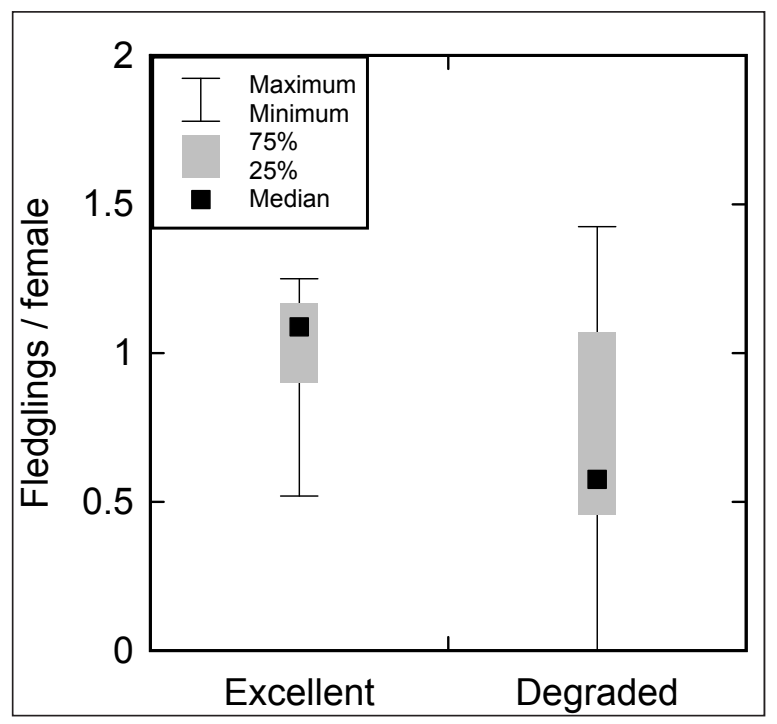

Figure D7. Comparison of reproductive success (fledglings per female) with excellent vs. degraded habitat; distribution of management-area results over 10 water years.

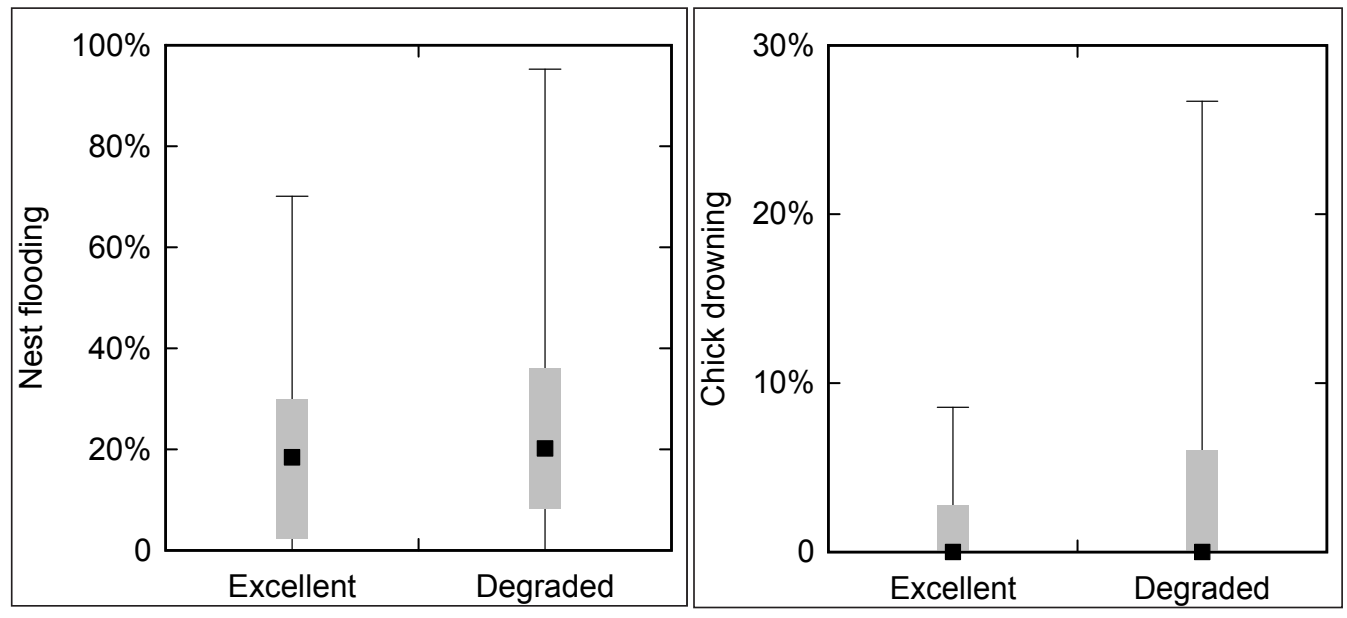

Figure D8. Distribution of (left) nest flooding and (right) chick drowning rates (percentage of all nests and chicks that were destroyed by flooding, by year) for excellent vs. degraded habitat conditions. Results are the distribution of management-area averages over 10 water years.

More events of flooding and drowning mortality occurred with degraded habitat, with an "event" defined as the occurrence of at least one mortality at one site (Figure D9). The difference is especially obvious for nest flooding, in part because far fewer chicks were produced in the degraded habitat scenario (56\% as many as with excellent habitat), so there were fewer opportunities for chick mortality. 


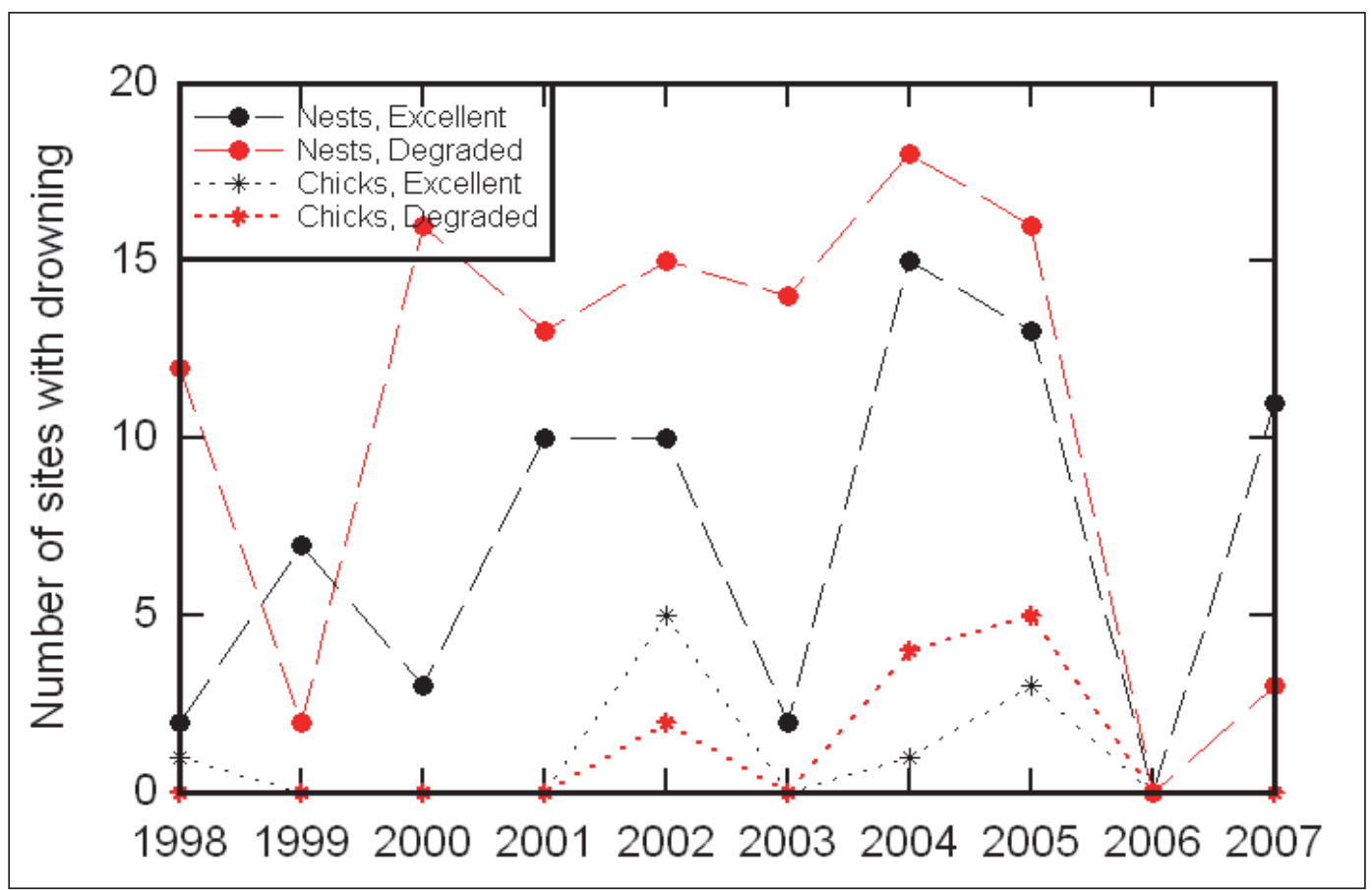

Figure D9. Number of sites with nest and chick mortality due to drowning, excellent vs. degraded sites.

In 1999 and 2007, nest flooding occurred at more sites in the excellent habitat scenario. This appears to have occurred because, in those years only, far fewer nests were produced with degraded habitat. There were no chick drownings in 2007 simply because no chicks even hatched that year.

Why was the intensity of drowning mortality not extremely different between the excellent and degraded habitat simulations? There were clear differences in the nest freeboard between the two habitat scenarios, but they were not extremely large, as illustrated by 1999, a high-flow year (Figure D10). Differences of 2-3 ft in nest elevation between excellent and degraded habitat likely help reduce flooding in moderate flow years but probably make little difference in significant floods. Degraded sandbar habitat typically has lower elevations but terns can, with the model's nest site selection rules, adapt to some extent by placing nests on higherelevation cells that might otherwise be avoided because of other variables such as distance to vegetation.

\section{Higher predator mortality when habitat conditions are poor}

This pattern was evaluated using the single replicate of degraded and excellent habitat simulations used for the previous two patterns. The results did indicate higher mortality due to predators and ORVs with degraded 


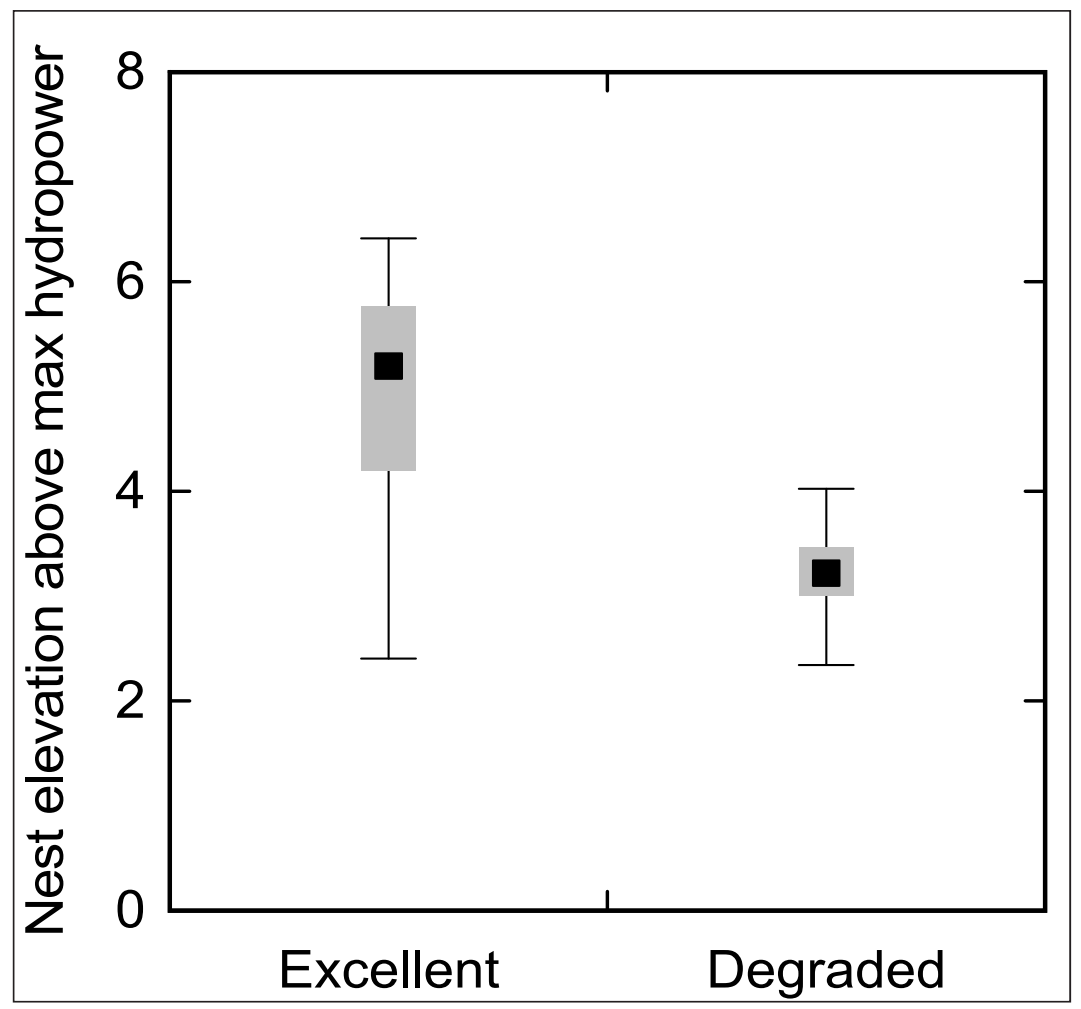

Figure D10. Distribution of nest freeboard (elevation difference between a nest and the water surface elevation at maximum hydropower flow, $\mathrm{ft}$ ) for excellent vs. degraded habitat, 1999. There were 369 nests in the excellent habitat simulation and 194 in the degraded simulation.

habitat, even though the model does not impose a higher risk of those mortality sources as a direct consequence of poorer habitat (Figure D11). The percentage of nests and chicks killed by predators and ORVs was, on average, $35-40 \%$ higher with degraded habitat. This difference could be stochastic in part but also appears to result from the lower overall number of nests and chicks with degraded habitat. When the same number of mortality agents occurs, the percentage of the population they consume will be higher when the population is smaller.

Predation occurred at a higher percentage of sites with degraded habitat (Figure D12). In the excellent habitat simulations, nest predation occurred at $38 \%$ of sites over all 10 simulated years, whereas this average predation occurrence rate was $51 \%$ with degraded habitat.

\section{Conclusions}

The least tern model appears to produce the general mortality dynamics that were expected from the literature and judgment: strong stochasticity in predation and disturbance mortality among sites and over time, but with strong and clearly distinguishable effects of flooding and habitat quality. 

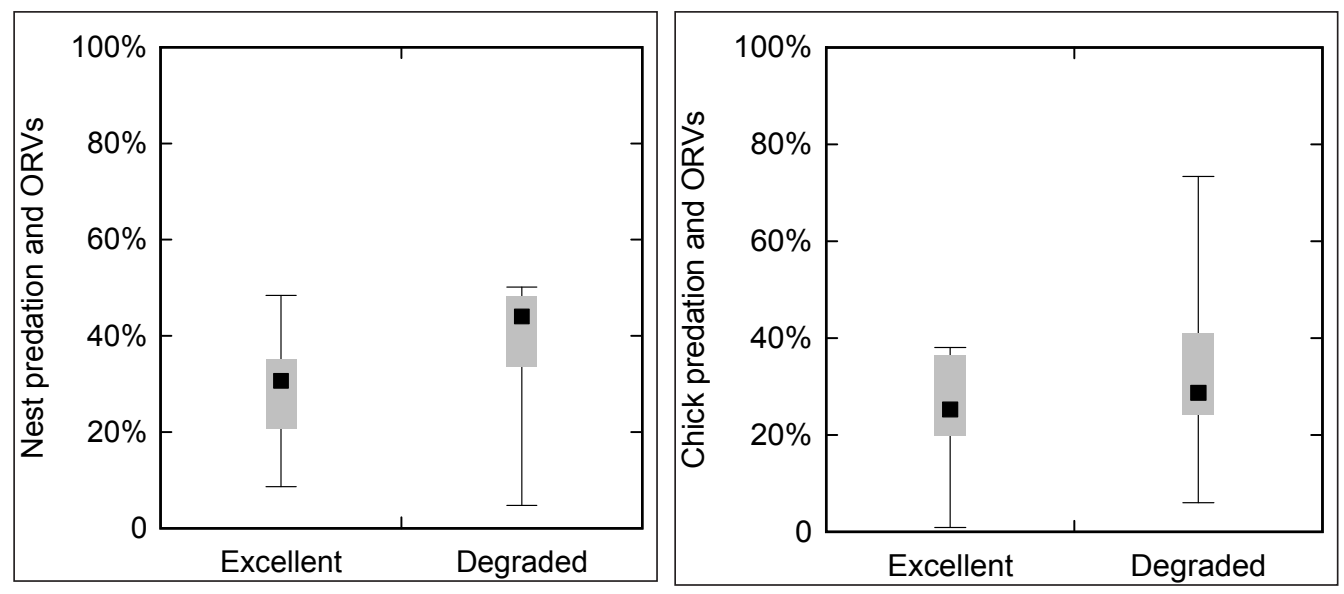

Figure D11. Percentage of nests (left) and chicks (right) killed by predators and ORVs with excellent vs. degraded habitat. Distributions are annual results from 1998-2007.

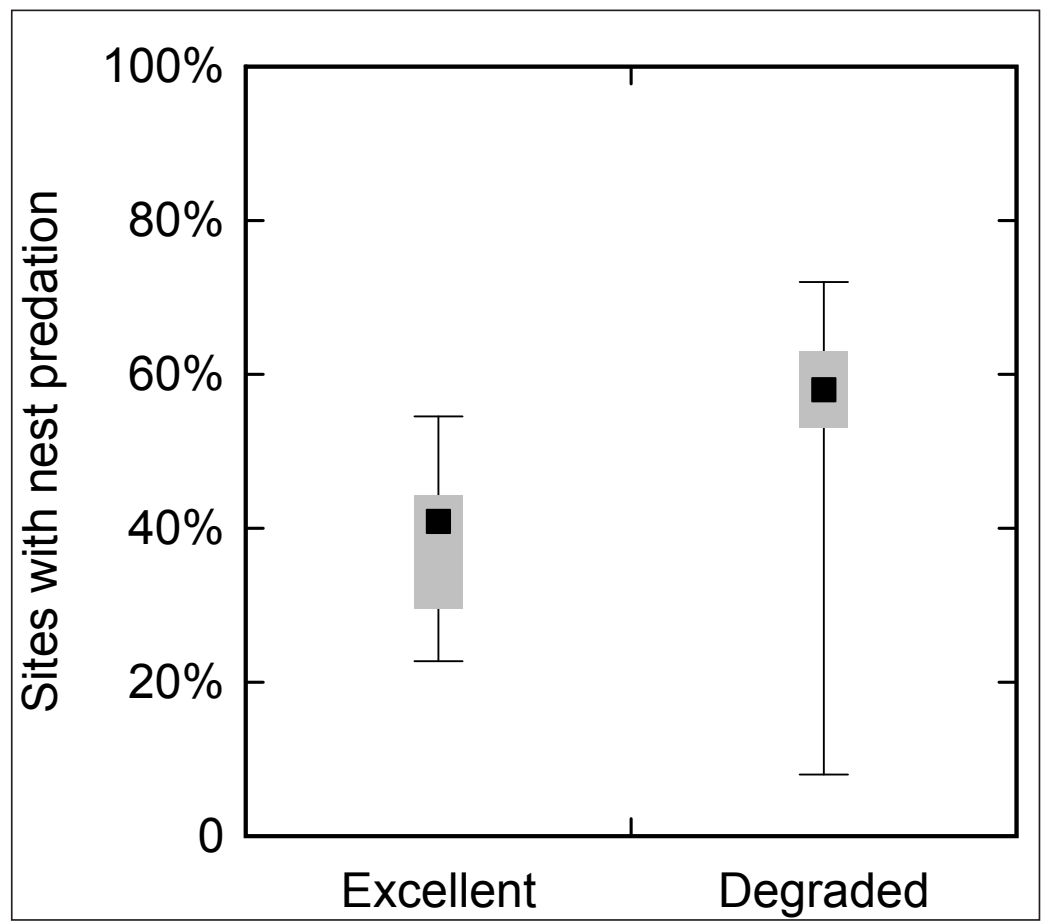

Figure D12. Percent of sites with any nest predation, comparing excellent vs. degraded habitat. Distributions are of results from water years 1999-2007.

In high-flow years, the model produced consistently high flooding mortality of nests and chicks; though chicks are affected less because they are mobile and only drown if the entire site is submerged. In such years, other mortality sources kill fewer numbers of nests and chicks because fewer remain alive after flooding. But the percentage of nests and chicks killed by predation and human disturbance was typically higher in high-flow years because the same number of mortality agents affects fewer live terns. 
According to the model, mortality kills more individuals during the nest stage than during the chick phase. In part this is because chicks are less vulnerable to flooding.

The one pattern that was not clearly reproduced is pattern 6 , a log-normal distribution of reproductive success at sites where success is greater than zero. The model produces more instances of high reproductive success than expected. Calibration of mortality parameters may well change these results so that they more closely reproduce the expected patterns.

The differences in flooding mortality between excellent (2008) and degraded (2006) sandbar habitat were clear but not extremely large. The relatively small difference between these scenarios appears to be that the difference in simulated nest elevations is on the order of $2 \mathrm{ft}$, which may be important in years of moderately high flow but is overwhelmed during major flood events. The model assumes that nesting terns place nests at locations providing good combinations of elevation, distance to forest, distance to bank, and distance to vegetation. Because the model uses nonlinear relations between these variables and nest site quality, terns may place more emphasis on elevation when elevation is relatively low. This is essentially an adaptive behavior that could partially make up for the lower freeboard available at degraded sandbars.

\section{References}

Akçakaya, H. R. J. L. Atwood D. Breininger C. T. Collins and B. Duncan. 2003. Metapopulation dynamics of the California least tern. Journal of Wildlife Management 67:829-842.

Byre, V. J. 2000. Productivity, habitat assessment, and management of least terns nesting along the Canadian River in central Oklahoma. Sam Noble Oklahoma Museum of Natural History, Occasional Papers 8: 1-13. Norman, OK: University of Oklahoma.

Kruse, C. D., K. F. Higgins, and B. A. V. Lee. 2001. Influence of predation on Piping Plover, Charadrius melodus, and Least Tern, Sterna antillarum, productivity along the Missouri River in South Dakota. Canadian Field-Naturalist 115:480-486.

Thompson, B.C., J. A. Jackson, J. Burger, L. A. Hill, E. M. Kirsch, and J. L. Atwood. 1997. Least Tern: Sterna antillarum. In Birds of North America. ed. A. Poole and F. Gill. Philadelphia, PA and Washington, DC: The Academy of Natural Science and the American Ornithologists Union.

U.S. Fish and Wildlife Service (USFWS). 2003. Amendment to the 2000 Biological Opinion on the operation of the Missouri River main stem reservoir system, operation and maintenance of the Missouri River bank stabilization and navigation project, and operation of the Kansas River reservoir system. 
U.S. Fish and Wildlife Service (USFWS). 2005. Biological Opinion addressing sixteen federally listed threatened or endangered species on the Arkansas, Canadian, and Red Rivers: Arkansas, Oklahoma, and Texas; and on the McClellan-Kerr Arkansas Navigation System, Arkansas and Oklahoma. 


\section{Appendix E: Sensitivity Analysis}

\section{Introduction}

This document describes a parameter sensitivity analysis of TernCOLONY. Parameter sensitivity analysis is a standard component of modeling programs. Its purposes include:

- Developing a more thorough understanding of how the model works,

- Understanding what the model says about how important its various processes are and what that implies about the system being modeled,

- Identifying good parameters to use in calibrating the model, and

- Prioritizing parameters and processes for additional study and refinement.

In its most basic form, parameter sensitivity analysis involves many executions of the model that each use different values of its parameters. A variety of techniques have been developed for analyzing how models respond to one parameter at a time, to the "interactions" when several parameters are varied together, and for analyzing "local" sensitivity to small changes in parameter values or "global" sensitivity to broad ranges of parameter values.

Complex individual-based models pose particular challenges for sensitivity analysis because of their high number of parameters, stochasticity, discontinuous and discrete processes, and multiple outputs. The most productive approach appears to be the simplest: looking at how a few key model results change as each parameter is varied by itself over a wide range of feasible values, and scaling the results to produce a "sensitivity index" that can be compared among parameters. This is the approach used here.

This sensitivity analysis complements pattern-oriented testing of colony and nest site selection (Appendices A and B), mortality and reproductive performance (Appendix C); and exploratory analyses that describe the behavior of the site-abandonment sub-model (Appendix D). 


\section{Methods}

The key steps in designing a sensitivity analysis are determining which parameters to analyze, what values of each to simulate, how to replicate simulations, and what outputs to examine. The following methods were used.

\section{Selection of parameters}

This step determines which of the model's parameters are analyzed.

"Parameters" in this context refers to the coefficients used in the equations and functions that the model uses to represent biological processes and habitat quality. Appendix A of the model description (Lott et al. 2012) lists the model's parameters for adults, chicks, nests, management areas, and model-level ("admin") processes. All of these parameters are included in the sensitivity analysis except five: two admin variables that define habitat quality ranges that do not affect model results, the admin random number generator seed, the management area parameter that defines which sites are included in a simulation, and the management area parameter for the mean number of adult terns arriving. The number of arriving terns was not included because it is a "driving variable" (likely to be varied routinely after the model is calibrated) instead of an equation or function coefficient.

TernCOLONY also includes a set of parameters that define the types and characteristics of mortality agents. For this analysis, the standard model version's four types of mortality agents were included: egg predators, chick predators, adult predators, and off-road vehicles (ORVs). Each mortality agent has parameters that define the daily probability that they will discover each nesting site, the mean number of days they stay at a site after discovering it, and the mean number (and type) of tern objects that they destroy each day when present. However, each of these parameters affects the number of terns killed by agents in a linear way, so the model is expected to have similar sensitivity to all the parameters for a particular mortality agent. For this reason (and because varying the individual parameters for each mortality type is very inconvenient), the model's sensitivity was analyzed only in relation to one parameter per agent type: the control variable that adjusts how often agents appear (for more detail on TernCOLONY's mortality agent submodel, see Lott et al. 2012). 


\section{Parameter ranges and values}

This analysis is designed to look at broad ranges of parameter values, in contrast to "local" sensitivity analyses that evaluate parameter effects over narrow ranges close to the standard values. This broad approach is chosen because (a) many parameters are quite uncertain and have wide ranges of potentially valid values, and (b) the effects of small changes in parameter values are typically hard to distinguish from randomness in a model as stochastic as this one.

The ranges of parameter values were determined by choosing minimum and maximum values below and above the standard values established in the model description document (Appendix A in Lott et al. 2012). These minimum and maximum values were based on the literature to the extent possible. Because of the scaling method used to determine relative sensitivity indices for the parameters, the choice of minimum and maximum parameter values can affect analysis results even when the model responds linearly to the parameter: since the model's sensitivity to a parameter tends to increase with the range of values. Even when literature and data on parameter ranges are available, judgment is required to choose the range of values to analyze. To guide this choice, the range of parameter values were viewed as approximating an $80 \%$ confidence interval on each parameter's value. Even when the ranges were based largely on judgment, the minimum and maximum values were chosen. It would therefore be expected that there is only a $10 \%$ chance that the best value of the parameter is below the minimum, and a $10 \%$ chance that it is above the maximum.

Nine values of each parameter were used in the analysis. For most parameters, the model was run with each parameter at its minimum value, three values spaced evenly between the minimum and the standard value, the standard value, three values spaced evenly between the standard and maximum value, and the maximum. The middle of these nine values is therefore the baseline scenario with standard values of all parameters. However, this method of selecting nine values could not be used for integer parameters with low values. For example, the minimum number of days between nesting attempts is an integer and has a standard value of 5 , and values as low as 2-3 are biologically unrealistic. For such parameters, the standard value was not the middle one; minimum days between nesting attempts, for example, could have values of $4,5,6,7,8,9,10,11$, and 12. In other cases (e.g., adultMaxNumBreedingAttempts), the realistic range is 
too narrow for nine different values, so some values were simulated more than once.

The range of values for each parameter and the basis for parameter ranges are summarized in Table E1.

Table E1. Parameter value ranges and basis.

\begin{tabular}{|c|c|c|c|c|}
\hline Parameter & Min & $\begin{array}{l}\text { Standard } \\
\text { Value }\end{array}$ & Max & Basis \\
\hline adminAbandSurvivalHorizon & 2 & 5 & 10 & $\begin{array}{l}\text { Estimate; broad range because parameter } \\
\text { is highly uncertain }\end{array}$ \\
\hline adminAdultsPerChick & 0.33 & 0.5 & 0.67 & $\begin{array}{l}\text { Minimum: one adult supports three chicks; } \\
\text { maximum: two adults for three chicks }\end{array}$ \\
\hline adminExpectedFledges & 0.4 & 1.0 & 1.5 & $\begin{array}{l}\text { Default is mean from Akçakaya et al. } \\
(2003) \text { after Os removed, lower values } \\
\text { common, values }>1.5 \text { rare }\end{array}$ \\
\hline adminQualDist2Bank01 & 50 & 100 & 200 & $\begin{array}{l}\text { Defaults from analyses of data presented in } \\
\text { U.S. Army Corps of Engineers (USACE) } \\
\text { (2011). Ranges reflect possibilities for } \\
\text { narrower/wider channels }\end{array}$ \\
\hline adminQualDist2Bank09 & 200 & 400 & 800 & $\begin{array}{l}\text { Defaults from analyses of data presented in } \\
\text { USACE (2011). Ranges reflect possibilities } \\
\text { for narrower/wider channels }\end{array}$ \\
\hline adminQualDist2ForestEdge01 & 200 & 400 & 500 & $\begin{array}{l}\text { Defaults from analyses of data presented in } \\
\text { USACE (2011). Ranges reflect possibilities } \\
\text { for narrower/wider channels }\end{array}$ \\
\hline adminQualDist2ForestEdge09 & 450 & 600 & 1000 & $\begin{array}{l}\text { Defaults from analyses of data presented in } \\
\text { USACE (2011). Ranges reflect possibilities } \\
\text { for narrower/wider channels }\end{array}$ \\
\hline adminQualDist2Veg01 & 25 & 50 & 90 & $\begin{array}{l}\text { Defaults from analyses of data presented in } \\
\text { USACE (2011). Ranges made up }\end{array}$ \\
\hline adminQualDist2Veg09 & 60 & 500 & 200 & $\begin{array}{l}\text { Defaults from analyses of data presented in } \\
\text { USACE (2011). Ranges made up }\end{array}$ \\
\hline adminQualFreeboard01 & 0.4 & 0.5 & 0.8 & $\begin{array}{l}<0.5 \text { is wet sand most of time, }>1.0 \text { is dry } \\
\text { most of time }\end{array}$ \\
\hline adminQualFreeboard09 & 0.6 & 1.0 & 1.5 & $\begin{array}{l}<0.5 \text { is wet sand most of time, }>1.0 \text { is dry } \\
\text { most of time }\end{array}$ \\
\hline $\begin{array}{l}\text { adminQualFreeboardAt- } \\
\text { MinSuitableFlow01 }\end{array}$ & 0.5 & 1.0 & 1.5 & $\begin{array}{l}<0.5 \text { is wet sand most of time, }>1.0 \text { is dry } \\
\text { most of time }\end{array}$ \\
\hline $\begin{array}{l}\text { adminQualFreeboardAt- } \\
\text { MinSuitableFlow09 }\end{array}$ & 1.5 & 3.0 & 5 & $\begin{array}{l}\text { Assumption = habitat quality increases with } \\
\text { elevation, shape of relationship unknown }\end{array}$ \\
\hline adultClutchProb1Egg & 0.05 & 0.1 & 0.15 & $\begin{array}{l}\text { Estimated; range is relatively narrow } \\
\text { because data are extensive }\end{array}$ \\
\hline adultClutchProb2Eggs & 0.3 & 0.42 & 0.5 & $\begin{array}{l}\text { Estimated; range is relatively narrow } \\
\text { because data are extensive. }\end{array}$ \\
\hline
\end{tabular}




\begin{tabular}{|c|c|c|c|c|}
\hline Parameter & Min & $\begin{array}{l}\text { Standard } \\
\text { Value }\end{array}$ & Max & Basis \\
\hline adultFracNonviableEggs & 0.02 & 0.06 & 0.1 & $\begin{array}{l}\text { Min and default from Kirsch (1990), } \\
\text { estimated maximum. }\end{array}$ \\
\hline adultMaxNumBreedingAttempts & 1 & 2 & 4 & $\begin{array}{l}\text { Range of realistic values; } 4 \text { has not been } \\
\text { reported in literature but is included } \\
\text { because the range is very narrow. }\end{array}$ \\
\hline adultMinDaysArrivalToEggLaying & 11 & 14 & 25 & Range of observed arrival-nesting intervals. \\
\hline adultMinNestArea & 4 & 37 & 80 & $\begin{array}{l}37 \text { is minimum observed value on Missouri } \\
\text { River (USACE 2011), other values are } \\
\text { included just to see how parameter } \\
\text { behaves }\end{array}$ \\
\hline adultMinRenestingInterval & 3 & 5 & 9 & $\begin{array}{l}\text { Observed range }=4-16 \text { days. Goal is } \\
\text { minimum. Massey and Fancher (1989)- } \\
67 \% \text { were } 7-9 d . \text { Maximum set to nine to get } \\
\text { seven values. }\end{array}$ \\
\hline adultNestQualityRange & 0.1 & 0.2 & 0.5 & $\begin{array}{l}\text { Nest site selection analysis indicates value } \\
\text { is greater than zero. }\end{array}$ \\
\hline adultSiteSelectionDistance & 2000 & 10,000 & 40,000 & $\begin{array}{l}\text { Experimental during trait development- } \\
\text { minimum is foraging range of most LETE } \\
\text { around breeding colonies }\end{array}$ \\
\hline adultSiteSelectionWaitDays & 4 & 10 & 15 & Estimate \\
\hline chickPeriodDurationMean & 18 & 20 & 22 & Range from USACE (2009). \\
\hline chickPeriodDurationSD & 0.67 & 1 & 2 & $\begin{array}{l}\text { default = range/3sd from USACE (2009), } \\
\text { min and max "guestimates" }\end{array}$ \\
\hline $\begin{array}{l}\text { magentAdultPred } \\
\text { - Excellent habitat: } \\
\text { - Degraded habitat: }\end{array}$ & $\begin{array}{l}1.0 \\
5.0\end{array}$ & $\begin{array}{l}3.0 \\
7.5\end{array}$ & $\begin{array}{l}5.0 \\
10.0\end{array}$ & $\begin{array}{l}\text { Calibration indicates } 3.0 \text { is a reasonable } \\
\text { center value for excellent habitat and } 8.0 \text { is } \\
\text { a reasonable center value for degraded } \\
\text { habitat }\end{array}$ \\
\hline $\begin{array}{l}\text { magentChickPred } \\
\text { - Excellent habitat: } \\
\text { - Degraded habitat: }\end{array}$ & $\begin{array}{l}1.0 \\
5.0\end{array}$ & $\begin{array}{l}3.0 \\
7.5\end{array}$ & $\begin{array}{l}5.0 \\
10.0\end{array}$ & $\begin{array}{l}\text { Calibration indicates } 3.0 \text { is a reasonable } \\
\text { center value for excellent habitat and } 8.0 \text { is } \\
\text { a reasonable center value for degraded } \\
\text { habitat }\end{array}$ \\
\hline $\begin{array}{l}\text { magentNestPred } \\
\text { - Excellent habitat: } \\
\text { - Degraded habitat: }\end{array}$ & $\begin{array}{l}1.0 \\
5.0\end{array}$ & $\begin{array}{l}3.0 \\
7.5\end{array}$ & $\begin{array}{l}5.0 \\
10.0\end{array}$ & $\begin{array}{l}\text { Calibration indicates } 3.0 \text { is a reasonable } \\
\text { center value for excellent habitat and } 8.0 \text { is } \\
\text { a reasonable center value for degraded } \\
\text { habitat. }\end{array}$ \\
\hline $\begin{array}{l}\text { magentORV } \\
\text { - Excellent habitat: } \\
\text { - Degraded habitat: }\end{array}$ & $\begin{array}{l}1.0 \\
5.0\end{array}$ & $\begin{array}{l}3.0 \\
7.5\end{array}$ & $\begin{array}{l}5.0 \\
10.0\end{array}$ & $\begin{array}{l}\text { Calibration indicates } 3.0 \text { is a reasonable } \\
\text { center value for excellent habitat and } 8.0 \text { is } \\
\text { a reasonable center value for degraded } \\
\text { habitat }\end{array}$ \\
\hline manareaFirstNestDate & 128 & 138 & 154 & $\begin{array}{l}\text { Slight reduction from range in } 29 \text { observed } \\
\text { values of 125-157 }\end{array}$ \\
\hline manareaFracDispersers & 0.05 & 0.15 & 0.4 & Estimated from data on "site fidelity" \\
\hline manareaLastFledgingDate & 242 & 244 & 257 & $\begin{array}{l}\text { Observed range of fledging dates, except } \\
\text { minimum value is higher to reflect } \\
\text { difference between actual and maximum } \\
\text { successful fledging dates }\end{array}$ \\
\hline
\end{tabular}




\begin{tabular}{|l|l|l|l|l|}
\hline & Min & $\begin{array}{l}\text { Standard } \\
\text { Value }\end{array}$ & Max & Basis \\
\hline manareaLastNestDate & 180 & 200 & 212 & $\begin{array}{l}\text { Slight reduction from range in observed } \\
\text { values of 178-216. }\end{array}$ \\
\hline manareaPeakNestDate & 146 & 155 & 163 & $\begin{array}{l}\text { Range of 16 observed values across range } \\
\text { of interior least terns. }\end{array}$ \\
\hline nestIncubationDurationMean & 19 & 21 & 24 & $\begin{array}{l}\text { Thompson et al. (1997) indicates a range of } \\
\text { 20-23. }\end{array}$ \\
\hline nestIncubationDurationSD & 1 & 1.5 & 2 & Unpublished data, USGS, Northern Prairies. \\
\hline
\end{tabular}

\section{Interaction with habitat conditions and replication via water years}

The sensitivity of the model to any parameter is likely to vary with environmental conditions and stochastic events occurring during simulation. Results based on only one simulation of one year, or one set of initial conditions, could exaggerate sensitivity to some parameters and underestimate sensitivity to others. In addition, site habitat conditions (e.g., excellent versus degraded habitat quality) and annual flow patterns (e.g., years with flooding versus years without flooding) are likely to affect model sensitivity to parameter values. Therefore, the sensitivity analysis is designed to both replicate the analysis and examine effects of habitat conditions and annual flow patterns by simulating each parameter value using four annual-flow inputs for each of two water year types, and both excellent and degraded habitat conditions.

The two water year types were identified by an analysis of historic data in Lott and Wiley (2012). This analysis classified each flow year from 1977 to 2008 at the Arkansas River study site into one of three types: "low," in which flows rarely exceeded normal hydropower generation flows during the breeding season, "reversal," in which floods begin after tern nesting starts, and "high," in which flooding occurs from the start of the breeding season. Low and reversal flow years are analyzed separately because flooding mortality is expected to dominate in reversal years while predation and disturbance are expected to dominate mortality in low-flow years. High-flow years are neglected to keep the sensitivity analysis from being too complex; they are less common and of less management interest because little can be done to mitigate their effects on tern breeding.

Excellent habitat conditions were simulated using the Keystone 2008 sandbar habitat input, the 32 sites in groups ARM and SAE. Degraded habitat conditions were simulated using the Keystone 2006 habitat input, 
the 25 sites in group SAD (see Main report, Chapter 3 for more detail on these two habitat input sets).

This combination of inputs results in 16 separate sets of input for each parameter. With nine values each for 36 parameters, this sensitivity analysis was based on 5,184 model runs (Table E2).

Table E2. Water year type and habitat condition scenarios for sensitivity analysis.

\begin{tabular}{|l|l|l|}
\hline \multirow{2}{*}{ Water Year Type } & \multicolumn{2}{c|}{ Habitat Conditions } \\
\cline { 2 - 3 } & Excellent & Degraded \\
\hline Low $(2000,2001,2003,2006)$ & 4 & 4 \\
\hline Reversal $(1997,2002,2004,2005)$ & 4 & 4 \\
\hline
\end{tabular}

\section{Outputs analyzed}

The ILT model produces a variety of outputs of potential interest, and each output may have different sensitivity to each parameter. However, analyzing sensitivity to many kinds of results makes the analysis much more difficult to interpret; it is best to focus, at least initially, on only the very few most important model results. Therefore, two output variables were chosen for analysis. However, simulation results were archived so other outputs can be examined later.

The first output variable analyzed is a direct measure of reproductive success: the number of fledglings per arriving female adult (referred to simply as "reproductive success" or RS). RS is calculated by dividing the number of fledglings by the number of female adult terns initialized by the model (which varies stochastically among runs).

The second output variable is a measure of the relative importance of flooding mortality. Its purpose is to allow users to determine the mechanism-flooding vs. mortality agents-by which parameters affect reproductive success. This mortality measure is the fraction of potential reproduction lost due to flooding (referred to as "flooding loss" or FL). FL is calculated by dividing the number of both eggs and chicks killed by flooding by the total number of eggs produced. (This measure is not a completely accurate measure of the effects of flooding mortality because female terns can attempt to create new nests after eggs or chicks are killed.) If this measure is sensitive to a parameter, then one can infer that the parameter's 
process strongly affects flooding mortality. If RS, but not FL, is sensitive to a parameter, then one can infer that the parameter's process affects either the number of eggs produced or mortality due to agents, and it should be straightforward to determine which. If the analysis shows either of these measures to be unexpectedly sensitive, or insensitive, to a particular parameter, further analysis can be conducted to understand the mechanism causing the sensitivity.

\section{Sensitivity index and ranking of parameters}

One purpose of sensitivity analysis is to rank the relative sensitivity of the model to its various parameters. Doing so requires a sensitivity index that reflects how much model results change with changes in the parameter's value, but this index must be comparable among parameters that have widely different values. The simple derivative (slope) of how a model output changes with the parameter's value would not meet this criterion because the slope is calculated by dividing the change in output by the change in parameter value; parameters with very small values would produce slopes far higher than those of parameters with high values. This problem is typically addressed by scaling the parameter values by the range of values used in the analysis. The minimum parameter value is given a scaled value of 0.0 , the maximum value is given a scaled value of 1.0, and intermediate values are scaled linearly between 0.0 and 1.0. The standard value of a parameter may or may not be halfway between the minimum and maximum, so its value may or may not be 0.5 .

The main sensitivity index used is the absolute value of the regression slope of the model outputs (FPF or LFF; Y axis) versus the scaled parameter value (X axis). This regression includes results from all replicates executed for each value of the parameter.

While this index is the ultimate measure of sensitivity used to rank parameters, several characteristics of the regression relationship are also examined to better understand sensitivity. First, each such relationship is plotted, with separate symbols for each water year type, and visually inspected to see whether there is a clear but nonlinear relationship that might be underrepresented by the sensitivity index. Second, the strength of the relationship is determined by tabulating whether the slope was positive or negative (whether the model output increases or decreases with the parameter's value) and the $p$ value at which the relationship is statistically significant. Third, Analysis of Covariance (ANCOVA) is used to determine if 
the relationship between model output and parameter value differs among water year types and habitat conditions (or an interaction between the two).

Individual parameters may be investigated more fully if there are indications such as clearly nonlinear response to the parameter, or strong effects of water year type or habitat conditions in the ANCOVA.

\section{Results}

Results for sensitivity of reproductive success are presented in Table E3. The only parameters with strong effects on reproductive success are those that control mortality agent levels and the maximum number of breeding attempts by female terns. As expected, mortality agent parameters have negative effects and number of breeding attempts has a positive effect on reproductive success.

Results for sensitivity of flooding loss are presented in Table E4. The only parameters that strongly affect how much mortality is due to flooding are also the mortality agent parameters. They are positively related to flooding loss, indicating that higher predation and ORV mortality leads to higher flooding mortality. The most likely mechanism for this relation is renesting: non-flooding mortality causes more renesting and hence more eggs and chicks, later in the summer, that could then be flooded. (A potential counteracting mechanism, that higher predation reduces the number of eggs and chicks left alive to potentially be flooded, appears less important.)

Water year type and habitat condition had relatively little effect on sensitivity results. For reproductive success, only one parameter had a significant $(\mathrm{p}<0.10)$ interaction with habitat conditions: the maximum number of breeding attempts. There were no significant interactions with water year type. For flooding loss, two of the mortality agent parameters (adult and nest predators) had significant interactions with water year type, and no parameters had interactions with habitat conditions.

Complete results are depicted graphically in the pages at the end of this appendix. (Raw results, and the R code used to do the statistical analyses, are located in the project repository at: /trunk/model/SensitivityAnalysis. The final R code is located in files with names ending in "v10.1.R".) 
Table E3. Sensitivity analysis results for reproductive success. Parameters are listed in order of highest to

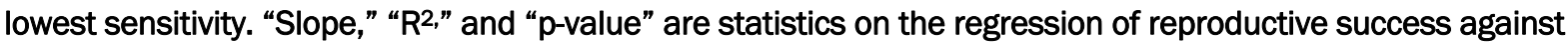
scaled parameter values. Negative slope indicates that increasing parameter values produced decreasing reproductive success. "Habitat condition p-value" indicates the significance of differences in regression results between excellent and degraded habitat conditions, with lower $p$-values meaning a stronger difference. "Water year p-value" indicates the significance of differences in regression results between low and reversal water year types.

\begin{tabular}{|c|c|c|c|c|c|}
\hline Parameter & Slope & $\mathrm{R}^{2}$ & p-value & $\begin{array}{l}\text { Habitat } \\
\text { p-value }\end{array}$ & $\begin{array}{l}\text { Water year } \\
\text { p-value }\end{array}$ \\
\hline magentNestPred & -1.12 & 0.36 & 0.00 & 0.39 & 0.19 \\
\hline magentAdultPred & -1.11 & 0.38 & 0.00 & 0.87 & 0.20 \\
\hline magentChickPred & -1.10 & 0.36 & 0.00 & 0.47 & 0.68 \\
\hline magentORV & -0.98 & 0.30 & 0.00 & 0.72 & 0.57 \\
\hline adultMaxNumBreedingAttempts & 0.51 & 0.10 & 0.00 & 0.06 & 0.51 \\
\hline adultFracNonviableEggs & -0.17 & 0.01 & 0.23 & 0.76 & 0.89 \\
\hline nestIncubationDurationMean & -0.16 & 0.01 & 0.27 & 0.55 & 0.93 \\
\hline chickPeriodDurationMean & -0.12 & 0.01 & 0.36 & 0.32 & 0.61 \\
\hline adultMinRenestingInterval & 0.12 & 0.01 & 0.38 & 0.38 & 0.57 \\
\hline adminQualDist2Bank09 & -0.11 & 0.00 & 0.43 & 0.98 & 0.69 \\
\hline adultClutchProb2Eggs & -0.10 & 0.00 & 0.49 & 0.42 & 0.67 \\
\hline adminExpectedFledges & -0.10 & 0.00 & 0.50 & 0.65 & 0.47 \\
\hline adminQualFreeboard01 & 0.10 & 0.00 & 0.50 & 0.26 & 0.65 \\
\hline adultSiteSelectionDistance & 0.08 & 0.00 & 0.55 & 0.82 & 0.69 \\
\hline manareaFirstNestDate & 0.08 & 0.00 & 0.58 & 0.61 & 0.75 \\
\hline adminQualFreeboardAtMinSuitableFlow09 & 0.08 & 0.00 & 0.58 & 0.73 & 0.83 \\
\hline manareaLastNestDate & -0.06 & 0.00 & 0.68 & 0.29 & 0.67 \\
\hline manareaFracDispersers & 0.06 & 0.00 & 0.65 & 0.58 & 0.48 \\
\hline adminQualDist2Veg09 & 0.06 & 0.00 & 0.69 & 0.78 & 0.85 \\
\hline adminQualDist2Veg01 & -0.06 & 0.00 & 0.69 & 0.47 & 0.30 \\
\hline adultMinNestArea & 0.06 & 0.00 & 0.69 & 0.30 & 0.39 \\
\hline adminQualDist2ForestEdge01 & -0.05 & 0.00 & 0.71 & 0.39 & 0.49 \\
\hline adminQualDist2Bank01 & -0.05 & 0.00 & 0.74 & 0.83 & 0.59 \\
\hline manareaLastFledgingDate & 0.04 & 0.00 & 0.74 & 0.96 & 0.92 \\
\hline adminQualFreeboard09 & 0.04 & 0.00 & 0.78 & 0.68 & 0.67 \\
\hline adminQualFreeboardAtMinSuitableFlow01 & 0.04 & 0.00 & 0.78 & 0.49 & 0.90 \\
\hline adultSiteSelectionWaitDays & -0.03 & 0.00 & 0.82 & 0.98 & 0.99 \\
\hline adultNestQualityRange & 0.03 & 0.00 & 0.83 & 0.68 & 0.61 \\
\hline manareaPeakNestDate & 0.03 & 0.00 & 0.85 & 0.88 & 0.93 \\
\hline adminQualDist2ForestEdge09 & 0.03 & 0.00 & 0.85 & 0.88 & 0.94 \\
\hline
\end{tabular}




\begin{tabular}{|l|l|l|l|l|l|}
\hline Parameter & Slope & $\mathrm{R}^{2}$ & p-value & $\begin{array}{l}\text { Habitat } \\
\text { p-value }\end{array}$ & $\begin{array}{l}\text { Water year } \\
\text { p-value }\end{array}$ \\
\hline adminAbandSurvivalHorizon & 0.02 & 0.00 & 0.88 & 0.43 & 0.45 \\
\hline adultMinDaysArrivalToEggLaying & 0.02 & 0.00 & 0.90 & 0.89 & 0.87 \\
\hline adultClutchProb1Egg & -0.01 & 0.00 & 0.92 & 0.85 & 0.78 \\
\hline chickPeriodDurationSD & -0.01 & 0.00 & 0.92 & 0.99 & 0.90 \\
\hline adminAdultsPerChick & -0.01 & 0.00 & 0.93 & 0.89 & 0.92 \\
\hline nestIncubationDurationSD & -0.01 & 0.00 & 0.97 & 0.30 & 0.38 \\
\hline
\end{tabular}

Table E4. Sensitivity analysis results for flooding loss. Format is the same as Table E3.

\begin{tabular}{|c|c|c|c|c|c|}
\hline Parameter & Slope & $\mathrm{R}^{2}$ & $p$-value & $\begin{array}{l}\text { Habitat } \\
p \text {-value }\end{array}$ & $\begin{array}{l}\text { Water year } \mathrm{p}- \\
\text { value }\end{array}$ \\
\hline magentORV & 0.12 & 0.02 & 0.09 & 0.99 & 0.41 \\
\hline magentChickPred & 0.10 & 0.02 & 0.13 & 0.93 & 0.29 \\
\hline magentNestPred & 0.08 & 0.01 & 0.24 & 0.85 & 0.08 \\
\hline magentAdultPred & 0.07 & 0.01 & 0.25 & 0.97 & 0.05 \\
\hline adultMaxNumBreedingAttempts & -0.06 & 0.01 & 0.27 & 0.63 & 0.30 \\
\hline manareaLastNestDate & -0.03 & 0.00 & 0.64 & 0.91 & 0.93 \\
\hline adminExpectedFledges & -0.03 & 0.00 & 0.67 & 0.84 & 0.45 \\
\hline nestlncubationDurationMean & 0.02 & 0.00 & 0.69 & 0.89 & 0.45 \\
\hline manareaFirstNestDate & -0.02 & 0.00 & 0.70 & 0.76 & 0.31 \\
\hline manareaPeakNestDate & -0.02 & 0.00 & 0.72 & 1.00 & 0.62 \\
\hline adultSiteSelectionDistance & -0.02 & 0.00 & 0.73 & 0.92 & 0.86 \\
\hline adminAbandSurvivalHorizon & 0.02 & 0.00 & 0.76 & 0.93 & 0.95 \\
\hline adultClutchProb1Egg & -0.02 & 0.00 & 0.78 & 0.98 & 0.80 \\
\hline adultMinDaysArrivalToEggLaying & 0.01 & 0.00 & 0.80 & 0.84 & 0.77 \\
\hline adminQualDist2Veg09 & -0.01 & 0.00 & 0.84 & 0.90 & 0.63 \\
\hline adminQualFreeboardAtMinSuitableFlow09 & -0.01 & 0.00 & 0.84 & 0.79 & 0.90 \\
\hline adultSiteSelectionWaitDays & 0.01 & 0.00 & 0.89 & 0.89 & 0.85 \\
\hline adminQualDist2ForestEdge09 & -0.01 & 0.00 & 0.89 & 0.97 & 0.75 \\
\hline adultMinNestArea & 0.01 & 0.00 & 0.89 & 0.94 & 0.70 \\
\hline nestIncubationDurationSD & 0.01 & 0.00 & 0.90 & 0.77 & 0.67 \\
\hline adminQualFreeboard09 & 0.01 & 0.00 & 0.91 & 0.94 & 0.75 \\
\hline adminQualDist2Bank01 & -0.01 & 0.00 & 0.91 & 0.93 & 0.87 \\
\hline adminQualFreeboard01 & 0.01 & 0.00 & 0.92 & 0.83 & 0.93 \\
\hline adminQualDist2Veg01 & 0.01 & 0.00 & 0.92 & 0.93 & 0.96 \\
\hline
\end{tabular}




\begin{tabular}{|l|l|l|l|l|l|}
\hline Parameter & Slope & $R^{2}$ & p-value & $\begin{array}{l}\text { Habitat } \\
\text { p-value }\end{array}$ & $\begin{array}{l}\text { Water year } \mathrm{p} \text { - } \\
\text { value }\end{array}$ \\
\hline adminAdultsPerChick & 0.00 & 0.00 & 0.93 & 0.93 & 0.88 \\
\hline adminQualDist2Bank09 & 0.00 & 0.00 & 0.93 & 0.92 & 0.99 \\
\hline adultClutchProb2Eggs & 0.00 & 0.00 & 0.94 & 0.91 & 0.89 \\
\hline manareaFracDispersers & 0.00 & 0.00 & 0.95 & 0.88 & 0.86 \\
\hline manareaLastFledgingDate & 0.00 & 0.00 & 0.97 & 0.94 & 0.84 \\
\hline adultMinRenestingInterval & 0.00 & 0.00 & 0.98 & 0.85 & 0.96 \\
\hline adultNestQualityRange & 0.00 & 0.00 & 0.98 & 0.90 & 0.84 \\
\hline adminQualFreeboardAtMinSuitableFlow01 & 0.00 & 0.00 & 0.99 & 0.87 & 0.98 \\
\hline adultFracNonviableEggs & 0.00 & 0.00 & 0.99 & 0.86 & 0.88 \\
\hline chickPeriodDurationSD & 0.00 & 0.00 & 0.99 & 0.99 & 0.96 \\
\hline chickPeriodDurationMean & 0.00 & 0.00 & 0.99 & 0.94 & 0.94 \\
\hline adminQualDist2ForestEdge01 & 0.00 & 0.00 & 1.00 & 0.96 & 0.71 \\
\hline
\end{tabular}

\section{Conclusions}

Overall, the sensitivity analysis leads to two strong conclusions about the mechanisms in the model. First, flooding mortality seems strongly and tightly controlled by the physical processes that are represented by flow and physical habitat input data representing the underlying environmental conditions of simulations, not model parameters. Previous experiments have shown that the model does produce strong effects of flooding that vary among water year types (Lott and Wiley 2012). These strong effects appear to arise mainly from the site topographic data and the relationships between flow and water surface elevation, not from the parameters controlling tern behavior. Second, predation and ORV mortality strongly affect reproductive success. This is certainly not surprising because they are the only processes other than flooding that can kill terns.

The analysis identified one parameter that seems especially important and uncertain: the maximum number of times an adult (perhaps especially, female) tern can attempt to breed. Research on this subject could be especially valuable for improving understanding of how river operations and predators affect tern reproductive success. Deciding whether and when to attempt breeding again could in fact be another important adaptive behavior. 


\section{References}

Akçakaya, H. R., Atwood, J. L., Breininger, D., Collins, C. T., and B. Duncan. 2003. Metapopulation dynamics of the California Least Tern. Journal of Wildlife Management 67: 829-842.

Kirsch, E.M. 1990. Final report 1990: Least Tern and Piping Plover on the lower Platte River in Nebraska. Unpublished report. Nebraska Game and Parks Commission.

Lott, C.A., and R.L. Wiley. 2012. Effects of dam operations on Least Tern nesting habitat and reproductive success below Keystone Dam on the Arkansas River. ERDC/EL CR-12-4. Vicksburg, MS: U.S. Army Engineer Research and Development Center.

Lott, C.A., S.F. Railsback, and C.J.R. Sheppard. TernCOLONY 1.o model description. ERDC/EL CR-12-3. Vicksburg, MS: U.S. Army Engineer Research and Development Center.

Massey, B.W. and J.M. Fancher. 1989. Renesting by California Least Terns. Journal of Field Ornithology 60: 350-357.

Thompson, B.C., J. A. Jackson, J. Burger, L. A. Hill, E. M. Kirsch, and J. L. Atwood. 1997. Least Tern: Sterna antillarum. In Birds of North America,ed. A. Poole and F. Gill. Philadelphia, PA: The Academy of Natural Scienceand Washington, DC:

American Ornithologists Union.

U.S. Army Corps of Engineers (USACE). 2009. Least Tern and Piping Plover Monitoring Handbook. U.S. Army Engineer District, Omaha.

U.S. Army Corps of Engineers (USACE). 2011. Final Programmatic Environmental Impact Statement for the Mechanical and Artificial Creation and Maintenance of Emergent Sandbar Habitat in the Riverine Segments of the Upper Missouri River. U.S. Army Engineer District, Omaha. 


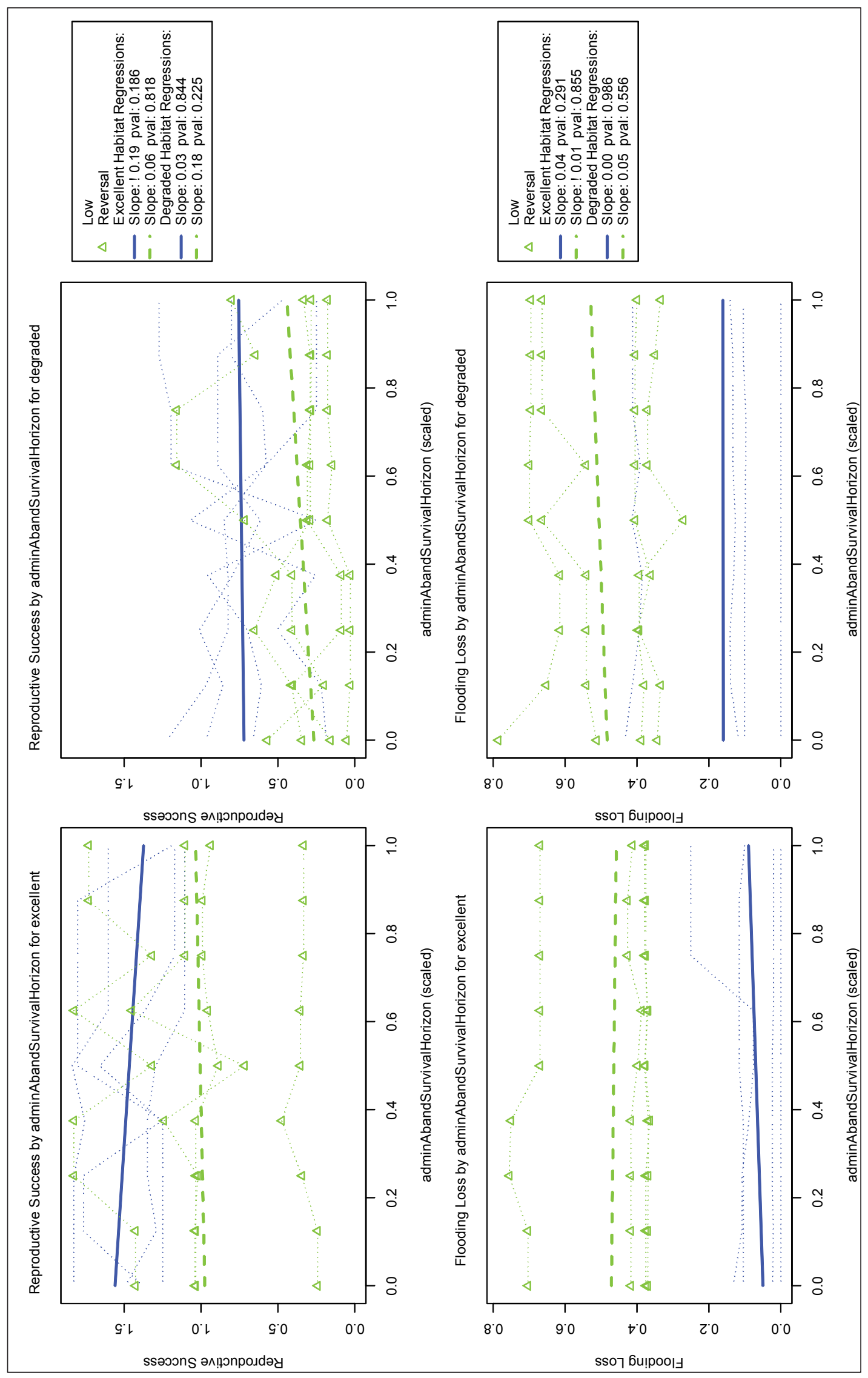




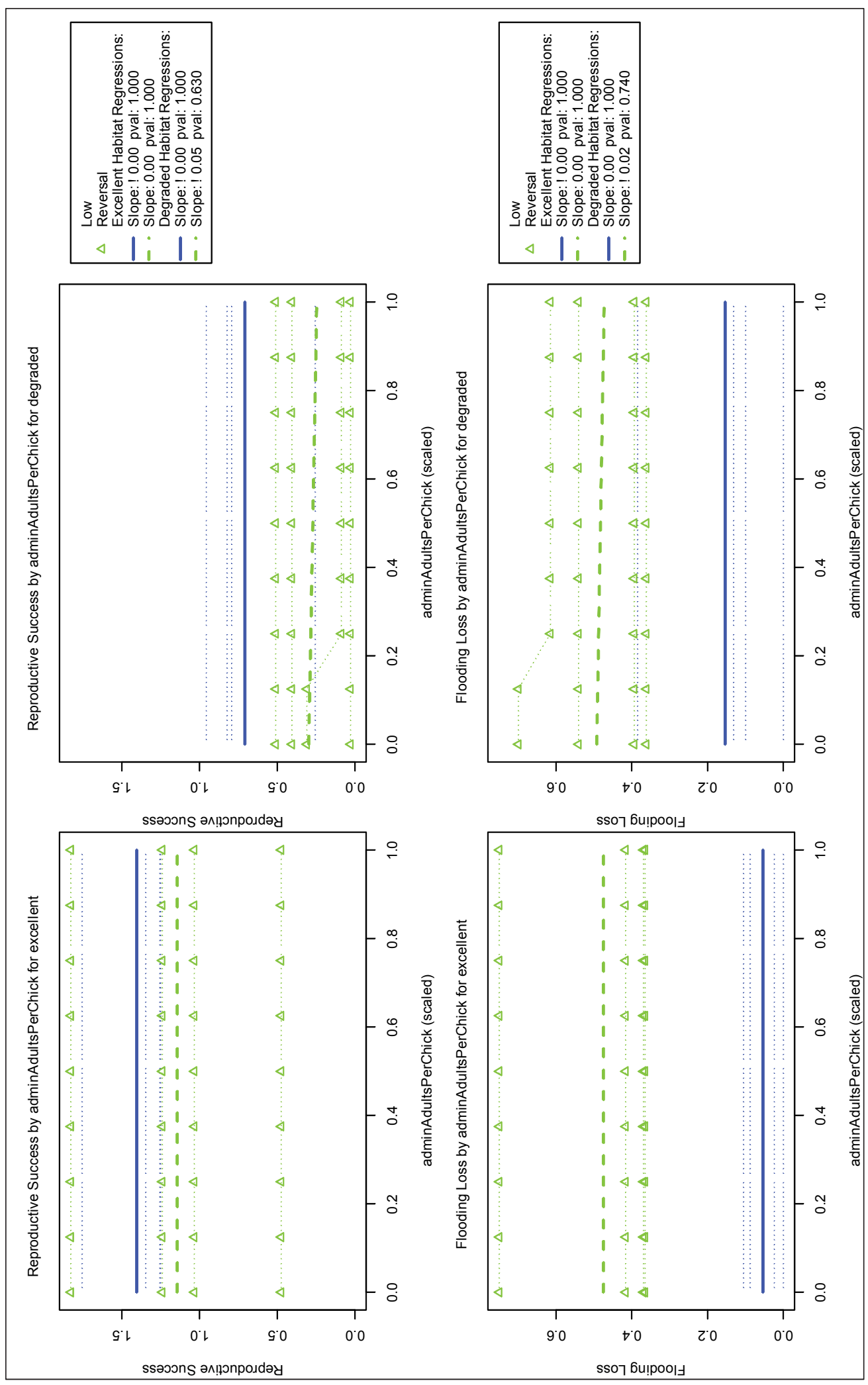




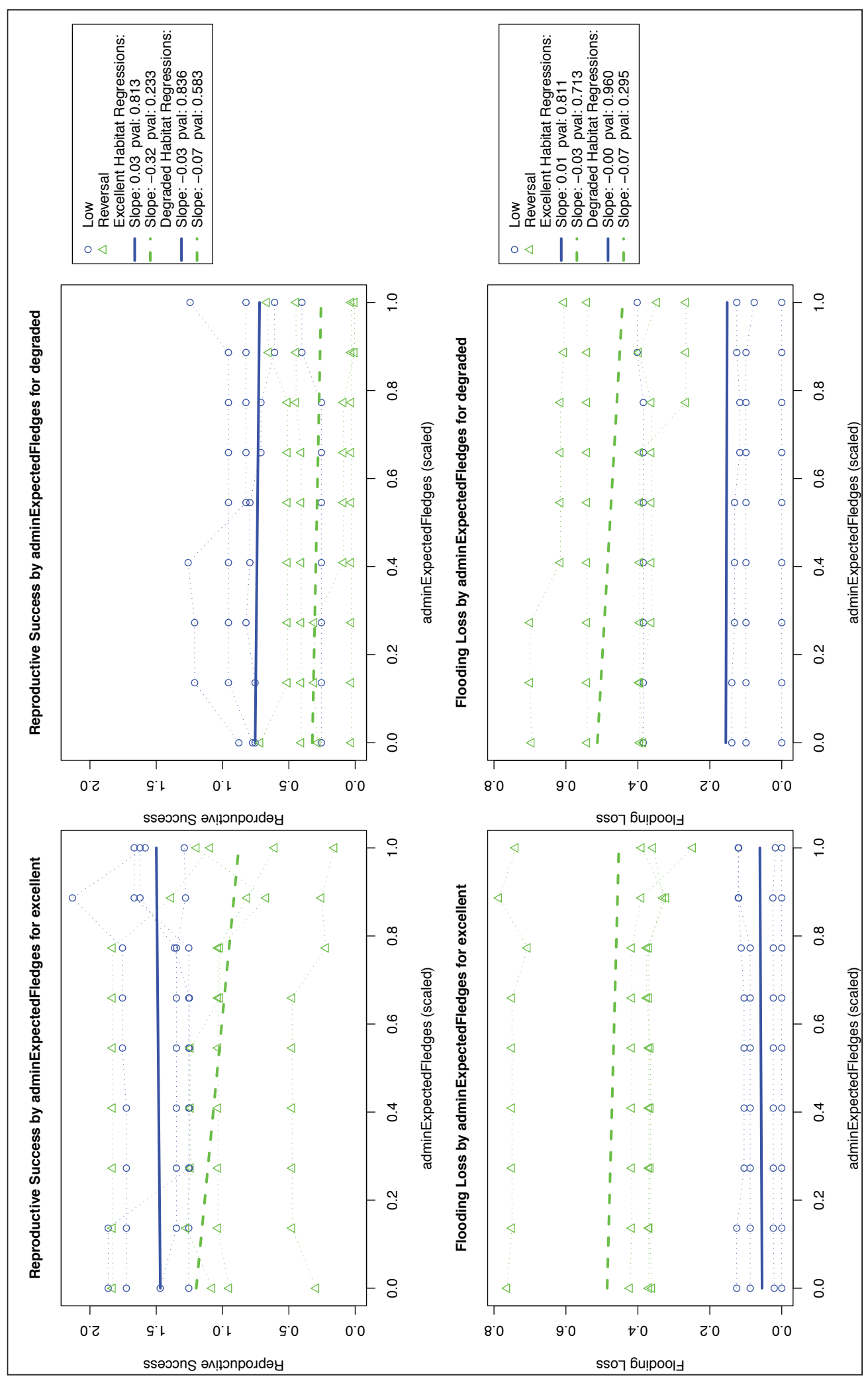




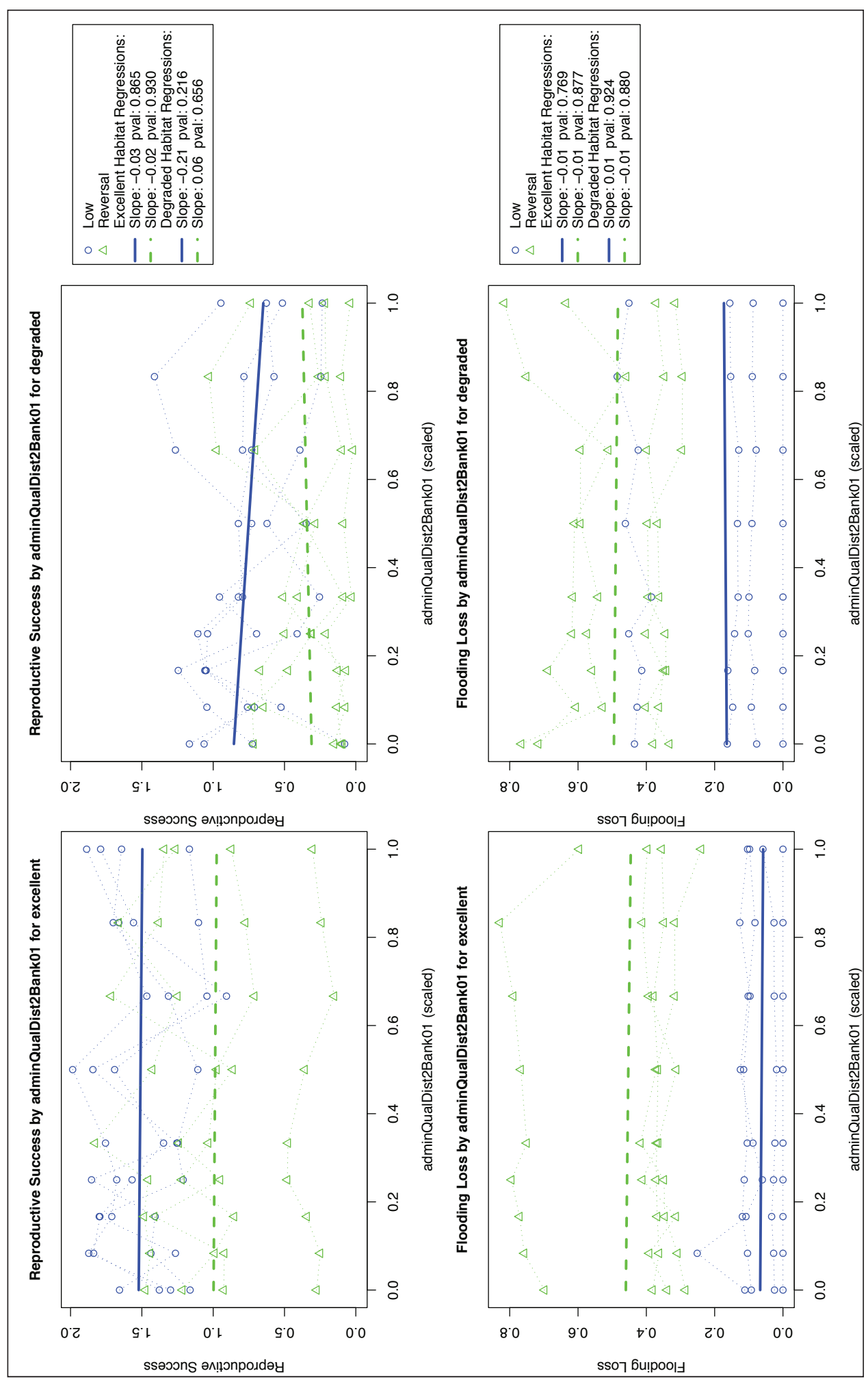




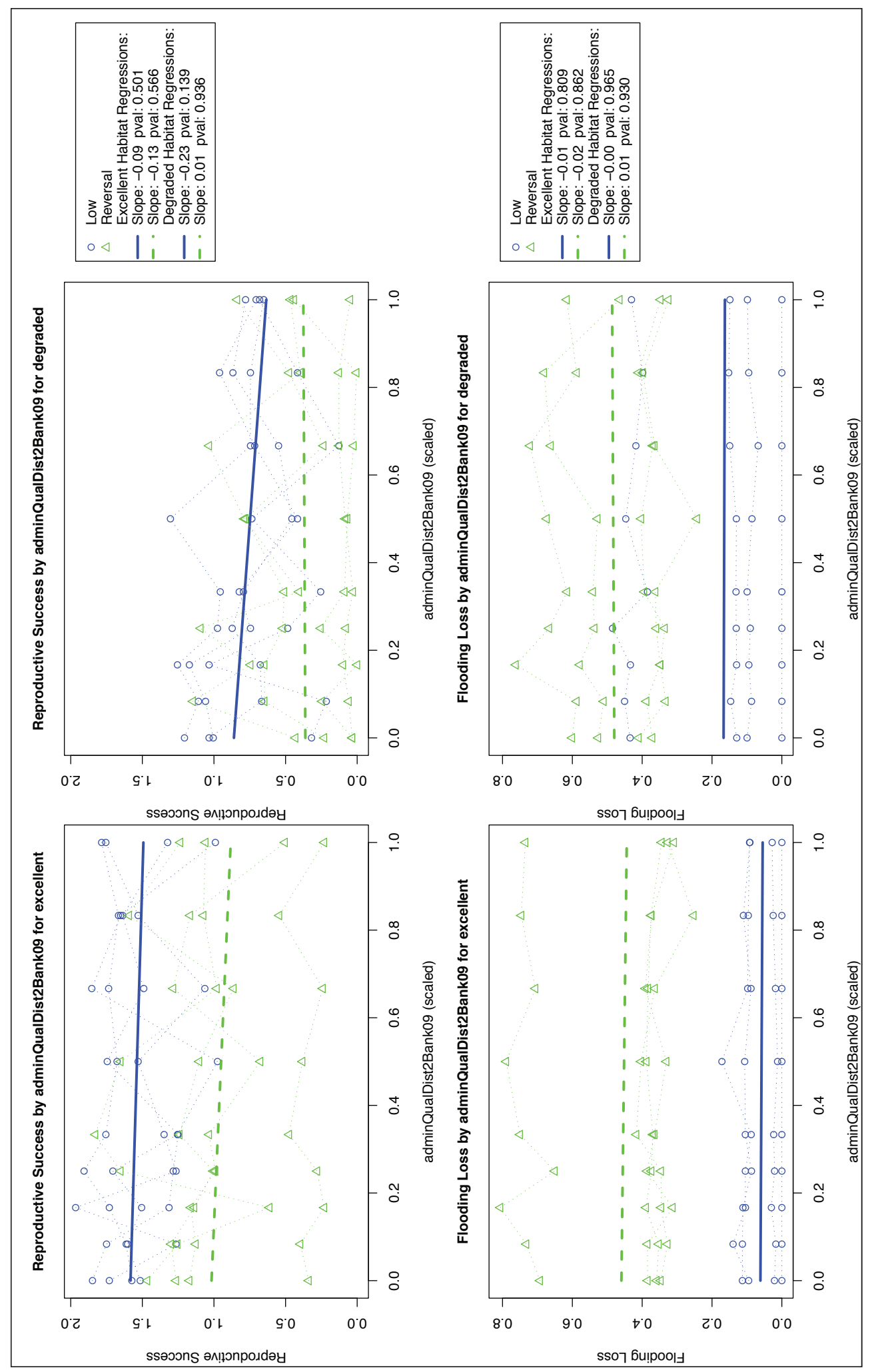




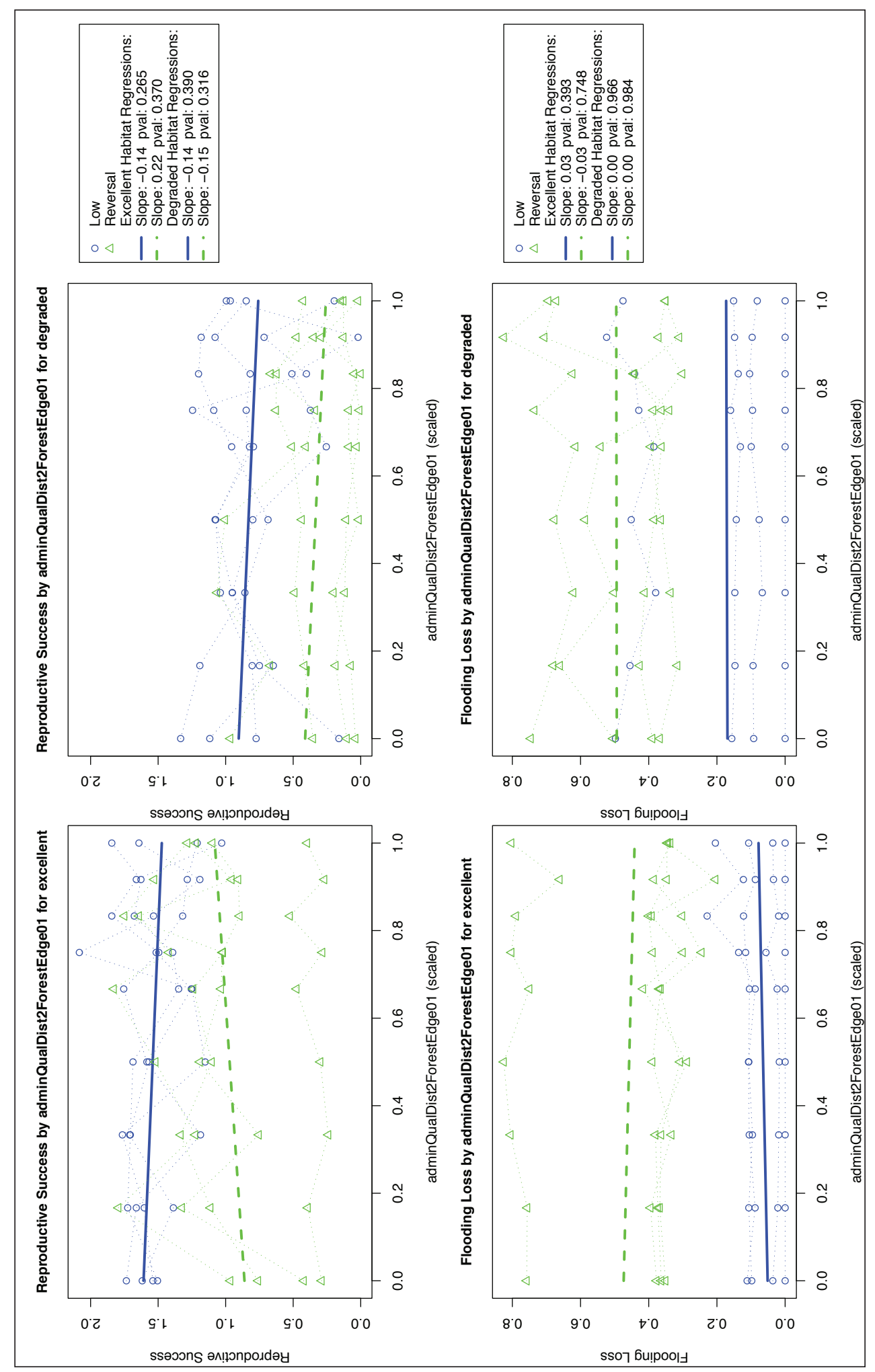




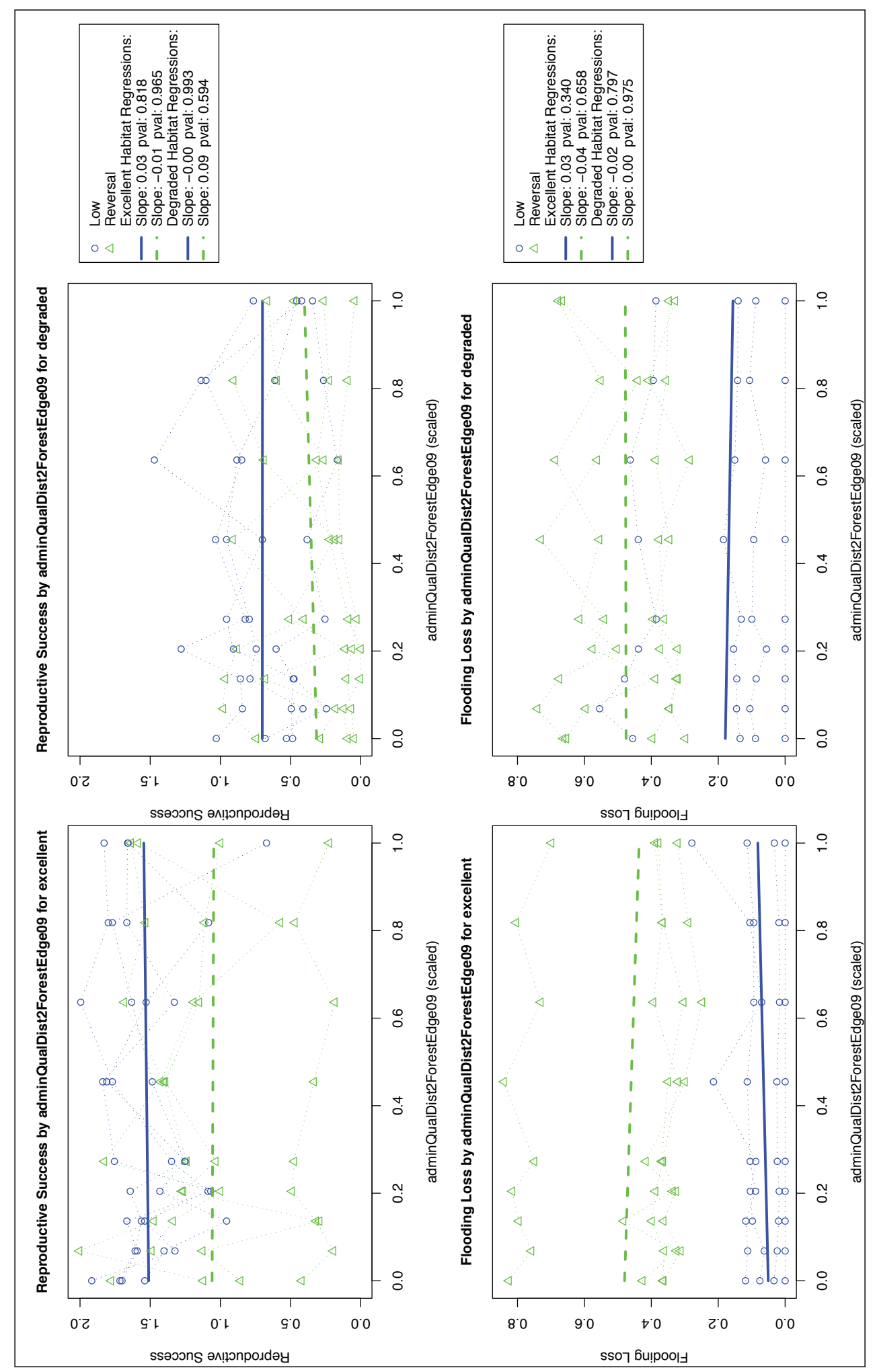




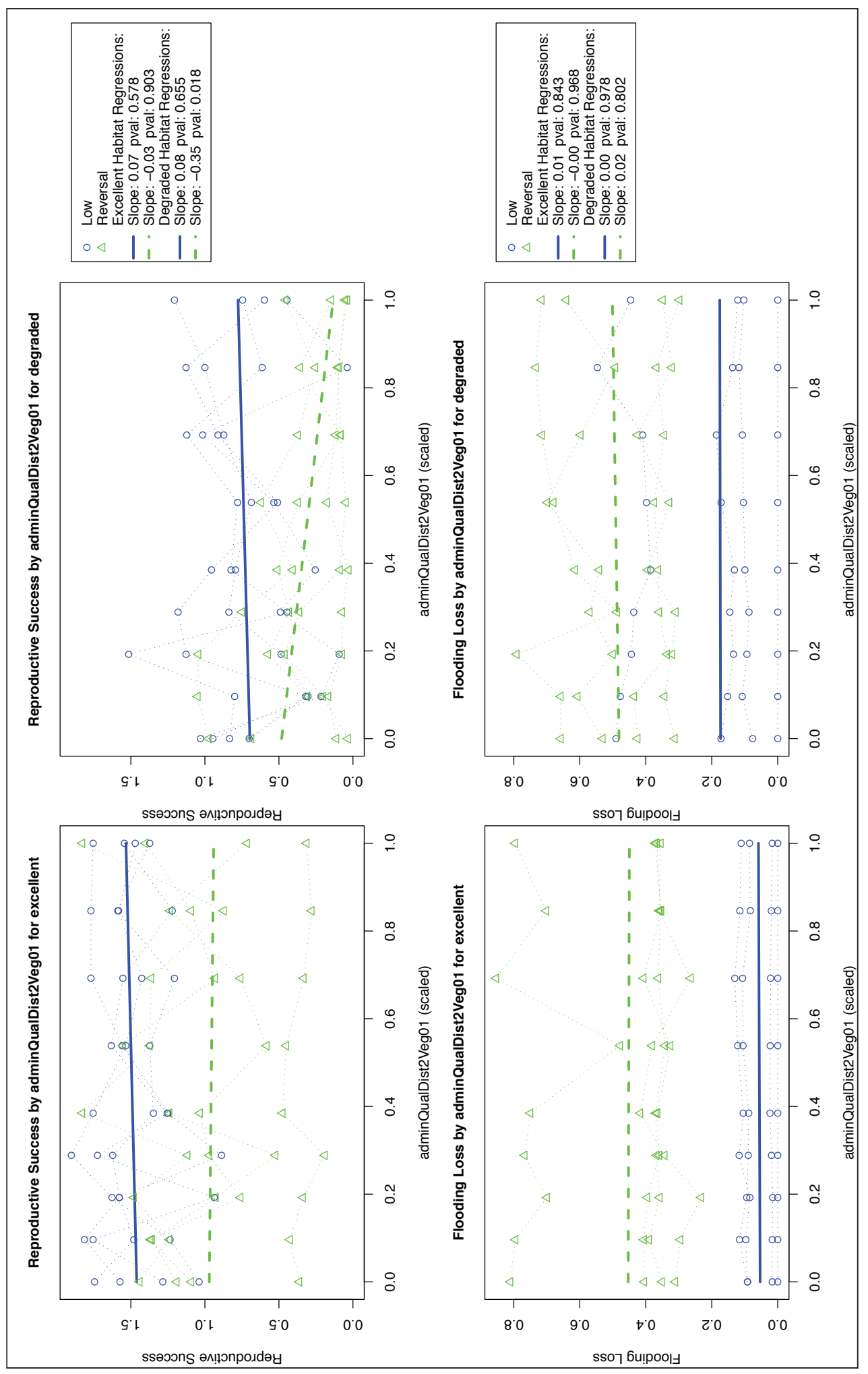




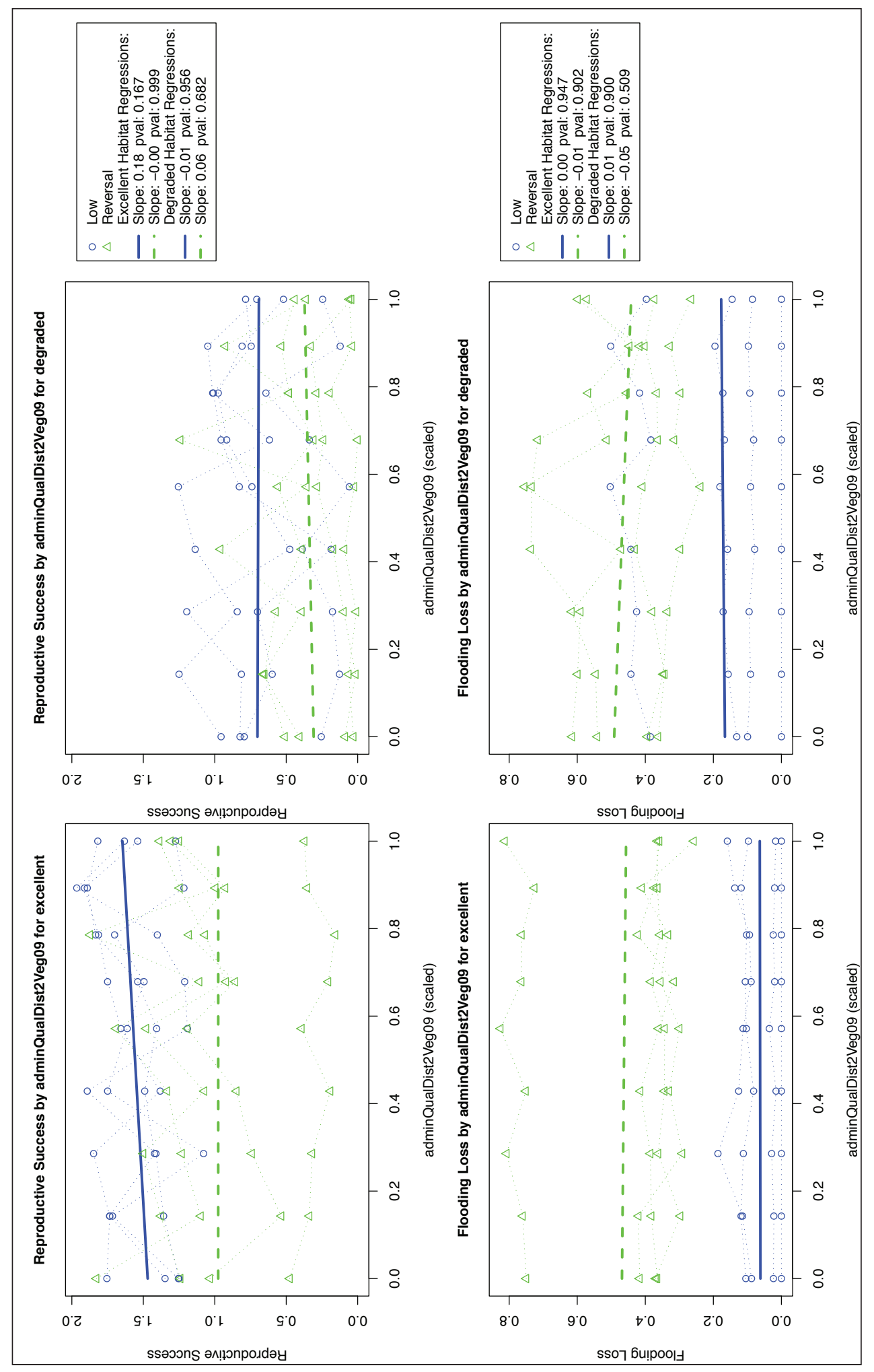




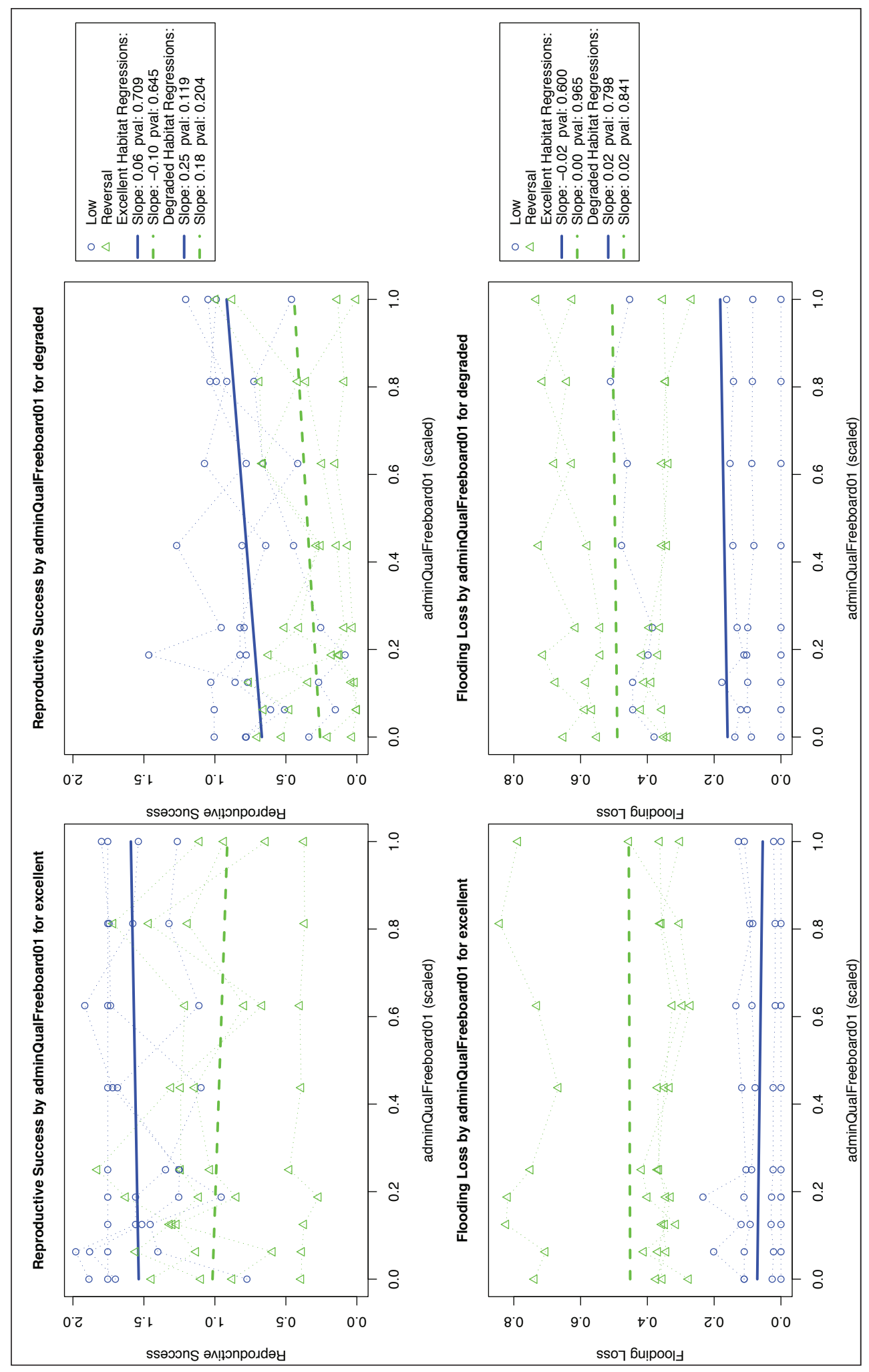




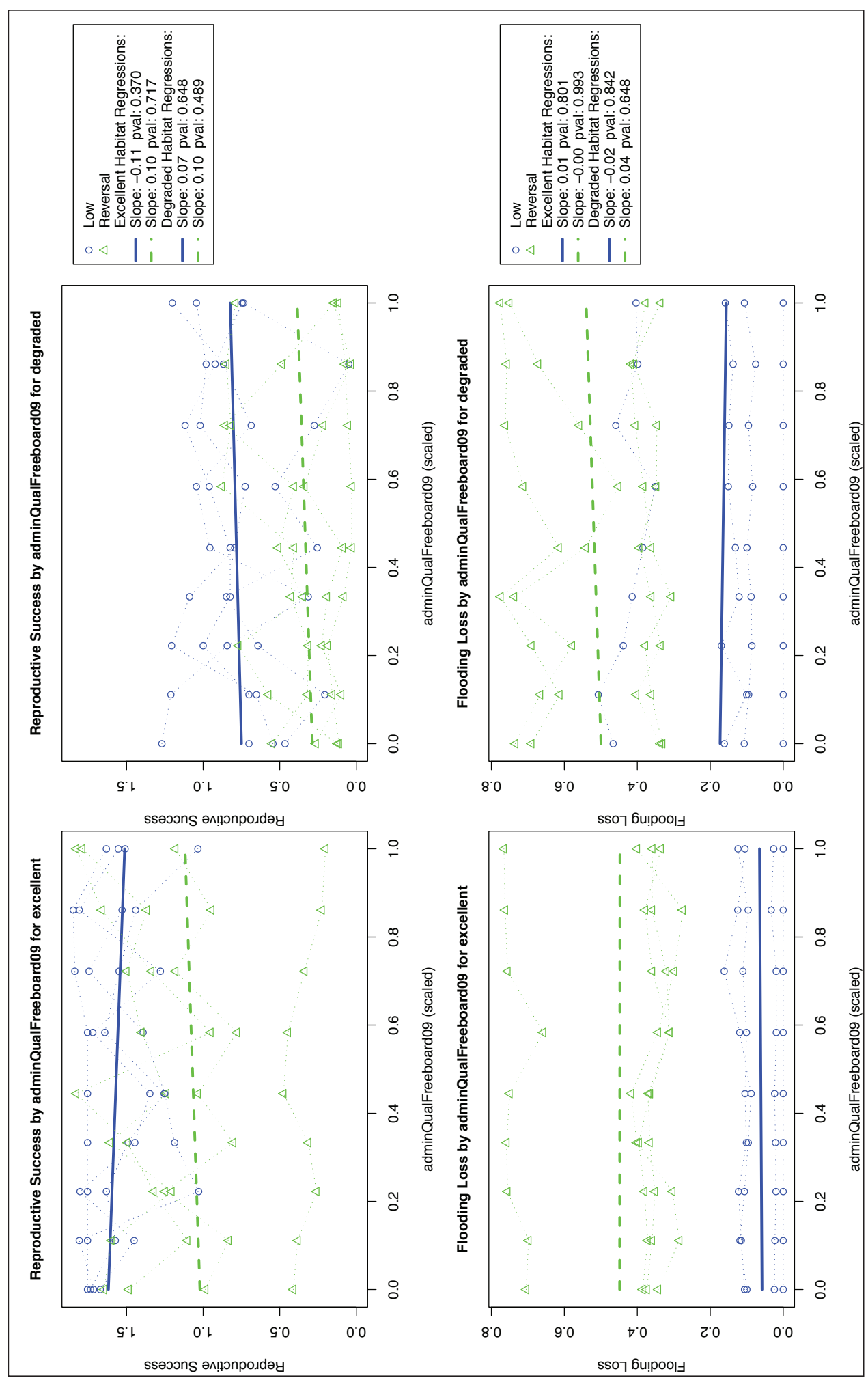




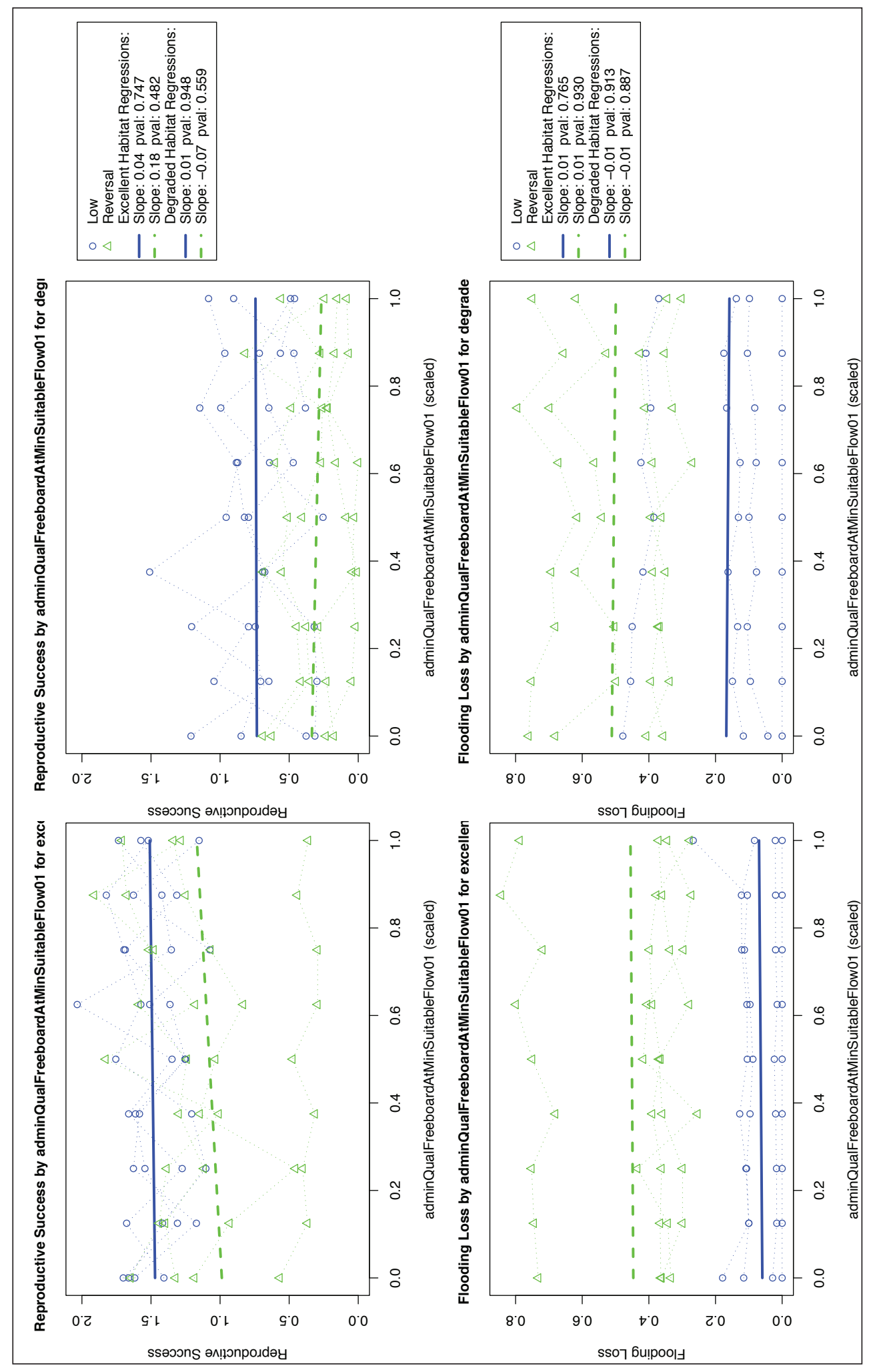




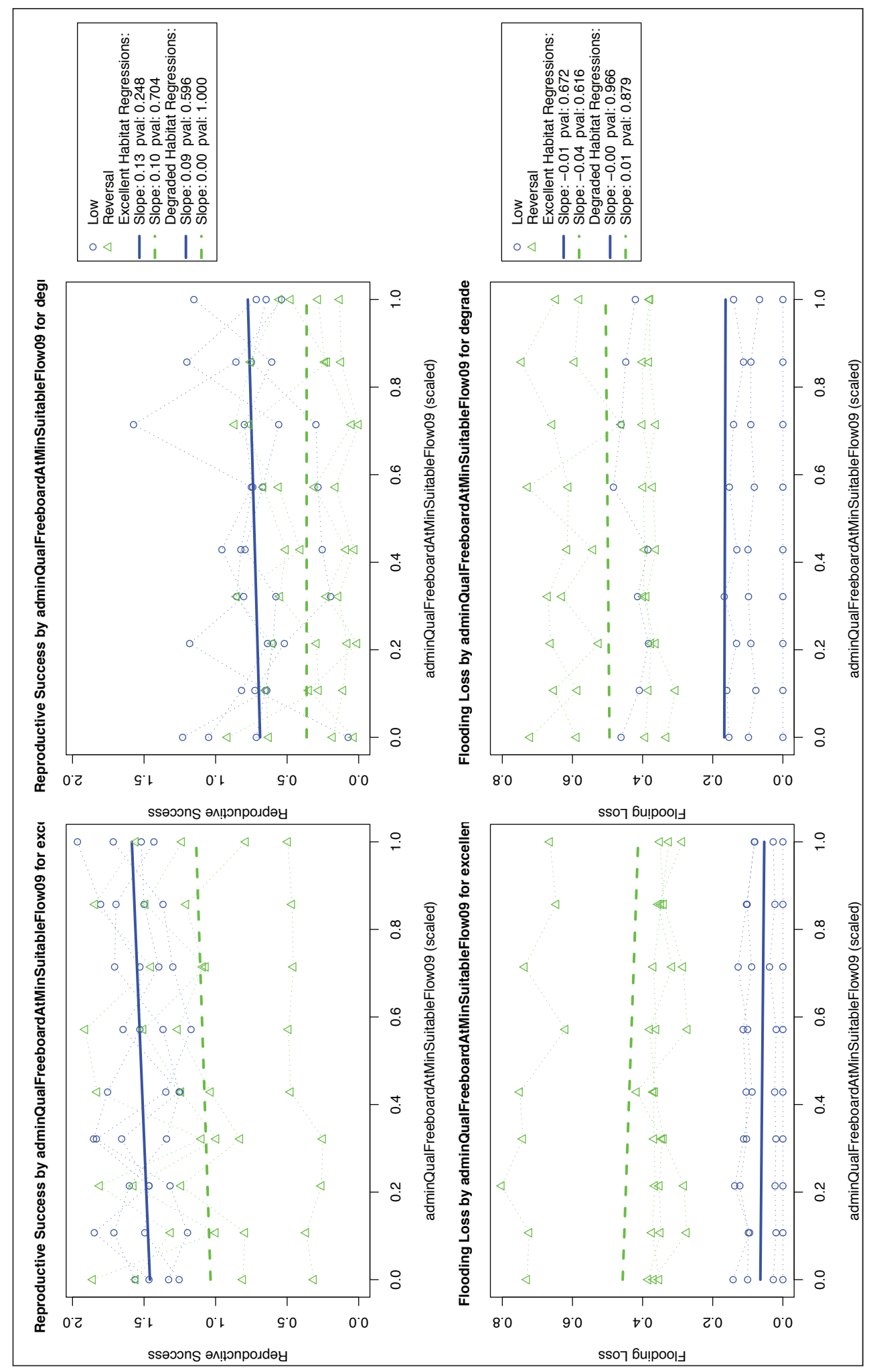




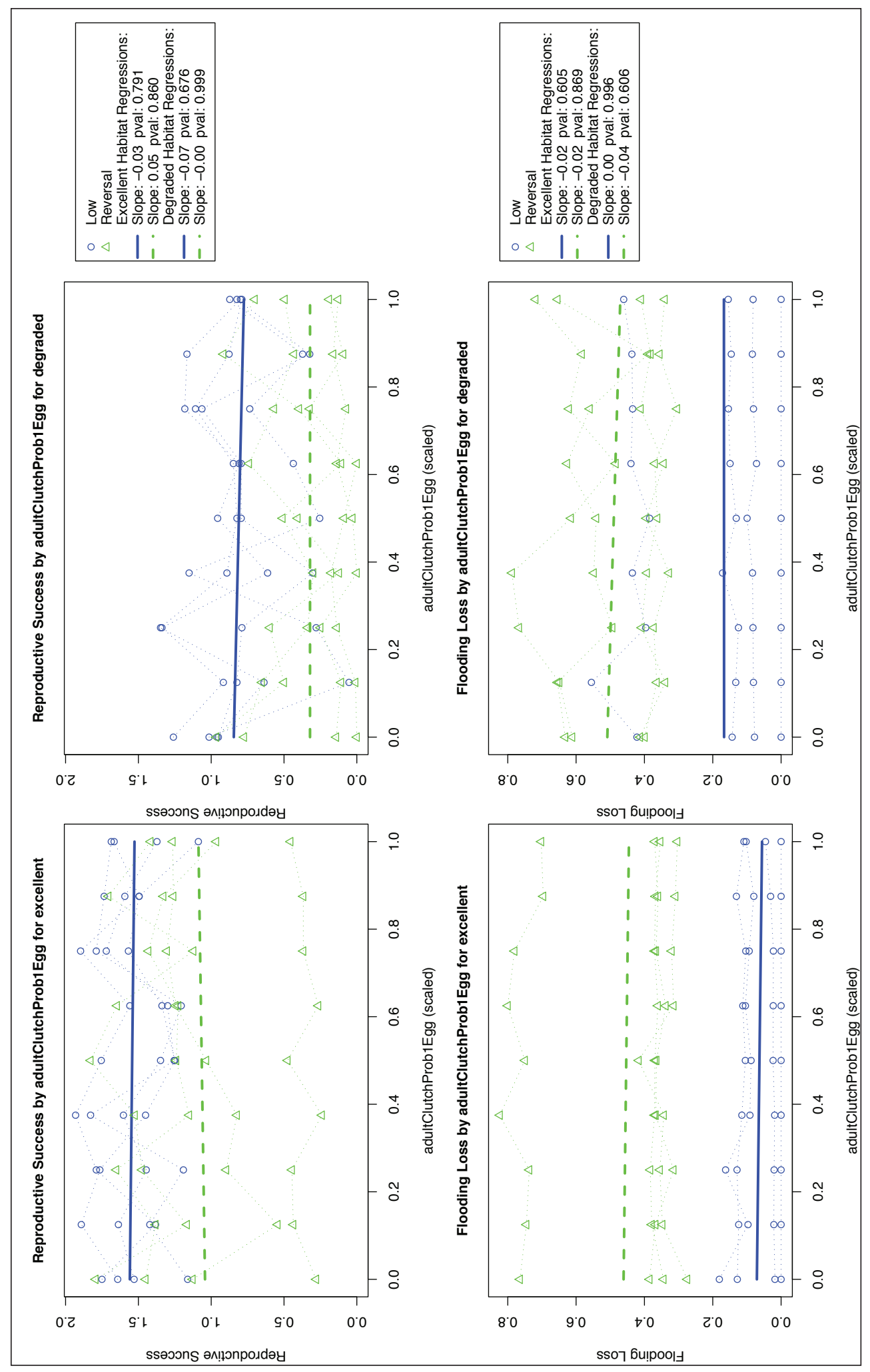




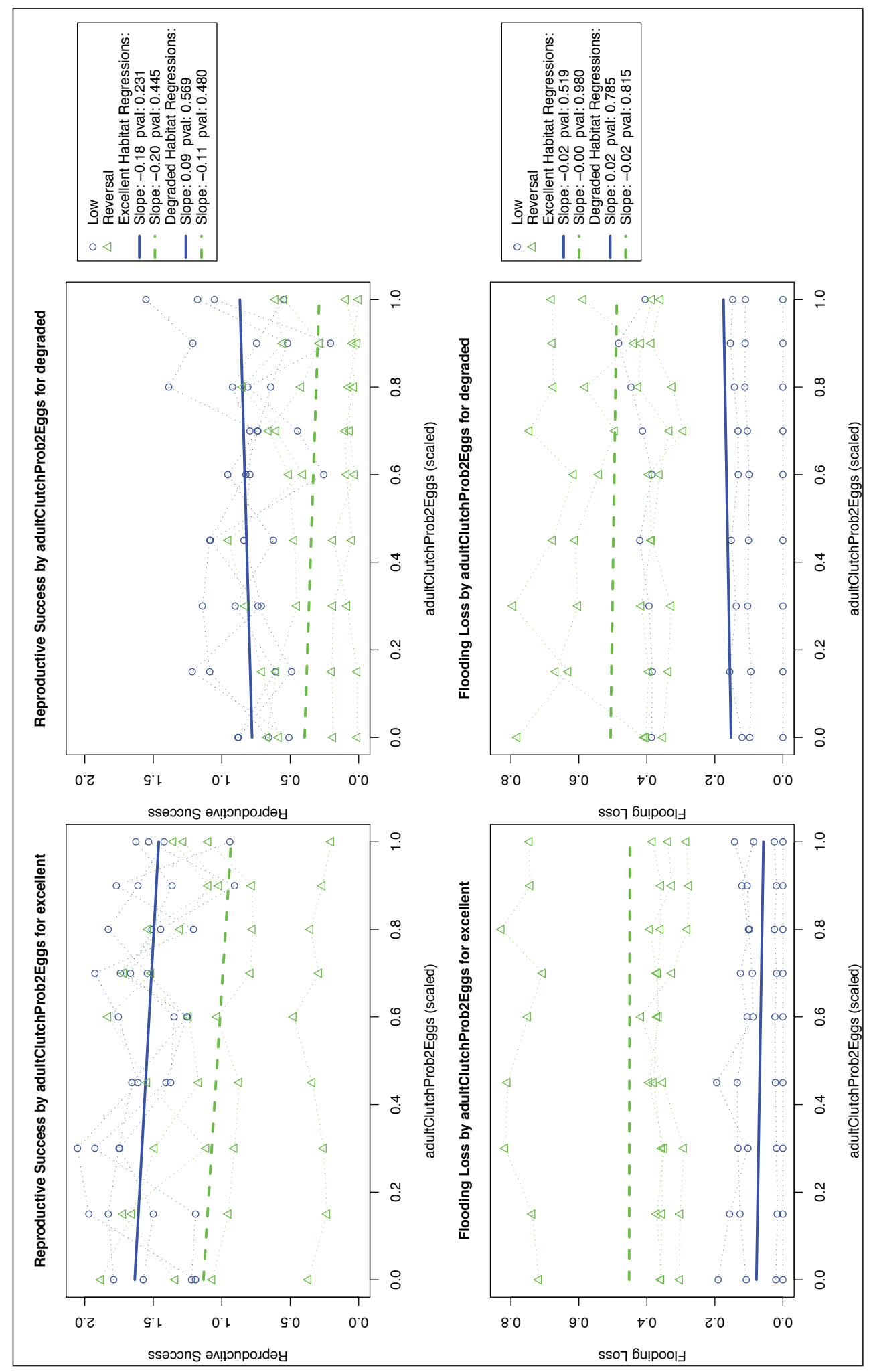




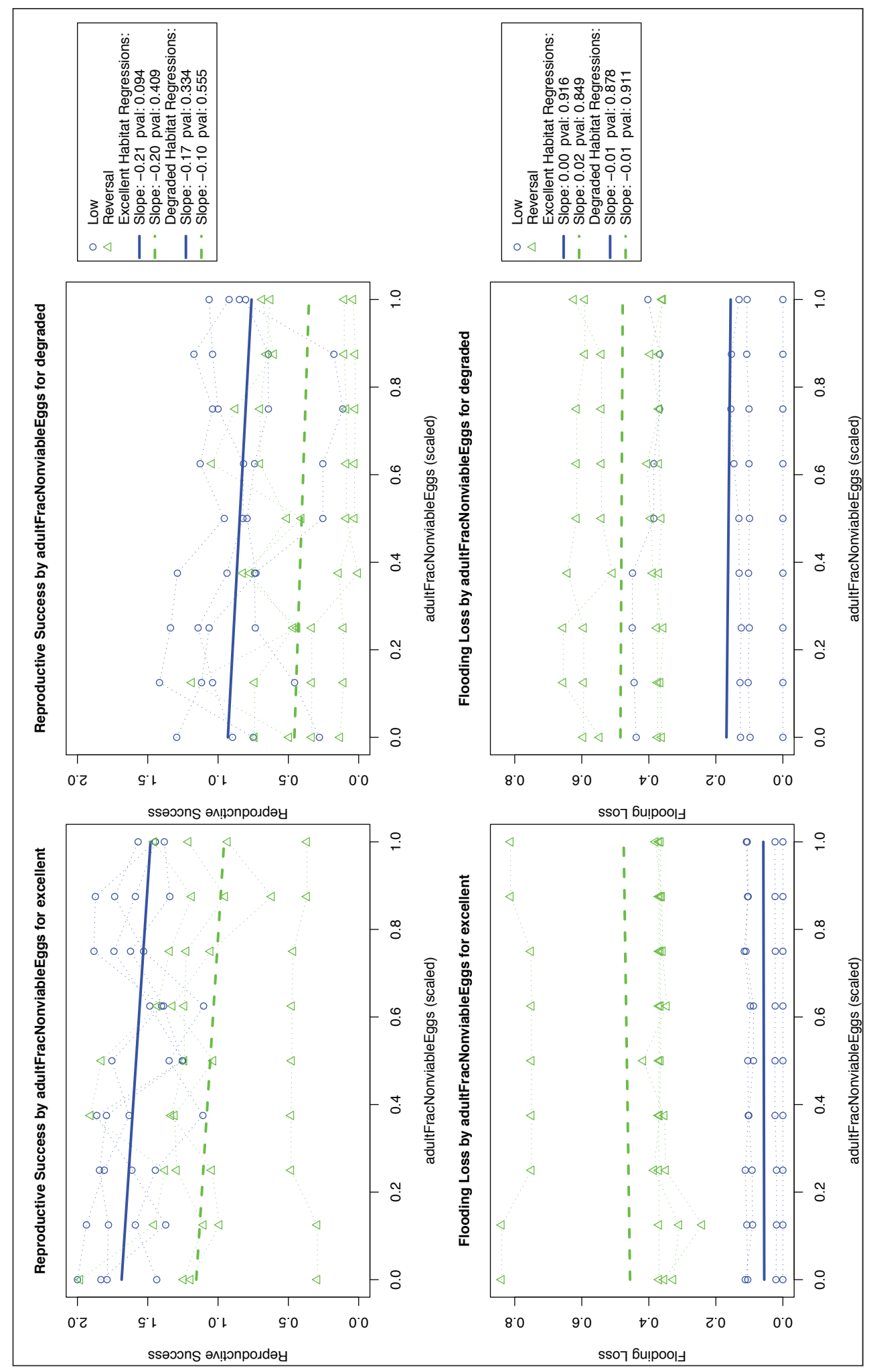




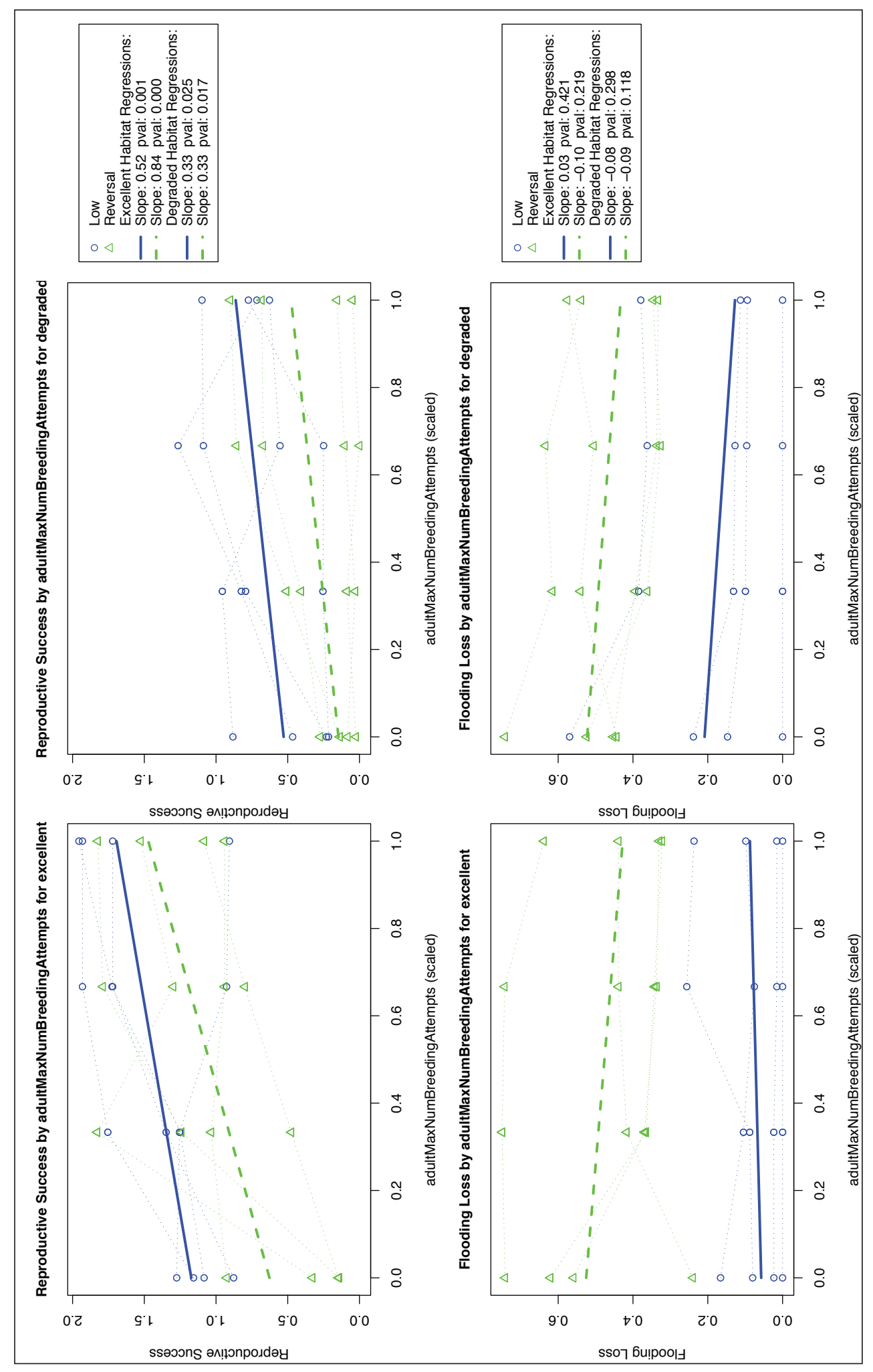




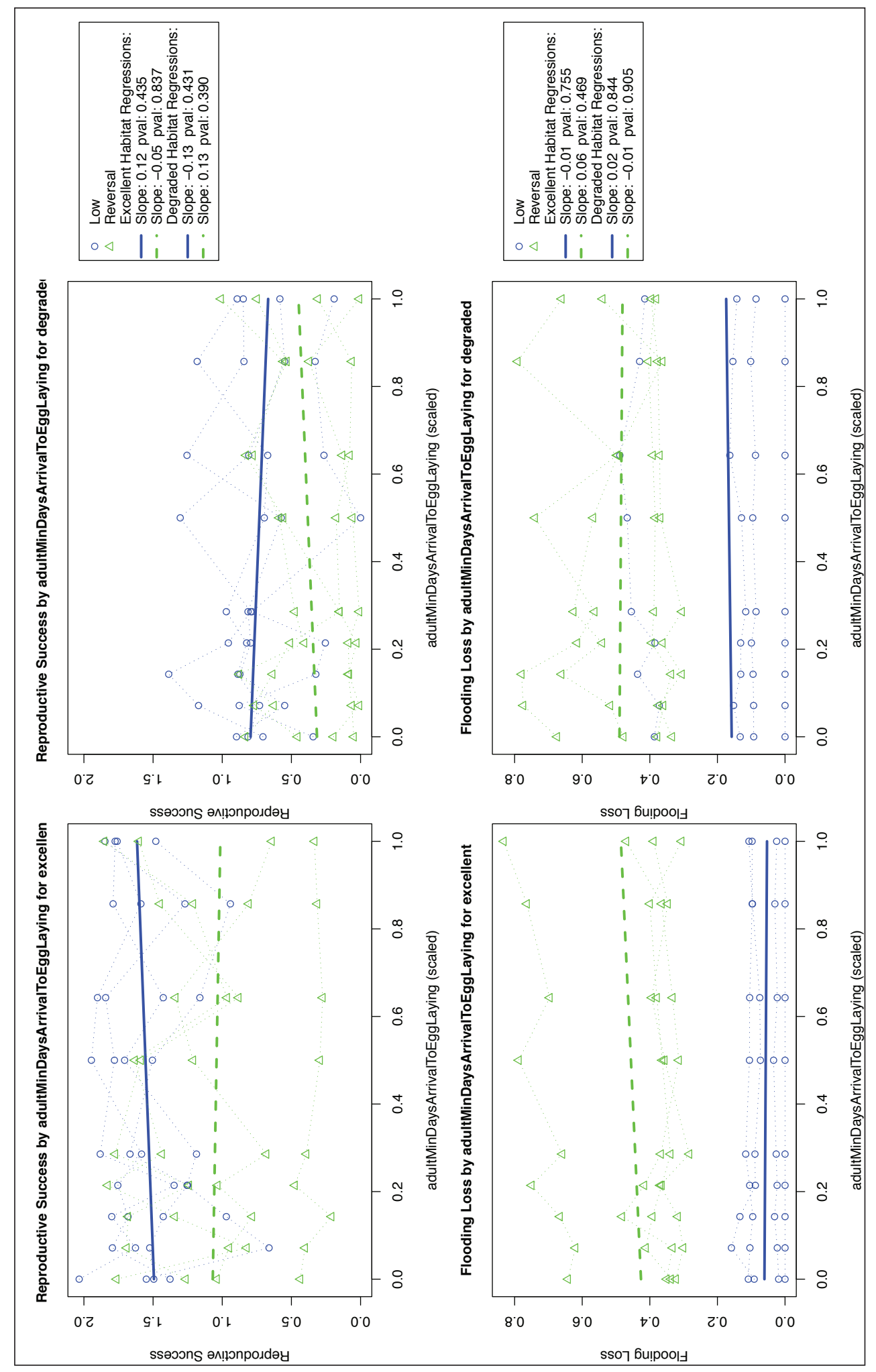




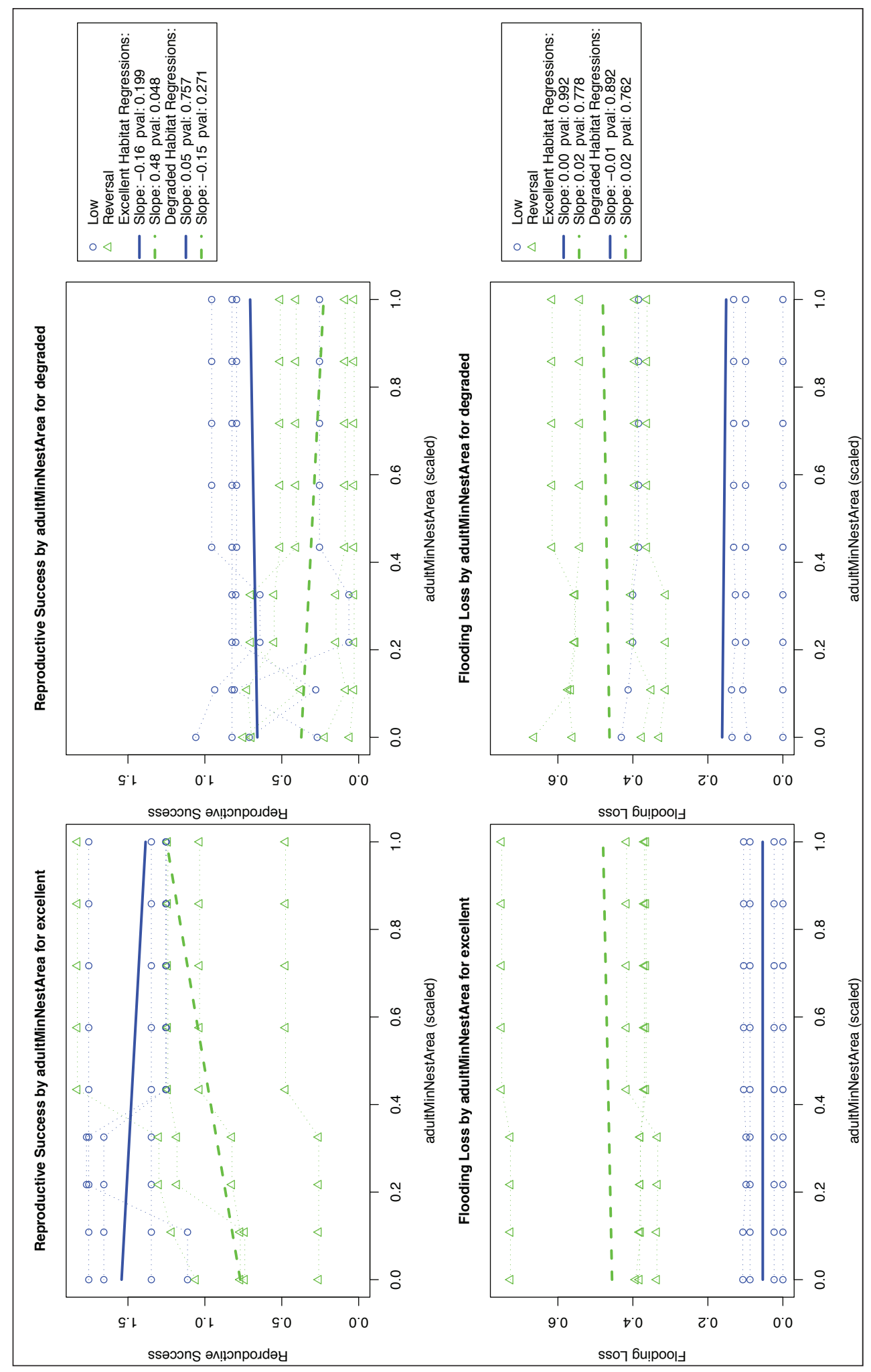




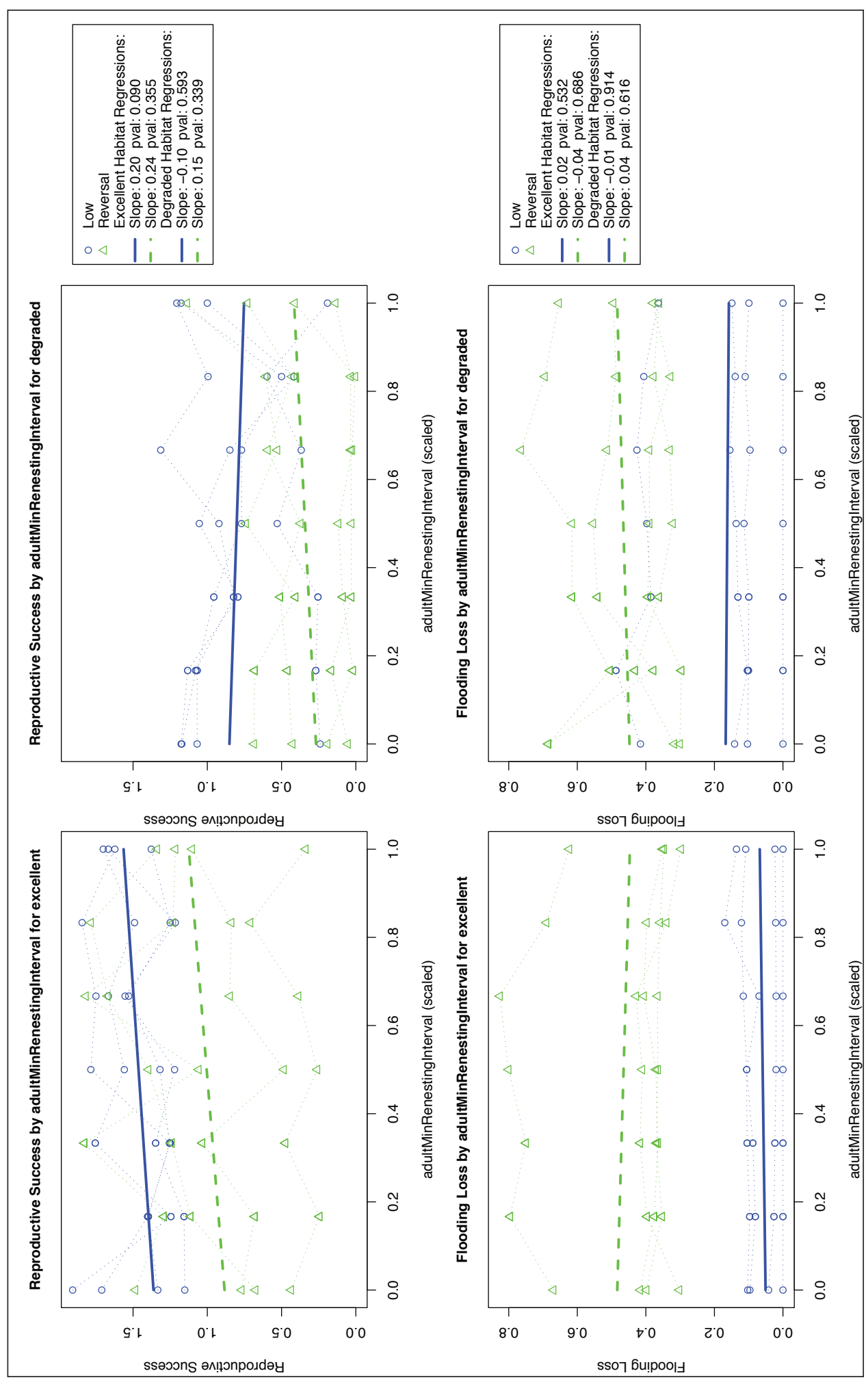




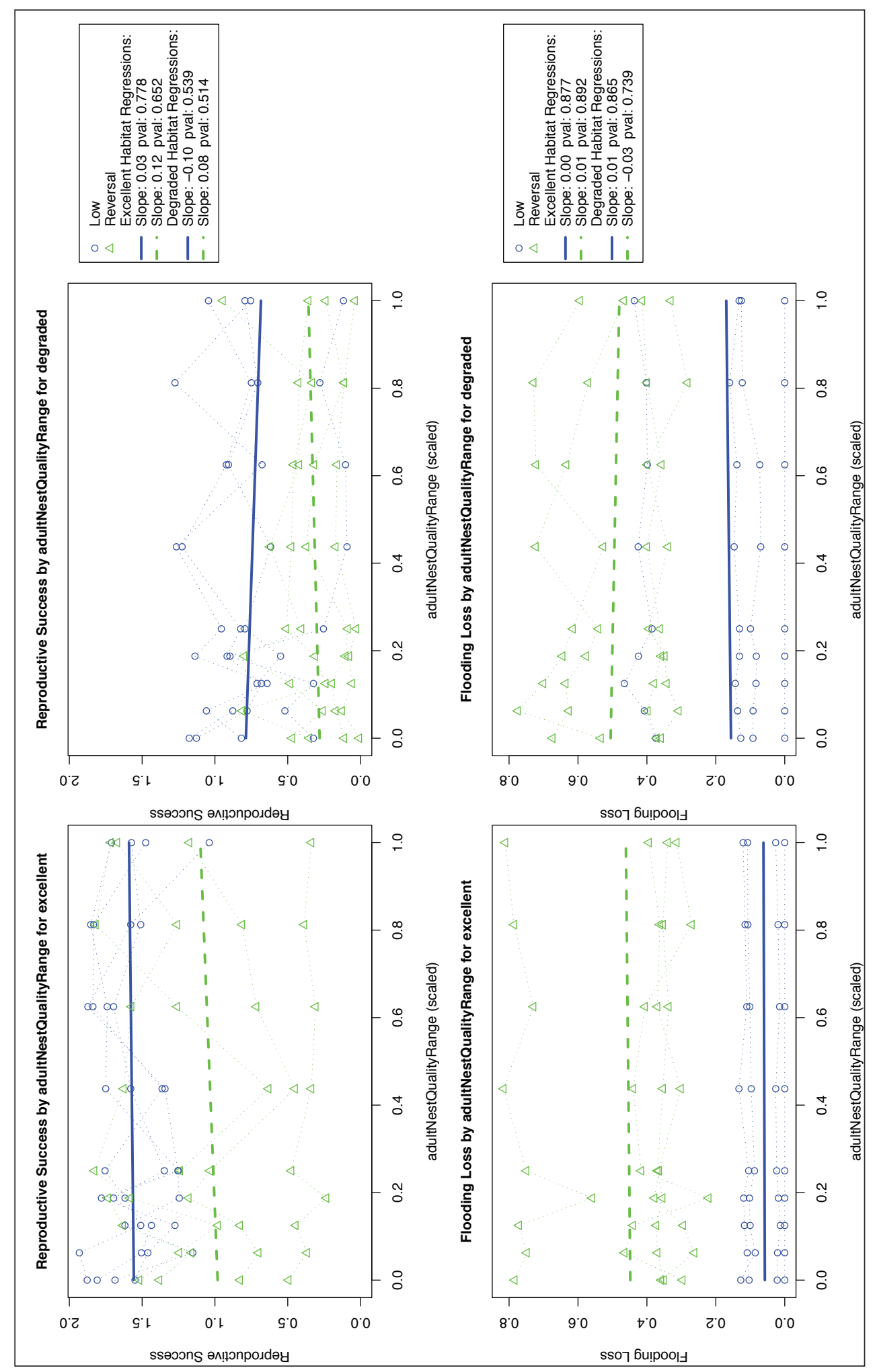




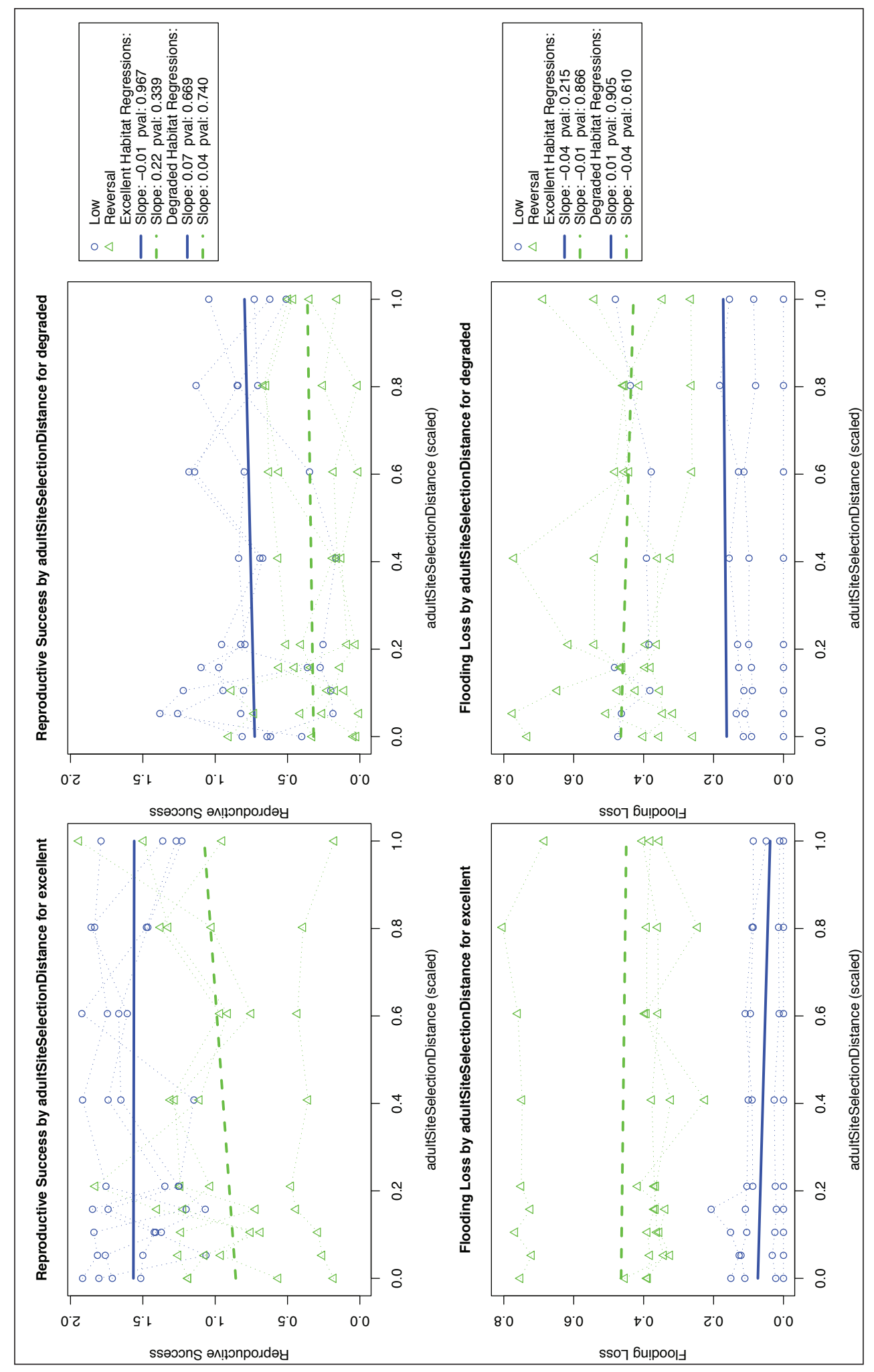




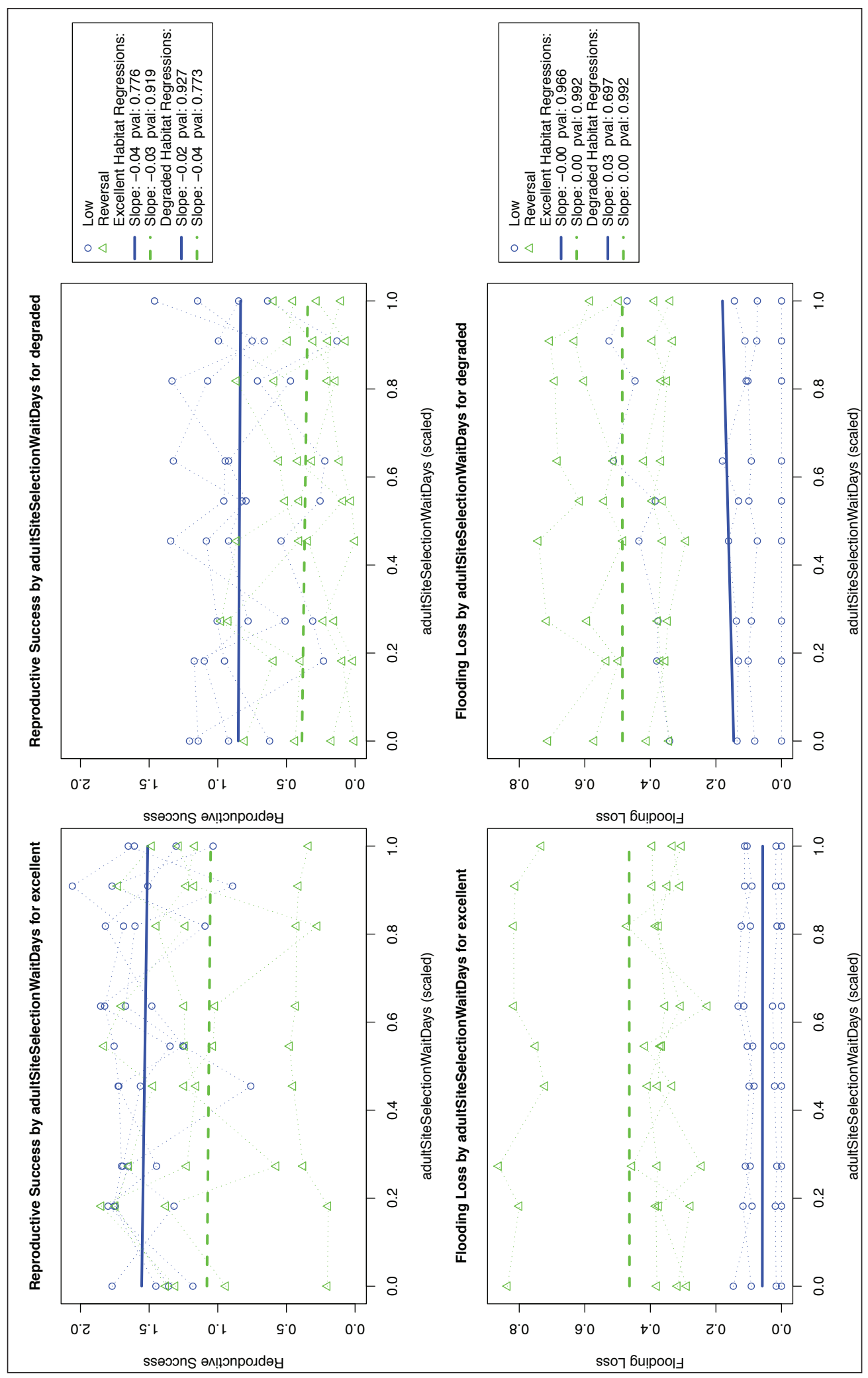




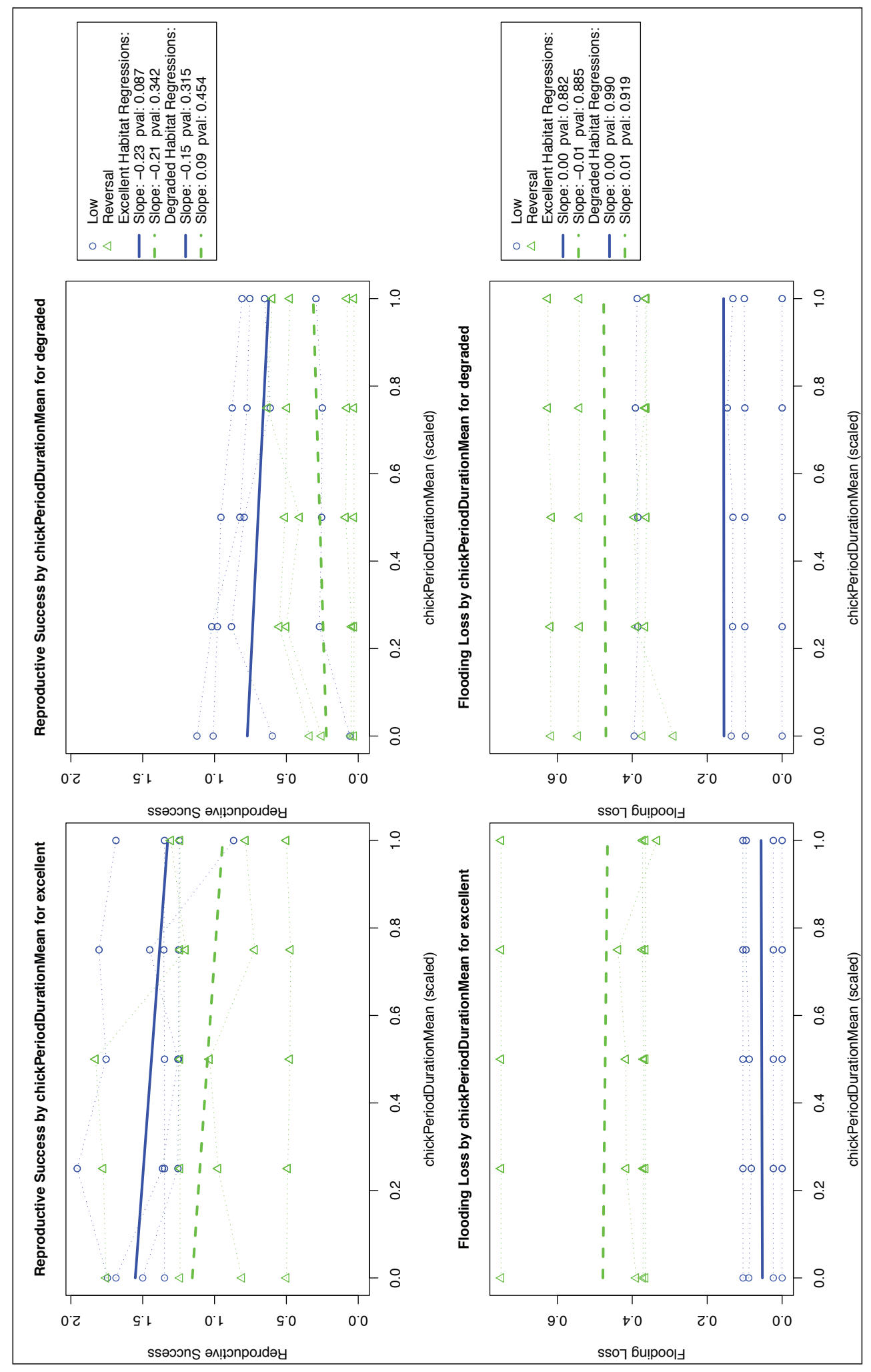




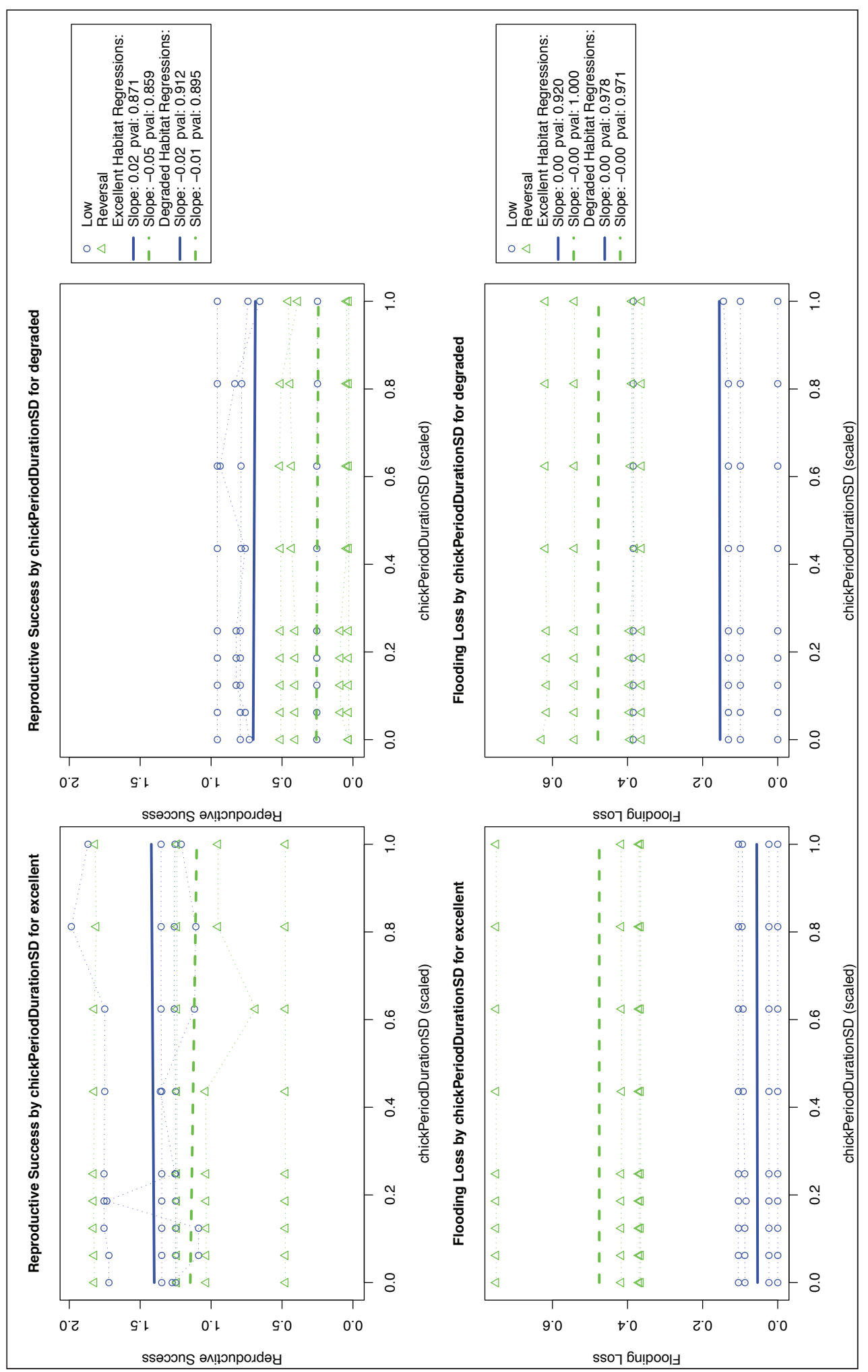




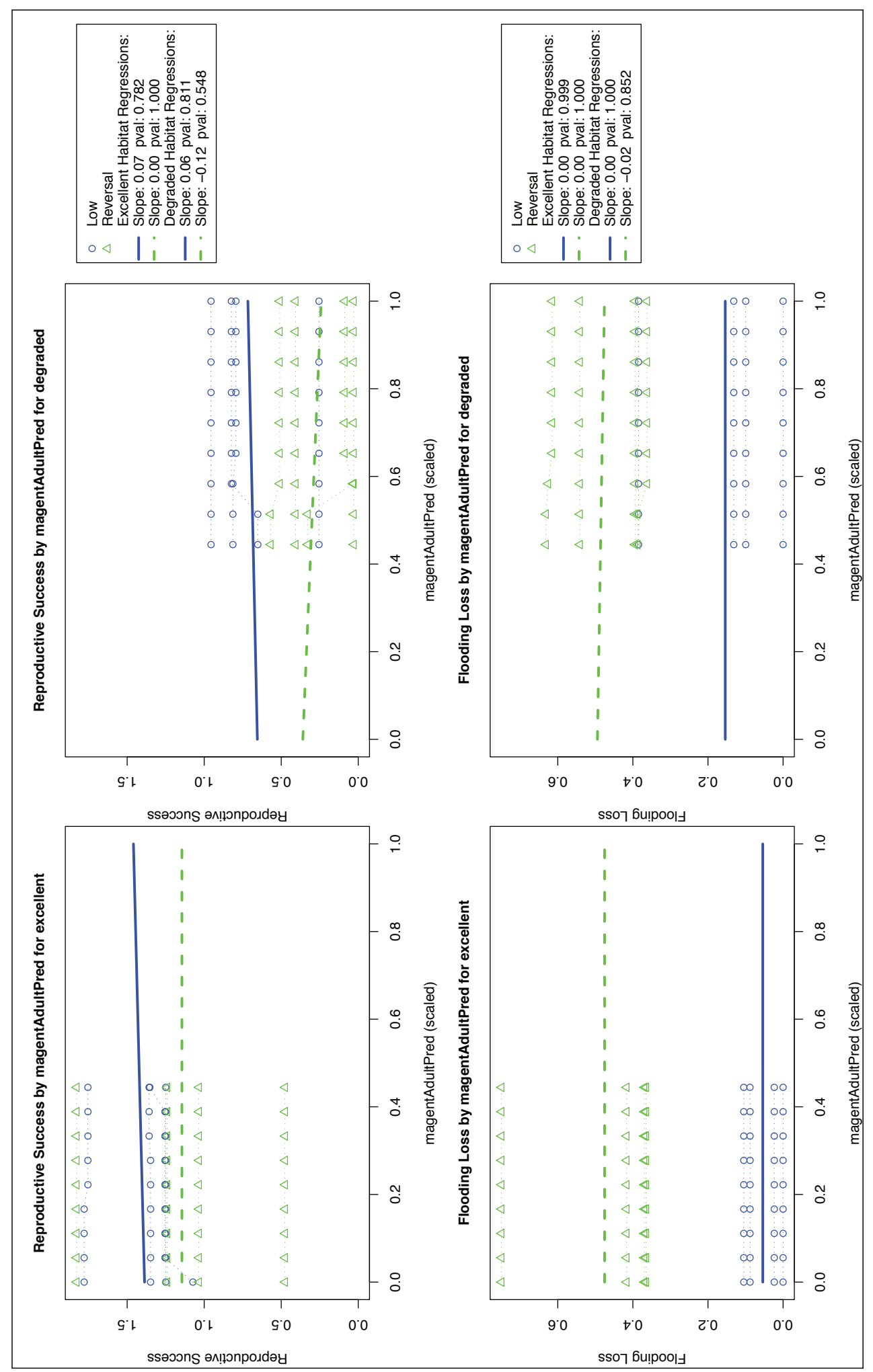




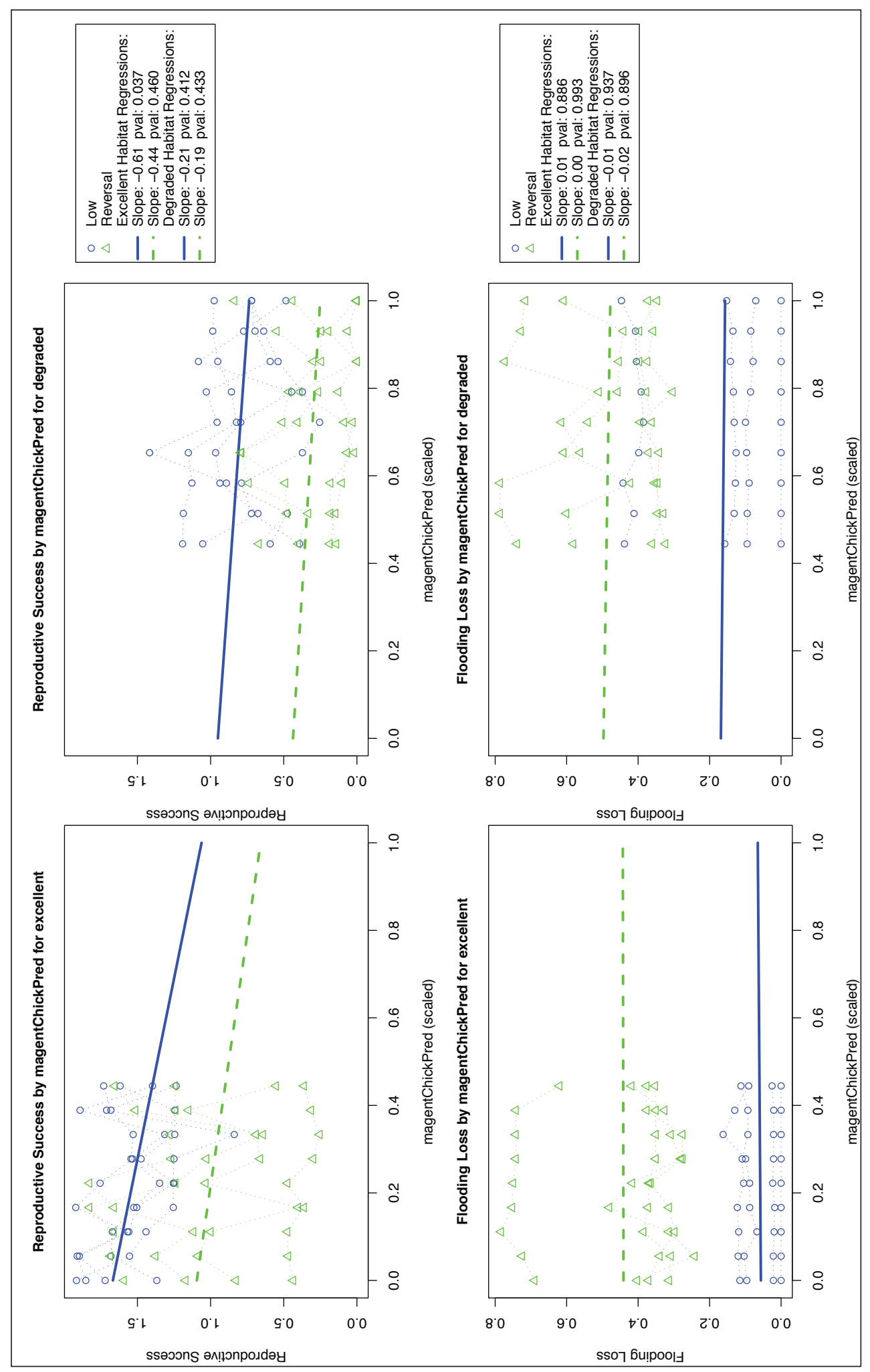




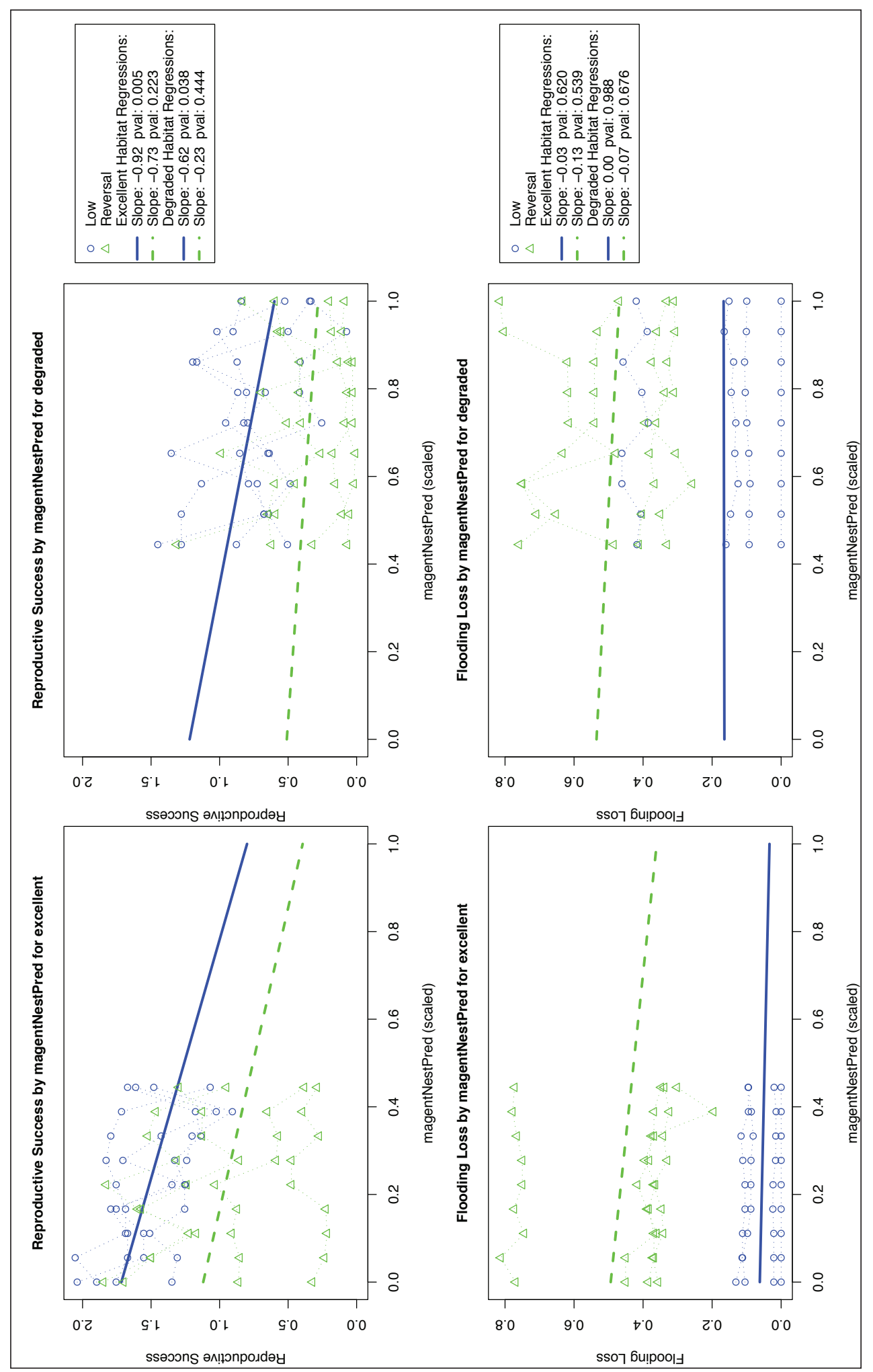




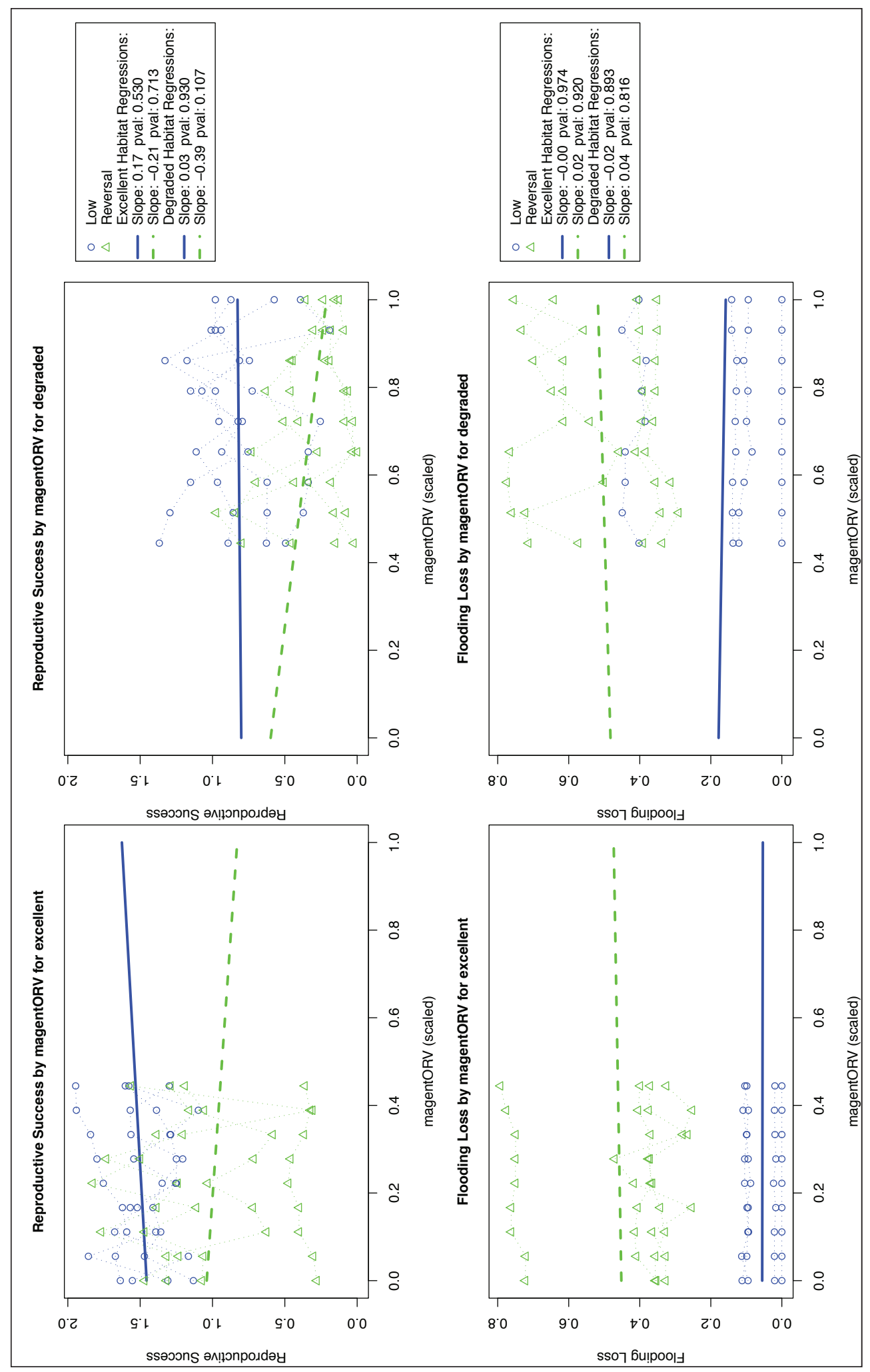




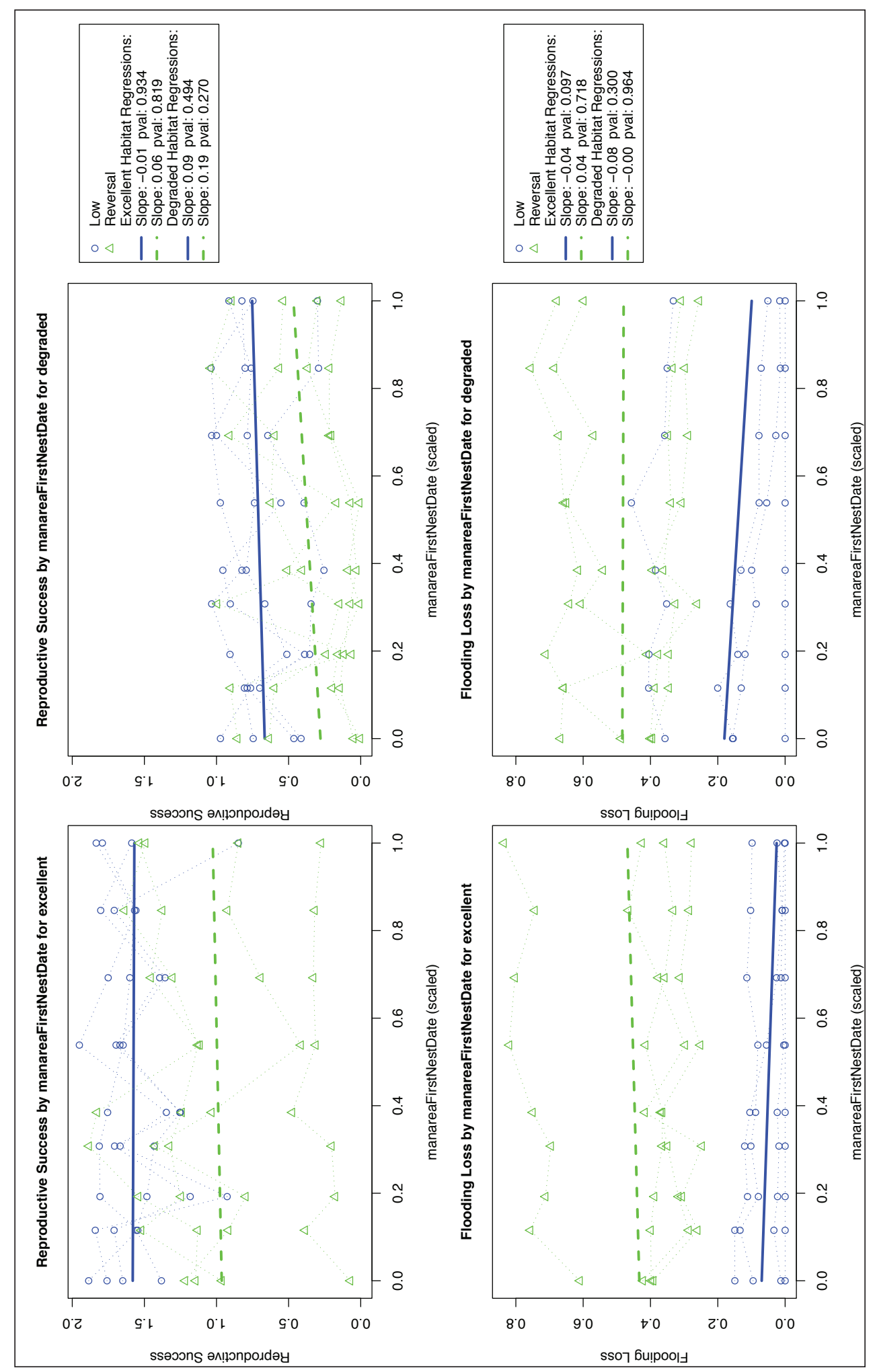




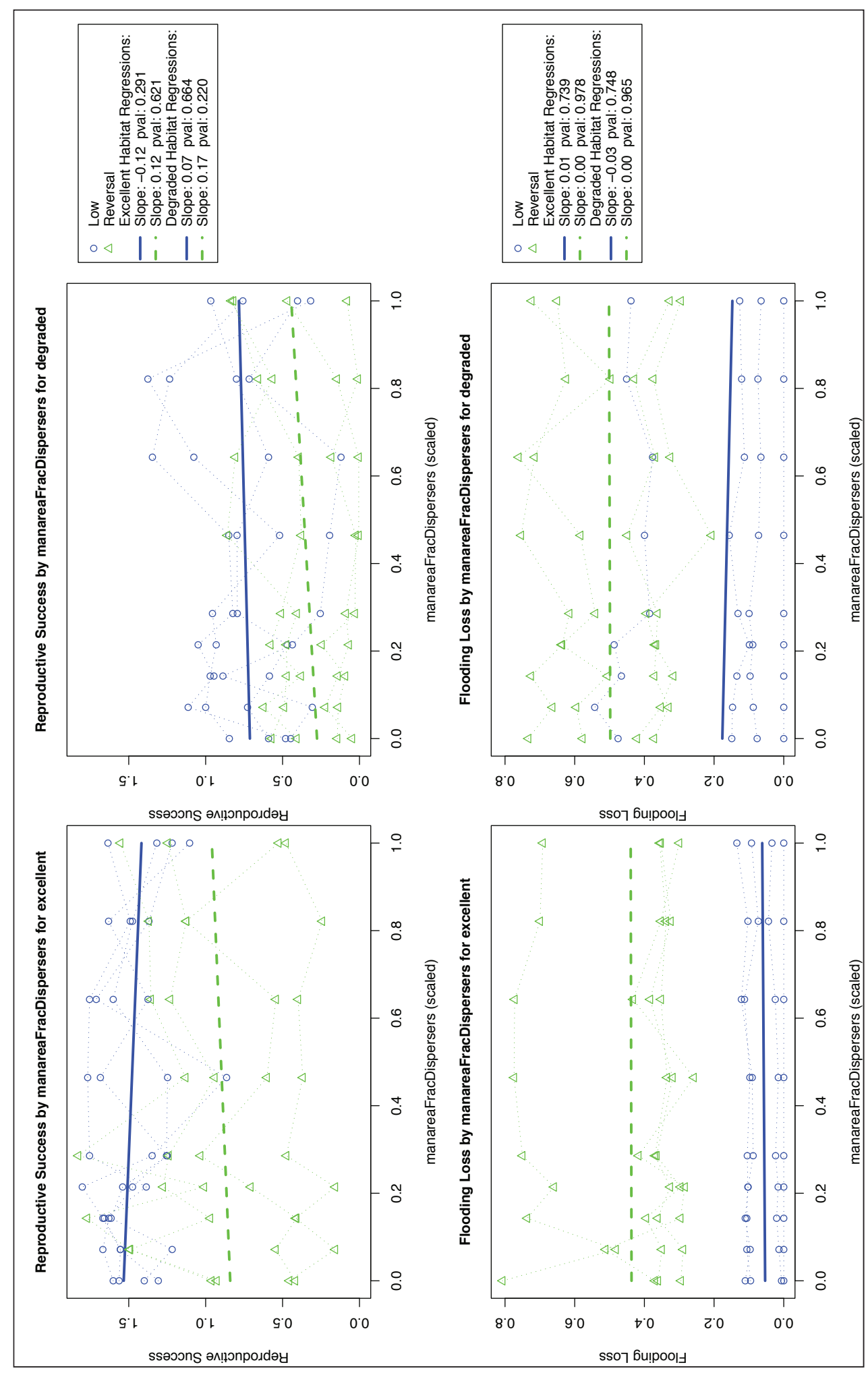




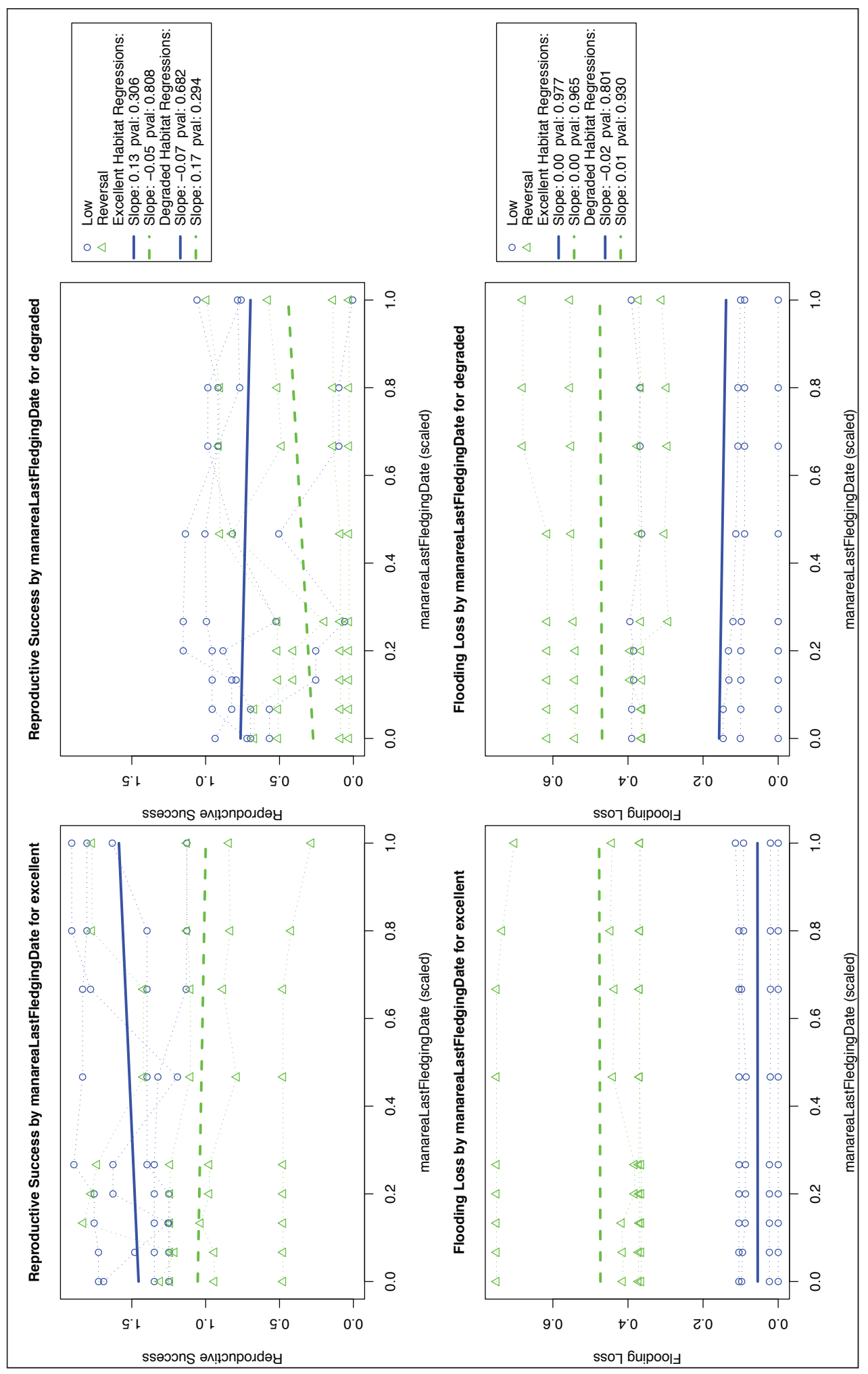




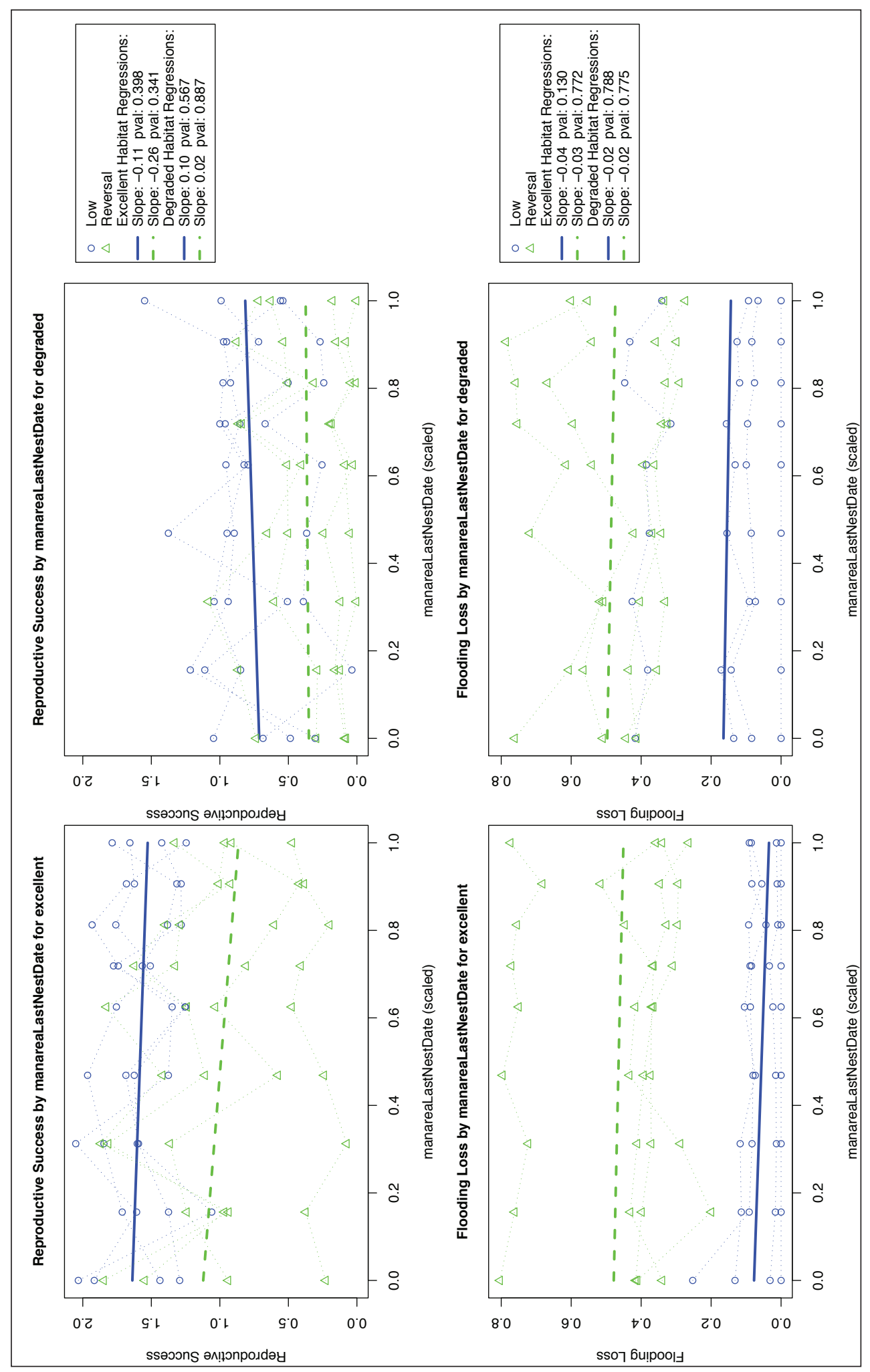




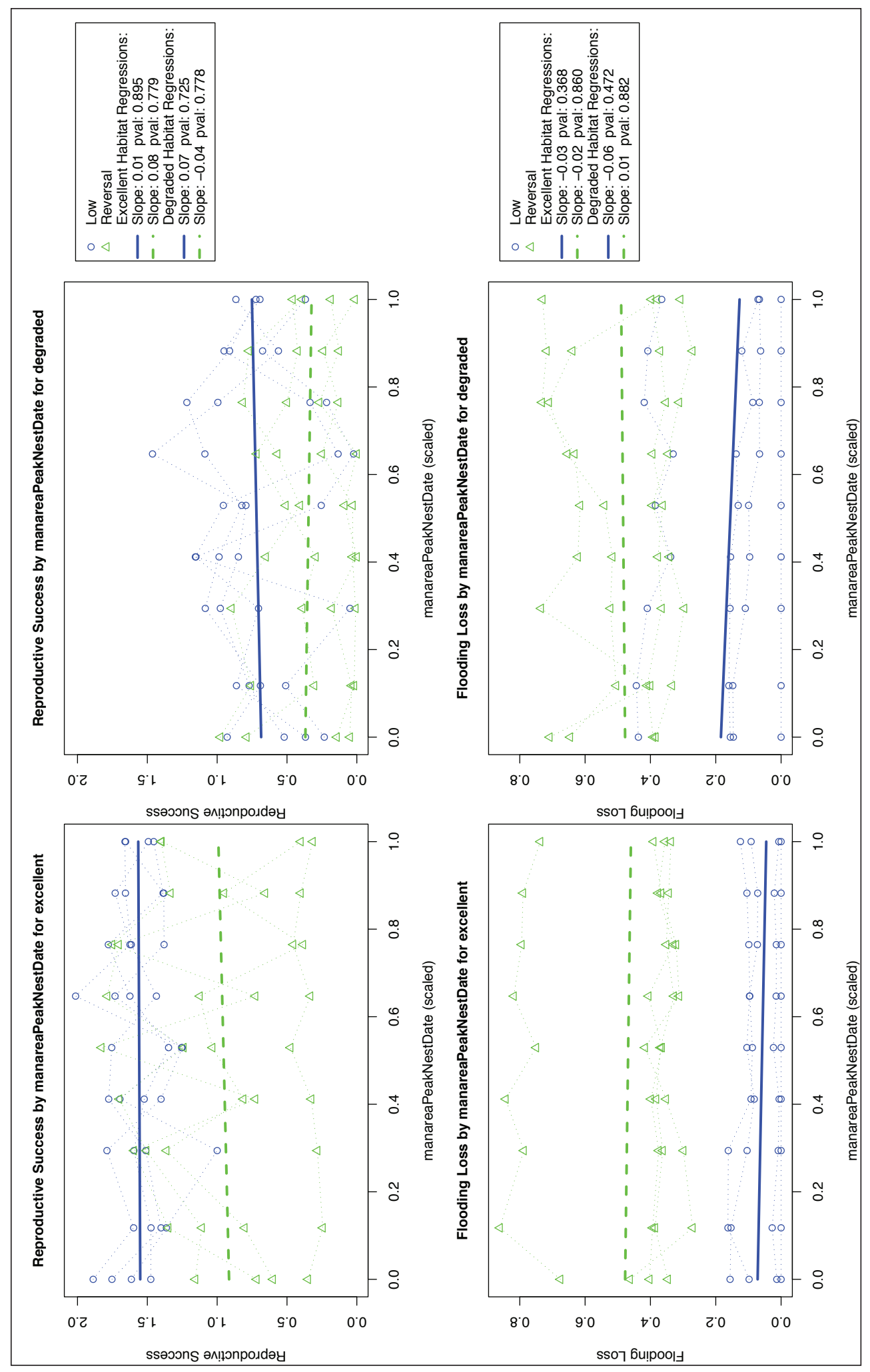




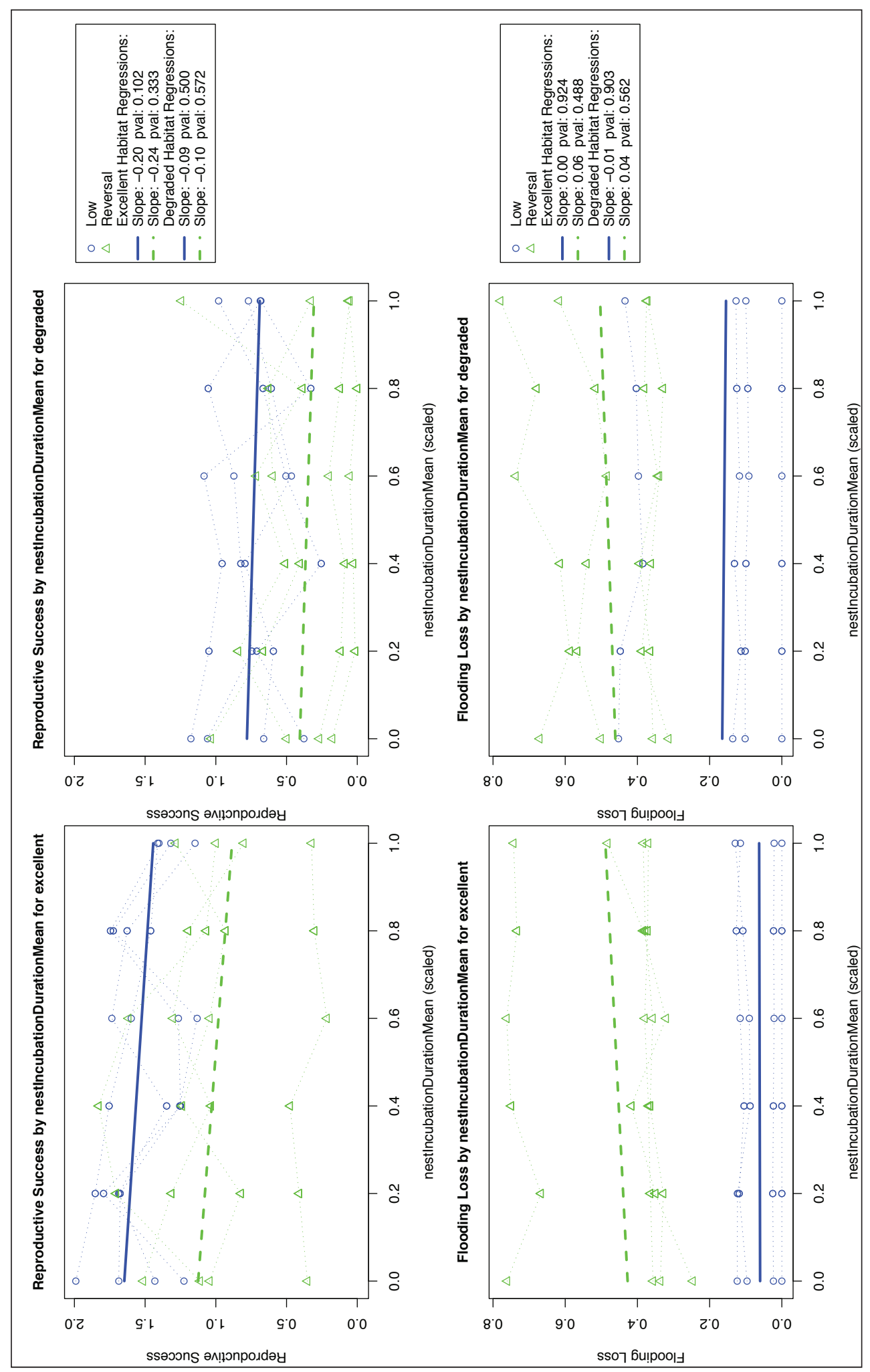




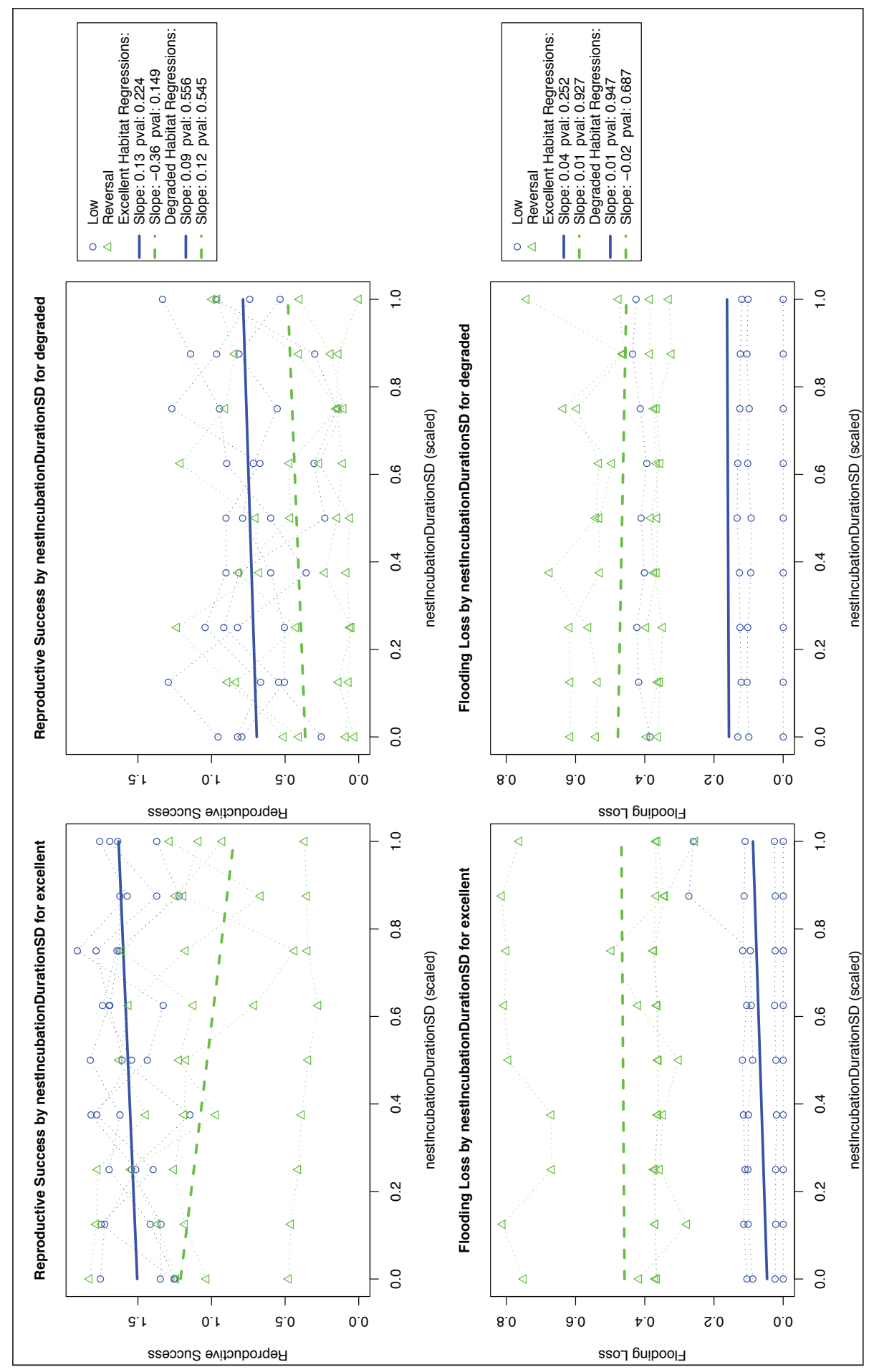




\section{Appendix F: Model Calibration}

\section{Introduction}

Calibration is the model development phase in which key parameters are adjusted to make the model "fit" a set of observed data. Calibration has the dual purposes of improving the model's accuracy and finding values for important but uncertain parameters. This appendix documents calibration of the Least Tern model.

The tern model was calibrated in two phases because it contains two distinctly different sets of processes affected by different parameters and behaviors. The first phase is site selection: how adult terns returning from migration select which sandbar site to attempt nesting at. Site selection is determined by traits and parameters for this decision. The second phase is calibration of reproductive success, the number of fledglings that the adults produce. Reproductive success can depend on site selection but is also strongly affected by processes, especially predation and disturbance, which happen at the nesting sites. Because reproductive success depends partly on site selection, it was calibrated after site selection. These two phases of calibration are documented separately below.

\section{Site selection calibration}

The important methods in model calibration are deciding which parameters to adjust, determining what criteria define acceptable calibration, and designing the simulation experiments to find good parameter values. The site selection calibration included an experiment to find good values for two parameters directly related to the colony site selection submodel (Appendix A) and an experiment to verify that site selection with the calibrated parameter values reproduces an important observed pattern: the use of newly available high-quality sandbars).

\section{Calibration parameters}

Calibration is ideally carried out by adjusting parameters that have strong effects on model results (so they do in fact "tune" the model) and high uncertainty (such that we have no better information than calibration upon which to base their value). Many of the model parameters are well defined by field data (e.g., parameters controlling clutch sizes, incubation 
periods). Some parameters based on field observations are less certain but still have well-known and relatively narrow ranges of reasonable values (e.g., arrival timing and last fledging date). Others are considerably more uncertain but at least were investigated during submodel development. An example is adminExpectedFledges in the site abandonment submodel, which is uncertain and not directly measurable, but found to have little effect on results (Appendix $\mathrm{F}^{1}$ ).

Two parameters controlling adult arrival are well suited for calibration. One is manareaFracDispersers, the fraction of adults that arrive at the management area at a random location instead of arriving near the site they occupied the previous year. The second is adultSiteSelectionDistance, the range over which an adult looks for the best available nesting site. These parameters are relatively uncertain, in part because the actual mechanisms determining how adults select sites are not well understood. These parameters are expected to have strong effects on patterns of nest site selection, which could affect fledgling production, especially during flood years.

\section{Calibration criteria}

Selecting calibration criteria involves identifying the observations that the model will be compared to, and determining exactly how model results will be compared to the observations to determine acceptable parameter values. For site selection, model results were compared to counts of tern nests made during field surveys; nest counts are considered more reliable than other measures of site use such as site-specific adult tern abundance.

The total number of nests at each sandbar site in the Keystone reach was estimated in 2005-6 and 2008 (US Army Engineer District, Tulsa, unpublished data). Data from 2005 provide input to initialize adult terns for 2006 (the site where the adults nested the previous year), and data from 2006 provided the same input for 2008 (2007 was not included because extreme flooding prevented field observations and nesting by terns). Hence, simulations could be compared to field data for 2006 and 2008. Only field observations from July were used because nest presence later in the summer could be dominated by hatching and mortality instead of by site selection.

\footnotetext{
1 Lettered appendices refer to appendices in Lott et al. (2012).
} 
It would be difficult and not very meaningful to try to calibrate the number of nests at each site, due to the stochastic nature of the model and the uncertainty in the nest counts. Instead, the model was calibrated against three measures of the distribution of colony sizes (number of nests at a site) within the Keystone reach. These measures are: (1) the percentage of sites that are occupied by a colony, (2) the percentage of all nests that are at the largest colony, and (3) the percentage of colonies that are small, defined as having 10 or fewer nests. Colonies with some adults but no nests were also included in the count of small colonies. These measures are defined as percentages so that the range of variation (and, hence, weight in the calibration) in all three are relatively similar.

The calibration fit was evaluated for each parameter combination as the sum of squared differences between model results and observations for the three measures, over all simulated water years and over all three measures of colony size. The sum of squared differences was used because it (a) does not let negative and positive differences offset each other, and (b) gives more weight to larger differences.

Colony sizes are evaluated from field observations as the total number of nests observed. The model results used in comparison are the total number of live nests at the site, not including any abandoned or destroyed by mortality agents. Simulated nests were counted if they hatched or were destroyed on the same day as the field survey the model was calibrated against.

The field observations used as calibration criteria are assembled in Table F1. These surveys counted the number of nests present at tern colonies. However, most of the surveys did not include the entire Keystone reach that was simulated; often, the Zink Island site (nearest RM: 523.4) or the sites upstream of it were not surveyed. Hence, Table F1 lists, in column 3, sites that were not surveyed and hence were excluded from the model results in the calibration analysis (the sites were simulated but their results ignored in analysis).

\section{Simulation experiments}

The calibration experiments for site selection simulated many combinations of manareaFracDispersers and adultSiteSelectionDistance and evaluated the calibration criterion for each. Details of the simulations are provided here. 
Table F1. Calibration criteria for site selection.

\begin{tabular}{|l|l|l|l|l|l|}
\hline Year & $\begin{array}{l}\text { Date } \\
\text { (Julian Date) }\end{array}$ & $\begin{array}{l}\text { Sites Not Surveyed } \\
\text { (nearest Corps RM) }\end{array}$ & $\begin{array}{l}\text { Sites } \\
\text { Occupied }\end{array}$ & $\begin{array}{l}\text { Nests at } \\
\text { Largest } \\
\text { Colony }\end{array}$ & $\begin{array}{l}\text { Small } \\
\text { Colonies }\end{array}$ \\
\hline $2006\left(1^{\text {st }}\right)$ & $7 / 7 / 2006(188)$ & 523.4 & $63 \%$ & $17 \%$ & $53 \%$ \\
\hline $2006\left(2^{\text {nd }}\right)$ & $7 / 19 / 2006(200)$ & - & $64 \%$ & $27 \%$ & $81 \%$ \\
\hline $2008\left(1^{\text {st }}\right)$ & $7 / 23 / 2008(205)$ & $524.5,529.6$ & $71 \%$ & $31 \%$ & $65 \%$ \\
\hline
\end{tabular}

Previous site distributions from 2005 were used for 2006 simulations; and previous sites from 2006 were used for 2008 , since there was no nesting in 2007.

Habitat input for the 2006 simulations was the 25-sandbar set synthesized to represent 2006 conditions, which were generally poor. Habitat input for the 2008 simulations was the set that represents the excellent habitat conditions after the 2007 flood. Six sandbars that appeared after 2008 were not included; 26 sandbars were simulated.

The ranges of parameter values considered covers the range of values considered feasible. For manareaFracDispersers the range of possible values is $0.0-1.0$, but values approaching 0.5 seem incompatible with the literature on "site fidelity." Hence values of 0.0, 0.05, 0.1, 0.2, and 0.4 were used.

The value of adultSiteSelectionDistance can be as low as zero, in which case all adult terns would wait for the number of days specified by parameter adultSiteSelectionWaitDays (10 days), then select the site nearest where they arrived. A high value of adultSiteSelectionDistance is $200,000 \mathrm{ft}$, about one half the total length of the Keystone reach; but analyses conducted to design the site selection trait indicated that only lower values produce realistic results. Values of $0 ; 5000 ; 10,000 ; 15,000 ; 20,000$; and 25,000 were used.

The response of the calibration variable, sum of squared differences (SSD) between simulated and observed numbers of nests, was calculated and analyzed separately for 2006 and 2008. The separate analyses allowed researchers to see whether the same parameter combinations fit results well before and after the 2007 flood improved habitat conditions. 


\section{Results}

The response of SSD for nest numbers to the two calibration parameters is illustrated via contour plots in Figure F1. These plots illustrate how the difference between model results and field observations varied with both calibration parameters; the best calibration is in regions of these plots where the contour value is lowest.
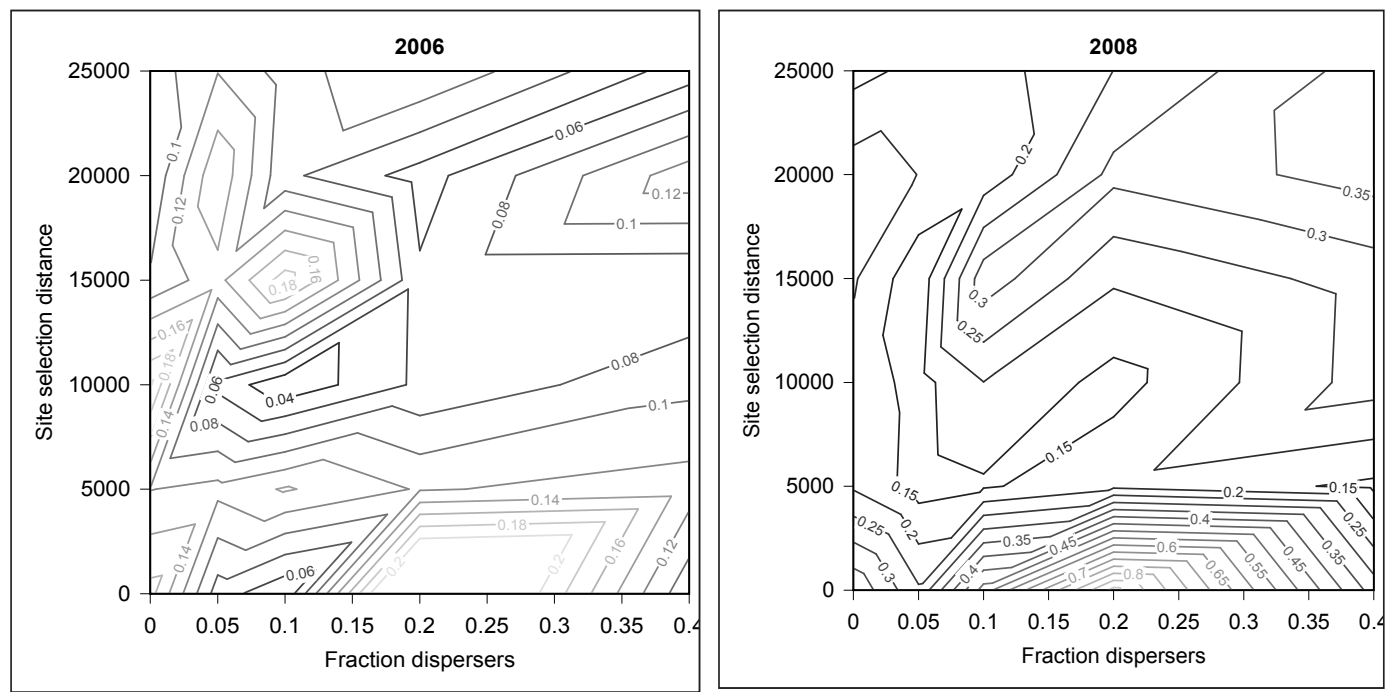

Figure F1. Site selection analysis results: response of SSD in nest abundance to parameters manareaFracDispersers and adultSiteSelectionDistance. Low values of SSD indicate the best fit between the model and field observations.

The best range of parameter combinations is around adultSiteSelectionDistance $=5000-12,000$ and manareaFracDispersers $=$ 0.05-0.2. The values adultSiteSelectionDistance $=10,000$ and manareaFracDispersers $=0.15$ appears to provide about the lowest SSD for both 2006 and 2008.

Detailed results are provided in Table F2 through Table F4. One conclusion from these detailed results is that the model reproduced site selection better under the degraded habitat conditions before 2007. In the 2008 simulations model terns occupied fewer sites than in the field observations; some sites were rarely or never selected. One potential (but not tested) explanation for the fewer sites used in 2008 is that terns were assumed to have used fewer sites in their previous year: the input for previous site use includes 19 sites for the 2008 habitat and 23 sites for the 2006 habitat; and the 2006 input includes sites distributed more evenly throughout the reach with fewer gaps. 
Table F2. Results for 2006 first survey.

\begin{tabular}{|c|c|c|c|c|c|c|c|c|}
\hline \multicolumn{2}{|c|}{ Parameter values } & \multicolumn{3}{|c|}{ Simulated } & \multicolumn{3}{|c|}{ Difference from observed } & \multirow{2}{*}{\begin{tabular}{|l} 
Result \\
SSD
\end{tabular}} \\
\hline $\begin{array}{l}\text { Fraction } \\
\text { dispersers }\end{array}$ & \begin{tabular}{|l|} 
Site sel \\
distance
\end{tabular} & \begin{tabular}{|l|} 
Sites \\
occupied
\end{tabular} & $\begin{array}{l}\text { Largest } \\
\text { colony }\end{array}$ & \begin{tabular}{|l|} 
Small \\
sites
\end{tabular} & \begin{tabular}{|l|} 
Sites \\
occupied
\end{tabular} & \begin{tabular}{|l} 
Largest \\
colony
\end{tabular} & \begin{tabular}{|l|} 
Small \\
sites
\end{tabular} & \\
\hline 0 & 0 & $50 \%$ & $17 \%$ & $75 \%$ & $13 \%$ & $-1 \%$ & $-22 \%$ & $6 \%$ \\
\hline 0 & 5000 & $67 \%$ & $20 \%$ & $75 \%$ & $-4 \%$ & $-3 \%$ & $-22 \%$ & $5 \%$ \\
\hline 0 & 10000 & $54 \%$ & $19 \%$ & $92 \%$ & $8 \%$ & $-2 \%$ & $-39 \%$ & $16 \%$ \\
\hline 0 & 15000 & $67 \%$ & $14 \%$ & $81 \%$ & $-4 \%$ & $3 \%$ & $-28 \%$ & $8 \%$ \\
\hline 0 & 20000 & $63 \%$ & $14 \%$ & $80 \%$ & $0 \%$ & $2 \%$ & $-27 \%$ & $7 \%$ \\
\hline 0 & 25000 & $54 \%$ & $18 \%$ & $62 \%$ & $8 \%$ & $-2 \%$ & $-8 \%$ & $1 \%$ \\
\hline 0.05 & 0 & $67 \%$ & $23 \%$ & $75 \%$ & $-4 \%$ & $-7 \%$ & $-22 \%$ & $5 \%$ \\
\hline 0.05 & 5000 & $46 \%$ & $19 \%$ & $82 \%$ & $17 \%$ & $-3 \%$ & $-28 \%$ & $11 \%$ \\
\hline 0.05 & 10000 & $63 \%$ & $17 \%$ & $73 \%$ & $0 \%$ & $-1 \%$ & $-20 \%$ & $4 \%$ \\
\hline 0.05 & 15000 & $58 \%$ & $19 \%$ & $86 \%$ & $4 \%$ & $-2 \%$ & $-32 \%$ & $11 \%$ \\
\hline 0.05 & 20000 & $63 \%$ & $33 \%$ & $87 \%$ & $0 \%$ & $-17 \%$ & $-33 \%$ & $14 \%$ \\
\hline 0.05 & 25000 & $63 \%$ & $26 \%$ & $73 \%$ & $0 \%$ & $-9 \%$ & $-20 \%$ & $5 \%$ \\
\hline 0.1 & 0 & $63 \%$ & $18 \%$ & $60 \%$ & $0 \%$ & $-1 \%$ & $-7 \%$ & $0 \%$ \\
\hline 0.1 & 5000 & $54 \%$ & $24 \%$ & $85 \%$ & $8 \%$ & $-7 \%$ & $-31 \%$ & $11 \%$ \\
\hline 0.1 & 10000 & $54 \%$ & $21 \%$ & $62 \%$ & $8 \%$ & $-5 \%$ & $-8 \%$ & $2 \%$ \\
\hline 0.1 & 15000 & $46 \%$ & $39 \%$ & $82 \%$ & $17 \%$ & $-22 \%$ & $-28 \%$ & $16 \%$ \\
\hline 0.1 & 20000 & $67 \%$ & $19 \%$ & $81 \%$ & $-4 \%$ & $-2 \%$ & $-28 \%$ & $8 \%$ \\
\hline 0.1 & 25000 & $58 \%$ & $26 \%$ & $71 \%$ & $4 \%$ & $-9 \%$ & $-18 \%$ & $4 \%$ \\
\hline 0.2 & 0 & $63 \%$ & $18 \%$ & $80 \%$ & $0 \%$ & $-2 \%$ & $-27 \%$ & $7 \%$ \\
\hline 0.2 & 5000 & $71 \%$ & $14 \%$ & $82 \%$ & $-8 \%$ & $3 \%$ & $-29 \%$ & $9 \%$ \\
\hline 0.2 & 10000 & $58 \%$ & $20 \%$ & $71 \%$ & $4 \%$ & $-4 \%$ & $-18 \%$ & $4 \%$ \\
\hline 0.2 & 15000 & $54 \%$ & $17 \%$ & $62 \%$ & $8 \%$ & $0 \%$ & $-8 \%$ & $1 \%$ \\
\hline 0.2 & 20000 & $58 \%$ & $20 \%$ & $71 \%$ & $4 \%$ & $-4 \%$ & $-18 \%$ & $4 \%$ \\
\hline 0.2 & 25000 & $63 \%$ & $26 \%$ & $67 \%$ & $0 \%$ & $-9 \%$ & $-13 \%$ & $3 \%$ \\
\hline 0.4 & 0 & $58 \%$ & $20 \%$ & $79 \%$ & $4 \%$ & $-3 \%$ & $-25 \%$ & $7 \%$ \\
\hline 0.4 & 5000 & $54 \%$ & $24 \%$ & $77 \%$ & $8 \%$ & $-7 \%$ & $-24 \%$ & $7 \%$ \\
\hline 0.4 & 10000 & $54 \%$ & $21 \%$ & $54 \%$ & $8 \%$ & $-4 \%$ & $-1 \%$ & $1 \%$ \\
\hline 0.4 & 15000 & $67 \%$ & $16 \%$ & $75 \%$ & $-4 \%$ & $1 \%$ & $-22 \%$ & $5 \%$ \\
\hline 0.4 & 20000 & $46 \%$ & $28 \%$ & $82 \%$ & $17 \%$ & $-11 \%$ & $-28 \%$ & $12 \%$ \\
\hline 0.4 & 25000 & $50 \%$ & $22 \%$ & $58 \%$ & $13 \%$ & $-5 \%$ & $-5 \%$ & $2 \%$ \\
\hline
\end{tabular}


Table F3. Results for 2006 second survey.

\begin{tabular}{|c|c|c|c|c|c|c|c|c|}
\hline \multicolumn{2}{|c|}{ Parameter values } & \multicolumn{3}{|c|}{ Simulated } & \multicolumn{3}{|c|}{ Difference from observed } & \multirow{2}{*}{\begin{tabular}{|l} 
Result \\
SSD
\end{tabular}} \\
\hline $\begin{array}{l}\text { Fraction } \\
\text { dispersers }\end{array}$ & $\begin{array}{l}\text { Site sel } \\
\text { distance }\end{array}$ & \begin{tabular}{|l} 
Sites \\
occupied
\end{tabular} & $\begin{array}{l}\text { Largest } \\
\text { colony }\end{array}$ & $\begin{array}{l}\text { Small } \\
\text { sites }\end{array}$ & $\begin{array}{l}\text { Sites } \\
\text { occupied }\end{array}$ & $\begin{array}{l}\text { Largest } \\
\text { colony }\end{array}$ & $\begin{array}{l}\text { Small } \\
\text { sites }\end{array}$ & \\
\hline 0 & 0 & $40 \%$ & $31 \%$ & $60 \%$ & $24 \%$ & $-4 \%$ & $21 \%$ & $10 \%$ \\
\hline 0 & 5000 & $40 \%$ & $38 \%$ & $80 \%$ & $24 \%$ & $-11 \%$ & $1 \%$ & $7 \%$ \\
\hline 0 & 10000 & $44 \%$ & $33 \%$ & $82 \%$ & $20 \%$ & $-6 \%$ & $-1 \%$ & $4 \%$ \\
\hline 0 & 15000 & $64 \%$ & $14 \%$ & $75 \%$ & $0 \%$ & $13 \%$ & $6 \%$ & $2 \%$ \\
\hline 0 & 20000 & $60 \%$ & $17 \%$ & $80 \%$ & $4 \%$ & $10 \%$ & $1 \%$ & $1 \%$ \\
\hline 0 & 25000 & $44 \%$ & $21 \%$ & $64 \%$ & $20 \%$ & $6 \%$ & $18 \%$ & $7 \%$ \\
\hline 0.05 & 0 & $56 \%$ & $18 \%$ & $86 \%$ & $8 \%$ & $9 \%$ & $-4 \%$ & $2 \%$ \\
\hline 0.05 & 5000 & $52 \%$ & $29 \%$ & $77 \%$ & $12 \%$ & $-2 \%$ & $4 \%$ & $2 \%$ \\
\hline 0.05 & 10000 & $56 \%$ & $19 \%$ & $79 \%$ & $8 \%$ & $8 \%$ & $3 \%$ & $1 \%$ \\
\hline 0.05 & 15000 & $52 \%$ & $27 \%$ & $92 \%$ & $12 \%$ & $0 \%$ & $-11 \%$ & $3 \%$ \\
\hline 0.05 & 20000 & $64 \%$ & $31 \%$ & $94 \%$ & $0 \%$ & $-4 \%$ & $-13 \%$ & $2 \%$ \\
\hline 0.05 & 25000 & $44 \%$ & $28 \%$ & $64 \%$ & $20 \%$ & $-1 \%$ & $18 \%$ & $7 \%$ \\
\hline 0.1 & 0 & $48 \%$ & $18 \%$ & $75 \%$ & $16 \%$ & $9 \%$ & $6 \%$ & $4 \%$ \\
\hline 0.1 & 5000 & $48 \%$ & $35 \%$ & $83 \%$ & $16 \%$ & $-8 \%$ & $-2 \%$ & $3 \%$ \\
\hline 0.1 & 10000 & $56 \%$ & $28 \%$ & $86 \%$ & $8 \%$ & $-1 \%$ & $-4 \%$ & $1 \%$ \\
\hline 0.1 & 15000 & $48 \%$ & $19 \%$ & $83 \%$ & $16 \%$ & $8 \%$ & $-2 \%$ & $3 \%$ \\
\hline 0.1 & 20000 & $60 \%$ & $28 \%$ & $87 \%$ & $4 \%$ & $0 \%$ & $-5 \%$ & $0 \%$ \\
\hline 0.1 & 25000 & $44 \%$ & $23 \%$ & $73 \%$ & $20 \%$ & $4 \%$ & $9 \%$ & $5 \%$ \\
\hline 0.2 & 0 & $36 \%$ & $19 \%$ & $44 \%$ & $28 \%$ & $8 \%$ & $37 \%$ & $22 \%$ \\
\hline 0.2 & 5000 & $48 \%$ & $28 \%$ & $83 \%$ & $16 \%$ & $0 \%$ & $-2 \%$ & $3 \%$ \\
\hline 0.2 & 10000 & $56 \%$ & $16 \%$ & $71 \%$ & $8 \%$ & $11 \%$ & $10 \%$ & $3 \%$ \\
\hline 0.2 & 15000 & $48 \%$ & $32 \%$ & $67 \%$ & $16 \%$ & $-5 \%$ & $15 \%$ & $5 \%$ \\
\hline 0.2 & 20000 & $52 \%$ & $28 \%$ & $85 \%$ & $12 \%$ & $-1 \%$ & $-3 \%$ & $2 \%$ \\
\hline 0.2 & 25000 & $44 \%$ & $13 \%$ & $100 \%$ & $20 \%$ & $14 \%$ & $-19 \%$ & $9 \%$ \\
\hline 0.4 & 0 & $52 \%$ & $23 \%$ & $77 \%$ & $12 \%$ & $4 \%$ & $4 \%$ & $2 \%$ \\
\hline 0.4 & 5000 & $44 \%$ & $42 \%$ & $82 \%$ & $20 \%$ & $-15 \%$ & $-1 \%$ & $6 \%$ \\
\hline 0.4 & 10000 & $44 \%$ & $17 \%$ & $100 \%$ & $20 \%$ & $10 \%$ & $-19 \%$ & $9 \%$ \\
\hline 0.4 & 15000 & $64 \%$ & $17 \%$ & $88 \%$ & $0 \%$ & $10 \%$ & $-6 \%$ & $1 \%$ \\
\hline 0.4 & 20000 & $56 \%$ & $22 \%$ & $79 \%$ & $8 \%$ & $5 \%$ & $3 \%$ & $1 \%$ \\
\hline 0.4 & 25000 & $60 \%$ & $16 \%$ & $93 \%$ & $4 \%$ & $11 \%$ & $-12 \%$ & $3 \%$ \\
\hline
\end{tabular}


Table F4. Results for 2008 first survey.

\begin{tabular}{|c|c|c|c|c|c|c|c|c|}
\hline \multicolumn{2}{|c|}{ Parameter values } & \multicolumn{3}{|l|}{ Simulated } & \multicolumn{3}{|c|}{ Difference from observed } & \multirow{2}{*}{$\begin{array}{l}\text { Result } \\
\text { SSD }\end{array}$} \\
\hline $\begin{array}{l}\text { Fraction } \\
\text { dispersers }\end{array}$ & \begin{tabular}{|l|} 
Site sel \\
distance
\end{tabular} & \begin{tabular}{|l} 
Sites \\
occupied
\end{tabular} & \begin{tabular}{|l|} 
Largest \\
colony
\end{tabular} & \begin{tabular}{|l|} 
Small \\
sites
\end{tabular} & $\begin{array}{l}\text { Sites } \\
\text { occupied }\end{array}$ & $\begin{array}{l}\text { Largest } \\
\text { colony }\end{array}$ & \begin{tabular}{|l|} 
Small \\
sites
\end{tabular} & \\
\hline 0 & 0 & $19 \%$ & $28 \%$ & $100 \%$ & $52 \%$ & $3 \%$ & $-35 \%$ & $39 \%$ \\
\hline 0 & 5000 & $31 \%$ & $42 \%$ & $50 \%$ & $40 \%$ & $-10 \%$ & $15 \%$ & $19 \%$ \\
\hline 0 & 10000 & $31 \%$ & $41 \%$ & $75 \%$ & $40 \%$ & $-9 \%$ & $-10 \%$ & $18 \%$ \\
\hline 0 & 15000 & $35 \%$ & $44 \%$ & $89 \%$ & $36 \%$ & $-13 \%$ & $-24 \%$ & $21 \%$ \\
\hline 0 & 20000 & $31 \%$ & $55 \%$ & $75 \%$ & $40 \%$ & $-23 \%$ & $-10 \%$ & $23 \%$ \\
\hline 0 & 25000 & $35 \%$ & $27 \%$ & $67 \%$ & $36 \%$ & $4 \%$ & $-2 \%$ & $13 \%$ \\
\hline 0.05 & 0 & $27 \%$ & $46 \%$ & $86 \%$ & $44 \%$ & $-14 \%$ & $-21 \%$ & $26 \%$ \\
\hline 0.05 & 5000 & $38 \%$ & $34 \%$ & $80 \%$ & $32 \%$ & $-2 \%$ & $-15 \%$ & $13 \%$ \\
\hline 0.05 & 10000 & $35 \%$ & $34 \%$ & $67 \%$ & $36 \%$ & $-3 \%$ & $-2 \%$ & $13 \%$ \\
\hline 0.05 & 15000 & $38 \%$ & $40 \%$ & $70 \%$ & $32 \%$ & $-8 \%$ & $-5 \%$ & $11 \%$ \\
\hline 0.05 & 20000 & $27 \%$ & $34 \%$ & $57 \%$ & $44 \%$ & $-3 \%$ & $8 \%$ & $20 \%$ \\
\hline 0.05 & 25000 & $31 \%$ & $37 \%$ & $63 \%$ & $40 \%$ & $-6 \%$ & $2 \%$ & $16 \%$ \\
\hline 0.1 & 0 & $15 \%$ & $75 \%$ & $50 \%$ & $55 \%$ & $-44 \%$ & $15 \%$ & $52 \%$ \\
\hline 0.1 & 5000 & $35 \%$ & $25 \%$ & $56 \%$ & $36 \%$ & $6 \%$ & $9 \%$ & $14 \%$ \\
\hline 0.1 & 10000 & $27 \%$ & $34 \%$ & $57 \%$ & $44 \%$ & $-3 \%$ & $8 \%$ & $20 \%$ \\
\hline 0.1 & 15000 & $23 \%$ & $37 \%$ & $33 \%$ & $48 \%$ & $-6 \%$ & $31 \%$ & $33 \%$ \\
\hline 0.1 & 20000 & $31 \%$ & $40 \%$ & $63 \%$ & $40 \%$ & $-8 \%$ & $2 \%$ & $17 \%$ \\
\hline 0.1 & 25000 & $31 \%$ & $39 \%$ & $75 \%$ & $40 \%$ & $-7 \%$ & $-10 \%$ & $18 \%$ \\
\hline 0.2 & 0 & $8 \%$ & $63 \%$ & $0 \%$ & $63 \%$ & $-32 \%$ & $65 \%$ & $92 \%$ \\
\hline 0.2 & 5000 & $31 \%$ & $44 \%$ & $75 \%$ & $40 \%$ & $-12 \%$ & $-10 \%$ & $19 \%$ \\
\hline 0.2 & 10000 & $38 \%$ & $38 \%$ & $80 \%$ & $32 \%$ & $-6 \%$ & $-15 \%$ & $13 \%$ \\
\hline 0.2 & 15000 & $35 \%$ & $45 \%$ & $89 \%$ & $36 \%$ & $-13 \%$ & $-24 \%$ & $21 \%$ \\
\hline 0.2 & 20000 & $27 \%$ & $59 \%$ & $86 \%$ & $44 \%$ & $-28 \%$ & $-21 \%$ & $31 \%$ \\
\hline 0.2 & 25000 & $27 \%$ & $21 \%$ & $43 \%$ & $44 \%$ & $10 \%$ & $22 \%$ & $25 \%$ \\
\hline 0.4 & 0 & $19 \%$ & $34 \%$ & $40 \%$ & $52 \%$ & $-3 \%$ & $25 \%$ & $33 \%$ \\
\hline 0.4 & 5000 & $35 \%$ & $30 \%$ & $56 \%$ & $36 \%$ & $1 \%$ & $9 \%$ & $14 \%$ \\
\hline 0.4 & 10000 & $19 \%$ & $38 \%$ & $60 \%$ & $52 \%$ & $-6 \%$ & $5 \%$ & $27 \%$ \\
\hline 0.4 & 15000 & $31 \%$ & $55 \%$ & $88 \%$ & $40 \%$ & $-24 \%$ & $-23 \%$ & $27 \%$ \\
\hline 0.4 & 20000 & $19 \%$ & $52 \%$ & $40 \%$ & $52 \%$ & $-21 \%$ & $25 \%$ & $37 \%$ \\
\hline 0.4 & 25000 & $15 \%$ & $52 \%$ & $50 \%$ & $55 \%$ & $-21 \%$ & $15 \%$ & $37 \%$ \\
\hline
\end{tabular}




\section{Effects of calibration on selection of new sandbars}

One characteristic of Least Tern site selection is that terns can rapidly find and use new high-quality sites. Since this pattern was not tested during the initial development of the colony site selection submodel (Appendix A), it is evaluated briefly here, since results were expected to be affected by both of the parameters varied during this calibration exercise. How the site selection calibration affects this ability in the model was evaluated by rerunning the 2006 calibration simulations with two additional high-quality nest sites that represent habitat restoration projects. The two sites were chosen arbitrarily from among the "SAR" sites developed for this kind of purpose; they are: SAR 503.0 and SAR 518.0 (Main report, Chapter 3). These sites were not included as locations where some of the terns had nested the previous year. The effects of calibration parameters were evaluated by plotting how many nests were built on these two new sandbars as adultSiteSelectionDistance and manareaFracDispersers varied (Figure F2).

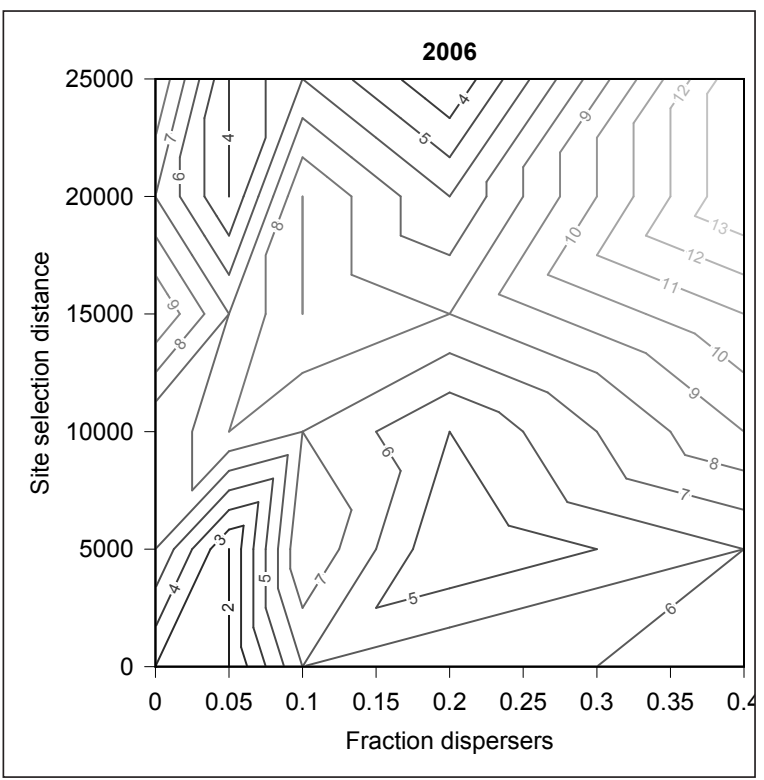

Figure F2. Contour plot of the total number of nests created on two new sandbars, in an experiment otherwise identical to the 2006 site selection calibration experiment.

As expected, nesting on the new sandbars increased with both of these calibration variables. At the parameter combination identified as best reproducing site selection observations (adultSiteSelectionDistance $=$ 10,000 and manareaFracDispersers $=0.15$ ) the number of nests on new 
sandbars was about half the maximum (6-7, compared to a maximum of 13). This experiment confirmed that adult terns do find and occupy good new sites with the calibrated parameter values.

\section{Reproductive success calibration}

\section{Calibration parameters}

Reproductive success is controlled by mortality after nesting, which results from flooding and predation and disturbance. Flooding mortality is relatively simple and well-defined, whereas predation and disturbance mortality are difficult to predict and observe. The parameters controlling mortality agents are especially appropriate for calibration, for several reasons. These parameters are especially uncertain because field observations of actual mortality events are rare, and predation and human disturbance mortality are almost certainly highly variable (Thompson et al. 1997). These parameters are also uncertain because the effects of several kinds of predators are represented by one set of parameters; all nest predators are modeled via one set of nest predation parameters, etc. (Lott et al. 2012). The most uncertain of these parameters are the discovery rate parameters, which control how frequently mortality agents appear. The other mortality parameters, which control how long mortality agents stay at a site and how many terns they kill, are at least based on conceptual understanding of the kinds of predators and disturbance they represent.

The mortality agent discovery rate parameters also very likely have strong effects on model results. The analysis of the mortality submodel (Appendix D) showed that the mortality agents have a dominant effect on reproductive success in years without high flooding mortality.

A complication with calibrating the mortality discovery rate parameters is that the parameters for different types of agents (nest, chick, and adult predators; ORVs) are likely to have very similar effects on the ultimate model results, number of fledglings produced. Hence, it would not be clear which of these would be best to adjust to match observed overall nesting success. However, these parameters are expected to have different effects on intermediate results such as nest and chick survival. 


\section{Calibration criteria}

No data useful for calibration of reproductive success are available from the Keystone reach data. Therefore, published observations from other sites were characterized and summarized (Tables F5-F6) after carefully screening the literature for methodological problems and relevance to the site.

Table F5. Literature for calibration of nest success.

\begin{tabular}{|c|c|c|c|c|c|c|c|c|c|c|}
\hline \multirow[b]{2}{*}{ Source } & \multirow[b]{2}{*}{ River } & \multirow[b]{2}{*}{ Habitat } & \multirow[b]{2}{*}{$n$ years } & \multirow[b]{2}{*}{ years } & \multicolumn{2}{|c|}{ median $\mathrm{n}$} & \multicolumn{3}{|c|}{ nest success } & \multirow{2}{*}{$\begin{array}{l}\text { Habitat } \\
\text { Conditions }\end{array}$} \\
\hline & & & & & sites & nests & median & $\min$ & $\max$ & \\
\hline $\begin{array}{l}\text { Szell and Woodrey } \\
\text { (2003) }\end{array}$ & Mississippi & River & 1 & 1995 & 4 & 1215 & 0.97 & & & Excellent \\
\hline Byre (2000) & Canadian & River & 6 & $\begin{array}{l}1991- \\
1995, \\
1998\end{array}$ & 5 & 45.5 & 0.76 & 0.33 & 0.87 & Good \\
\hline Jenniges (2004) & Central Platte & Sand pit & 12 & $\begin{array}{l}1992- \\
2003\end{array}$ & 6 & 34.5 & 0.735 & 0.48 & 0.88 & Excellent \\
\hline $\begin{array}{l}\text { Brown and } \\
\text { Jorgensen (2010) }\end{array}$ & Lower Platte & Housing & 1 & 2010 & 4 & 66 & 0.724 & & & poor \\
\hline Lingle (1993) & Central Platte & Sand pit & 6 & $\begin{array}{l}1985- \\
1990\end{array}$ & 10 & 62 & 0.615 & 0.59 & 0.73 & good \\
\hline $\begin{array}{l}\text { Leslie et al. } \\
(2000)\end{array}$ & Arkansas (OK) & River & 1 & 1993 & 20 & 345 & 0.61 & & & excellent \\
\hline Kirsch (1996) & Lower Platte & River & 2 & $\begin{array}{l}1987- \\
1988\end{array}$ & 3.5 & $?$ & 0.605 & 0.49 & 0.72 & good \\
\hline Kirsch (1996) & Lower Platte & Sand pit & 4 & $\begin{array}{l}1987- \\
1990\end{array}$ & 5.5 & $?$ & 0.59 & 0.46 & 0.72 & fair \\
\hline $\begin{array}{l}\text { Brown and } \\
\text { Jorgensen (2008, } \\
\text { 2009) }\end{array}$ & Lower Platte & River & 2 & $\begin{array}{l}2008 \\
2009\end{array}$ & 8 & 207 & 0.5775 & 0.364 & 0.791 & excellent \\
\hline Lingle (1993) & Central Platte & River & 3 & $\begin{array}{l}1985, \\
1987, \\
1990\end{array}$ & 3 & 11 & 0.52 & 0.5 & 0.64 & poor \\
\hline $\begin{array}{l}\text { Brown and } \\
\text { Jorgensen (2008, } \\
2009,2010)\end{array}$ & Lower Platte & Sand pit & 3 & $\begin{array}{l}2008- \\
2010\end{array}$ & 10 & 211 & 0.512 & 0.356 & 0.632 & good \\
\hline Hill (1985) & Salt Plains & Salt Flats & 3 & $\begin{array}{l}1982- \\
1984\end{array}$ & $?$ & 77 & 0.512 & 0.429 & 0.746 & good \\
\hline Meduna (2006) & Red & River & 2 & $\begin{array}{l}2003- \\
2004\end{array}$ & 9 & 177.5 & 0.16 & 0.16 & 0.16 & good \\
\hline
\end{tabular}


Table F6. Literature for calibration of fledging success.

\begin{tabular}{|c|c|c|c|c|c|c|c|c|c|c|c|}
\hline Source & River & Habitat & $\mathrm{n}$ years & years & sites & chicks & median & Min & $\max$ & control & conditions \\
\hline $\begin{array}{l}\text { Jenniges } \\
\text { (2004) }\end{array}$ & Central Platte & Sand pit & 12 & $\begin{array}{l}1992- \\
2004\end{array}$ & 6 & 59.5 & 0.8795 & 0.352 & 6 & y & excellent \\
\hline $\begin{array}{l}\text { Leslie et al. } \\
(2000)\end{array}$ & Arkansas (OK) & River & 1 & 1993 & 20 & 285 & 0.5 & & & $\mathrm{n}$ & excellent \\
\hline $\begin{array}{l}\text { Brown and } \\
\text { Jorgensen } \\
(2008,2009)\end{array}$ & Lower Platte & River & 2 & $\begin{array}{l}2008- \\
2009\end{array}$ & 8 & 118.5 & 0.4835 & 0.434 & 0.533 & $\mathrm{n}$ & excellent \\
\hline Kirsch (1996) & Lower Platte & Sand pit & 4 & $\begin{array}{l}1987- \\
1990\end{array}$ & 5.5 & $?$ & 0.35 & 0.24 & 0.38 & $n$ & fair \\
\hline Kirsch (1996) & Lower Platte & River & 2 & $\begin{array}{l}1987- \\
1988\end{array}$ & 3.5 & $?$ & 0.205 & 0.14 & 0.27 & $n$ & good \\
\hline $\begin{array}{l}\text { Brown and } \\
\text { Jorgensen } \\
(2009,2010)\end{array}$ & Lower Platte & Sand pit & 2 & $\begin{array}{l}2009- \\
2010\end{array}$ & 10 & $?$ & 0.1365 & 0.059 & 0.214 & $n$ & fair \\
\hline $\begin{array}{l}\text { Brown and } \\
\text { Jorgensen } \\
\text { (2010) }\end{array}$ & Lower Platte & Housing & 1 & 2010 & 4 & $?$ & 0.032 & & & $n$ & poor \\
\hline
\end{tabular}

Calibration of reproductive success focused on excellent instead of degraded habitat conditions, for two reasons. First, most of the published observations available for comparison to model results are from good to excellent conditions, with very little information contrasting good and poor conditions at the same sites. Second, the analysis of the mortality submodel that preceded calibration (Appendix D) confirmed the model produces lower reproductive success when habitat conditions are poor.

Reproductive success calibration also focused on years when flooding mortality was low, because flooding can dominate reproductive success when it occurs. Instead, the focus is on calibration of predation and disturbance mortality.

Because reproductive success is highly variable and not well quantified, this calibration phase used "categorical" criteria: ranges of acceptable results were defined instead of trying to closely match specific values. These criteria describe survival through two life stages: nests and chicks. "Nest success" (Table F5) is defined as the percentage of nests at a sandbar site that produce at least one chick. Calibration criteria for nest success are derived from information in Table F5 with emphasis on studies of rivers with good to excellent habitat conditions. Criteria for the lower limit of nest success is harder to define because the model produces many small colonies where 
success is often zero if one or two predators appear. "Fledging success" (Table F6) is the percentage of chicks at a site that survive until they fledge. Calibration criteria for fledging success are derived from information in Table F6, emphasizing values from rivers with good to excellent habitat. The criteria ranges are subjective and cannot be treated as absolute or definitive.

One set of calibration criteria was used for the first reproductive success experiment, and then a revised set of criteria was used for the second experiment.

The criteria used in the first experiment are:

- The maximum nest success among sites, in each year, is greater than $60 \%$.

- The percentage of sites with zero nesting success, in each year, is less than $25 \% .^{1}$

- At least $80 \%$ of sites have fledging success greater than $20 \%$, in each year.

- The mean fledging success over all sites is between 40 and $80 \%$, in each year. (The data in Table F6 report success in terms of the median across sites; however, in the model results the median across sites is dominated by the many small colonies that often have $100 \%$ fledging success.)

- The number of fledglings per female adult tern is greater than 1.0, averaged across all sites and years. This criterion is simply to reflect that overall reproductive success should be relatively high in the conditions simulated in these experiments: non-flood years with excellent habitat.

The criteria used in the second experiment were revised to better match how variability among years and sites was reported in the literature. These criteria are:

- Nest success, averaged over all sites within a year, is between 50 and $85 \%$.

- Sites with zero nesting success are fewer than $20 \%$ of all sites, over all years.

- Fledging success, averaged over all sites within a year, is between 30 and $70 \%$.

\footnotetext{
1 This was based on Akcakaya et al. (2003), which summarized many years of site-specific data for California Least Terns.
} 
- Sites with zero fledging success are fewer than $20 \%$ of all sites, over all years.

\section{Simulation experiment 1}

Because the calibration criteria for reproductive success are not specific to the study site or any particular year, the calibration simulations do not need to closely match actual conditions in the Keystone reach. Instead, flow input can be used for water years prior to 2007 with the 2008 habitat conditions. The mortality analysis (Appendix D) indicated that flooding mortality was low in 1998, 2000, 2001, 2003, and 2006. Therefore, those five years were simulated with the habitat input from 2008.

Each of the five water years was simulated with each combination of values for the mortality discovery rate parameters magentAdultPred, magentChickPred, magentNestPred, and magentORV. These parameters each scale the intensity of one type of mortality (the frequency at which mortality agents appear), over a range of 0.0 to 10 . The mortality analysis produced reasonably realistic reproductive success when all of these parameters were set to 3.0, so the calibration was initially built around that range. The first part of the experiment (labeled "Calibration 1" in output and analysis files) used all combinations of these parameters each having values of 1.0, 3.0, and 5.0, for 81 parameter combinations. Each combination was used to simulate the five water years, for a total of 405 model runs. A second part of the experiment focused more closely on the parameter ranges that looked best in the first experiment, holding magentAdultPred constant at 2 and using values of 1.0, 2.0, and 3.0 for the other three mortality agent rates, for a total of 27 parameter combinations and 135 model runs. (This second part of experiment 1 is labeled "Calibration 4" in the output and analysis files.) A total of 108 parameter combinations were therefore examined in experiment 1.

The simulation experiments used the values of adultSiteSelectionDistance $(10,000)$ and manareaFracDispersers (0.05) developed in the first phase of calibration.

\section{Results of experiment 1}

Three of the five criteria for reproductive success were met in over $50 \%$ of calibration runs. The first fledging success criterion, that $80 \%$ of sites have fledging success greater than $20 \%$, was met in only $14 \%$ of the model runs. 
The overall reproductive success criterion of greater than 1.0 fledgling per female was met in $47 \%$ of the model runs. The standard values of 3 for all mortality agent rates met 3.2 of the 5 criteria on average across the five years.

The calibration results indicate that the lowest values of the mortality agent rates best meet the calibration criteria, especially the criterion for fledging success greater than $20 \%$ (Table $\mathrm{F} 7$ ). The parameter combinations that met the most criteria (out of 5 ) had values of 1 for the mortality agent discovery rates, except that the parameter for adult predators did not seem to be important.

From this first calibration experiment, it can be concluded that:

- Low values of the mortality agent discovery rate parameters best meet the calibration criteria.

- The most limiting criterion is that less than $20 \%$ of sites have fledging success less than $20 \%$.

- Adult mortality appears to have relatively little effect on fledging or nest success. (This issue will be addressed more formally in the sensitivity analysis.)

- In years with little flooding and excellent habitat, the model predicts (as a rule of thumb) that the number of fledglings per female adult is usually greater than 1.0 when the mean value of the four mortality agent discovery parameters is less than 2.5 .

Table F7. Reproductive success calibration results for experiment 1: the parameter combinations that met at least four of the five calibration criteria, averaged over five water years.

\begin{tabular}{|c|c|c|c|c|}
\hline magentAdultPred & magentNestPred & magentChickPred & magentORV & $\begin{array}{l}\text { Average number } \\
\text { of criteria met }\end{array}$ \\
\hline 1 & 1 & 1 & 1 & 4.4 \\
\hline 3 & 1 & 1 & 1 & 4.4 \\
\hline 5 & 1 & 1 & 1 & 4.4 \\
\hline 3 & 1 & 1 & 3 & 4.2 \\
\hline 1 & 2 & 1 & 3 & 4.0 \\
\hline 2 & 1 & 1 & 1 & 4.0 \\
\hline 5 & 1 & 1 & 3 & 4.0 \\
\hline
\end{tabular}




\section{Simulation experiment 2}

The first reproductive success experiment indicated that fewer mortality agents should occur in simulations. Yet the goal was to keep the calibrated value of the mortality control parameters magentAdultPred, magentChickPred, magentNestPred, and magentORV near 3.0 for convenience and clarity in model applications, especially looking at situations such as degraded habitat conditions in which predation and disturbance mortality are expected to be higher. Therefore, for the second reproductive success experiment, the underlying mortality agent frequency parameter mamMaxDiscoverRate was adjusted for each of the four kinds of mortality. (The probability of a new mortality agent appearing at a site is mamMaxDiscoverRate times magentIntensity divided by 10 (see Sect. 8.10 of the model description). The value of mamMaxDiscoverRate was changed from 0.001 to 0.0003 for adult predators, from 0.065 to 0.02 for chick and nest predators, and from 0.05 to 0.017 for ORVs. These changes cause the model to produce nearly the same mortality intensity with magentAdultPred, magentChickPred, magentNestPred, and magentORV all set to 3.0 that it previous did with these parameters set to 1.0.

With the underlying mortality agent rates thus adjusted, calibration experiment 2 included two sets of simulations. The first part of experiment 2 ("calibration 6B" files) simulated all combinations of magentChickPred, magentNestPred, and magentORV equal to 2.0, 3.0, and 4.0. The value of magentAdultPred was constant at 3.0 as it showed little effect on results in the reproductive success experiments. The second part ("calibration 7B") held magentAdultPred and magentNestPred constant at 3.0 and simulated all combinations of magentChickPred and magentORV equal to 3.0, 4.0, 5.0, and 6.0.

A second change implemented in experiment 2 is changing the value of parameter adultMaxNumBreedingAttempts from 3 to 2. This change resulted from reconsideration of the literature on repeat nesting, which is relatively ambiguous.

Finally, experiment 2 used a revised set of calibration criteria, as explained above). 


\section{Results of experiment 2}

With the revised mortality frequency parameters and calibration criteria, most parameter combinations (except those with the highest ORV mortality) met four of the five criteria. However, only a very few parameter combinations met the criteria of fledging success between 40 and $70 \%$ : fledging success was $>70 \%$ for all but three combinations. This criterion is especially important because it is the only criterion providing an upper limit on reproductive success. The scenarios meeting this fledging success criterion had high ORV mortality and moderately high chick predation.

One parameter combination met all five criteria: magentAdultPred $=3.0$, magentChickPred $=4.0$, magentNestPred $=3.0$, and magentORV $=5.0$. That this particular combination met all five criteria was no doubt partly stochastic; additional simulations would probably have found that this combination and several others with magentORV in the range of 5-6 meet all five criteria some but not all of the time. These values are, however, sufficient to define the region in which reproductive success is best calibrated.

These calibrated values can be used to calculate new values of mamMaxDiscoverRate for chick predators and ORVs to reset the best values of magentChickPred and magentORV to 3.o. These new values of mamMaxDiscoverRate are 0.027 (chicks), and o.028 (ORV).

\section{Conclusions and final parameter values}

This analysis used a variety of information to estimate values of especially important and uncertain parameters, while causing the Least Tern model to produce realistic results at both the final stage (reproductive success as fledglings per female adult) and at several intermediate stages (site selection, nest success, and chick survival). Given the limitations of field observations of Interior Least Terns and the model's stochasticity, calibration is not expected to produce extremely clear and narrow ranges of parameter values. However, even the relatively general and broad calibration criteria here let one draw important inferences about good values for several parameters.

The parameter values developed in this analysis have been adopted as new standard values and included in the model description. They are: 
- adultSiteSelectionDistance $=10,000 \mathrm{ft}$

- manareaFracDispersers $=0.15$

- mamMaxDiscoverRate for adult predators $=0.0003$

- mamMaxDiscoverRate for chick predators $=0.027$

- mamMaxDiscoverRate for nest predators $=0.022$

- mamMaxDiscoverRate for ORVs = 0.028.

With these parameter values, the standard values of magentAdultPred, magentChickPred, magentNestPred, and magentORV remain at 3.0. In addition to these changes, the value of adultMaxNumBreedingAttempts is set to 2 .

These new parameter values were evaluated by simulating the five calibration years, with five replicates each (files labeled "calibration 9"). The model produced results typical for relatively high reproductive success (Table F8). The results, including overall reproductive success as fledglings per female, were quite variable among the five replicates for each year.

Table F8. Reproductive success results with parameter values resulting from calibration: Mean and range over five replicates of each of the calibration years.

\begin{tabular}{|l|l|l|l|l|l|}
\hline Result & 1998 & 2000 & 2001 & 2003 & 2006 \\
\hline $\begin{array}{l}\text { Reproductive success: } \\
\text { fledges per female }\end{array}$ & 1.5 & 1.2 & 1.7 & 1.7 & 1.5 \\
& $(1.3-1.7)$ & $(0.6-1.7)$ & $(1.5-2.1)$ & $(0.8-2.1)$ & $(1.1-1.8)$ \\
\hline $\begin{array}{l}\text { Renesting: fraction of } \\
\text { females nesting two times }\end{array}$ & 0.33 & 0.40 & 0.40 & 0.33 & 0.35 \\
& $(0.13-$ & $(0.23-$ & $(0.28-$ & $(0.20-$ & $(0.16-$ \\
$0.53)$ & $0.78)$ & $0.53)$ & $0.58)$ & $0.56)$ \\
\hline $\begin{array}{l}\text { Nest success: fraction of } \\
\text { nests producing at least } \\
\text { one chick }\end{array}$ & 0.69 & 0.59 & 0.65 & 0.69 & 0.65 \\
\hline $\begin{array}{l}\text { Fledging success: fraction } \\
\text { of chicks surviving }\end{array}$ & 0.75 & $(0.30-$ & $(0.50-$ & $(0.35-$ & $(0.45-$ \\
& $(0.67-$ & $0.77)$ & $0.73)$ & $0.79)$ & $0.81)$ \\
\hline
\end{tabular}

After reviewing Table F8 and finding the results for both overall reproductive success and fledging success slightly high compared with estimates from empirical studies, an additional set of experiments were run using each of the new default parameter values listed above, with the exception of mamMaxDiscoverRate for chick predators, which was increased to 0.33 , 0.38 , and 0.43 . Simulations with this parameter value set to 0.43 reduced both fledging success and reproductive success slightly and had minor effects on other summary statistics. Consequently, 0.43 was made the 
default parameter value for mamMaxDiscoverRate for chick predators in the final version of the model description (Lott et al. 2012).

\section{References}

Akçakaya, H. R., Atwood, J. L., Breininger, D., Collins, C. T., and B. Duncan. 2003. Metapopulation dynamics of the California Least Tern. Journal of Wildlife Management 67: 829-842.

Brown, M. B., and J. G. Jorgensen. 2008. 2008 Interior Least Tern and Piping Plover monitoring, research, management, and outreach report for the Lower Platte River, Nebraska. Joint Report of the Tern and Plover Conservation Partnership and the Nebraska Game and Parks Commission.

Brown, M. B., and J. G. Jorgensen. 2009. 2009 Interior Least Tern and Piping Plover monitoring, research, management, and outreach report for the Lower Platte River, Nebraska. Joint Report of the Tern and Plover Conservation Partnership and the Nebraska Game and Parks Commission.

Brown, M. B., and J. G. Jorgensen. 2010. 2010 Interior Least Tern and Piping Plover monitoring, research, management, and outreach report for the Lower Platte River, Nebraska.

Byre, V. J. 2000. Productivity, habitat assessment, and management of least terns nesting along the Canadian River in central Oklahoma. Sam Noble Oklahoma Museum of Natural History, Occasional Papers 8: 1-13. University of Oklahoma, Norman, OK.

Hill, L.A. 1985. Breeding ecology of Interior Least Terns, Snowy Plovers, and American Avocets at Salt Plains National Wildlife Refuge, Oklahoma. M.S. Thesis.

Jenniges, J. J. 2004. Least Tern and piping plover nesting at managed nesting sites on the central Platte River 1991 through 2003. In Proceedings, Third Missouri River and North American piping plover and Least Tern habitat workshop/ symposium, 39-50. Brookings, SD: South Dakota State University.

Kirsch, E. M. 1996. Habitat selection and productivity of least terns on the lower Platte River, Nebraska. Wildlife Monographs:1-48.

Leslie, D. M., G. K. Wood, and T. S. Carter. 2000. Productivity of endangered least terns (Sterna antillarum athalassos) below a hydropower and flood-control facility on the Arkansas River. Southwestern Naturalist 45:483-489.

Lingle, G. R. 1993. Nest success and flow relationships on the central Platte River. In Proceedings of the Missouri River and its tributaries: Piping Plover and Least Tern Symposium, 69-72. Brookings, SD: South Dakota State University.

Lott, C.A., S.F. Railsback, and C.J.R. Sheppard. 2012. TernCOLONY 1.o model description. ERDC/EL CR-12-3. Vicksburg, MS: U.S. Army Engineer Research and Development Center.

Meduna, L. 2006. Population status, breeding biology, and habitat selection of Interior Least Terns (Sterna antillarum athalassos) on the Red River, Arkansas. M.S. thesis, Arkansas Tech University, AR. 
Szell, C. C., and M. S. Woodrey. 2003. Reproductive ecology of the Least Tern along the Lower Mississippi River. Waterbirds 26: 35-43.

Thompson, B.C., J. A. Jackson, J. Burger, L. A. Hill, E. M. Kirsch, and J. L. Atwood. 1997. Least Tern: Sterna antillarum. In Birds of North America, ed. A. Poole and F. Gill. Philadelphia, PA and Washington, DC: The Academy of Natural Science and the American Ornithologists Union. 


\section{Appendix G: Software verification}

\section{Introduction}

This appendix outlines the tests that were conducted to verify that all critical model calculations (also referred to as model "behaviors") as specified by the TernCOLONY model description (Lott et al. 2012) are successfully implemented in the model software. The overall approach to this task is to run the model with inputs and parameters configured to test a certain behavior or group of behaviors. Data relevant to the direct observation of the behavior outcomes are written to text files during model execution. Then, based on the same set of inputs and model parameters, an independent calculation is undertaken to reproduce the model behaviors. If the model output and independent calculations are consistent, the software is considered verified for that particular behavior. If there is any discrepancy, then a critical review of both the model code and the independent calculation is conducted to determine and correct the source of the discrepancy.

Table G1 contains a log of the verification process, including a brief description of each test, a reference to the actual files where the tests can be found in the Least Tern Subversion (SVN) repository, and the date when test files were reviewed by the project manager, Steve Railsback. The following sections provide brief summaries of each verification test. Note that many of these summaries refer to specific data and results that are accessible in the files listed in Table G1, which are available upon request.

The files referenced in Table G1 are the final test documents. In some cases, these files were the product of a cycle of tests that identified and corrected mistakes in both the tern model software and the testing code.

\section{Adult arrival}

This verification is based on a model run (30 replicates) that was used to compare the arrival distribution to a Netlogo program provided by Steve Railsback that used the same method of determining arrival numbers. Because both of these implementations are stochastic, the test was made by comparing the statistical distribution of results, not the exact results. 
Table G1. Interior Least Tern Model Software Verification Log (all documents are archived in the Subversion repository at trunk/model/Verification)

\begin{tabular}{|c|c|c|c|}
\hline Submodel & Model Processes Tested & Document Name, Date Committed & $\begin{array}{l}\text { Test Review } \\
\text { and Log } \\
\text { Update }\end{array}$ \\
\hline Adult arrival & $\begin{array}{l}\text { Range of arrival dates; total } \\
\text { number of adults; percent } \\
\text { female; distribution of arrivals } \\
\text { over time. }\end{array}$ & $\begin{array}{l}\text { Adult Arrival Submodel/ } \\
\text { ArrivalBook_Complete.xlsm 8/3/2010 }\end{array}$ & SFR 9/1/10 \\
\hline Nest initiation & $\begin{array}{l}\text { Number of eggs; egg viability; } \\
\text { incubation duration; range of } \\
\text { nesting dates; Max breeding } \\
\text { attempts not exceeded. }\end{array}$ & $\begin{array}{l}\text { Clutch Size Submodel/ parameter- } \\
\text { test_clutchprobs/ } \\
\text { NestsBook_Complete.xlsm 8/27/2010 } \\
\text { Clutch Size Submodel/ parameter- } \\
\text { test_fracviable_try2/ } \\
\text { NestsBook_Complete.xlsm 8/27/2010 } \\
\text { Renesting submodel/retests/ parameter- } \\
\text { test_renesting_try3 }\end{array}$ & $\begin{array}{l}\text { SFR 9/1/10, } \\
12 / 1 / 10\end{array}$ \\
\hline Habitat update & All cell habitat variables & $\begin{array}{l}\text { Habitat Update/ cellsTEST.xIsm } \\
8 / 20 / 2010\end{array}$ & SFR 9/1/10 \\
\hline Mortality agents & $\begin{array}{l}\text { Rate of mortality agent } \\
\text { arrivals; } \\
\text { agent duration; } \\
\text { numbers killed }\end{array}$ & $\begin{array}{l}\text { MortalityAgents/ } \\
\text { VerificationSummary-MortalityAgents.docx }\end{array}$ & $\begin{array}{l}\text { SFR } \\
11 / 11 / 10\end{array}$ \\
\hline $\begin{array}{l}\text { Nest site } \\
\text { selection (original } \\
\text { trait: use high- } \\
\text { quality cell) }\end{array}$ & $\begin{array}{l}\text { Nest site selection on highest- } \\
\text { quality available cell }\end{array}$ & $\begin{array}{l}\text { Nest Placement/ nestplacement- } \\
\text { manysites/ Nest-PlacementBook.xlsm } \\
\text { Nest Placement/ nestplacement- } \\
\text { onesitelargepop/ Nest-PlacementBook.xlsm } \\
\text { Nest Placement/ smallpop-onesite try2/ } \\
\text { Nest-PlacementBook.xlsm }\end{array}$ & SFR $9 / 1 / 10$ \\
\hline $\begin{array}{l}\text { Nest site } \\
\text { selection (final } \\
\text { trait: use cell } \\
\text { chosen randomly } \\
\text { from high-quality } \\
\text { range) }\end{array}$ & $\begin{array}{l}\text { Nests are placed in cells with } \\
\text { habitat quality in range } \\
\text { specified by parameters. Nests } \\
\text { are not in cells with vegetation } \\
\text { or under water, or below peak } \\
\text { hydro flow elev. or too many } \\
\text { other nests. }\end{array}$ & $\begin{array}{l}\text { Drowning_Abandonment_Mortality/ } \\
\text { da_mortality-test/Nest- } \\
\text { PlacementBook.xlsm }\end{array}$ & $\begin{array}{l}\text { SFR } \\
11 / 11 / 10\end{array}$ \\
\hline $\begin{array}{l}\text { Site } \\
\text { abandonment }\end{array}$ & $\begin{array}{l}\text { Calculation of expected } \\
\text { reproduction if stay, abandon }\end{array}$ & $\begin{array}{l}\text { SiteAbandonment/ VerificationSummary- } \\
\text { SiteAbandonment.docx }\end{array}$ & $\begin{array}{l}\text { SFR 9/2/10, } \\
7 / 1 / 11\end{array}$ \\
\hline $\begin{array}{l}\text { Site identification } \\
\text { (trait 4) }\end{array}$ & $\begin{array}{l}\text { Number of "disperser" and } \\
\text { "returner" adults; } \\
\text { identification of candidate } \\
\text { sites }\end{array}$ & $\begin{array}{l}\text { SiteSelection/VerificationSummary- } \\
\text { Siteldentification.docx }\end{array}$ & $\begin{array}{l}\text { SFR } \\
11 / 11 / 10\end{array}$ \\
\hline Adult mating & $\begin{array}{l}\text { Adults mate as soon as a } \\
\text { partner of opposite sex is } \\
\text { available, so at end of each } \\
\text { tick there should be at most } \\
\text { one unmated adult. }\end{array}$ & $\begin{array}{l}\text { Mating Submodel/mating- } \\
\text { check/MatingBook.xlsm }\end{array}$ & $\begin{array}{l}\text { SFR } \\
11 / 30 / 10\end{array}$ \\
\hline Drowning of nests & $\begin{array}{l}\text { Nests drown if and only if } \\
\text { water elevation is above nest } \\
\text { elevation }\end{array}$ & $\begin{array}{l}\text { Drowning_Abandonment_Mortality/ } \\
\text { da_mortality-test2/Nest-DeathBook.xlsm }\end{array}$ & $\begin{array}{l}\text { SFR } \\
11 / 30 / 10\end{array}$ \\
\hline
\end{tabular}




\begin{tabular}{|l|l|l|l|}
\hline Submodel & Model Processes Tested & Document Name, Date Committed & $\begin{array}{l}\text { Test Review } \\
\text { and Log } \\
\text { Update }\end{array}$ \\
\hline $\begin{array}{l}\text { Drowning of } \\
\text { chicks }\end{array}$ & $\begin{array}{l}\text { If a chick drowns, then \# dry } \\
\text { acres =0; if \# dry acres = 0, } \\
\text { then no chicks survive }\end{array}$ & $\begin{array}{l}\text { Drowning_Abandonment_Mortality/ } \\
\text { da_mortality-test2/Chick-DeathBook.xIsm }\end{array}$ & $\begin{array}{l}\text { SFR } \\
11 / 30 / 10\end{array}$ \\
\hline $\begin{array}{l}\text { Mortality of nests } \\
\text { due to loss of } \\
\text { parents }\end{array}$ & $\begin{array}{l}\text { Nests that have no parent ID } \\
\text { are killed. }\end{array}$ & $\begin{array}{l}\text { Drowning_Abandonment_Mortality/ } \\
\text { da_mortality-test2/Nest-DeathBook.xlsm }\end{array}$ & $\begin{array}{l}\text { SFR } \\
11 / 30 / 10\end{array}$ \\
\hline $\begin{array}{l}\text { Mortality of } \\
\text { chicks due to loss } \\
\text { of parents }\end{array}$ & $\begin{array}{l}\text { Chicks that have no parent ID } \\
\text { are killed-unless their parents } \\
\text { left because a sibling chick } \\
\text { fledged. }\end{array}$ & $\begin{array}{l}\text { Drowning_Abandonment_Mortality/ } \\
\text { da_mortality-test2/Chick-DeathBook.xIsm }\end{array}$ & $\begin{array}{l}\text { SFR } \\
11 / 30 / 10\end{array}$ \\
\hline Re-nesting & $\begin{array}{l}\text { Adults (male and female) go } \\
\text { through correct sequence of } \\
\text { mating, nesting, unmating at } \\
\text { renesting, etc. }\end{array}$ & $\begin{array}{l}\text { Renesting submodel/retests/parameter- } \\
\text { test_renesting_try3/AdultsBook.xlsm and } \\
\text { PropertiesBook.xlsm }\end{array}$ & $\begin{array}{l}\text { SFR } \\
7 / 1 / 2011\end{array}$ \\
\hline
\end{tabular}

Parameter values from the configuration file are shown in Column $\mathrm{O}$ and match the parameter values used in the Netlogo program. Columns P and Q refer to minimum and maximum values across all replicates for each parameter, while columns $\mathrm{R}$ and $\mathrm{S}$ show average values of these parameters and the standard deviation.

Columns $\mathrm{T}$ and $\mathrm{U}$ are results from the Netlogo program mentioned above. Details about the Netlogo program itself can be found in SVN at Adult Arrival Submodel/ arrivaltest/AdultArrivalTest (Netlogo from Steve).xlsx. Columns $\mathrm{V}$ and $\mathrm{W}$ show the percent difference in average parameter values between the NetLogo program and the model run.

\section{Results}

1. No replicates violated the first and last arrival dates specified in the properties files; that is, terns always arrived a minimum of one day after First Arrival Date, and never arrived later than one day before Last Arrival Date.

2. The average number of terns arriving in the model across all replicates closely matches that specified in PropertiesBook (496 terns arriving vs 500 terns specified in the properties).

3. Average distribution of tern gender (0.4918) closely matches the 0.5 probability of being female specified in Lott et al. (2012a).

4. Since both the Netlogo program and the full TernCOLONY model are stochastic, it is not expected that the Peak Arrival Date or total number of adults (manareaNumAdults) exactly match the parameters specified in the 
PropertiesBook. However, the average Peak Arrival Date and number of adults for the Netlogo program and TernCOLONY varied by less than $0.2 \%$, indicating that the Least Tern Arrival submodel reliably produces the correct distribution of terns.

\section{Nest initiation}

This verification tested the following submodels: Clutch Size Submodel, Egg-Laying Submodel. The summary sheets show statistics on results across all replicates for each set of model run replicates. Cells marked in green on the summary sheets indicate model results differing from the specified parameter values by less than $5 \%$ using the standard formula for percent error (if numeric) or results that otherwise verify model constraints or procedures defined in Lott et al. (2012). Cells marked as red indicate percent errors in numeric results greater than $5 \%$ or values that otherwise indicate errors in the ILT model's behavior.

This macro tests the following parameters:

- adultClutchProb1Egg

- adultClutchProb2Eggs

- adultFracNonviableEggs

- nestIncubationDurationMean

- nestIncubationDurationSD

- manareaFirstNestDate

- manareaPeakNestDate

- manareaLastNestDate

- adultMinDaysArrivalToEggLaying

- adultMinRenestingInterval

The following tests were performed:

- Egg-laying events are tracked for each nest to ensure that eggs are never laid on consecutive days.

- The distribution of clutch sizes in surviving nests is calculated and compared to parameter values.

- The distribution of incubation durations in surviving nests is calculated and compared to parameters.

- First and last nest initiation dates are determined and compared to parameter values. Peak nest initiation date is also calculated but not numerically compared to the parameter manareaPeakNestDate. 
- The fraction of nonviable eggs in surviving nests is calculated and compared to adultFracNonviableEggs.

- For each tern, nest initiation events are counted and compared to model output to verify correct tracking of nesting attempts.

- For each tern, nest initiation events are checked to verify that the time intervals specified by adultMinDaysArrivalToEggLaying and adultMinRenestingInterval.

Results

- Egg-laying events were verified to never occur on consecutive days.

- The nest initiation date parameters did not show any inconsistency, that is, no nests were initiated before manareaFirstNestDate nor were any initiated after the last date possible as specified by nestIncubationDurationMean, chickPeriodDurationMean, and manareaLastFledgeDate.

- Of the clutch size parameters, the tests resulted in very rare occurrences when the percent difference between the parameter value and the observed outcome to be greater than $5 \%$, but in these cases the difference was not statistically significant at the $5 \%$ significance level.

- The nest incubation observed outcomes never deviated from the model parameter values by any significant amount.

- The fraction of viable and non-viable eggs never deviated from the model parameter values by any significant amount.

- No time intervals related to egg laying and renesting were violated.

\section{Habitat update}

This test verifies the calculation of habitat quality index in the Interior Least Tern (ILT) Model. Cell qualities were logged for three ticks at a limited number of sites and checked against independent calculations of quality as detailed in the sheets "cells" and "PeakFlowParameters". Cell quality calculations were verified as correct for a tolerance of $0.01 \%$.

\section{Mortality agents}

To test whether the random draws associated with mortality agent arrival, duration, and adult/nest/chick kills are consistent with the parameters specified in the model run, outputs from the model were processed and plotted as histograms for visual inspection. The mean value of the observed outcome is included in each plot along with the p-value associated with a 
t-test on that outcome. Results: Based on visual inspection and the calculated p-values, the observed distributions were consistent with the expected distribution and the model parameter values.

A separate analysis was performed to verify that the number of adults/ chicks/nests that should be killed by mortality agents, do indeed die. In the file kills.csv, the number of adults/nests/chicks that are supposedly killed by each mortality agent are logged. Then, to remove the complexity of accounting for kills due to floods, a fabricated water year was used which causes zero flooding events.

Any time an adult/chick/nest dies in the model, it still logs to its respective file (adults.csv,chicks.csv,nests.csv) on the same day of its death, but the value in the column isAlive will be false. By comparing the number of dead adults/chicks/nests to the number logged in kills.csv, one can verify whether the sub-model is behaving as expected.

Results

No inconsistencies were observed.

\section{Nest site selection}

Notes: A verification was conducted on a previous version of the nest site selection trait. This test is listed in Table G1 but not described here for brevity.

The following tests are performed to verify the nest site selection submodel (nests should be randomly placed in cells that are within the high quality range as specified in the model description):

1. For each cell selected for nest placement, the quality of the cell is checked against the nestQualityRange parameter.

2. For each cell selected for nest placement, the cell elevation is compared to the current daily water surface elevation (WSE).

3. For each cell selected for nest placement, the cell elevation is compared to the WSE at peak hydropower flow.

4. For each cell containing nests, the number of nests in the cell are checked against the parameter adultMinNestArea. 
Results

No inconsistencies were found between observed nest placements and Lott et al. (2012).

\section{Site abandonment}

To test whether site abandonment was implemented correctly, outputs from the model were used to independently calculate whether a site should be abandoned in each time step of a model run. The result of this calculation was compared to the result computed inside the model.

The two parameters compared are E_A and E_S, the expected productive of abandoning the site and remaining at the site respectively. An R script was written to perform the independent calculation. The script simply tests if the value of $\mathrm{E} \_\mathrm{A}$ and $\mathrm{E} \_\mathrm{S}$ calculate are within $1 \mathrm{E}-8$ of the value calculated by the model.

\section{Results}

No inconsistencies were found between the model output and the independent calculation.

\section{Site identification (trait 4)}

To test whether site identification trait 4 was implemented correctly, outputs from the model were used to independently calculate which sites among the candidate sites should be identified as candidate sites by the adult.

An R script, SiteIdentification. $R$ was written to perform the independent calculation as follows:

- For each site selection event that was logged to tern_site_selections.csv

- Use the data from site_XXXXXX.csv to determine all of the sites with non-zero suitable habitat in the tic associated with the selection event.

- Of those suitable sites, determine which of them are within adultSiteSelectionDistance/ 2 of the adult's location field: thalwegMilesFromDatum (files used are site-data.csv and tern_site_selection.csv) 
- If o sites were found within the specified distance, then find the single closest site in the entire management area with suitable cells exposed.

- Compare the list of expected candidate sites to the list of candidate sites logged by the model, note if they are inconsistent.

For each run, the script tests all of the site selection events and prints whether there were any inconsistencies. To test whether the adult initialization submodel is error-free, the data from adult-arrival.cs $v$ was also analyzed for each run to compare the distribution of adult previous site locations to the model input. By loading the data from previous-site.csv and knowing the value for the parameter manareaFracDispersers, one knows how many adults should have randomly assigned arrival locations and how many should arrive at each site in the table tblTernPreviousSite. Results are reported as the number of inconsistencies between expected and observed results in adult-arrival.csv.

\section{Results}

No inconsistencies were found between the model output and the independent calculation.

\section{Adult mating}

Since mating does not depend on parameters, no parameter values are tested. This test checks that on each day at each site, there are either 0 males or o females available for mating. (If both a single male and female are present, they should mate with each other.)

\section{Results}

There were no days when both unmated males and females remained at the end of a tick.

\section{Drowning and loss-of-parents mortality for nests}

These tests do not test the Site Abandonment submodel itself; only the mortality of nests that are abandoned is verified. No specific parameters are used in these tests. The following tests are performed:

1. For each tick, the elevation of each nest is compared to the water surface elevation (WSE). Nests that are drowned when WSE < nest elevation, or 
nests that survive when WSE > nest elevation, are marked red. Otherwise nests are marked green.

2. For each tick, the parent IDs (mother and father) are checked. Nests that do not have IDs for both parents and are killed, or nests that have at least one surviving parent and survive, are marked green. Otherwise nests are marked red.

\section{Results}

No nests were marked red meaning that no inconsistencies were found.

\section{Drowning and loss-of-parents mortality of chicks}

These tests do not test the Site Abandonment submodel itself; only the mortality of chicks is verified. No specific parameters are used in these tests. The following tests are performed:

1. For each tick, the available dry acres metric at each site is checked. Chicks that are drowned when there are dry acres available, or chicks that survive when there are no dry acres available, are marked red. Otherwise chicks are marked green.

2. For each tick, the parent IDs (mother and father) are checked. Chicks that do not have IDs for both parents and are killed, or chicks that have at least one surviving parent and survive, are marked green. Otherwise chicks are marked red.

\section{Results}

No chicks were marked red meaning that no inconsistencies were found.

\section{Re-nesting}

This test involved tracking the reproductive status of every tern in a series of model runs to ensure that it follows the correct sequence and only changes when the appropriate criteria (as specified in Lott et al. [2012]) have been satisfied. The following checks are conducted:

1. The number of times a female's status changes to "Laying" is counted and compared to the model output for breeding attempt number. Ensures that this count does not exceed the maximum allowable breeding attempts specified by the model parameter.

2. Ensures that only mated terns create nests. 
3. Ensures that the minimum wait time between arrival to management area and nesting is observed.

Results

No inconsistencies were observed between model outputs and the expected behavior.

\section{Reference}

Lott, C.A., S.F. Railsback, and C.J.R. Sheppard. 2012. TernCOLONY 1.o model description. ERDC/EL CR-12-3. Vicksburg, MS: U.S. Army Engineer Research and Development Center. 


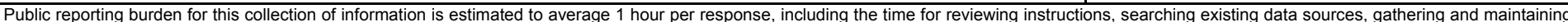

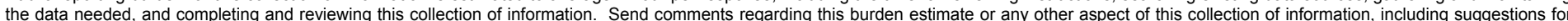

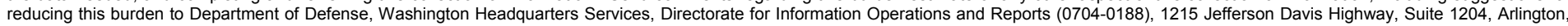

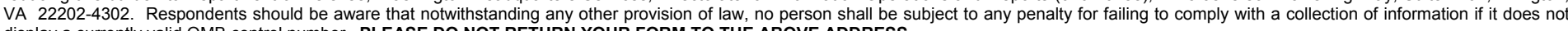
display a currently valid OMB control number. PLEASE DO NOT RETURN YOUR FORM TO THE ABOVE ADDRESS.
1. REPORT DATE (DD-MM-YYYY) 2. REPORT TYPE
3. DATES COVERED (From - To)

June 2013 Final report

\section{TITLE AND SUBTITLE}

Developing and testing TernCOLONY 1.0: An Individual-based Model of Least Tern Reproduction

5a. CONTRACT NUMBER

5b. GRANT NUMBER

5c. PROGRAM ELEMENT NUMBER

\section{AUTHOR(S)}

Casey A. Lott, Steven F. Railsback, Colin J.R. Sheppard, and Michael C. Koohafkan

5d. PROJECT NUMBER

5e. TASK NUMBER

5f. WORK UNIT NUMBER

\section{PERFORMING ORGANIZATION NAME(S) AND ADDRESS(ES)}

8. PERFORMING ORGANIZATION REPORT

Coastal and Waterways Program Coordinator

American Bird Conservancy, 1209 Shenandoah Drive NUMBER

Boise, ID 83712;

Lang, Railsback, and Associates

250 California Ave., Arcata, CA 95521

\section{SPONSORING / MONITORING AGENCY NAME(S) AND ADDRESS(ES)}

10. SPONSOR/MONITOR'S ACRONYM(S)

U.S. Army Corps of Engineers

Washington, DC 20314-1000

ERDC/EL CR-13-2

\section{DISTRIBUTION / AVAILABILITY STATEMENT}

Approved for public release; distribution unlimited.

\section{SUPPLEMENTARY NOTES}

\section{ABSTRACT}

The TernCOLONY simulation model is an individual-based model of Least Tern reproduction that was developed to better understand how reservoir operations (and other management activities) affect Least Tern breeding populations on large rivers. This report documents the process of model development, including defining the model's purpose, its structure, its various submodels, and major inputs. This document supplements the TernCOLONY model description (Lott et al. 2012a), which provides the complete formulation of the model with enough detail to make the model reproducible. This document summarizes the pattern-oriented approach taken in developing the model's major behavioral traits and submodels (adult tern colony and nest site selection, site abandonment, re-nesting, and various mortality submodels). The report also documents the extensive process of independent verification of the model's code that was undertaken prior to a whole model sensitivity analysis and parameter calibration (also reported here). The tests reported in this document provide the basis for the final submodels, behavioral traits, and parameter values that are reported in the model description and represented in the model' s code (Lott et al. 2012a). The web version of the model, available at http://www.leasttern.org, is introduced. The web version provides the graphical interface through which most users will explore TernCOLONY. Finally, future directions in the implementation of TernCOLONY on different river reaches are summarized to address a variety of different management applications and discuss the potential for adapting the model to other contexts (e.g., other habitats or species).
15. SUBJECT TERMS
Habitat and flow datasets
Reproduction model

Least Tern

Least Tern reproduction

TernCOLONY

\begin{tabular}{|c|c|c|}
\hline \multicolumn{3}{|c|}{ 16. SECURITY CLASSIFICATION OF: } \\
\hline a. REPORT & b. ABSTRACT & c. THIS PAGE \\
\hline UNCLASSIFIED & UNCLASSIFIED & UNCLASSIFIED \\
\hline
\end{tabular}

\begin{tabular}{|l|c|}
$\begin{array}{l}\text { 17. LIMITATION } \\
\text { OF ABSTRACT }\end{array}$ & $\begin{array}{l}\text { 18. NUMBER } \\
\text { OF PAGES }\end{array}$ \\
& 203 \\
\hline
\end{tabular}

\begin{tabular}{|l|}
\hline $\begin{array}{l}\text { 19a. NAME OF RESPONSIBLE } \\
\text { PERSON }\end{array}$ \\
\hline $\begin{array}{l}\text { 19b. TELEPHONE NUMBER (include } \\
\text { area code) }\end{array}$ \\
\hline
\end{tabular}

